\title{
Applications of Porous Electrodes to Metal-Ion Removal and the Design of Battery Systems
}

\author{
Gary Ceorge Trost
}

(Ph.D. thesis)

\section{Materials and Molecular Research Division, Lawrence Berkeley Laboratory and Department of Chemical Engineering, University of California,} Berkeley, California 94720

\author{
September 1983
}

\section{DISCLAIMER}

\begin{abstract}
This report was prepared as an account of work sponsored by an agency of the United States Government. Neither the United States Government nor any agency thereof, nor any of their employces, makes any warranty, express or implied, or assumes any legal liability or responsibility for the accuracy. completeness, or usefulness of any information, apparatus, product, or process disclosed, or represents that its use would not infringe privately owned rights. Refer. ence herein to any speciðjc commercial product, process, or service by trade name, trademark, manufacturer, or otherwise does not necessarily constitute or imply its endorsement, recommendation, or favoring by the United States Government or any agency thereof. The views and opinions of authors expressed herein do not necessarily state or reflect those of the United States Government or any agency thereof.
\end{abstract}

The United States Department of Energy has the right to use this thesis for any purpose whatsoever including the right to reproduce all or any part thereof. 
Applications of Porous Electrodes to Metal-Ion Removal and the Design of Battery Systems

Copyright $\odot 1983$

by

Gary George Trost 
Appliations of Porous Electrodes to Metal-Ion Rernoval end the Design of Battery Systems

Gary G. Trast

\title{
Materials and Molecular Research Division, Lawrence Berkeley Laboratory and Deparment of Caemical Engineering, University of California, Berkeley, California 94720
}

September 1983

\begin{abstract}
This dissertation first treats the use of porous electrodes as electrochemical reactors for the removal of dilute metal ions. Second, a methodology for the scale-up of porous electrodes used in battery applications is given.

The removal of $4 \mu \mathrm{Pb} / \mathrm{Cc}$ in $1 M$ sulfuric acid feed streams was investigated in atmospheric and high-pressure, fow-through porous reactors. Or primary concern is the ability of the reactor to emove lead in the presence of a competing bydrogen side reaction. The atmospheric reactor used : :eticulated vitreous arbon porous bed that had been coated in situ with a mercury film. The best results show a $98 \%$ removal of lead from the feed stream Results are summarized in a dimensionless plot of Sherwood number vs. Péclet number. Highpressure, porous-electrode experinents were performed to investigate the effect of pressure on the current efinciency of the lead-removal process. Pressures were varied up to 120 bar on electrode beds of copper or lead-coated spheres. The copper spheres showed high hydrogen evolution rates whicb inbibited lead deposition, even at higb cathodic overpotentials. The use of lead spheres inhibited hydrogen evolution but often resulted in the formation of lead sulfate layers; these layers were difficult to reduce back to lead.
\end{abstract}

Experimental data of one-dimensional porous battery electrodes are combined with a model for the current collector and cell connectors to predict ultimate specific energy and maximum 
specific power for complete battery systems. The discharge bebavior of the plate as a whole, including the effects of the electrochemical resistance and grid (current-collector) resistance, is first presented as a function of depth of discharge. These results are combined with the voltage and weight penalties of the interconnecting bus and post, positive and negative active material. cell container, etc. to give specific results for the lithium-aluminum/iron sulfide hightemperature battery. Subject to veriation are the number of positive electrodes, prid conductivity, minimum current-collector weight, and total delivered capacity. The battery an be opt inized for maximum energy or power, or a compromise design may be selected. 
for my porents

who always support me 


\section{Acknowedgement}

I wish to thank Professor John Newman for the support, guidance, and patience that be bas given me throughout this work Professor Newman is a dedicated educator and researcher and has a strong commitment to his students.

I will always appreciate the encouragement I received from my colleagues and friends, especially Mark Orazen for our many long discussions. My family in Illinois and Minnesota and my extended family in Berkeley bave always supported me.

I wish to acknowledge the machine shop personnel for their help in fabricating much of the experimental apperatus. Howard Wood deserves a special thanks for his patience and many hours of consultation. Thanks are also due to Lex Carbini, Scott Forrest, and Wayne Leung for theil intributions to the rotating-disk experiments.

This work was supported by the Assistant Sectetary of Conservation and Renewable Energy, Ofiice of Energy Systems Research, Energy Storage Division of the U.S. Department of Energy under Contract DE-AC03-76SF00098. 


\section{Applications of Porous Electrodes to Metal-Ion Removal \\ and the Design of Battery Systems}

\section{Coatents}

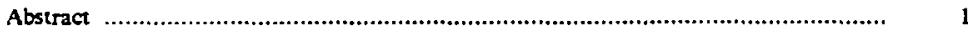

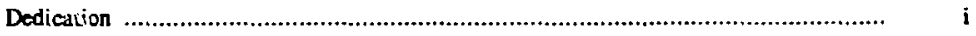

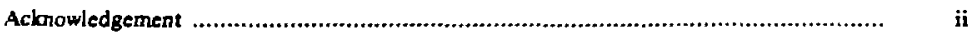

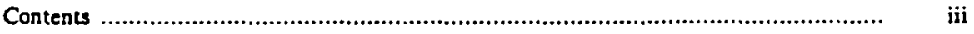

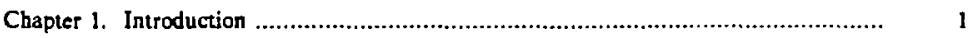

Chapter 2 Lead Deposition on a Rotating-Disk Electrode ...................................

Chapter 3. Electrochemical Removal of Dilute Lead Ions from Aqueous Sulfuric Acid

Waste Streams ..................................................................... 27

83.2. Almospheric, Porous-Electrode Experiments ..................................... 41

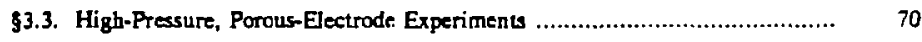

Chapter 4. Porous Battery Electrodes ..................................................... 103

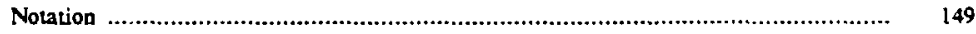

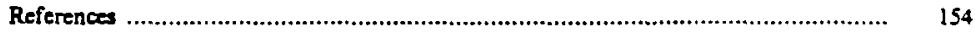

Appendix A. Instrumentation in Electrocbemical Systers .................................... 105

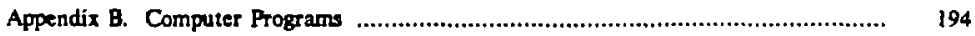




\section{Copter 1. Introduction}

\subsection{Introduction}

This dissertation is concerned with flow-through porous electrodes as industrial electrochemical reactors and porous electrodes used for battery applications. A porous electrode is a three-dimensional, porous matrix or packed bed with a high interfacial area per unit volume. For dilute reactants, a large interfacial area is necessary to promote intimate contact of the reactants with the electrode. In battery applications, a high surface-area-to-volume ratio is also required to provide a large number of reaction sites in close proximity to the reactants. An overview of porous electrodes as electrochemical reactors and as battery electrodes is presented. including a summary of the development of the governing equations and their solution for several limiting cases.

Specificaly, the experimental removal of dilute lead jons from aqueous waste streams is investigated in both an atmospheric and higb-pressure, flow-tbrough porous electrode. In flowthrougb configurations, a feed stream is pumped through the porous-electrode bed. Measured effluent concentrations are used to calculate overall mass-transfer coeficients, which characterize the performance of the electrocbemical reactor.

Either experimental or micromodeling data of porous battery electrodes are used as a basis for the subsequent design and scale-up of battery systems. A methodology is developed for the prediction of specific energy and specific power for complete battery systems. A computer program and results are presented for the litbium-aluminum/iron sulfide bigh-temperature battery.

\subsection{Heary-Metul Remord}

Heavy metals can be potential environmental pollutants, even at very low concentrations. Lead, in particular, is regarded as an insidious pollutant in both air and water, ${ }^{l}$ although there 
is disagreement on what is the major source source of lead pollution. As of mid 1980, U.S. industry consumed 1.3 million tons of lead annually, 600,000 tons of which may be returned to the environment. Lead is ingested througb air, drinking water, and food. Water sources and land are contaminated with beavy metals trom industrial waste streams and landfill; airbome lead from industry and vehicle emissions is deposited on crope or soil and ands up in food. Apparently the U.S. Food and Drug Administration bas not set definite limits on the maximum tolerable lead content in food, but it has been recommending that levels be reduced' Drinting water standards require lead concentrations less than $0.05 \mathrm{Mg} / \mathrm{cc}$. In 1980 the U.S. Environmental Protection Agency (EPA) pnuposed ambient air standards of $1.5 \mu \mathrm{g} / \mathrm{m}^{3}$, and the U.S. Occupational Safety and Health Administration (OSHA) ${ }^{2}$ wanted eight-hour, work-place exposure limits of $50 \mu \mathrm{g} / \mathrm{m}^{3}$. More recenuly, OSHA is proposing to roll back the $50 \mu \mathrm{g} / \mathrm{m}^{3}$ standard to $150 \mu \mathrm{g} / \mathrm{m}^{3}$ for some of the lead industries, such as primary and secondary smelting. ${ }^{3}$ Often industries concerned with airborne lead also must have controls on aqueous lead emissions. A smelting operation for recycling lead, for example, may involve a washing ojerakion with battery acid.

In this dissertation we are concerned with aqueous waste streams. Industries directly involved with aqueous heavy-metal wastes include lead-acid battery manufacturers, metal platers and finishers, the photographic processing industry, the printing industry, mining and mineral processing, and printed-circuit-board manufacturers. The effluent stream from a lead-acid battery plant, for example, may contaia aqueous lead ion concentrations on the order of $5 \mu g / c c$ (approximately 5 parts per million), and this level must be reduced before discharge to the eavironment. Many of the industrial effluents are not treated at the source but are added to the sewer system to be handled by the municipal waste treatment facilities. Surges in heavy-metal consentrations can kill the biomass in biological treatment plants.

The traditional disposal methods for dealing with aqueous metal wastes usually involve a two step process of precipitation, followed by a filtration or settling process. The disposal 
metbods for the resulcing waste sludges in 1981 inc'sded landfilling, thermal processing, and ocean disposal." The heavy metals are left with these sludges and are not removed. Recent proposals by the EPA and increased restrictions on landfill disposal sites are causing magufacturess to lock at new technology for cleaning heavy-metal waste streams' at the source. Paricularly for the plating industry, changes in bath formulations bave caused interference with the more traditional routes for reducing metal effluent concentrations.

Various methods have been investigated for the removal of lead from wastewaters. A lime precipitation technique ${ }^{7}$ was reported to lower lead effluens in a wire manufacturing wastewater to $5.0 \mathrm{\mu g} / \mathrm{cc}$. An improved process add $2 \mathrm{mg} \mathrm{Na}_{2} \mathrm{CO}_{3}$ per ma $\mathrm{Pb}$ to the simple lime process and is able to reduce lead contents to $0.3 \mu \mathrm{g} / \propto$. This effluent may still need a follow-up treatment to lower lead values even further. Another process using colloidal adsorption on ferric hydroxide followed by foam flotation with a sodium lauryl sulfate surfactant has been reported to be economically competitive with lime precipitation. Effluent lead concentrations of 0.1 $\mu g / \propto$ were obtained, and sludge volumes were reported to be lower than for lime precipitation. Orher metal-removal methods include filtration" (removal of suspended solids from battery wastewaters), adsorption on a zeolite, ${ }^{10}$ biological treatment, ${ }^{11}$ solid and liquid ion-exchange, reverse osmosis, and electrodialysis.

Electrochersical processes should not be overlooked as methods for environmental control. Electrochemical precipitation processes, for example, have been reported to have advantages over other precipitation processes. 5.12 Or importance, bowever, is that the electrorhemical process can often directly process the waste stream without the addition of chemicals. Kuhn ${ }^{13,14}$ prents a survey of electrochemical methods which includes a discussion on athodic and anodic processes, the treatment of gascous effluents, and electroflotation.

To remove low concentrations iî metals electrocheinically, a bigh surface-area-to-volume ratio of electrode is needed. Flowsthrough porous electrodes meet this requirement and have been shown to be an effective means for removal of various beavy-metal ions. Copper, ${ }^{15}$ silver, $^{16}$ 
and mercury ${ }^{17}$ removal systems bave been studied both theoretically and experimentally. Unfortunately, in the case of dilute lead removal from an acid electrolyte, the thermodynamic potential for lead discharge is more than $300 \mathrm{mIV}$ cathodic of the competing water deconiposition reaction. However, the high kinetic resistance to hydrogen evolukion on lead gives hope that the process can be run at good current efilciencies.

\subsection{Battery Desigu}

The past twenty years have seen a renewed interest in battery invention and development for electric-vehicle and load-leveling applications. It is of some interest, therefore. to examine the history ${ }^{12}$ of the secondary (rechargeable) electric battery, fuel cell, and electric vejicle. Gautherot (1802) and then Ritter (1803) recorded a series of experiments that first showed evidence for "secondary piles" or "acoumulators." Schönbein observed that hydrogen and oxygen generated from a primary battery "pile" could be rtacted on platinum electrotes to give secondary (discharge) currents. William R Grove (1839) showed that these secondary currents could be obtained by using external vessels of hydrogen and oxygen gas in an electrolytic cell with platinum electrodes. In 1859 Gaston Planté was researching the behavior of differen: metals after cbarging. He found that the strongest secondary currents occurred when using silver electrodes in an acid electrolyte. Lead gave the next best discharge currents, and the electrode was found to improve on cycling. This led to the invention of the lead-acid battery.

The United States electric-vehicle industry started with the introduction of an electric vehicle by Fredrick Kimball in 1888 . From this time to the early 1900 's, the electric vehicle competed against the internal combustion engine and the stesm engine for personal transportation. The peak of electric-vehicle production was in 1916 when 6000 passenger cars and 4000 commercial vehicles were produced. Since then the commercial market has increased for such items as lift trucks a.d golf carts, but the passenger vehicle was discontinued by 1933. The iroi-nickel oxide battery was developed by Thomas Edison in 1901. This battery competed with the lead-acid battery for industrial use until the 1920's. The iron-nickel and lead-acid 
batteries remain candidates for electric-vebiclc use today.

The Space Age promoted a renewed interest in the development of direet energy conversion (especially for fuel cells), and the oil crisis of the 1970"s led to development of new kutery systems. Congres, in 1976, specifically funded a mulu-year, multi-million dollar program to develop electric-vehicle technology. The electricity required to charge batteries can be obtained from any of a number of routes, thereby reducing the dependence of energy generation on any specific energy source. In 1982 the total U.S. electrical mergy mansumption was delivered from the following fuel sourcos: cosl as a fuel generated 61.0\% natural gas 16.3\% nuclear $15.0 \%$ and oil $7.7 \%$. Thus, oil plays a relatively minor role : ${ }^{20}$ electrical generation (compared to transportation), but its use could be reduced furtiser if electric-uulity. lad-leveling stonge becomes available. Presently, the more expensive fossil fuels must be used to meet peak power demands. Laad leveling would eliminate the need for utilizing more expensive fuels and would aliow for a power-plant design based on an i....age power demand. On the other hand, in 1980, $27 \%$ of the total U.S. energy consumption went into transportation, $97 \%$ of which was derived from oil. Thus, the electric vehiele stands to make a substantiał impact on ihe amount of oil used to fuel vebicles. It is interesting to note that the electric ueilities already have enougb off-peak capacity to handle an increased demand fro'n electric vehicles.

The widespread effor to develop advanced batiery systems bas led to a large number of candidate systems. As a mensure of desirability or jerformance, the specific energy and specific power of these systems are of ten compared to the lead-acid battery. The quoted specific energy velues, bowever, are often theoretical values calculated on the tasis of active materials only. These values oftea do not include the weight of the electrolyte, container, etc. In contrat, the energy and power values of the lead-acid battery are based on a complete battery package. Furthermore, the lead-acid battery is stil] undergoing major development and has doublet in specific energy over the past 15 years. Fo: this reason, caution should be used when comparing 
2 new system $w$ the lead-acid system. The candidate systems are usually classified as "near term" or "advanced." Near term represents a 5 to 10 year lead time, and advanced systems are not expected to see commercial development in less than 10 years. The classification of a system may change the nickel zinc battery is no longer expected to become commercially viable in the next 10 years due to continued problems with low cycle life. On the other hand, the advanced lead-acid battery could be used in electric vehicles today, if the consumer were willing to have an $80 \mathrm{~mm}$ driving range with modest acceleration and speed performance. To increase the driving range and performance, a battery with a bigher specific energy and specific power than the lead-acid battery is needed.

The near-term battery systems all bave aqueous electrolytes. Aqueous systems, bowever, share an inherent thermodynamic limitation of the decomposition of the solvent (oxygen evolution at the positive electrode and hydrogen evolution at the negative electrode) at $1.23 \mathrm{~V}$. Furthermore, some of the ligbtweight, energetic couples that hold some promise for higher specific energy batteries are not stable in water. Thus, the search for light, energetic couples has resulted in nonaqueous, ambient-lemperature electrolytes and high-temperature, molten-salt electrolytes. The ambient-temperature organic electrolytes, however, have poor conductivities comfared to aqueous systers. The molten-salt electrolytes conduct well, but have materials compratibility problems at the elevated temperatures. For fiscal year 1983, Congress specifically appropriated funds for the continuing development of the high-temperature, molten-salt sodiumsulfur battery; the primary, aluminum-air system; and the aqueous, zinc-bromine system. Other batteries, such as the lead-acid and iron-nickel oxide systems, received substantial funds as well. In fiscal year 1981, the total funds provided by all government sources for battery research and development was $\$ 45.7$ million." All of these systems have their advantages and disadvantages. A recent review of the status of battery systems and recommendations for research is provided in reference 21 . 
The many candidate systems for vehicle use and the large dollar expenditures warrant effors to establish qualitative and quantitative procedures for the evaluation of the ultimate performanes of a given system. Presently, parametric or empirical studies are done to determine the effect of design variables on battery performance. The battery design can be attacked in two stages. Firse, micro-modeling (from fundamental principles) of the single cell can be combined with, and compared to, experimental results on small cells. These data combine to form a basis for the behavior of the smail cell. Second, these data can be used to predict the ultimate specific energy and specific power that can be expected from the battery when the cells are combined into a complete system.

\subsection{Chapter Sumnnies}

Chapter 2 describes a seriz of rotating-disk studies on carbon and lead. Investigation of lead deposition in a high-pressure cell gave start-up problems associated with the initiation and subsequent nucleation of lead on the electrode. Rotating-disk studies were undertaken to examine the behavion of lead deposition on a variety of substrates. The objectives of the rotating-disk studies were to determine the effect of surface preparation (mechanical and electrochemical), electrode substrate, and applied potential on the lead and bydrogen electrochemical reactions. The ability to plate lead at limiting current, the quality of the lead. deposith and the current efficiency of the process are all important for the design of the porous metal-renoval system.

Chapter 3 investigates the feasibility of removing lead from dilute, aqueous waste streams in botb an atmospheric and high-pressure porous electrode. A reticulated vitreous carbon substrate was used in the atmospheric experimunts, and copper-coated spheres were used for the bigh-pressure experiments. Several electrolytes were investigated, but the study focused on a 1 $\boldsymbol{M}$ sulfuric acid electrolyte because of the industrial application of a waste stream from a leadacid battery plant. A summary of the development of the governing equations for porous electrodes is also included from reference 22 
Chapter 4 develops a macro-model of porous battery electrodes. A computer model that utilizes fundamental small cell data (from either experimental work and/or micro-modeling work) is developed that predicts the energy and power performance of a scaled-up battery. The model also yields specific scale-up criteria, such as the dependence of the current-collector weight on plate area In general, voltage and weight penalties of the current collectors, interconnecting bus and post, electrolyte, positive and negative active material, and cell container are taken into account. Subject to variation are the number of positive electrodes, grid conductivity, minimum curreat-collecter weight, and total delivered capacity. The battery can be optimized for maximum energy or power, or a compromise design may be selected. The model is general and may be applied to many types of battery systems. Results have been obtained for the lithium-aluminum/iron sulfide high-temperature battery. A sumumary of important considerations for the use of porcus electrodes in battery applications as well as selected micro-modeling results are aiso presented, taken largely from reference 22.

Appendix A discusses sume electronic and electrochemical grounding and s-ielding problems encountered during the experimental work

Appendix $\mathbf{B}$ documenis the programs used in generating the scale-up predictions for the lithium-aluminum / iron sulfide battery. 


\section{Cupter 2. Lead Deposition on a Rotating-Disk Electrode}

\section{Introduction}

The rotating-disk electrode has found widespread use in the study of electrolytic diffusion and electrochemical kinetios. An introduction and survey of the rotating disk is given by Riddiford. ${ }^{22}$ Other systems that may be useful for anajytical work include the rotating ring-disk system. $^{24 r}$ the rotating-cylinder electrode (which may have practical industrial applications as well), the rotating-hemispherical electrode, 29 and the rotating-cone electrode. ${ }^{30}$

The rotating-disk electrode is a popular analytical tool because the laminar velocity profile $^{31,32}$ and limiting mass-transfer (limiting-current) behavior ${ }^{3,34}$ are well known. The rotating disk is one of the few geometries where the nass-transfer boundary layer (and therefore limiting-current distribution) is uniform across the face of the electrode, allowing for some decoupling of the mass-transfer effects from the electrode geometry. Newman ${ }^{35}$ gives analytical axpansions for the limiting mass flux to the disk surface for both high and low Schmidt numbers. These expansions can be used directly in the interpretation of experimental, masstransfer-limited results. Newman has extended the rotating-disix analysis to inciude the calculation of the primary current distribution, ${ }^{36}$ where concentration variations and kinetic limitations are ignored; the secondary current distribution, ${ }^{77}$ where concentration variations are still neglected but kinetic polarization is taken into account; and also the complete solution, ${ }^{37}$ wher: mass transfer, ohmic potential variations, and kinetic irreversibilities must all be taken inte account.

Dificulties encountered in a series of high-pressure, porous-electrode experiments led to a study of the behavior of lead deposition on a rotating-disk electrode. First, problems arose in being able to initiate lead discharge reproducibly on the electrode substrates. Second, loss of potential control during an experimental run often led to lead dissolution, which could not be 
reversed (refer also to chapter 3). Thus, we wanted to examine the effect of surface preparation, electrode substrate, and applied voltage (including cycling) on the initiation and subsequent nucleation of lead. Also of importance thas the current efficiency of the limiting-current deposition and how easily lead can be plated at limiting current before the side reaction inhibits further deposition. Some evidence was seen that lead would not discharge in the presence of severe bydroges evolution, even under large eathodic polarizations.

By varying the disk rotation speed or the bulk lead concentration, the rotating-disk experiment can determine if lead is plating at the limiting current and also possibly the quality of the limiting-current deposit. Loosely adherent, powdery deposits are commonly found when plating at the mass-transfer limiting current. A poor deposit may break from the electrode substrate and re-dissolve in the electrolyte. After limiting-current behavior is established, the results can also be used to calculate the diffusion coefficient of lead in the sulfuric acid electrolyte. The diffusion coefficient is necessary for the prediction of mass-transfer coefincients in porous electrodes. Dimensionless mass-transfer rates can be calculated and compared to the results of otber metal investigations (see chapter 3).

Cyeling the applied potential to the disk was examined to determine the effect of a reactor malfunction on the subsequent behavior of the bed. A period of open circuit or an anodis excursion in potential will cause lead sulfate layers to form on the lead substrate. Of particular importance is the electrochemical behavior of lead sulfate layers under catbodic polarization.

Preliminary experiments were done with a copper electrode; hi'wever, lead and glassy carbon electrodes were concentrated on because of the higher bydrogen overpotential on these materials. Any electrode substrate, if successful, will begin to behave like a lead electrode as deposition continues. Thus, it is especially important to know how the lead electrode behaves in the sulfuric acid enviconment. 


\section{Tbeory}

The limiting mass-transfer behavior of a rotating-disk electrode for very high Schmidt numbers is given by the Levich equation $a^{34}$

$$
N_{l n}=0.62 v^{1 / 2} Q^{1 / 2} \mathrm{Sc}^{-2 / 3} c_{b},
$$

where $N_{i n}$ is the normal component of the dux of species $i$ to the disk surface, $y$ is the kinematic viscosity of the solution, $\mathbf{D}$ is the rotational speed of the disk, $S e$ is the dimensionless Schmidt number, and $c_{b}$ is the bulk concentration of the limiting spectis $i$. The extension of this solution for $\mathrm{Sc}$ numbers greater than 100 takes the form: ${ }^{38}$

$$
\frac{i_{i n} s_{t}}{n F\left(c_{b}-c_{0}\right) \sqrt{n}}=\frac{0.62048 S \mathrm{c}^{-2 / 3}}{1+0.2980 S \mathrm{c}^{-1 / 3}+0.14514 \mathrm{Sc}^{-2 / 3}+\alpha\left(\mathrm{Sc}^{-1}\right)},
$$

where $i_{i n}$ is the normal component of the current density of species $i, c_{0}$ is the uniform surface concentration of species $i$ (taken to be zero at liniting current), $F$ is Faraday's constant, and $s_{i}$ and $n$ are the stoichiometric coefficient and the number of electrons transferted in the electrode reaction as represented by $\sum s_{1} M_{1}^{2} \rightarrow n e^{-}$. From equation $2-2$, it is seen that a plot of the limiting current vs. either the bulk concentration or the square root of rotation speed should yield a straight line. A strajght line, then, indicates that lead is placing at the limiting current. Independent knowledge of the solution kinematic viscosity and bulk concentration can be used with the limiting-current measurements to ealculate the diffusion coefficient of the limiting species.

Equation 2-1 or 2-2 is restricted to a single electrode reaction. A secondary reaction will cause a plot of the measured current vs. either bulk concentration or square root of angular velocity to have a non-zero intercept. If we assume that the background current is constant, the slope of these plots an still be expected to be given by equation 2-2

\section{Experimental}

The experimental apparatus consists of a Pine Instruments ASR analytical rotator, a Pine Instruments RDE 3 potentiostat, and a quartz glass cell used to hold the electrolytic solution. A 
schematic of the glass cell is given in figure 2-1. Side chambers are shown for the PI-Rb counterelectrode screen and the saturated calomel reference electrode. They are separated from the main comparment by glass frits, which inbibit convective and diffusive mixing between the catholyte ssilution and either of the reference or the counterelectrode electrolytes. Also shown is a port for deoxygenating the catholyte using a nitrogen sparger. A mechanism for electrolyte removal and addition was needed for experiments that varied the bulk concentration of lead in the electrolyte.

A schematic of the instrumentation used is given in figure 2-2. A Hewlett-Packard model 7047A X-Y recorder and two Keithley multimeters, models 173A and 178 , monitored the cell current and applied potential from the current and voltage outputs on the potentiostat. The ASR speed control set the speed of the analytical rotator. The revolutions per minute (rpm) of the disk could be controlled manually or through an externally applied voltage. A Princeton Applied Research model 175 universal programmer was used as input to the speed control for thuse experiments that swept the rotation speed. The internal voltage generator of the potentiostat was used to sweep the working vs. reference potential. In order to reduce electromagnetic noise, coaxial cable was used to shield the reference electrode, and the common rail of the potentiostat was connected to the case (earth) ground.

All electrodes were polished using a Buehler Ecomet III polishing wheel. The copper electrode was polished with $600 \mathrm{grit}$ wet/dry paper followed by successive polishing with 9, 3, and/or 1 micron diamond paste, depending on the degree of polishing desired. The glassy carbon electrode could be polished with the diamond paste, but it was found that this was not necessary to activate the surface for lead deposition; it was only required that any previously deposited lead be removed with 600 grit paper. The lead electrode was found to be too soft to polish with the diamond paste. A good finish was obtained by polishing lightly with 600 grit paper at approximately $300 \mathrm{rpm}$ using a 50/50 mixture of liquid detergent and water as a lubricant. Fine polishing is achieved with jewelers rouge and lubricant on Buehler microcloth at 


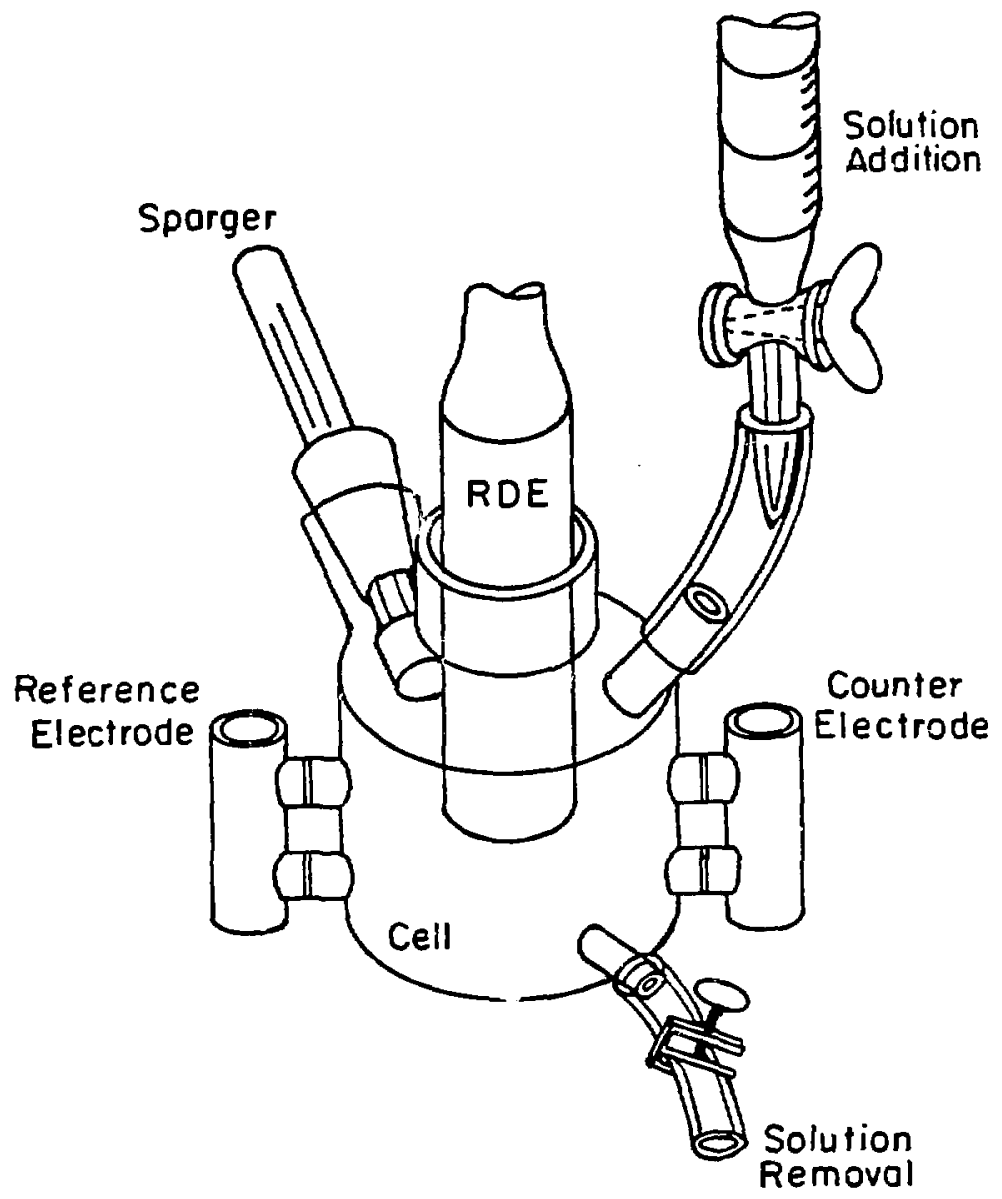

XBL $839-6452$

Figure 2-1. Schematic of the glass cell used in the rotating-disk-elestrode (RDE) experiments. 


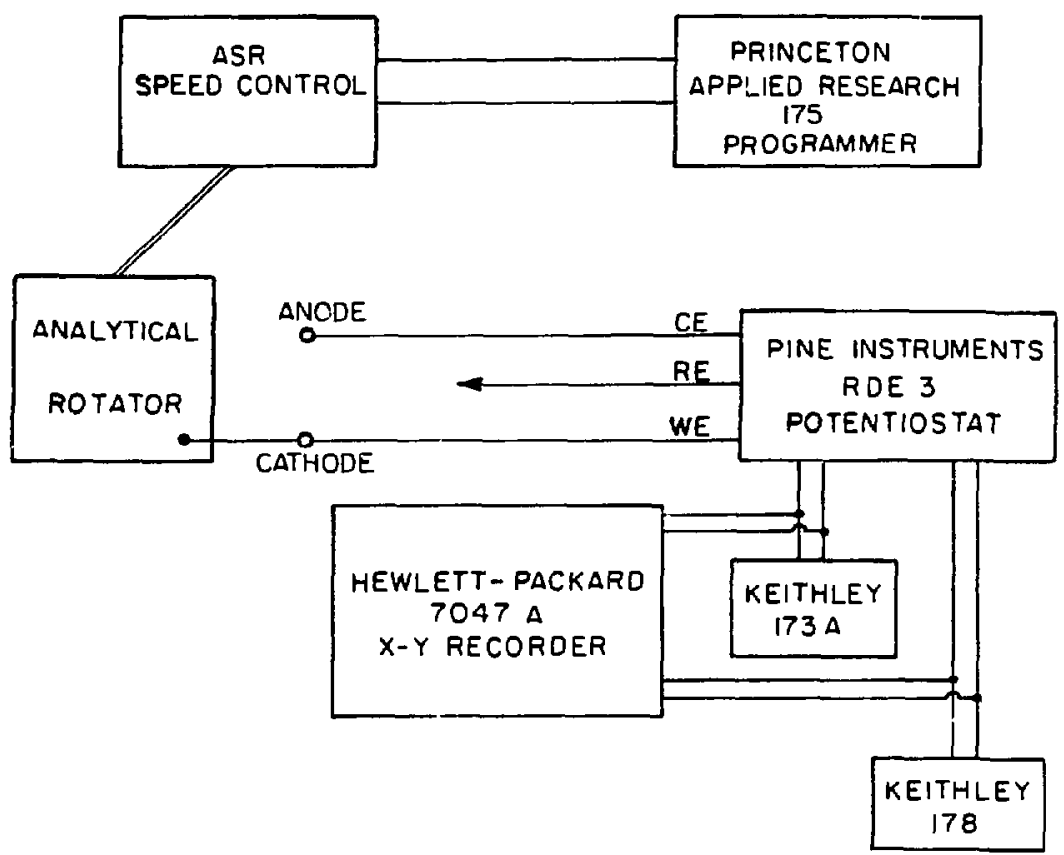

$\times 84839-6453$

Figure 2-2. Schematic of the electrical instrumentation used in the rotating-disk experiments. 
400 rps The use ef the soap/water mixture prevents the buildup of rouge on the electrode. Polishing proceeds with medium pressure, followed by light pressure for approximately 20 minutes. The microcloth should be replaced after each hour of use due to a buildup of lead.

Electrolytic solutions were made up from J. T. Baker reagent grade lead sulfate and Mallinckrodt analytical reagent sulfuric acid. Dilutions vere made from deionized water with a specific resistance greater than $16 \mathrm{M} \Omega$-em A few experiments were run with very pure J. T. Baker UItrex grade sulfuric acid and Johnson Mathey Puratronic grade lead sulfate to determine any effect of impurities on the observed currents. Electrolyte was purged with presaturated nitrogen to remove dissolved oxygen.

Atomic adsorption spectruscopy (AA) with a flane detector tuned to a $283.3 \mathrm{~nm}$ wavelength was used to asalyze lead samples. (A $217.0 \mathrm{~nm}$ wavelength, although more sensitive than the $283.3 \mathrm{~nm}$ wavelength, gav poor results.) Standards and blanks were made in dilute nitric acid solutions. Comparisons between nitric acid and sulfuric acid standards showed no difference in the measured concentrations. All samples were run an a Ferkin-Elmer spectrometer. Accuracy should be within $5 \%$ for concentrations on the order of 5 ppm with a lower limit of detection of $0.4 \mathrm{ppm}( \pm 20 \%)$. Stroblems in repraducibility, however, made some of the AA results suspect. An alternative technique such as differential pulse anodic stripping voltammetry ${ }^{3,40}$ at 3 hanging mercury drop could be used to verify or replace the AA method.

\section{Results}

Some visual evidence was seen that lead could be deposited on a copper electrode, but any limiting-current plateau was completely obscured by the high hydrogen production. The background currents were found to be a function of the degree of electrode polishing and were not very reproducible. Background current curves on lead and carbon showed that lead should in able to deposit on these substrates at reasonable current efficiencies. Again, however, the background currents were not reproducible. 
The lead electrode was used in determining the current-voltage behavior of a lead electrode on cycling, to demonstrate the correct Levich behavior, and to measure the diffusion coefficient. The glassy carbon electrode was used in background current experiments, and although found to be inferior to the lead electrate in inbibiting hydrogen production, it showed good hydrogen evolution characteristios.

\section{Current-Voltage Behavior of a Lead Eectrode}

When a lead electrode is immersed in $1 M$ sulfuric acid, a $\mathrm{PbSO}_{4}$ layer begins to form. The Pourbaix diagram ${ }^{41,42}$ shows lead to be stable at potentials more catbodic than $-0.356 \mathrm{~V}$ vs. a hydrogen reference electrode for sulfate activities of unity and values of $\mathrm{pH}$ up to approximately 8 . With respect to the saturated calomel reference electrode, then, the formation of lead sulfate would be expected to occur at approximately $-0.6 \mathrm{~V}$.

One volsage sweep on a clean, freshly polished lead electrode is given in figure 2-3. The solution is saturated $\mathrm{PbSO}_{4}$ in $1 \mathrm{M} \mathrm{H}_{2} \mathrm{SO}_{4}$. Care was taken to keep the applied voltages sufficienty cathodic to avoid the formation of $\mathrm{PbSO}_{4}$. An apparent plateau is seen over the voltage range of -0.6 to $-\mathrm{j} .9 \mathrm{~V}$. Past $-1.0 \mathrm{~V}$, hydrogen evolution begins to dominate. Background current curves, without lead in solution, were not reproducible, so that the value of the plateau current could not necessarily be attributed to lead deposition. (Limiting-current behavior is demonstrated below.) From potentials of $-0.6 \mathrm{~V}$ to $-1.0 \mathrm{~V}$, repeated sweeps show good reproducibility with figure 2-3. Ther is some hys ieresis and deviation in the curves in the hydrogen regime.

Figure 2-4 shows the complete anodic and cathodic sweeps for the same set of experiments as in figure 2-3. Al potentials anodic of $-0.55 \mathrm{~V}$, a $\mathrm{PbSO}_{4}$ film begins to form Bullocl: et al. ${ }^{\text {*3 }}$ have studied the corrosion of lead in $1 M$ sulfuric acid at potentials between 0.4 and $1.0 \mathrm{~V}$ vs. a $\mathrm{Hg} / \mathrm{Hg}_{2} \mathrm{SO}_{4} / 1 \mathrm{MH}_{2} \mathrm{SO}_{4}$ reference electrode. They conclude that an initial layer of $\mathrm{PbSO}_{4}$ forms which then inhibits acid diffusion to the $\mathrm{Pb} / \mathrm{PbSO}$ interface. As the interfacial acid concentration decreases, basic lead sulfales and lead oxides begin to form. Higher valence lead 


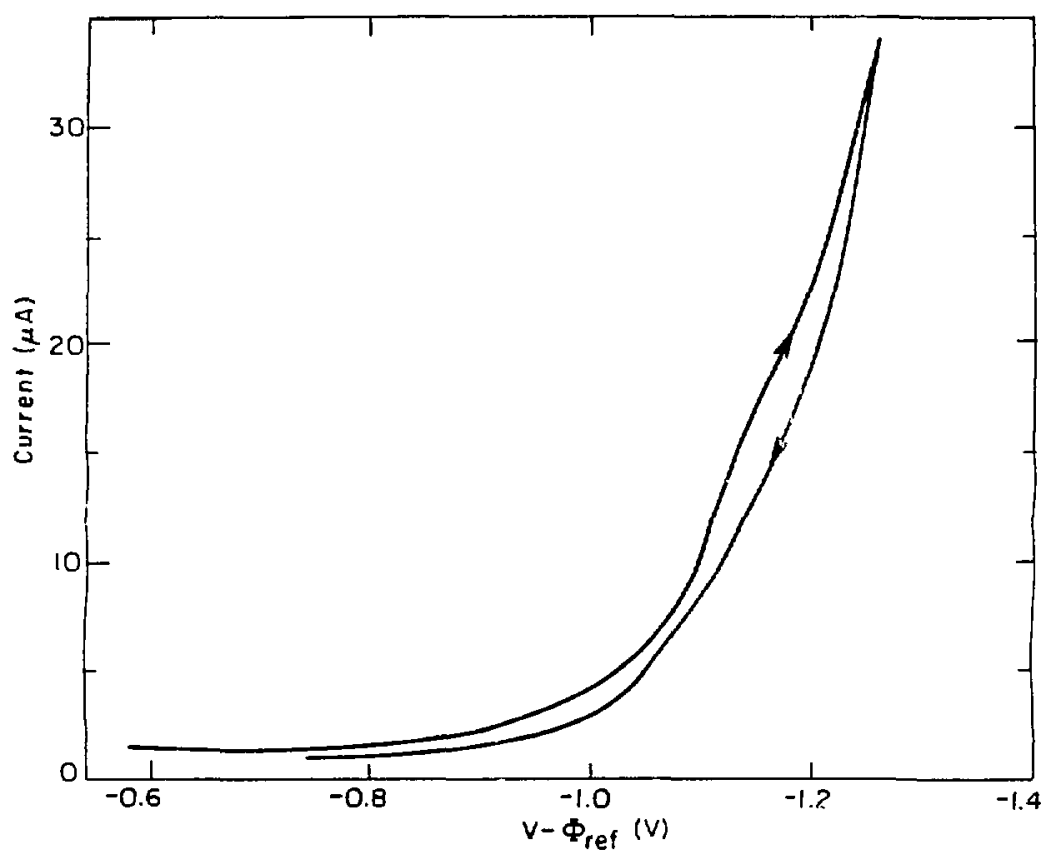

XEL 839-64 S4

Figure 2.3. Current-voltage behavior of a freshly cleaned lead electrode in a saturated $\mathrm{PbSO}_{4}, \mathrm{M} \mathrm{H}_{2} \mathrm{SO}_{4}$ electrolyte. 


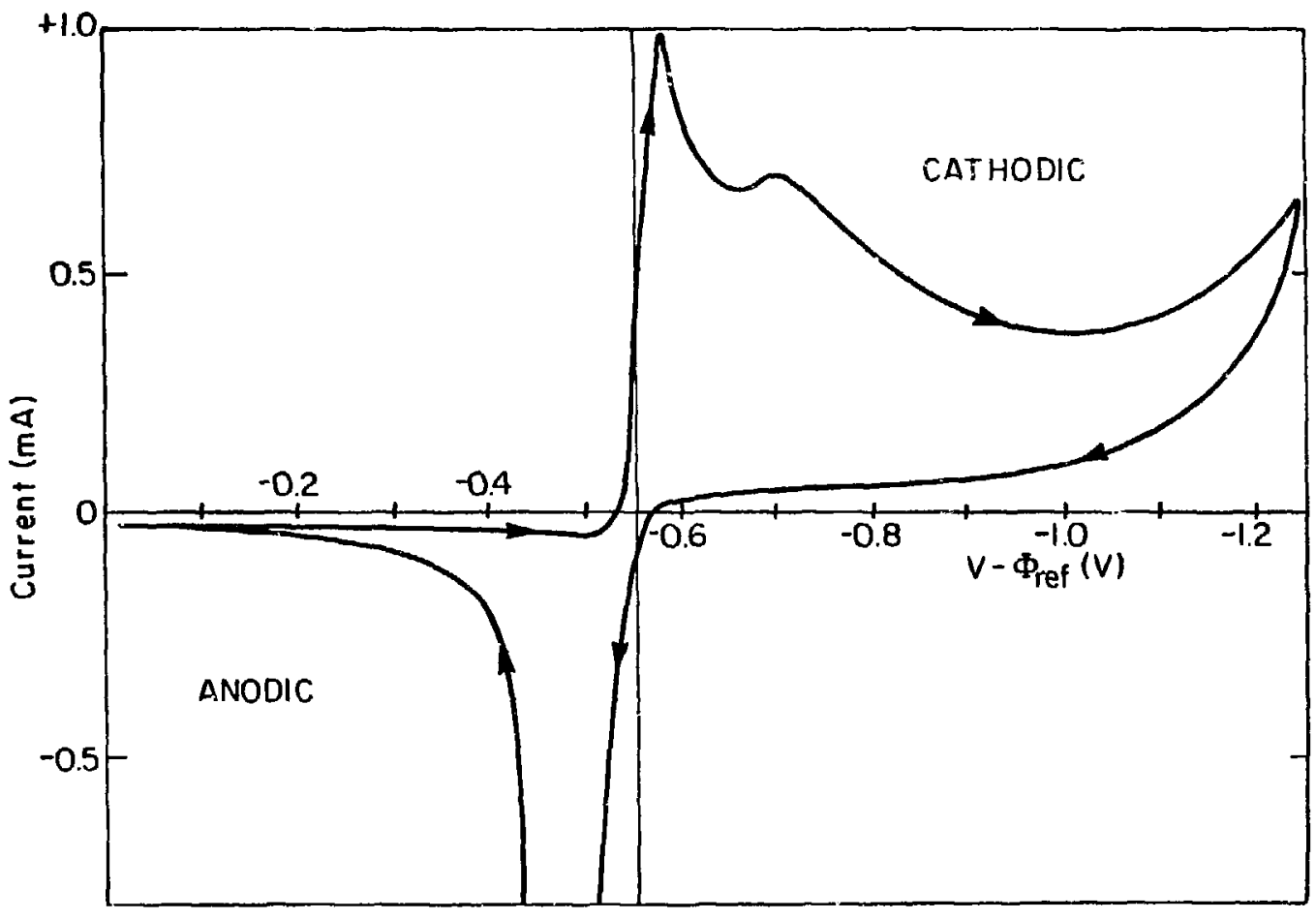

X나 839-6435

Figure 2-4. Complete anodic and cathodic sweep of a lead rotating-disk electrode in a saturater $\mathrm{PbSO}_{4}, 1 \mathrm{M} \mathrm{H}_{2} \mathrm{SO}_{4}$ electrolyte. 
oxides can form at longer times at the more ancdis potentials. Here an anodic $\mathrm{FbSO}_{4}$ peak is formed at potentials positive of -0.55 V. A non-conducting $\mathrm{PbSO}_{4}$ layer begins $t$ cover the active electrode area The anodic current drops back toward zero as the potential sweep continues, and the electrode becomes passivated. On the return cathodic sweep, oxidized surface species are reduced bacik to lead at approximately $-0.6 \mathrm{~V}$. The currents obtained in this peak are mucb higher than the limiting current for plating from t $t$. bulk solution and must therefore be arising from reactant species right at the electrode surface. The cal hodic prak tapers off into a limiting current region for the buik lead deposition. The area under tbe cathodic curve is less than the area under the anodic curve for eacb sweep indicating that not all of the higher valence lead is reduced back to $\mathrm{Pb}^{\circ}$. In fact, there was some evidence that even after prolonged cathodic polarizations, the surface could not be reduced completely back to lead. Repeated cycles show an increase in both anodic and cathodic currents due tc an overall increase in active electrode area as the electrode cycles from $\mathrm{PbSO}_{4}$ to $\mathrm{Pb}$ to $\mathrm{PbSO}_{4}$. A second cathodic peak is seen to form at approxinately $-0.7 \mathrm{~V}$ sor later cycles. This may be due to the reduction of other Po(I) species that could be formed at later times as the surface becomes more porous and thus possibly more basic.

\subsection{Limiting Current vs. Lead Concentration}

Limiting-current curves witb a lead electrode were taken as a function of bulk $\mathrm{Pb}$ (II) cencentration. The lead concentration was varied by either the addition of a saturated lead sulfate solution or the addition of only the supporting electrolyte Initially, a I $\mathrm{M} \mathrm{H}_{2} \mathrm{SO}_{4}$ solution was sparged with nitrogen to remove dissolved oxygen. Additions of 15 in $20 \mathrm{ml}$ of saturated $\mathrm{PbSO}_{4}$ in $\mathrm{H}_{2} \mathrm{SO}_{4}$ were then made. Current vs. time sweeps were recorded to det: ranine steady-state currents and to insure complete sparging. The cell potential was held constant at $-0.70 \mathrm{~V}$ vs. a saturated calomel reference electrode, and the rotation speed was held constant at $1000 \mathrm{rpm}$ 
Figure 2-5 shows the data for the limiting currents obtained for the various Pb(II) concentratiuns. The circles represent the limiting currents corresponding to concentrating the solution frcm no lead to approximately $2.8 \mu \mathrm{g} / \mathrm{cc} \mathrm{Pb}(\mathrm{II})$. The triangles represent the serial dilution of the $\mathrm{PO}$ (II) concentration by the addition of $\mathrm{I} \mathrm{M} \mathrm{H}_{2} \mathrm{SO}_{4}$. All lead concentrations were determined by atomic adsorption spectroscopy with a flame detector.

The data shown in figure 2-5 should all fall on a straight line as given by equation 2-2. The con-zero intercepts of this figure indicate the presence of background currents. Also seen in this figure is a change in the value of the slopes for the two sets of data. Although the reasons for the difference in slopes is unclear, it may be related to the changing electrode surface as new lead is deposited. If the lead reaction is truly mass-transfer controlled, a kinetically altered surface will have no effect on the magnitude of the lead limiting current. The new surface, however, could be expected to change the bydrogen discharge kinetios, which could lead to a decrease in the intercep. Furthermore, the slope of the curve is directly proportional to the total active surface area An increase in slope, therefore, may be indicating an increase in surface area with time. Thus, the difference in slopes is likely due to a combination of changes in both background kinetics and active surface area.

From equation 2-2, the slope of the limiting current vs. concentration curve should equal

$$
\frac{0.62048 n F \sqrt{n \Omega} A S c^{-2 / 3}}{1+0.2980 S c^{-1 / 3}+0.14514 S c^{-2 / 3}+0\left(S c^{-1}\right)}
$$

The data fall between two limiting slopes of $0.99 \frac{\mu \mathrm{A}-\mathrm{cm}^{3}}{\mu \mathrm{g}}$ and $1.3 \frac{\mu \mathrm{A}-\mathrm{cm}^{3}}{\mu \mathrm{g}}$ which yield diffusion coefficients of $2.3 \times 10^{-6} \mathrm{~cm}^{2} / \mathrm{s}$ and $3.5 \times 10^{-6} \mathrm{~cm}^{2} / \mathrm{s}$ respectively. The linearity of the lines is evidence that the Levich equation is being followed even though the hydrogen binetics and total active surface area appear to be changing.

\subsection{Limiting Current vs. Rotution Speed}

From equation 2-2, a plot of limiting current us. square root of rotation speed should also yield a straight lint of slope 


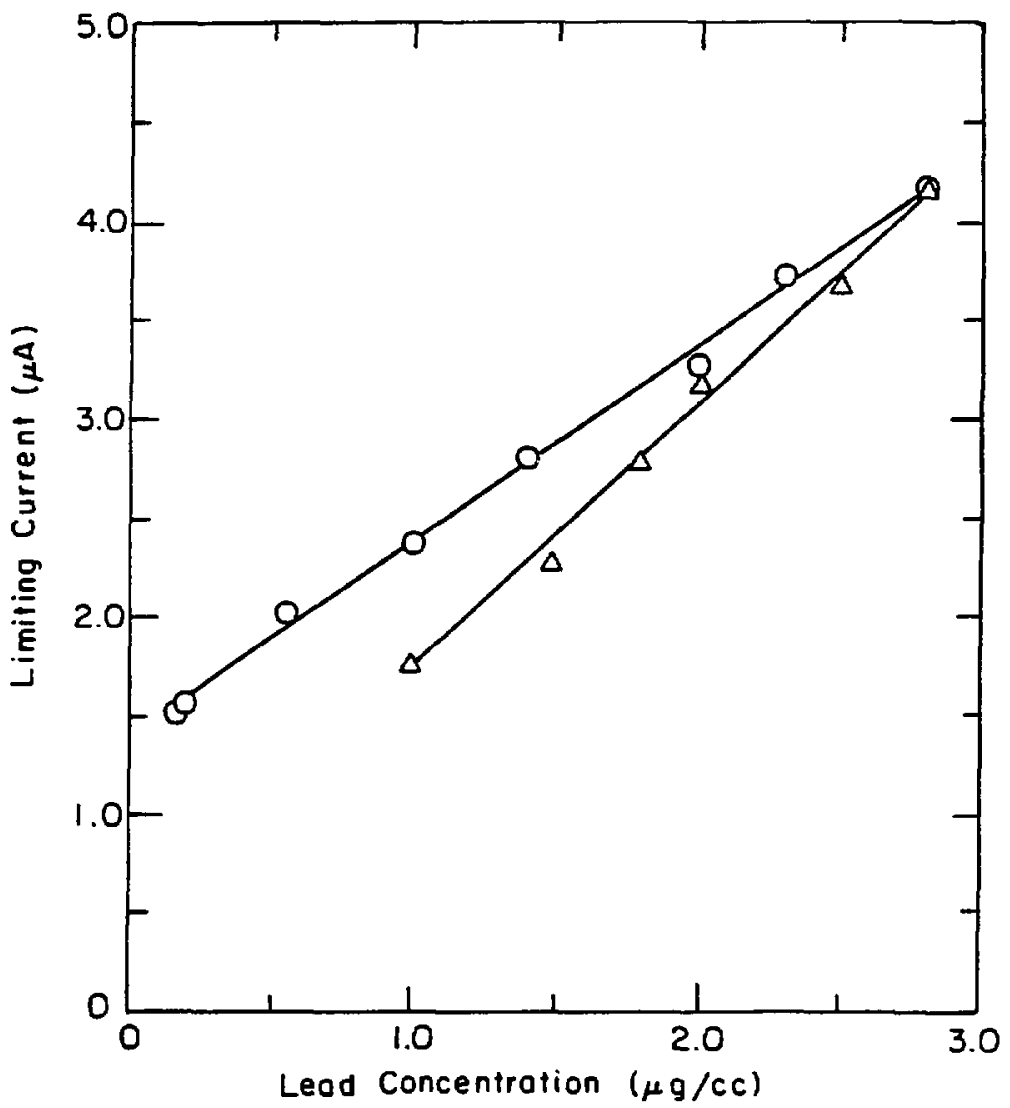

$X \theta<839-6457$

Figure 2-5. Limiting current ws. measured lead concentration on a lead rotating-disk electrode in $1 \mathrm{M} \mathrm{H}_{2} \mathrm{SO}_{4}$. 


$$
\frac{0.62048 n F \sqrt{y} A S c^{-2 / 3} c_{b}}{1+0.2980 S c^{-1 / 3}+0.14514 S c^{-2 / 3}+0\left(S c^{-1}\right)} .
$$

Limiting current vs. rotation speed plots with a lead electrode were obtained by sweeping the Pine Instruments ASR speed control with a Princeton Applied Research universal programmer. Sweep rates were sel at $5 \mathrm{rpm} / \mathrm{s}$ and were varied from approximately 100 to $1500 \mathrm{rpm}$ Applied voltages were maintained at $-0.70 \mathrm{~V}$ vs. a saturated calomel reference electrode. The data show some hysteresis with currents typically $5 \%$ higher on the return sweep (from higher to lower rotation speeds).

Figure 2-6 shows data for a series of ratational sweeps. The top line of this figure (triaggles) is data for a reverse sweep from higher to lower rotational speeds, and the next line (squares) is for an earlier forward sweep. The lower line combines data for both a forward and reverse sweep, taken after the data above. There appeass to be a change in the background binetics within the data, but all the slopes lie very close to each other and are equal to 0.498 $\mu A-s^{\text {h }} \pm 1.5 \%$ The last data taken from this series of runs (figure 2-7) showed a deviation from the straight line at rotational speeds greater than approximately $775 \mathrm{rpm}$. The initial slope cf the data, however, corresponds closely to the value given above.

Although the slopes obtained showed excellent agreement, the uncertainty in the bulk concentration prevents an accurate determination of the diffusion coeficient from these data. The solution was made up to be saturated, but it was not analyzed with AA For a bulk concentration of $4.5 \mu 8 \mathrm{~Pb} / \mathrm{cm}^{3}$, the difusion coeficient is calculated from equation 24 to be $2.8 \times 10^{-6} \mathrm{~cm}^{2} / \mathrm{s}$. The corresponding value for a concentration of $3.5 \mu \mathrm{g} \mathrm{Pb} / \mathrm{cm}^{3}$ is $4.1 \times 10^{-6}$ $\mathrm{cm}^{2} / \mathrm{s}$. The "best" value of $4.0 \mu \mathrm{Pb} / \mathrm{cm}^{3}$ yields a diffusion coefficient of $3.35 \times 10^{-6} \mathrm{~cm}^{2} / \mathrm{s}$.

\subsection{Curreat-Voluge Beharior of a Carton Electrode}

Background-current curves on a glassy carbon electrode showed that this electrode was suitable for lead deposition at reasonable current efficiencies. Voltage sweeps for lead deposition on a freshly cleaned earbon electrode are shown in figure 2-8. The top curve 


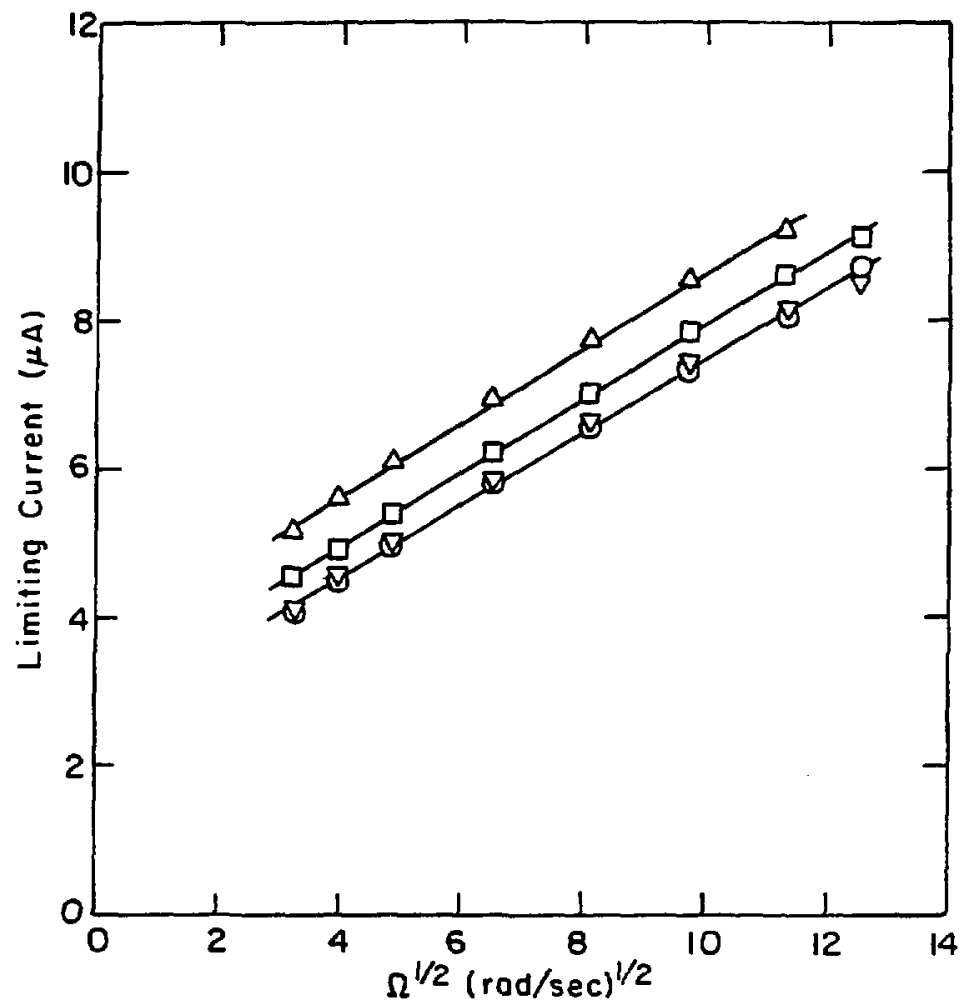

$\times 84639-6458$

Figure 2-6. Limiting current vs. square root of angular velocity for lead deposition on a lead rotating-disk electrode. 


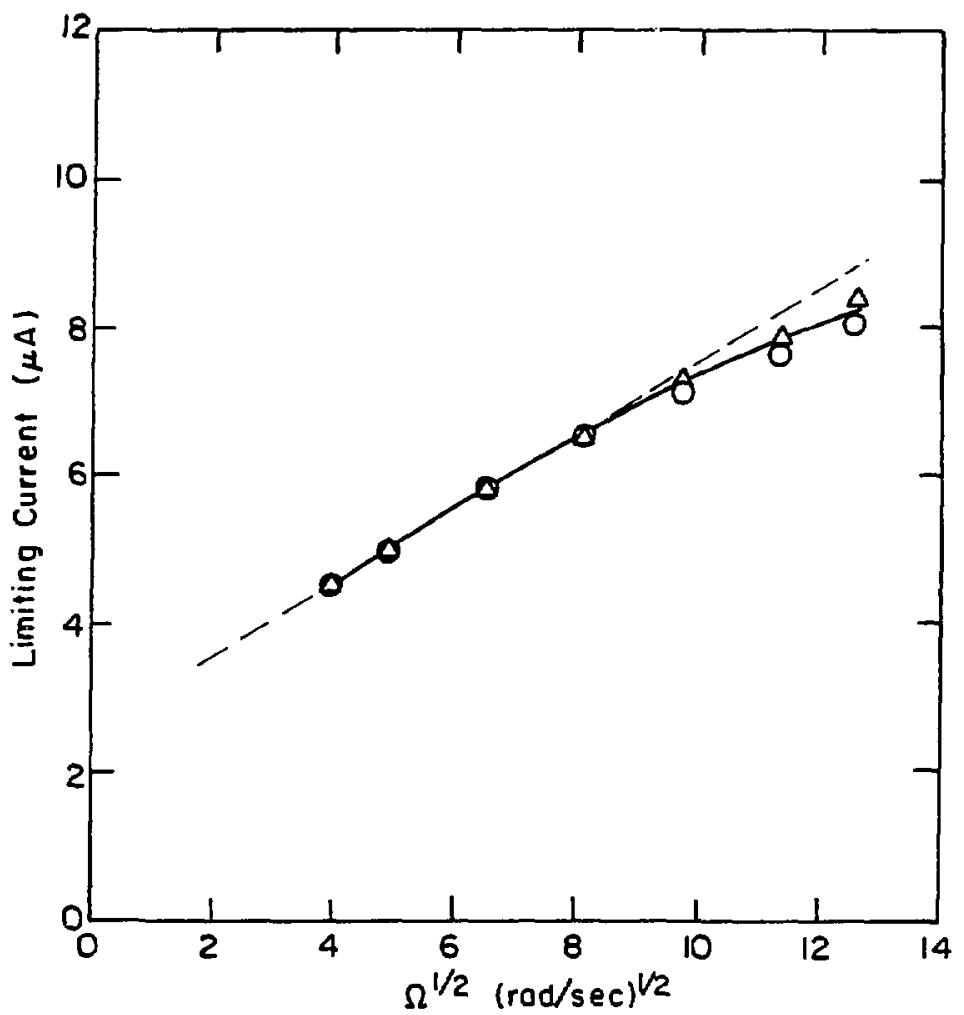

XBL839.6459

Figure 2-7. Last data taken from the set of experiments in figure 2-6, showing a deviation from linearity at higher rotation speeds. 


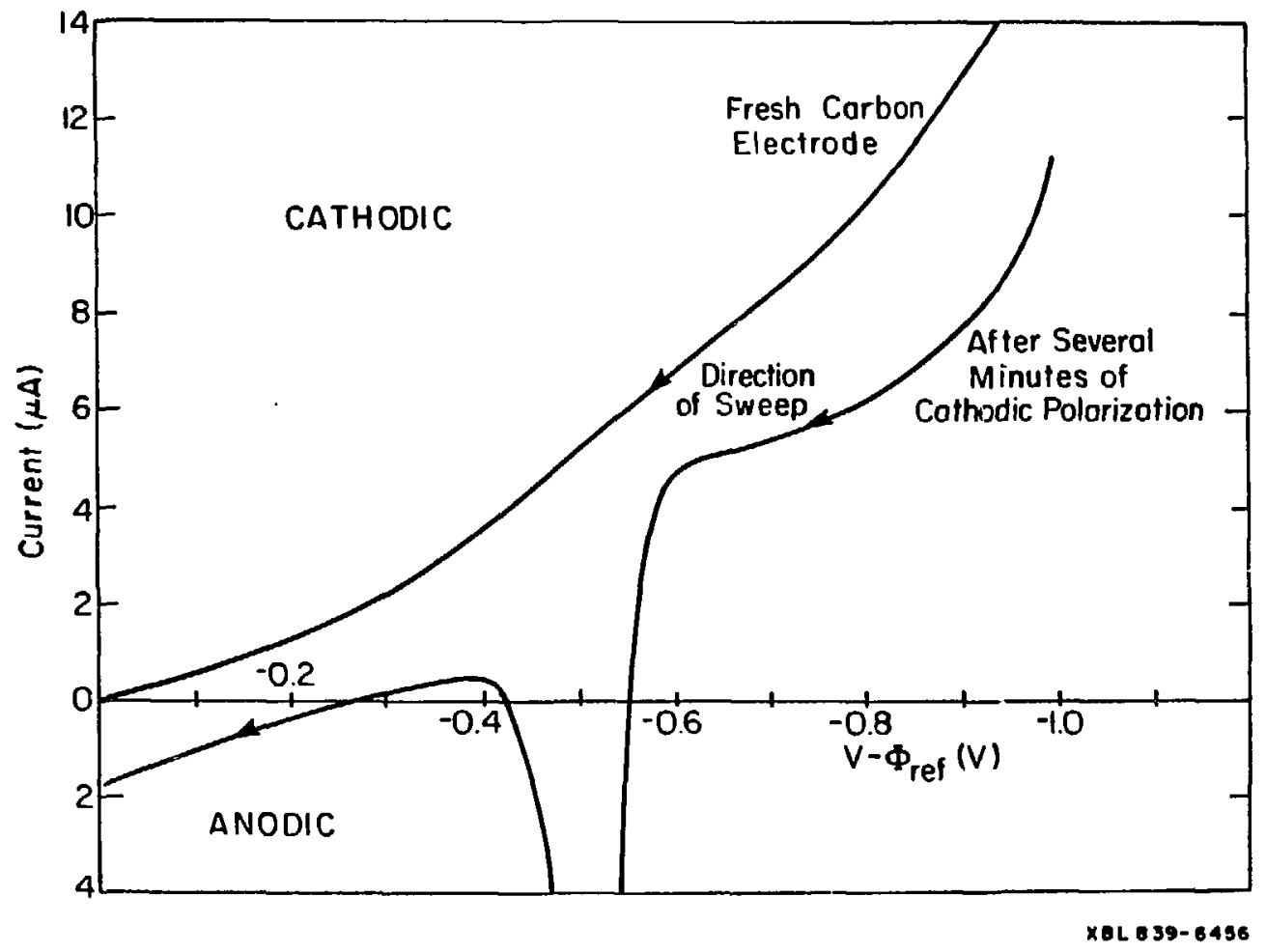

Figure 2-8. Voltage sweeps for lead depasition on a glassy carbon electrode. Electrolyte is saturated $\mathrm{PbSO}_{4}$ in $1 M$ $\mathrm{H}_{2} \mathrm{SO}_{\mathbf{4}}$. 
corresponds to an carly sweep where no lead has been deposited. After several minutes of cathodic polarization, the bottom curve was taken. The characteristic anodic peals corresponding to the formation of lead sulfate indieates that lead deposition has taken place.

\subsection{Conclusions}

The lead and carbon substrates both showed good kinetic eesistance to hydrogen evolution. Lead, bowever, easily forms an oxide layer on exposure to air which must be carefully removed before use. Furthermore, lead forms a sulfate layer when immersed in sulfuric acid. This lead sulfate layer proved difficult to reduce back to lead. For these reasoni a carbon electrode may be easier to use in the porous-electrode studies. The carbon surface doxs not aeed any particular "activation" or mechanical preparation.

After lead deposition has begun, care must be taken to keep electrode potentisls sufficiently eathodic to avoid the formation of lead sulfate. It is unclear why the electrode cannot be cycled like a lead-acid battery; this may be due to a different crystal structure formed when the lead deposits at limiting current. Organic additives (used in the lead-acid battery or plating-bath formulations) could have a beneficial effect on the quality of lead deposit.

The best estimate from the limiting current vs, concentration and the limiting current vs. rotational speed curves yields a diffusion coefficient of $3 \times 10^{6} \mathrm{~cm}^{2} / \mathrm{s} \pm 30 \%$. This yalue will be used in the calculation of dimensionless mass-transfer rates in chapter 3. 


\section{Chapter 3. Dectrocbemical Remord of Dilute Lead Ions from Aqueous Sulfuric Axid Waste Stream}

\section{Introduction}

A though the rotating-disk electrode is an excellent analytical tool, it is not useful as an industrial reactor for the removal of lead from aqueous solutions. Porous electrodes have been considered for the removal of dilute metal ions as wcil as other reactor and battery applications. A brief introduction to porous electrodes, including a review of their governing equations, is now presented.

Thorous electrodes an be used in low-through configurations as in fuel cells, redox energy storage systems, and chemical reactors or in closed configurations as in many primary and secondary batteries. Thus, porous electrodes find potential applications as electrochemical reactors in a variety of areas. Recently, Sioda and others ${ }^{4 /}$ discuss porous-electrode applications in electrowinning, fixed-bed and fluidized-bed electrolysis, ind analytical detection. Fow through porous electrodes are reviewed by Newman ind Tiedemann. ${ }^{45}$ The mass transfer of reacting species within the fixed bed and the ohmic potential variation throughout the bed are treated in detail. A second review article treats porous electrodes with regard to battery applications. A literature survey is given in each review.

Two distinguishing features of porous electrodes are the intimate contact of the electrode with the solution (and possibly a gaseous phase) and the high surface-area-to-volume ratio that can be obtained. The high surfacs-area-to-volume ratio is important to applications where the intrinsic rate of the heterogeneous, electrochemical reaction is slow. In processes using doublelayer adsorption, the bigh surface area is again important. Dilute reactants in solution require the close proximity of solution and electrode to enhance mass transfer to the electrode surface. In battery or fucl-cell applications, porous electrodes offer a means for storing the soluble 
reactants in close proximity to the electrode surface. For non-conducting reactants of low solubility, another solid phase (as in batteries) or gas phase (as in fuel cells) may be incorporated into the system.

Flow-through porous electrodes could find applications in the area of metal processing. This includes the purification, electrowinning, and possibly electroplating of aluminum, copper, magnesium, sodium, manganese, nickel, gold, silver, and chromium The electrorefining of aluminum from an aluminum-manganese alloy might involve a flow-through porous anode in order to prevent the dissolved manganese from reaching the cathode. Solutions too dilute to treat with solid electrodes in electrowinning processes may be treated witb a flow-througb porous electrode. Dilute aqueous metal removal and recovery of copper, ${ }^{15}$ silver, $^{16}$ and mercury ${ }^{17}$ have been studied in fixed-bed, flow-through porous electrocies. Copper was recovered from feed streams of 667 ppm with efluent concentrations less than I ppm, with simultaneous production of a concentrated stream of $47,660 \mathrm{ppm}$ Copper recovery has also been investigated in fluidized-bed reactors. ${ }^{47,4}$ Gold can readily be recovered from plating baths which have deteriorated, and streams from processing photographic emuisions can be reduced to less than 1 ppm silver. Mercury contamination in brine solutions bas been reduced to concentrations as low as $5 \mathrm{ppb}$ from feed streams of $50 \mathrm{ppm}{ }^{17}$ Reduction of contaminants usually requires processing of large volumes of dilute solutions. For metal removal, consideration must be made for the periodic removal of material from the matrix. Oxidation of organic contaminants, however, can proceed with no retention of solids.

The use of porous electrodes in electo-organic syntheses may provide an economical alternative to other chemical routes. The electrochemical synthesis may give higher yields under less severe operating constraints. The ability to control the electrode potential allows optimization for a particular reaction product, while minimizing side reactions or multiple products. A bibliography of electro-organic syntheses has been recently compiled by Swann and Alkire." 
Energy storage and conversion systems may use flow-through porous electrodes. Flowredox systems, zinc-chlorine bydrate storage systems, and fuel cells are some examples. It has also been shown that the performance of some primary or secondary batteries could be enbanced by a fresb supply of electrolyte. ${ }^{30,51}$ A promisin zinc-bromine secondary battery system uses a flowing electrolyte.

Flow-through porous electrodes also find applications in fundamental studies. Appel and Newman ${ }^{52}$ apply a limiting-current method for the measurement of mass-transfer coefficients at very low Reynolds numbers. Fedkiw and Newman ${ }^{\text {s3 }}$ summarize mass-transfer results of several workers. Their own results are correlated by using a dual-sized, straight-pore model to represent the actual, complex pore geometry.

\subsection{Governing Equations}

The many potential applications of porous electrodes wartant efforts to describe the system mathematically. One can then scale-up a system or predict the result of a change in operating parameters. This modeling can lead to desịns that optimize or maximize the desired process. Less detailed modeling can be a guide in screening various altemaxives such as newly proposed battery systems. It is important, then, to develop guidelines as to the behavior of porous electrodes.

Porous electrodes are inherently different from planar electrodes due to the intimate contact of the solution and matrix phases. Here the current lows within the matrix and the solution phases and exchanges between the matrix and solution nonuniformily througbout the bed. An electrical analog that ean belp picture the inherent complications is seen in figure 3-1. This figure shows two porous electrodes operating as an electrolytic cell. The subscripts 1 and 2 refer to the matrix and solution phases respectively. Subscripts a and $\mathrm{c}$ refer to the anode and cathode, and $R$, represents the resistance due to the separator. When current flows through the porous electrode, the electrical double-layer capacity (represented by $C_{d}$ ) is charged. This is a net flow of current through the solution causing a change in solution composition near the 


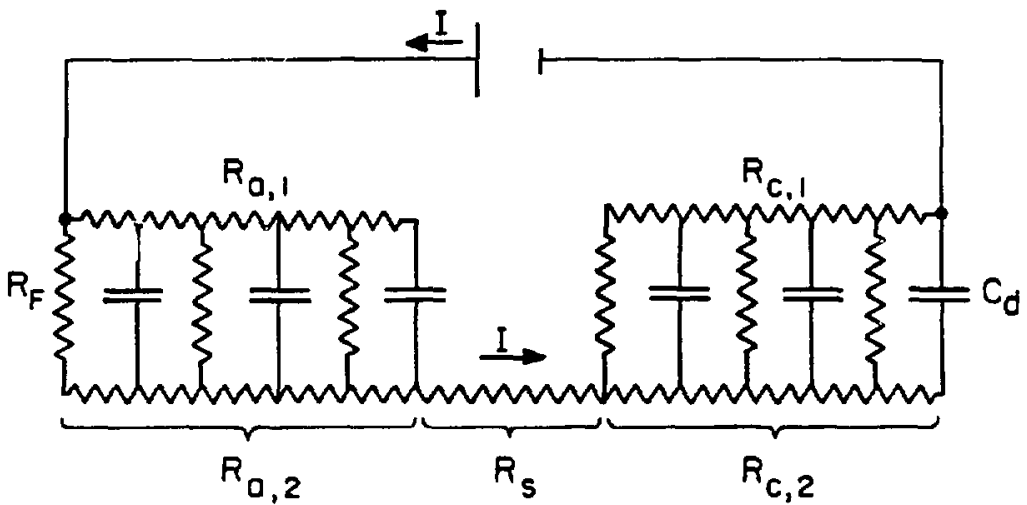

XBL 833-5452

Figure 3-1. Simplified electrical analog of a porous anode and cathode (subscripts a and c respectively) showing the resistance in the matrix phases (subscript 1) and solution phases (subsctipt 2). Also shown is the faradaic charge-transfer resistance $\left(R_{f}\right)$, electrical double-layer capacity $\left(C_{d}\right)$, and separator resistance $\left(R_{S}\right)$. 
interface. In parallel to this process, net current flows via a faradaic reaction where $\boldsymbol{R}_{\boldsymbol{f}}$ represents the charge-transfer resistance of the electrochemical reaction. These processes occur nonuniformly throughout the volume of the porous bed. It is cautioned that this figure is meant to serve as a guide in thinking about the distribution of reactions in porous electrodes, but it is not a substitute for modeling the porous electrode with the approptiate governing equations. Mass transfer of reacting species, for example, is not considered in the electrical analog.

The mathematical description of porous electrodes assumes a macro-homogeneous system The porous bed is represented as the superposition of two continua, a matrix and a solution. The actual geometric detail of the bed is ignored, and average physical parameters such as porosity and surface area are used. This type of analysis leads to a volume-averaged approach in the derivation of the governing differential equations. 34 ,ss

A schematic of a section of a porous bed is shown in figure 3-2 The volume-averaged material balancess of a species $i$ within a flooded porous bed in the absence of homogeneous chemical reactions takes the form

$$
\frac{\partial\left(e c_{1}\right)}{\partial t}=a j_{m}-\nabla \cdot N_{1}
$$

Here three different averages are used. is the forosity or void volume fraction. $a$ is the specific interfacial area (surface area of pore walls per unit volume of bed). $c_{i}$ is the concentration averaged over the volume of solution in the pores. $\epsilon c_{i}$, then, is the superficial concentration averaged over the bed volume (matrix plus pores). $j_{i n}$ is the normal component of the pore wall fux of species $t$ into the solution relative to the velocity of the pore wall, averaged over the interfacial area. $N_{1}$ is the average hux of species $i$ in the pore solution averaged over the cross-sectional area of the pore plus matrit

With the fux $N$, referenced to the cross-sectional area of the pore plus matrix, the superficial current density $\boldsymbol{I}_{2}$ in the solution phase is given as 
Porous electrode

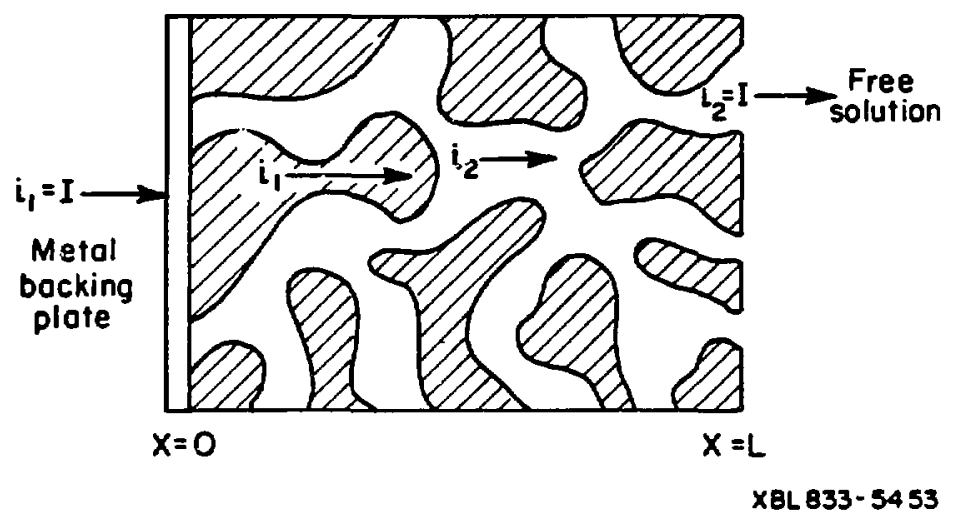

Figure 3-2 Schematic of a one-dimensional porous electrode showing current flow in the matrix $\left(i_{1}\right)$ and solution $\left(i_{2}\right)$ phases. 


$$
\mathbf{I}_{2}=\boldsymbol{F} \boldsymbol{\Sigma}_{1} \mathbf{z}_{1}
$$

Similarly, I , the current density in the matrix phase, is defined to refer to the superficial area and not to the area of an individual phase.

The matrix and solution phases are taken to be electrically neutral. For the solution, then,

$$
\sum_{i} z_{i} c_{i}=0
$$

We have assumed that the electrical double luycr at the matrix-pore interface is a small volume compared to our averaging volume. This assumption may break down for very dilute solutions and high-surface-area electrodes. Electroneutrality requires that the divergence of the total current density $\left(i_{1}+i_{2}\right)$ is zero, charge leaving the matrix must enter the solution. Thus,

$$
\boldsymbol{\nabla} \cdot \mathbf{I}_{1}+\nabla \cdot \mathbf{i}_{2}=\mathbf{0}
$$

A combination of equations $3-1,3-2$, and $3-3$ gives

$$
\nabla \cdot i_{2}=a r \sum_{i} z_{j} j_{i n}=a i_{n} .
$$

where $i_{n}$ is the average transfer current density from the matrix to the solution phase. $\nabla \cdot i_{2}$ is the transfer current per unit volume of the electrode $\left(A / \mathrm{cm}^{3}\right)$ and is positive for anodic currents. For a single electrode reaction represented as

$$
\sum_{i} s_{i} M_{i}^{2} \rightarrow \text { ne: }
$$

Faraday's law becomes

$$
a f_{m}=-\frac{a s_{1}}{n F} i_{n}=-\frac{s_{1}}{n F} \nabla \cdot i_{2} .
$$

Substitution into equation 3-1 and neglect of double-layer charging yield

$$
\frac{\partial\left(t c_{l}\right)}{\partial t}-\nabla \cdot N_{1}-\frac{s_{l}}{n F} \nabla \cdot i_{2} .
$$

A kinetic polarization equation relating the local rate of reaction (transfer current density) to the surface concentrations and interfacial potential drop is needed. For the porous electrode, the kinetic equation takes the form 


$$
\nabla \cdot I_{2}=\operatorname{aio}_{0}\left[\exp \left(\frac{a_{s} F}{R T} \eta_{s}\right)-\exp \left(\frac{-a_{c} F}{R T} \eta_{s}\right)\right] .
$$

Porosity changes can be taken into account by a solid-phase material balance for a single electrode reaction:

$$
\frac{\partial e}{\partial t}=-A_{0} \nabla \cdot I_{2}
$$

where

$$
A_{0}=-\sum_{\substack{\text { solld } \\ \text { pheser }}} \frac{s_{1} M_{t}}{\rho_{1} n F} .
$$

Transport processes are needed to complete our description. Obris law for the matrix phase is

$$
I_{1}=-\nabla \Phi_{l}
$$

where $\sigma$ is an effective matrix conductivity dependent on the composition of solid phases, the manner in which the granules of the conducting phases are connected together, and the volume fraction of conducting phase or phases.

For a dilute electrolytic solution in the pores, the flux of a mobile solute can be at:ributed to diffusion, dispersion, migration, and convection:

$$
\frac{N_{1}}{e}=-\left(D_{1}+D_{l}\right) \nabla c_{l}-z_{i} u_{i} F c_{i} \nabla \Phi_{2}+\frac{\nabla c_{i}}{e} \text {. }
$$

where $u_{f}$ is an ionic mobility and $D_{l}$ is an ionic diffusion coefficient, both corrected for the tortuosity of the pores. $D_{a}$ represents the effect of axial dispersion. A discussion of the effect of axial dispersion on the average mass-transfer coefficient is found in the review article by Newman and Tiedemann; 45 see also Fedkiw and Newman. ${ }^{50}$ The current density in the solution phase can now be represented by

$$
i_{2}=-x \nabla s_{2}-\epsilon F \sum_{i} z_{i} D_{i} \nabla c_{i} \text {. }
$$

where $a-\epsilon F^{2} \sum_{l} z_{1}{ }^{2} u_{j} c_{j}$. The second term in equation 3-14 represents the diffusion potential. As a consequence of electroneutrality, convection and dispersion make no contribution to the curtent density. 
We should also recognize here that otber forms of the transport equations may be necessary to describe a system. The appropriate equations for a concentrated binary electrolyte are given in Newman and Tiedemann, 46 and two binary molten salts are treated by Pollard and Newman." When necessary, the full multicomponent transport equations can be used.

In sumimary, the equations presented above have been found to describe adequately porous electrodes in many cases. A certain level of complexity is necessary in order to treat the simultaneous interaction of the physical processes. Equations 3-1, 3-2, 3-3, and 3-13 govern the transport, conservation, and electrical neutrality in the solution phase. Equation $3-12$ covers the transpon in the matrix phase. Equations 3-4 and 3-9 couple the species in the bulk phase to the electrochemical processes occurring at the interface. These equations are normally considered boundary conditions in systems not involving porous electrodes, but here they are applied throughout the volume of the bed.

\subsubsection{Limiting-Current Anatysis}

Let us now illustrate an imporant design principle for flow-tbrough porous electrodes. ${ }^{45.15}$ Consider the case of reducing a species $i$ at the limiting cursent in an excess of supporting electrolyte. Equation $3-1$ becomes

$$
\frac{d N_{1}}{d x}=a j_{i=4}
$$

for a one-dimensional, steady-state material balance. (A onedimensional analysis is appropriate when the current flows parallel to the velocity, as shown in (a) and (b) of figure 3-3.) In the absence of migration in an electric field for the reacting species, the superficial flux of species $i$ in the direction of the superficial fluid velocity is (from equation 3-13)

$$
N_{1}=-\left(D_{i}+D_{1}\right) \frac{d c_{1}}{d x}+c_{i} v
$$

The local fux to the wall is given by a local mass-transfer coefficient $k_{m}$ such that

$$
j_{i n}=k_{m}\left(c_{b}-c_{1}\right)--k_{m} c_{1} \text {. }
$$

where the wall concentration $c_{t 0}$ has been set equal to zero at limiting current. Substitution of 


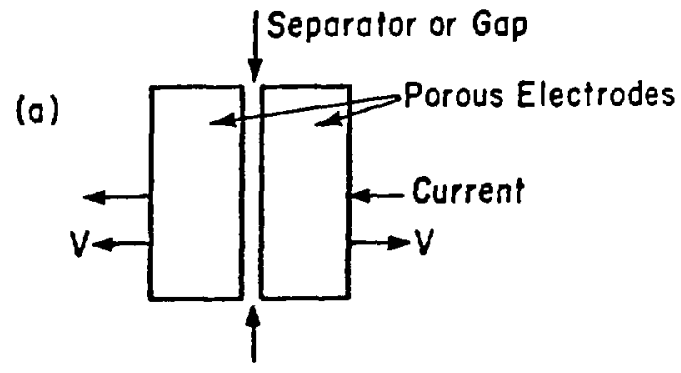

Direction of Flow

(b)
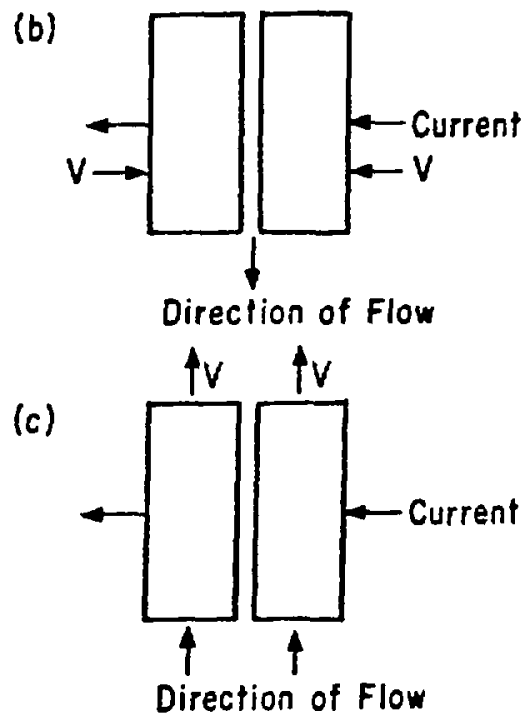

XBL 796-10074

Figure 3-3. Various configurations of electrode placement relative to the direction of fluid flow. (a) and (b) are flow-through configurations (current and fuid flow are peraltel), and (c) is the flow-by configuration (current flows perpendicular to auid flow). 
equations $3-16$ and 3-17 into the continuity equation $3-15$ gives

$$
v \frac{d c_{1}}{d x}=\epsilon\left(D_{1}+D_{1}\right) \frac{d^{2} c_{1}}{d x^{2}}-a k_{m} c_{j} .
$$

Equation 3-18 governs the concentration distribution of species I throughout the reactor. It is solved subject to the Danckwers, 98 Wemer and Wilhelm ${ }^{\text {s9 }}$ boundary conditions for the concentration of species $i$ at the inlet $(x-0)$ and the outlet $(x-L)$ of the reactor. This formulation assumes that an inert packing extends from the active portion of the bed in both the upstream and downstream directions. A result of the constraints that the concentration of species $i$ cannot increase without bounds and that the concentration and flux should be continuous is

$$
\frac{d c_{1}}{d x}=0 \text { at } x=L
$$

For the upstream boundary condition, an inlet concentration of $c_{0}$ and continuous concentration and flux give

$$
c_{a} v=c_{i} v-c\left(D_{l}+D_{a}\right) \frac{d c_{i}}{d x} \text { at } x=0 .
$$

Under this condition, the concentration at the inlet of the bed will be less than $c_{o}$ because some of the reactant will bave diffused abead to the active portion of the bed. The solution to equation 3-18 subject to boundary conditions 3-19 and 3-20 is

$$
\theta-\frac{e^{-\rightarrow / \theta}+\frac{D^{\prime}}{B^{2}} e^{\Delta / \sigma^{\prime}} \exp \left[-\alpha L\left(\frac{1}{B}+\frac{B}{D^{\prime}}\right)\right]}{B+\frac{D^{\prime}}{B^{2}}(1-B) \exp \left[-\alpha L\left(\frac{1}{B}+\frac{B}{D^{\prime}}\right)\right]},
$$

where we bave introduced the quantities

$$
\begin{aligned}
& \theta=\frac{c_{1}}{c_{0}}, y-\frac{a k_{m} x}{v}, D^{\prime}=\frac{c a k_{m}}{v^{2}}\left(D_{1}+D_{a}\right) . \\
& B=\frac{1+\sqrt{1+4 D}}{2}, \text { and } \alpha=a k_{m} / v .
\end{aligned}
$$

Note that equation $3-21$ simply reduces to 


$$
\begin{aligned}
& c_{1}=c_{0} e^{-x} \\
& \text { or } \theta=e^{-y}
\end{aligned}
$$

when the effects of axial dispersion and diffusion are ignored.

The behavior of the current density in solution is governed by equation 3-18 when Faraday's law is substituted for the local flux to the wall. Equation $3-18$ becomes

$$
v \frac{d c_{1}}{d x}-{ }_{c}\left(D_{1}+D_{a}\right) \frac{d^{2} c_{1}}{d x^{2}}-\frac{s_{1}}{n F} \frac{d i_{2}}{d x} .
$$

For an upstream counterelectrode, the current density $i_{2}$ must 80 to zero at the back of the electrode as all the current has been transferred to the matrix and current collector. Using this boundary condition and integrating equation 3-24 give

$$
v\left(c_{t}-c_{L}\right)-c\left(D_{i}+D_{a}\right) \frac{d c_{i}}{d x}-\frac{s_{i}}{n F} i_{2},
$$

where the subscript $L$ refers to the exit of the reactor. Ohm's law for the solution (equation $3-$ 14) is taken as

$$
t_{2}=-x \frac{d \phi_{2}}{d x} .
$$

The diffusion potential has been igr ored here, a good assumption when an excess of supporting electrolyte is present. Integration of equation 3-26 subject to equations 3-25 and $3-22$ gives the local variation of potential through the bed. This result is expressed as

$$
\Phi_{2}(L)=\phi_{2}(0)-\frac{n F v c_{0}}{s_{R}^{\alpha}} \frac{v}{a k_{m}}\left[B^{2} \theta_{L} e^{\alpha L / D}-\frac{D^{\prime}}{B}-\left(\alpha L+1+D^{\prime}\right) \theta_{L}\right] \text {. }
$$

Figure $3-4$ shows the nature of the potential variation through the electrode bed. The potential in the matrix is constant through the length of the bed if the matrix conductivity is very high. The finite solution conductivity, however, causea a variation in solution potential as the current flows from the front to the back of the electrode. The potential driving force at the back of the electrode $\Phi_{1}-\Phi_{2}(L)$ must be large enough to insure limiting current, while the potential difference at the front of the alectrode must not be large enough to bave secondary reactions, such as hydrogen evolution. Thus, we bave a maximum allowable obmic potential drop in our reactor. As the bracketed quantity in equation 3-27 is of order unity, the coefficient of this 


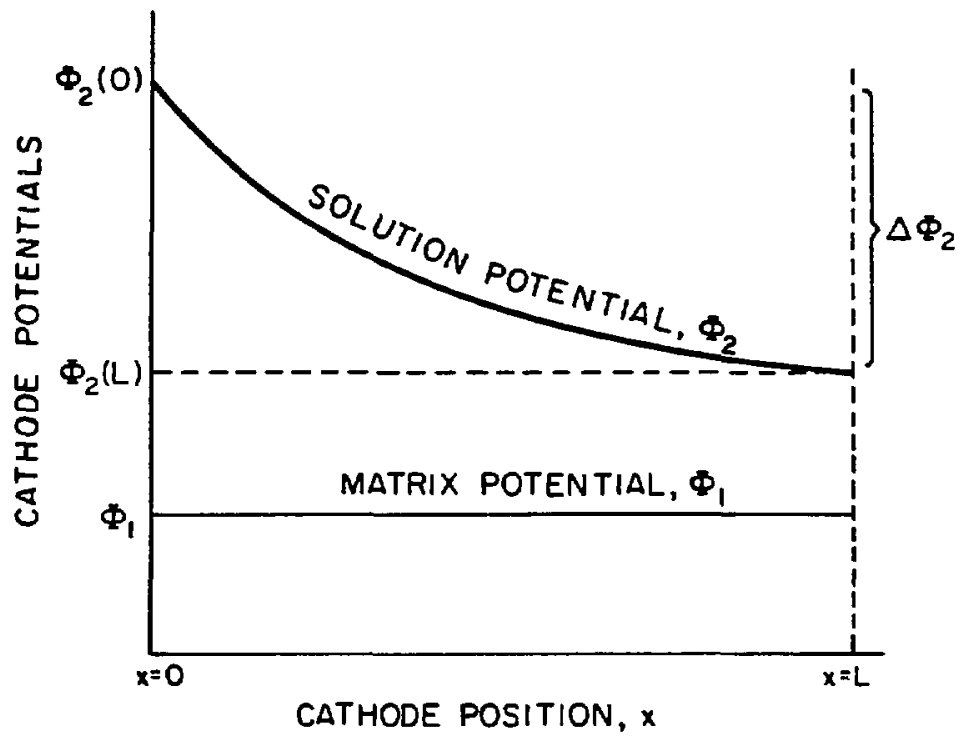

XBL B34.5488

Figure 3-4. Variation of solution and matrix potentials as a function of position through a porous cathode. Matrix conductivity is infinite. 
quantity represents the magnitude of the potential variation in the porous bed. Thus we see that, for given values of $c_{0}$ and $\alpha_{1}$ side reactions limit the maximum flow rate through the bed. Since $v / a k_{m}$ represents the order of magnitude of the distance through the reactor where the reaction occurs to an appreciable extent, a limit on the velocity also limits the useful thickness of the bed.

In designing a porous electrode, $\Phi_{2}(L)-\Phi_{2}(0)$ can be assigned a maximum value based on data that might be taken on rotating-disk eiectrode. Equation $3-27$ can then be solved for the velocity $v$, if the mass-transfer coefficiene is bnown. What is left to be specified, then, is the length of the electrode. The electrode length is governed by the desired degree of conversion. Equation 3-21 can be solved for $L$ if $y$ is replaced by $\alpha L$ and $\theta$ is replaced by $\theta_{L}$, the desired conversion.

\subsubsection{Mase-Transfer Coefficieat}

In order 10 predict the performance of a porous electrode, the mass-transfer behavior of the bed must be known. The mass-transfer coeficient $k_{m}$ introduced in equation $3-1$ ? is a local value. Local values of wall and bulk concentration are not easily measured, however, and we require an overall mass-transfer coeficient based on iniet and outlet reactant concentrations. The overall mass-transfer coeficient $\bar{k}_{m}$ is defined on the basis of the total molar flux to the wall and a log-mean concentration driving force.

$$
\frac{v\left(c_{0}-c_{L}\right)}{a L}-\bar{k}_{m}\left\{\frac{(\Delta c)_{0}-(\Delta c)_{L}}{\ln \frac{(\Delta c)_{0}}{(\Delta c)_{L}}}\right\} .
$$

At limiting current the wall concentration approaches zero, and we obtain

$$
\bar{k}_{m}-\frac{\nu}{a L} \ln \left(\frac{c_{0}}{c_{L}}\right) .
$$

Evaluation of equation 3-21 at the exit of the reactor and substitution of $\theta$ into equation 3-29 yield the relationship between the average and local mass-transfer coefficient. 


$$
\bar{k}_{m}=\frac{k_{m}}{B}+\frac{v}{a L} \ln \frac{B+\frac{D^{\prime}}{B^{2}}(1-B) \exp \left[-\alpha L\left(\frac{1}{B}+\frac{B}{D^{\prime}}\right)\right]}{1+\frac{D^{\prime}}{B^{2}}}
$$

Setting $D^{\prime}$ equal to zero neglects the effect of axial dispersion, and $\bar{k}_{m}=k_{m}$. Newman and Tiedenann ${ }^{4 s}$ present a graphical solution for determining the length of the bed when the masstransfer coefficient is given by a correlation. Fedkiw and Newman ${ }^{\text {s3 }}$ present a dual-sized, straight-tube model which adequately represents the mass-transfer coefilicients at low Reynolds numbers.

\subsection{Atmospheric, Porous-Electrode Experiments}

Here we are concerned with operating a flow-through reactor at limiting current as a means for removing lead from solution. Of primary importance is the ability of the reactor to remove lead in the presence of a competing bydrogen side reaction.

\subsubsection{Introduction}

To design the reactor from the start, we need to consider the relative placement of both the anode and current collector. ${ }^{60}$ Qualitatively, an upstream counterelectrode will yield the bighest reactant concentration and the highest potential driving force at the front of the electrode. A downstream counterelectrode will bave the maximum reactant concentration where the potential driving force is smallest. Thus, this latter configuration might appear to give a more uniform reaction distribution throughout the bed. It is important then to consider the best configuration to achieve a given objective. Calculations show that the best configuration for achieving low effluent concentrations is with an upstream counterelectrode. This rule applies for both bigh and low ratios of $\sigma / \alpha$. In fact, a limiting-cursent distribution cannot be achieved for a system utilizing a downstream counterelectrode (except for short reactors). For very high values of $\sigma / x$, the matrix potential is constant, and placement of the current collector is not important. For moderate matrix conductivities, the optimum placement of the current collector depends on the particular chemical system being investigated and the actual value of $\sigma / \kappa$. 
The Pourbaix diagram showing the competition between the hydrogen side reaction and the lead deposition is seen in figure 3-5. The potentials were calculated vs, the standard bydrogen reference electrode neglecting activity coefficients and any liquid-junction potentials. The lead discharge follows

$$
U=U^{*}+\frac{R T}{2 F} \ln \left(\frac{c_{p^{2+}}}{p_{0}}\right) .
$$

The bydrogen side teaction is a function of pressure as well as concentration;

$$
F U=R T \ln \left(\frac{c_{\mathrm{H}^{+}}}{\rho_{0}}\right)-\frac{1}{2} R T \ln p_{\mathrm{H}_{2}},
$$

where $p_{a}$ is the density of the pure solvent $(g / c), U^{\infty}$ is the standard cell potential, and $p_{\mathrm{H}_{2}}$ is the partial pressure of hydrogen (atm). Deviations of the pertial pressure of hydrogen from the total pressure amount to only $0.7 \mathrm{mV}$ at 100 atm pressure when the second virial coefficient is included as a correction from ideality. Also shown for comparison is the potential for mercury removal from $4 \mathrm{M}$ brine solutions. For the predominate species $\mathrm{HgCl}_{4}{ }^{2-}$,

$$
U=U^{+}+\frac{R T}{2 F} \ln \left(\frac{\rho_{0}^{3} c_{\mathrm{H}_{1} \mathrm{C}_{4}^{2}}}{c_{a^{4}}^{4}}\right) .
$$

The $\mathrm{Pb}$ (II) species in solution are actually complexed with the sulfuric acid ${ }^{41}$ Thus, the actual potentials needed to be in equilibrium with a given lead concentration are even more negative than is shown in figure 3-5 or given by equation 3-31. Also note that figure $3-5$ is valid only for the the lead/lead(II) equilibrium of equation 3-31. Other solid or ionic species may exist that would limit the range of allowable lead concentrations.

The solubility of $\mathrm{PbSO}_{4}$ in $\mathrm{H}_{2} \mathrm{SO}_{4}$ shows an interesting maximum and minimum ${ }^{61}$ In pure water, the solubility of lead sulfate is estimated to be $27 \mu \mathrm{gb} / \infty \mathrm{c}$ at $25^{\circ} \mathrm{C}^{\dagger}$ Addition of sulfuric acid begins to lower the lead sulfate solubility due to the effect of the common sulfate ion. In $0.086 \% \mathrm{H}_{2} \mathrm{SO}_{4}$, the solubility has dropped to $3.53 \mu \mathrm{g} \mathrm{Pb} / \mathrm{cc}$. The solubility coninues to decrease to a local minimum of $3.11 \mu \mathrm{g} / \mathrm{ec}$ at $0.3 \% \mathrm{H}_{2} \mathrm{SO}_{4}$ where further increases in sulfuric

'This value wa alaulated from equation 3-36 by uring the activity coefficieat of lead sulfate fopual to unity. 


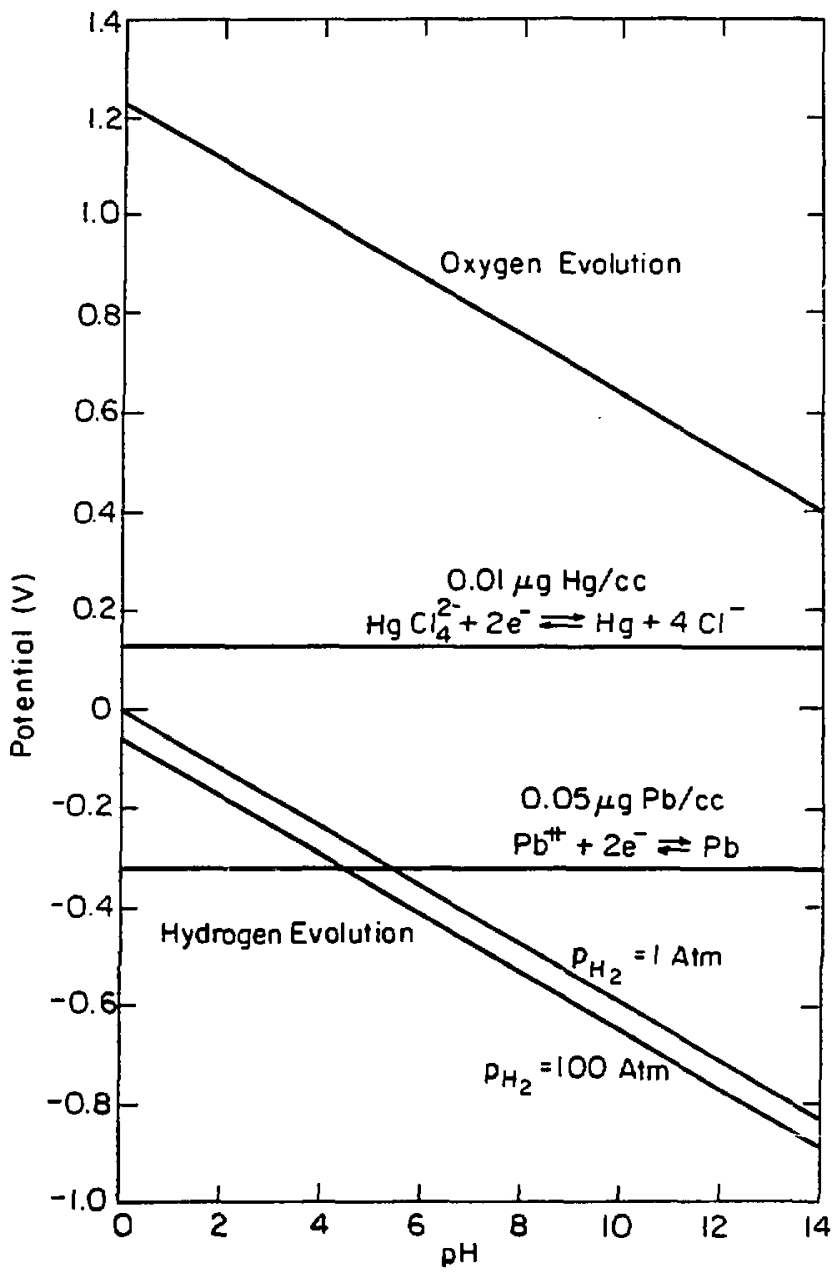

XBL 039-6460

Figure 3-5. Pourbaix dizgram showing the thermodynamic potential required to discharge mercury, lead, hydrogen, and oxygen. 
acid concentration cause the solubility to rise. A local maximum of $4.56 \mu \mathrm{g} / \mathrm{cc}$ is reached at $10 \% \mathrm{H}_{2} \mathrm{SO}_{4}$. Data were taken up to $50.0 \% \mathrm{H}_{2} \mathrm{SO}_{4}$, where the solubility has fallen to $0.74 \mu \mathrm{g} / \mathrm{cc}$. Af $0^{\circ} \mathrm{C}$ the local maximum and minimum occur at approximately the same acid concentrations and yield solubilities of $1.95 \mu \mathrm{g} / \propto c$ and $1.40 \mu \mathrm{g} / \mathrm{cc}$ respectively. As an aside, it is interesting to note that the solubility of $\mathrm{Hg}_{2} \mathrm{SO}_{4}$ in sulfuric acid closely follows the shape of the $\mathrm{PbSO}_{4}$ curve; the ratio of $\mathrm{Hg}_{2} \mathrm{SO}_{4}$ to $\mathrm{PbSO}_{4}$ solubility remains essentially constant over acid plus salt concentrations of $0.002 M$ up to $3.5 \mathrm{M}^{61}$

The solubility of $\mathrm{PbSO}_{4}$ in water is approximately 10 times the value of the local minimum at $0.3 \% \mathrm{H}_{2} \mathrm{SO}_{\text {. }}$. It was suggested that the initial decrease from the pure-water solubility was due to the common-ion effect and the subsequent rise and fall around the local maxima was controlled by the sulfate/bisulfate equilibrium from the sulfuric acid. This is in agreement with the possible complexed forms of lead in solution.

The solubility data for lead in sulfuric acid allow the estimation of the activity coefficient of lead sulfate. For the chemical reaction $\mathrm{Pb}^{2+}+\mathrm{SO}_{4}{ }^{2}-\mathrm{PbSO}_{4}$, the equilibrium condition an be expressed as $\mu_{p_{0}}{ }^{2+}+\mu_{s o}-\mu_{p a s o}$, where $\mu$ is the electrochemical potential of species i. Relating the electrochemical potential to the activity of each species yields

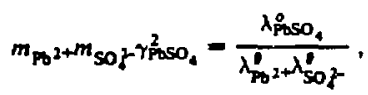

where $m_{i}$ is molality of species $i, \gamma_{\mathrm{HSO}}$, is the mean-iunic activity coefficient of $\mathrm{PbSO}_{4}, \lambda_{f}^{\prime}$ is a property related to the secondary reference state, and $\lambda_{\mathrm{pasO}}^{0}$, is the absolute activity of $\mathrm{PbSO}_{4}$ The thermodynamic standard electrode potentials for lead and lead sulfate can be combined to give

$$
\frac{\lambda_{\mathrm{p}^{2+}+\lambda_{\mathrm{So}}}}{\lambda_{\mathrm{PasO}}^{0}}-\exp \left(\frac{0.356-0.126}{R T / 2 F}\right)=6 \times 10^{7} \mathrm{~kg}^{2} / \mathrm{mol}^{2} .
$$

Thus, equations 3-34 and 3-35 give, 


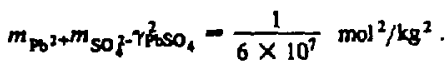

For a $10 \%$ sulfuric acid solution, the actual sulfate molality is dependent on the bisulfate/sulfate equilibrium If we assume complete dissociation, $m$ so, is calculated to be $1.13 \mathrm{~mol} / \mathrm{kg}$. From the data on the solubility of lead in $10 \%$ sulfuric acid, we can then calculate $r^{2} \mathrm{SO}_{4}=7.15 \times 10^{-4}$, based on stoichiometric dissociation of $\mathrm{H}_{2} \mathrm{SO}_{4}$. This number would be expected to remain approximately constant and could be used over a range of lead concentrations. If needed, however, the detailed solubility data could be used to continue to map out the complete behavior of the activity coefficient as a function of molality.

In summary, then, we see that at high acid concentrations and low lead concentrations, bydrogen car evolve preferentially to lead deposition based on thermodynamic considerations. For increases in cell pressure by factors of ten, the hydrogen half-cell potential moves cathodic by approximately $30 \mathrm{mV}$. In actual cell operation, even at high pressures, the electrode must be polarized thodically relative to the decomposition potential of the acid solution. Whether bydrogen actually evolves and at what rate will be determined by the surface kinetics and possibly riss-transfer considerations.

Erdey-Gruz ${ }^{62}$ summarizes the Tafel plots for hydrogen evolution on vaious metals aiter several authors. The binetic constants are very sensitive to the state of the electrode surface and any impurities. Although the results of the various authors vary, qualitatively it is seen that the bydrogen overpotential on lead lies between mercury and carbon.

The effect of pressure on the binetics of bydrogen evolution has not been siudied in as much detail. Bircher and Harkins ${ }^{63}$ studied hydrogen evolution on $\mathrm{Ni}, \mathrm{Pb}$, and $\mathrm{Hg}$ electrodes at bydrogen pressures between 0.014 and 1 atm Knobel studied $\mathrm{Pt}, \mathrm{Pb}, \mathrm{Cu}$, and Ni between 0.029 and 1 atm and Cassel and Krumbein ${ }^{6 s}$ and Casisel and Voigts studied bydrogen evolution on $\mathrm{Pt}, \mathrm{Ni}$, and $\mathrm{As}$ at higher pressures up io 19 atm. All of these studies showed no effect of pressure on the cell voltage required to maintain a given curtent density. Thus, pressure had no effect on the forward rate erm (hydrogen production), and the surface 
overpotential simply followed the offset in thermodynamic potential at the various pressures. Hills and Kinnibrugh ${ }^{67}$ studied hydrogen production on $\mathrm{Hg}$ for pressures ranging from 250 to $1500 \mathrm{~atm}$. In these experiments they fixed the coneentration of molecular hydrogen in the solution. Relative to a constant current density, they found small differences in the surface overpotential, on the order of $8 \mathrm{mV}$ difference between the two cases of $250 \mathrm{~atm}$ and $1500 \mathrm{~atm}$ Thus, the reactor pressure will have a negligible effect on the forward rate term, but possibly a substantial effect on the reverse term.

Returning to the limiting-current analysis given above, we see in figure 3-4 the qualitative variation of the solution potential from front to back of the electrode. The minimum concentration attainable ${ }^{64}$ in the porous electrode will be the concentration of lead that would be in equilibrium with the potential at the exit of reactor. At $-0.322 \mathrm{~V}$ vs. the normal hydrogen reference electrode, figure 3-5 yields a minimum attainable lead concentration of $0.05 \mu \mathrm{g} \mathrm{Pb} / \mathrm{cc}$. This value corresponds to the wall concentration, however, and the actual bulk exit concentration will be greater.

We could polarize the porous electrode to arbitrarily large negative values in order to decrease the effluent lead concentration, but as pointed out above, the rate of secondary bydrogen evolutiod will limit reactor performance. Even if the loss of current efficiency is tolerated, at least three other effects must be considered. The first is tiut some evidence was seen that the lead deposition reaction and hydrogen evolution reaction do not occur in parallel (independently) at high current densities. Second, the additional current generated by the increased potential my all go into hydrogen evolution and none into lead depasition; the differential current efliciency may be zera. Third, the onset of gas nucleation causes a stirring of the solutios, "pretting the concentration profile within the reactor. Equation $3-22$ shows the exponential dependence of bulk concentration on distance through the porous bed. The majority of reactant is removed in an entrance region of depth $1 / \alpha-y / a k_{m}$ where the exit to inlet concentration ratio is raduced to a value of $1 / e$. Each added "penetration" length to the 
reactor decreases the effluent concentration by another factor of $1 / e$. Thus, although the back end of the electrode bas a relatively low current for the main reaction, significant reductions in efflueat concentration can still be obtained. This exponential variation in composition is easily upset, however, by any gas nucleation, especially at the exit of the reactor.

Trainham and Newran ${ }^{6 *}$ extend the governing equations presented above to include the effect of a side reaction, eg. hydrogen evolution. The gas is assumed to remain dissolved in solution so that the hydrodynamics and mass-transfer coefficient are unaltered. The reaction rate. current efficiency, wall concentration, and bulk concentration are all presented as functions of distance through the electrode. The obmic potential drop through the reactor was calculated as a function of the exit potential driving force $\Phi_{1}-\Phi_{2}(L)$. This reduces to the value given by equation $3-26$ only for large negative polarizations with no side reaction. The onsel of hydrogen evolution causes a sharp increase in potential drop at the higher polarizations, especially if the bydrogen evolves preferentially at the rear of the electrode.

\subsection{Experimental System}

The experimental system was initially setup to study the removal of mercury from brine solutions. ${ }^{17}$ In these experiments, mercury was cathodically deposited during the experimental run and then anodically stripped in preparation for the next run. Roughly, eleven mercury experiments were run over a period of 9 months. Each experiment ran for one to two days, processing approximacely 15 liters of brine feed. At the end of the last run, the mercury was not stripped from the bed in preparation for the lead experiments. A film of mercury on the bed, even if nonuniformly distributed through the bed, would help reduce hydrogen evolution or: the porous cathode. The experimental apparatus was not altered in any way for the lead removal runs; the brine solution was simply purged from the experimental apparatus by running a lead, sulfuric acid feed through the system 


\subsection{Cell Design}

A schematic of the experimental cell is given in figure $3-6$, and a photograph is given in figure 3-7. The anode was placed on top of the working electrode, which corresponds to the upstream-counterelectrode configuration discusued above. The cell proper was composed of four parts: an anode chamber, a feed ring, a cathode chamber, and a catholyte outlet flange, al! fabricated from lucite. Adjoining pieces were bolted together (flange to flange) with six, I0-32 socket-head, stainless steel sctews. All fluid seals were made with Viton Q-rings; a 1/8 inch wall, 3 1/4 inch ID Oring sealed the carhode compartment to the catbolyte exit flange, a 1/8 inch wall, $23 / 8$ inch ID Oring sealed the cathode compartment to the bottom of the feed ring, and a $3 / 32$ inch wall, 1 13/16 inch ID Oring sealed the feed ring to the anode compartment.

An inert, Pt-Rh screen spot-welded to a $1 / 4$ inch tantalum rod was used as an anode for oxygen evolution. To prevent back mixing of the oxygen into the catholyte, a Nafion (DuPont Company) perfluorostulfonic acid ion-exchange membrane was placed near the top of the feed ring. A separate porous lucite disk (cross-hatched in figure 3-6) was "force-6t" over the ionexchange membrane, holding it in place during cell operation. A vent tube was placed just below the Nafion membrane in the side of the feed ring. This tube allowed for the removal of gat when flling the cell or during reactor operation.

Upstream and downstreim reference-electrode compartments were tapped into the side of the feed sing and catholyte exit flange respectively. (See figure 3-7.) Either Beckmann Quartz Fiber Junction Saturated Calomel or Beckmann Saturated ( $\mathrm{K}_{2} \mathrm{SO}$ ) Mercurous Sulfate Sleeve Junction ("40455) reference electrodes were used to monitor the solution potentials. The upstream reference electrode controlled the applied voltage to the cell. During operation a giass copillary tube was attached to the mouth of the electrode port and fed down to the top of the porous bed. In this manner the majority of ohmic drop between the top of the bed and the reference-lectrode tap was eliminated. The downstream reference electrode was below the exit of the bed, and no ohmic potential drop corrections were necessary. Fluid was restricted from 


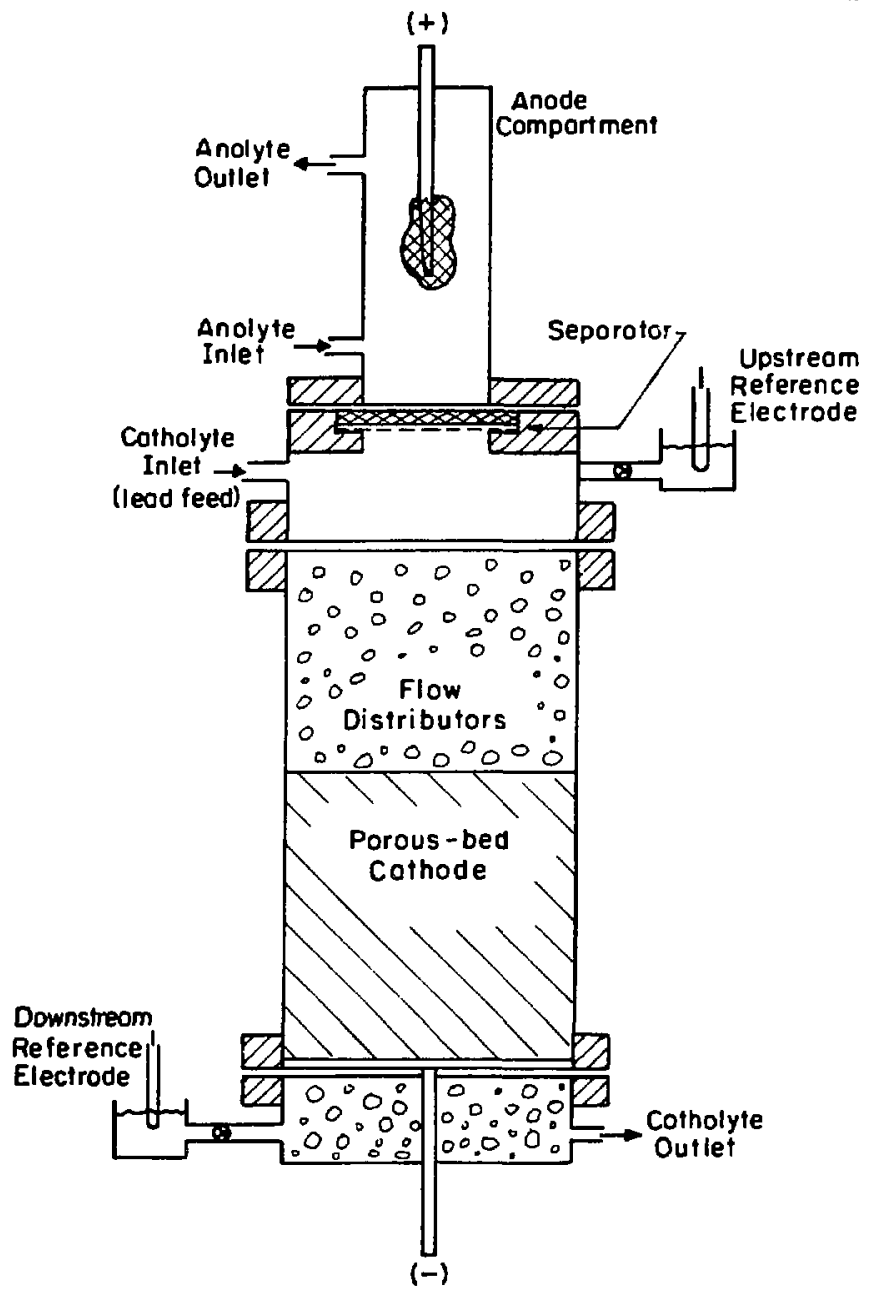

XBL $839-6461$

Figure 3-6. Schematic of the atmospheric, porous-electrode experimental cell. 


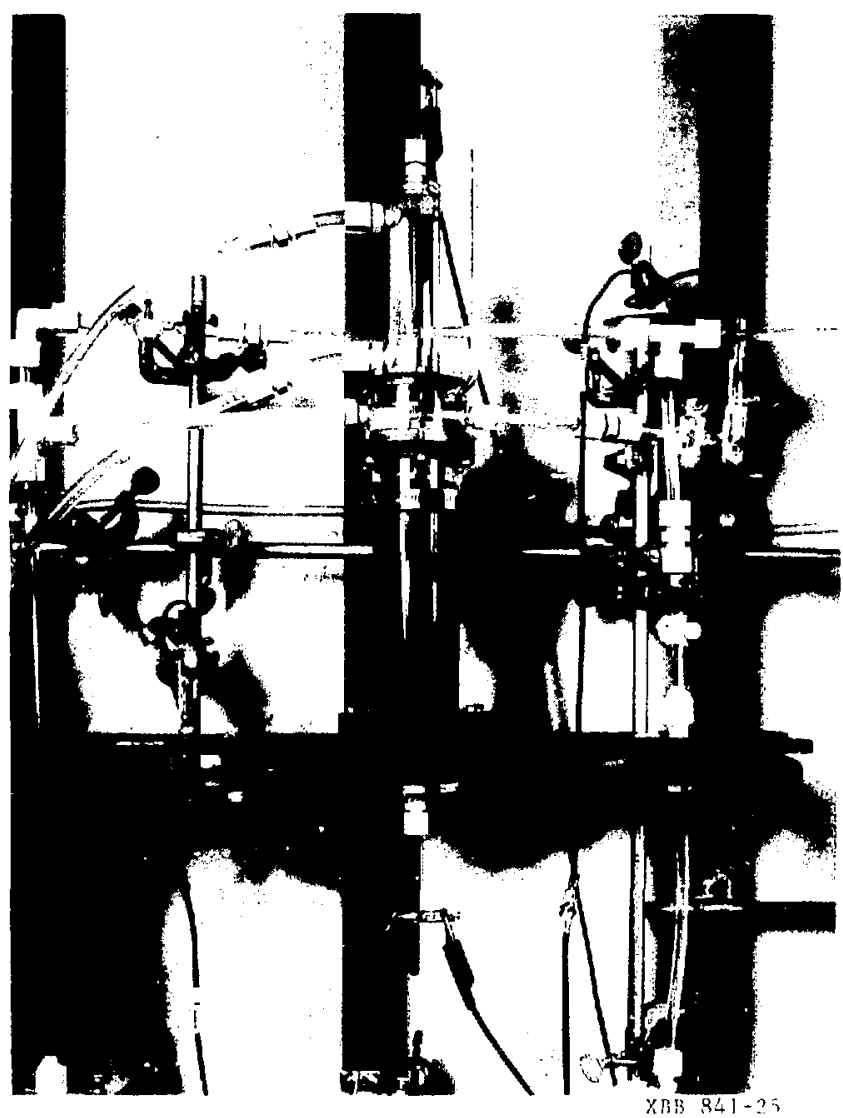

Figure 3-7. Photograph of the experimental cell showing the reticulated vitreous carbon bed, anode compartment, feed ring. and reference electrodes. Also seen are the inert flow distributors. 
fowing out the reference-electrode ports by glass stopcocks. Electrical continuity was insured by simply wetting tbe stopoock

The catbode compartment beld the porous packed bed, the current collector, and the flow distributors. The cross-sectional area of the cell measured $20.27 \mathrm{~cm}^{2}$, and reactor lengths up to 10 inches could be used. Inert glass beads were placed before and after the porous bed to provide an entry and exit region lor fluid flow. A uniform flow distribution is necessary to prevent the channeling of fluid around active portions of the bed.

The cathode current collector was a $3 / 32$ inch thick tantalum plate bored with an array of number 56 wire drill boles to allow for fluid flow. A $1 / 4$ inch tantalum rod, welded to the center of the plate, was used to provide electrical continuity to the bed. The rod was fed out of the bottom of the cell and sesled with a polypropylene compression fitting. A small amount of Pl-Rh screen had been spot-welded to the current collector face for protection against hydrogen embrittlement. This was highly undesirable in the lead experimis, however, because of platinum's catalytic activity toward hydrogen evolution. The back of the current collector plate and rod were Kynar (Pennwalt Corporation, Philadelphia, PA) coated to eliminate electrochemical reactions below the porous bed. The separate pieces of the cell are shown in figures 3.8 and $3-9$. Figure 3.8 sbows the anode chamber, feed ring (with vent tube and capiliary tube), and lucite disk that beld the Nafion membrane. Figure 3-9 shows the cathojyte outlet flange, current collector (bottom view), and cathode chamber.

\subsubsection{Catbode Material}

The catbode material used was a reticulated vitreous carbon (RVC) porous matrix purchased from ERG, Incorporated, Oakland, CA. This material is a an open-pore, glassycarbon "foam" material, which combines the properties of glass and nomal industrial caroons. It has a rigid, porous structure of bigh void volume (97 percent) and high specific surface area (66 $\mathrm{cm}^{2} / \mathrm{cm}^{3}$ ). The material is very brittle, but it can be machined (shaved or cut to length) if done carefully. A photograph of the RVC matrix is given in figure $3-10$. 


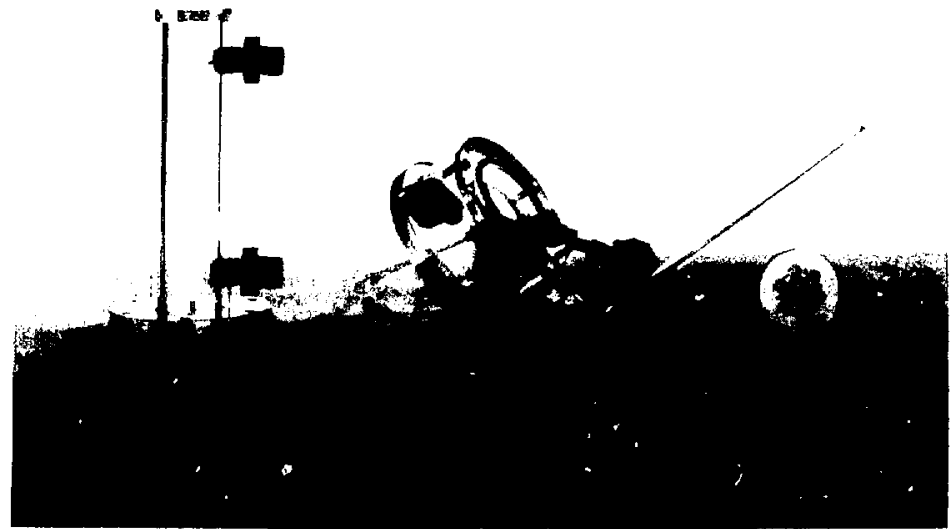

XBB 841-26

Tigure 3-8. Photograph of the anode chamber. feed ring, and lucitc disk. 


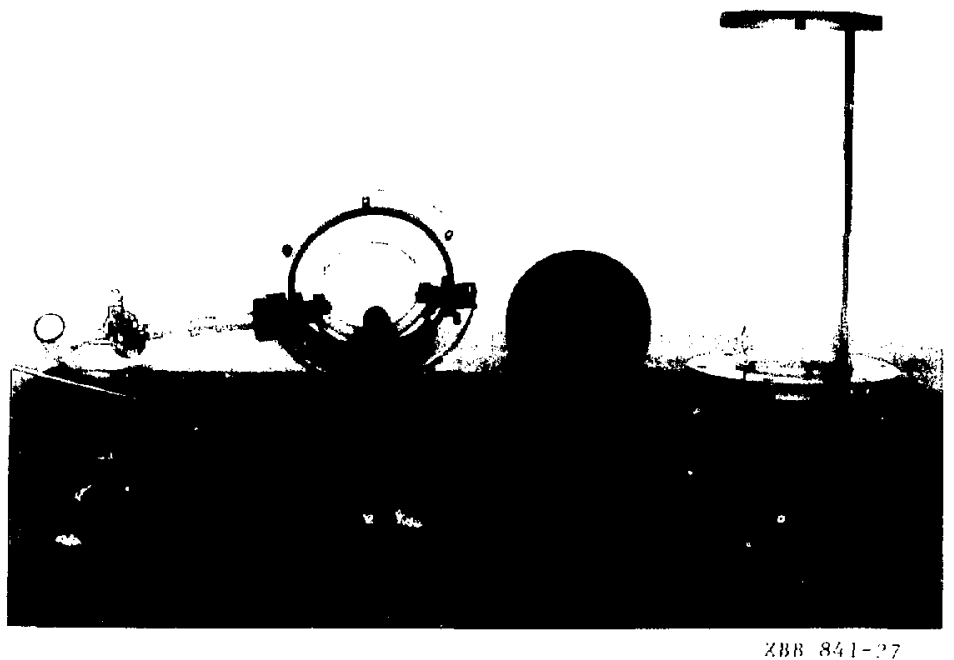

Hegure 3-9 Photograph of the catholyte outlet flange, current collector. and ciath de chamber 


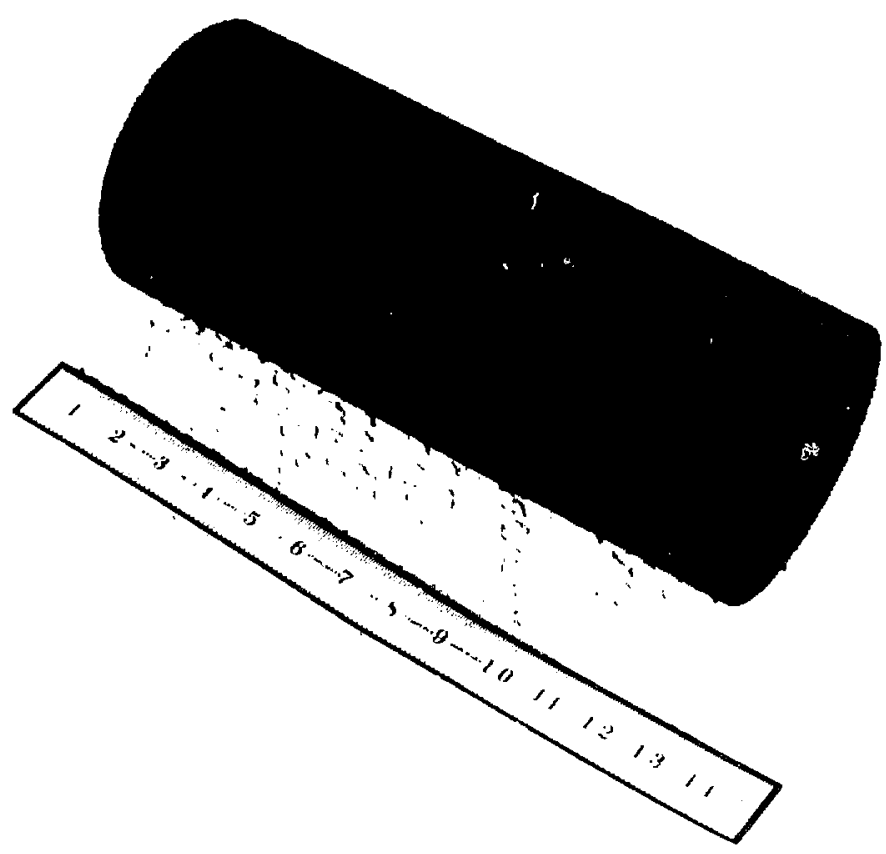

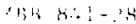

Figure 3-10 Plotograph of the reticulated virsene carbon matrax 
Various types of porous carbon electrodes have been studied over the years. Heise, ${ }^{70}$ in 1939, described several applications for porous carbon electrodes in electrochemical operations. Recenty, reticulated vitreous carbon bas seen applications in electrochemistry as a new electrode material. ${ }^{7}$ RVC bas a high electrical conductivity and is resistant to corrosive environments. It is presently being evaluated, for example, as as a current collector in a molten-salt, sodium-sulfur, cramic electrolyte cell $\left(\mathrm{Na} / \mathrm{Na}_{2} \mathrm{O} \cdot \mathrm{xA}_{2} \mathrm{O}_{3} / \mathrm{SCl}_{3} \mathrm{AlCl}_{2}\right.$ in $\mathrm{AJCl}_{3}-\mathrm{NaCl}$, $T=250^{\circ} \mathrm{C}$ ) being considered for electric-vehicle applications.

RVC has also seen applications in analytical chemistry. Blaedel and $\mathrm{Wang}^{72}$ have studied the anodic stripping voltammetry of $\mathrm{Cu}(\mathrm{II}), \mathrm{Pb}(\mathrm{II}), \mathrm{Cd}(\mathrm{II})$, and $\mathrm{Zn}$ (II) on a mercury-coated RVC electrode. Lead concentrations in the range of $5 \times 10^{-7} M$ could be analyzed. They first deposited a mercury film $\mathrm{m}$ the RVC from a $0.5 \times 10^{-3} \mathrm{M} \mathrm{HgCl}_{2}, 0.1 \mathrm{M} \mathrm{KCl}$ solution held at a potential of $-0.8 \mathrm{~V}$ vs. a $\mathrm{Ag} / \mathrm{AgCl} / 0.1 \mathrm{M} \mathrm{KCl}$ reference electrode. If necessary, plating was done in a quiescent solution to promote a uniform distribution of mercury throughout the volume. In their work, anodic sweeps were kept below $+0.1 \mathrm{~V}$ to prevent mercury dissolution. When deliberately stripping off the mercury, the voltage was maintained at $+1.0 \mathrm{~V}$ for at least 30 minutes. This may be important when considering how to regenerate a bed that has degraded in performance. Very recently Wang and Dewald"3 report on the use of a flow-through RVC electrode for the removal of metals. Effuents were monitored with anodic stripping voltammetry on a mercury-coated RVC electrode. Good removal of lead from nitrate solutions was reported, but the details of the competing hydrogen side reaction and the mass-transfer coefficients are not given.

The reticulated vitreous arbon used for these experiments was five inches long with an outer diameter machined to fit the cathode compartment. When pressed into the cathode chamber, the RVC was a tight fit, and a separate mechanical seal was not necessary to prevent channeling around the outside of the packed bed. A photograph of the cathode chamber showing the RVC bed in the cell is given in figure $3-11$. 


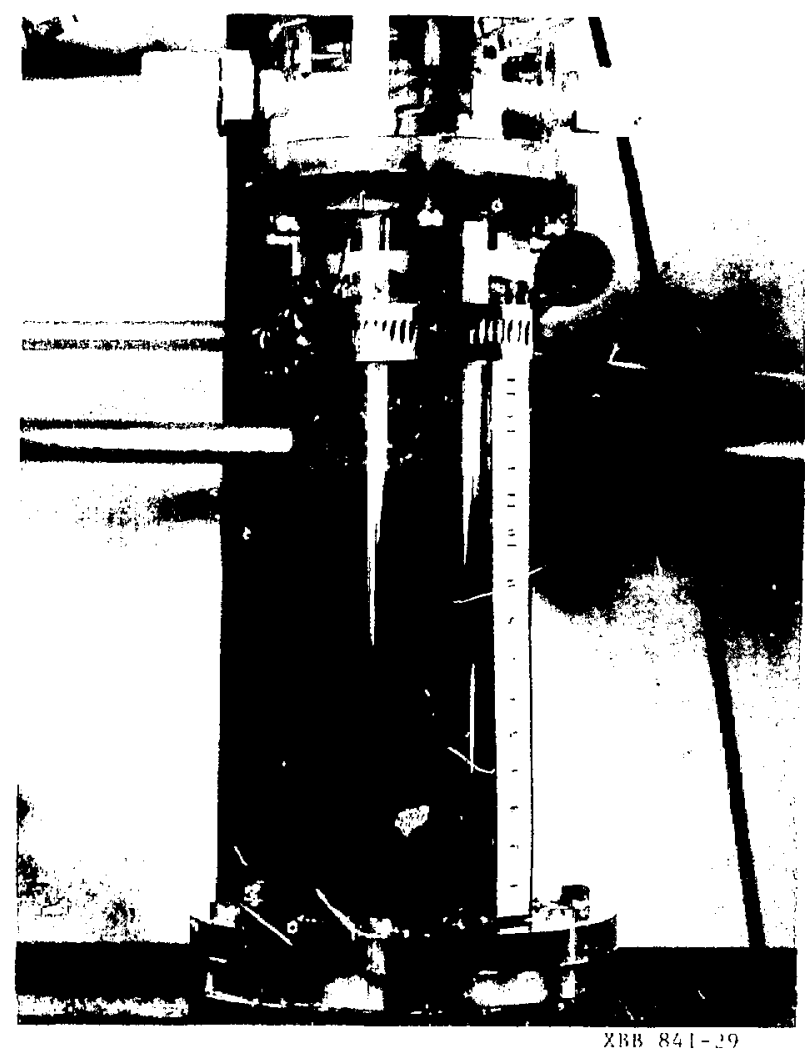

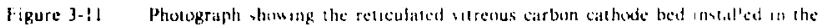
experimentis system Niso seen are the unert llow distributurs 


\subsection{Flon Syste:}

The flow system was designed so that the reactor could be run with either an upstream or downstream counterelectrode. Data were taken only for the upstream configuration, however. where reactant was pumped into the feed ring above the inert glass spheres. During the reactor operation, the feed solution was sparged with nitrogen to eliminate interference with oxygen reduction on the cathode. Deoxygenated feed solution was pumped through a Gilmont flow meter and into the experimental system with a Fluid Metering pump. Pulsations in flow caused by the pump were reduced with a flow damper before entering the reactor. All tubing was made from Bev-A-Line (Thermoplastic Scientific, Incorporated), and all fittings were made of polypropylene. The anode compartment was upstream of the cathode, separated by a Nafion ion-exchange membrane. A separate metering pump was used to circulate anolyte continuously through this chamber. As oxygen evolved on the screen, the bubbies rose and were swept out of the anode chamber as the electrolyte circulated. Anolyte make-up was the same as the feed solution and was replenished from time to time to maintain feed $\mathrm{pH}$.

\subsubsection{Electrical Setup}

A schematic of the instrumentation is seen in figure 3-12. The potential of the working electrode relative to the upstream reference electrode was controlled with an AIS (division of Floyd Bell Associates, Incorporated) model V-2LR-D potentiostat. This potentiostat operates by floating all potentials off earth (case) ground. The reference electrode is shielded and driven to prevent leakage currents and capacitive pickup. A working-sense lead is provided as a separate voltage tap to eliminate errors due to obmic potential drops in the workirg-electrode lead. Current and applied voltages were read directly from the digital meters after checking for agreesnent between the ostput meters and independent measurements. A Keithley model 173A multimeter with an input impedance of $10^{9} \Omega$ was used to monitor the ohmic drop through the bed. 


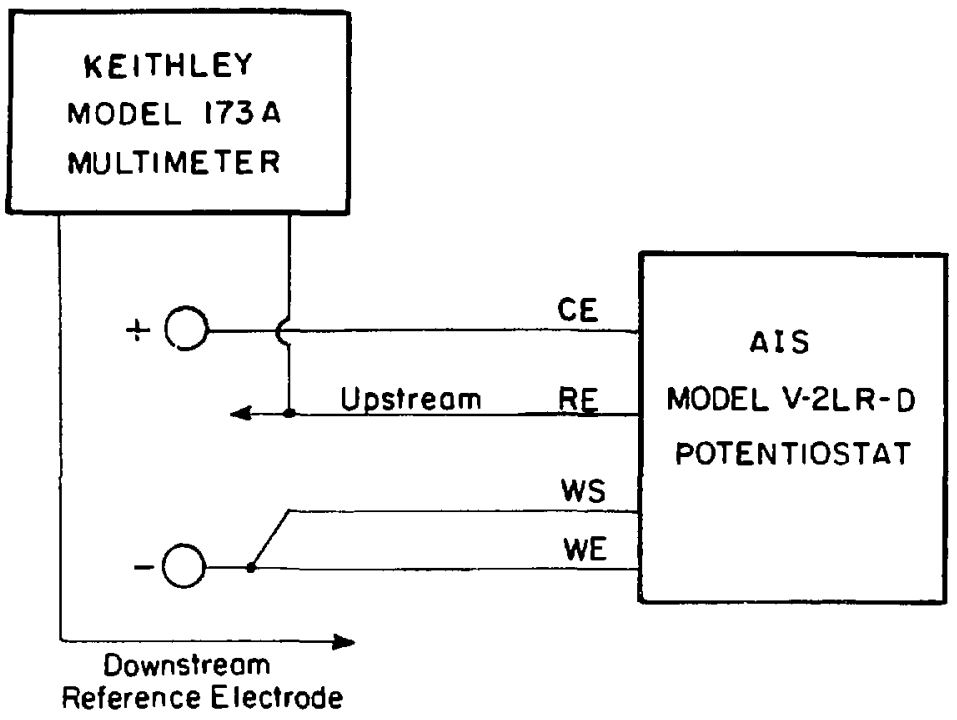

XBL $839-6462$

Figure 3-12. Schematic of the electrical instrumentation used in the atmospheric porouselectrode experiments. 
The entire fluid system was isolated from all ground potentials. The Fluid Metering pump bead, for example, was made out of ceramic and was electrically isolated from its case. No fluid came into contact with any metal outside the electrochemical cell. These considerations assured that ground-loop problems would be minimized.

A photograph showing the entire apparatus is given in figure 3-13.

\subsubsection{Procedure}

Electrolytic solutions were made up from J. T. Baker reagent grade lead sulfate and Mallinckrodt analytical reagent sulfuric acid. Dilutions were made from deionized water (SYBRON/Barnstead model D3613 reverse asmosis and ion excharge) with a specific resistance greater than $16 \mathrm{M} \Omega$-cm. Feed solutions were "pre-sparged" with nitrogen in a 50 liter holding tank to remove dissolved oxygen. Solutions were transferred from the bolding tank to a six liter Elenmeyer flask where deoxygenation continued with a nitrogen sparger and magnetic stirrer. (See figure 3.13.) The nitrogen was left on throughout the run, and feed solution was transferred froin the holding tank to the flask as necessary.

No special treatment of the reticulated vitreous carbon was done. The mercury that had been plated during the last series of mercury experiments was left on the RVC electrode to help inhibit hydrogen evolution. In this sense, the electrode was not well characterized because of the nonuniform distribution of mercury through the bed.

The system was completely purged of brine solution before data was taken on the lead system. Al least 10 bed volumes of lead feed solution were passed through the reactor for each point taken. The flow rate was monitored from a flow meter at the pump exit, but the actual flow rates recorded were always measured with a graduated cylinder and stopwatch. Samples were taken at the exit of the catholyte in polyethylene vials that had been soaked in $6 \mathrm{M}$ nitric acid for at least 24 hours. 


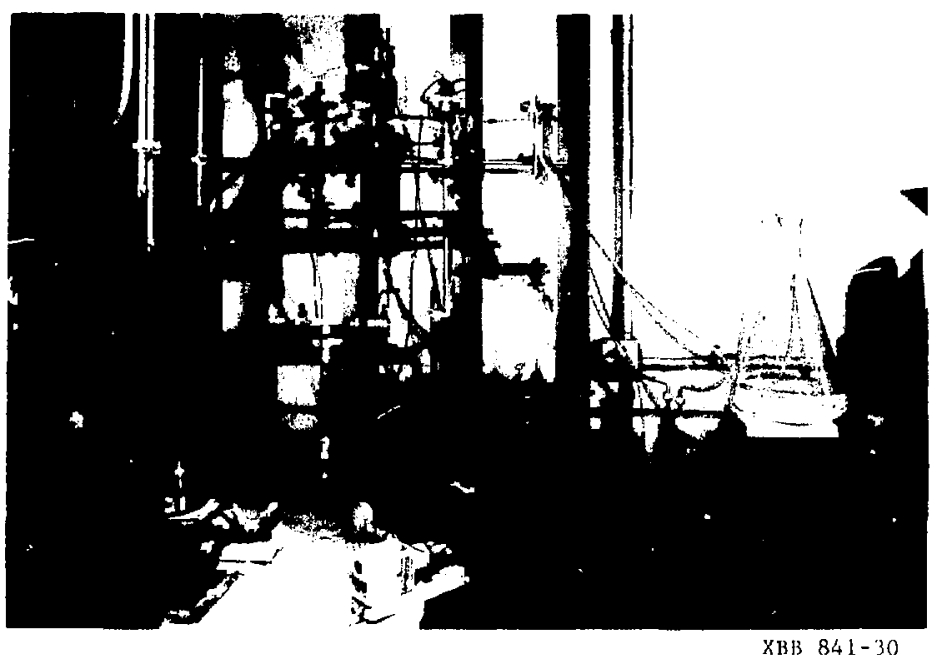

Figure 3.13. Photograph of the entire porous-electrode experimental system. 


\subsection{Results}

The results obtained on the RVC eiectrode are very promising but not conclusive. Four relevant experimental runs are described in some detail below.

Run A was the first set of data taken on the RVC electrode after the mercury-removal experiments. The results of a polarization curve taken for a flow rate of $115 \mathrm{cc} / \mathrm{min}$ are given in figure 3-14. The data plotted are the partial lead currents, calculated from the measured effluent concentrations. The flow rate used was the maximum that the pump could deliver and corresponded to approximately 0.5 bed volumes per min. This high flow rate was used to help sweep fluid past the electrode bed before the onset of bydrogen nucleation. The knee of the limiting-current curve is seen to occur at approximately $-1.0 \mathrm{~V}$ vs. a saturated calomel reference electrode. At this point the obmic drop was measured to be $175 \mathrm{mV}$, and the back of the electrode was at a potential of $-0.825 \mathrm{~V}$ relative to a saturated calomel reference electrode. Although no nucleation of hydrogen was observed throughout this run, the current efficicncy was still very poor. Figure 3-15 shows the total measured current and the calculated partial bydrogen current for this run. At limiting current (or very close to limiting current) the current efficiensy is approximately 7.5\% After termination of this rur, the potential relative to the reference electrode was approximately $-0.5 \mathrm{~V}$. This open-cireujt value is very likely a corrosion potential, as it lies between the potentials for the anodic formation of lead sulfate and the catbodic reduction of hydrogen ions. Furbermore, the reactor bed showed trapped gas after sitting for 24 hours. Since th: bed was lushed with fresh feed solution after shutdown, the trapped gas could not have come from hydrogen that was produced during the experiment; the gassing must have come from the corrosion reaction. The negative plate of the lead-acid battery undergoes self-discharge processes where lead is converted to lead sulfate and hydrogen gas is produced. Thus, a corrosion reaction of lead to lead sulfate can be expected to occur to some extent waile sitting at open circuit. The corrosion reaction may occur to a greater extent here than in a lead-acid battery because of the available surface for hydrogen evolution on the 


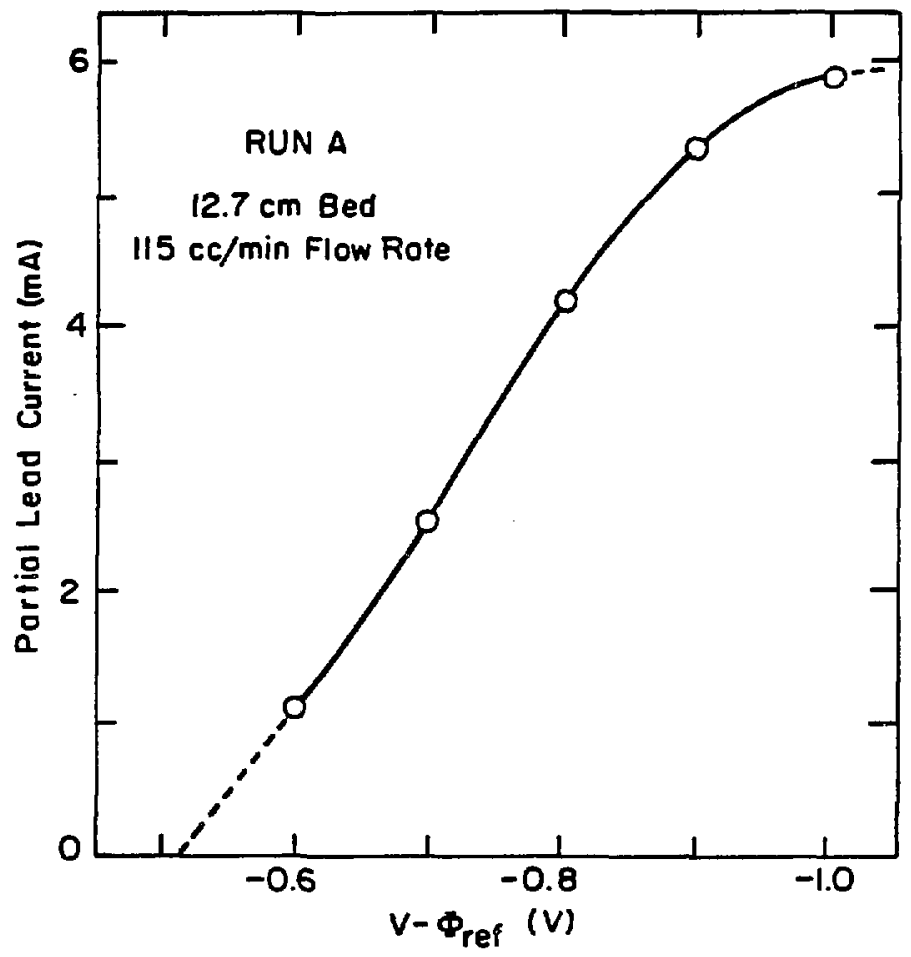

XBL $839-6463$

Figure 3-14. Calculated partial lead currents vs. applied potential (relative to a saturated calomel reference electrode). 


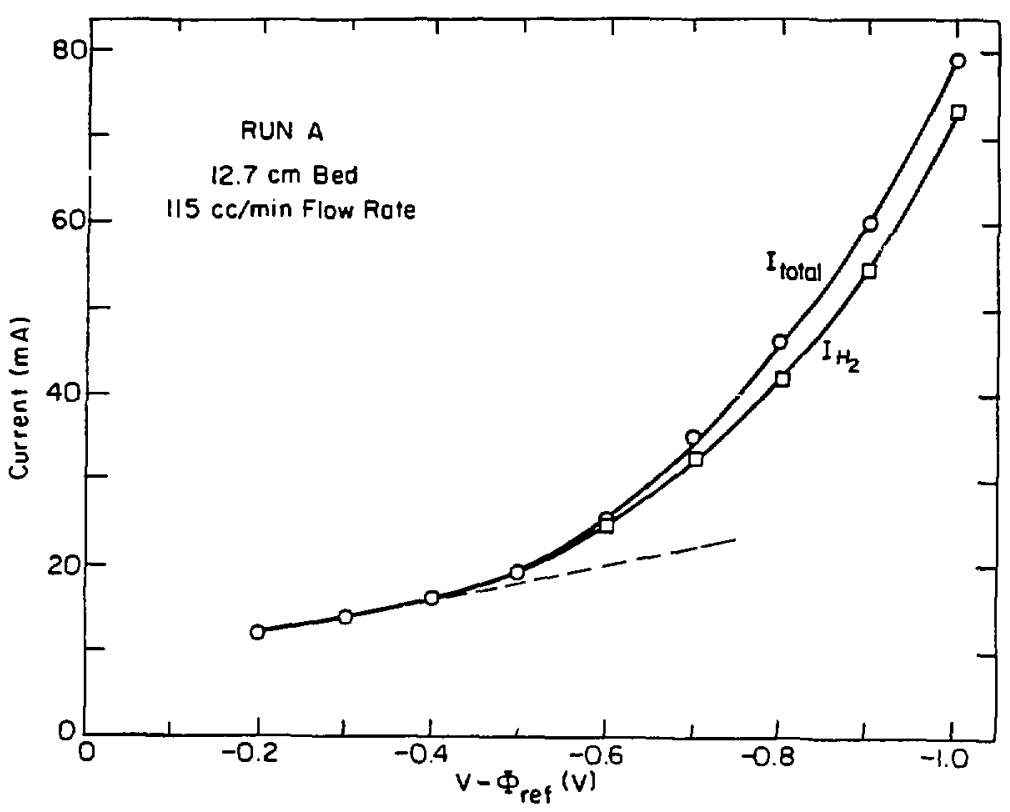

XOLOJ9-6464

Figure 3-15. Measured total current and calculated partial hydrogen current v5. applied potential, demonstrating the poor current efficiency. Applied potential is relative to a saturated calomel reference electrode. 
current collector.

Af the start of run B (approximately 36 bours after completion of run A), the working vs. reference potential had risen to approximately $+0.2 \mathrm{~V}$. It is not clear what balf cell or corrosion potential the reference electrode was sensing This potential lies in the thermodynamic region where lead sulfate would be expected to be the only stable solid phase. Since the potential has been driven positive, it is likely responding to some dissolved oxygen in the solution.

A polarization curve was taken for a flow sate of $48 \mathrm{cc} / \mathrm{min}$, begirning at a potential of $-0.5 \mathrm{~V}$. At this potential the measured effluent concentration was greater than the feed concentration. These observations support the conclusion above that the measured potential of $-0.5 \mathrm{~V}$ at the end of run $\mathrm{A}$ was a corrosion potential. The start of run B, then, was dealing with trying to reduce the lead sulfate that had formed from run A As $-0.6 \mathrm{~V}$ polarization, the outlet concentration dropped down to the feed value. This can be compared to figure 3-14 where some lead had been removed at $-0.6 \mathrm{~V}$ on the fresh earbon bed.

A series of flow rates was run at polarizations of -0.9 and $-0.95 \mathrm{~V}$ to determine how well the reactor could remove lead at lower flow rates. Lowering the flow rate increases the concentration of molecular hydrogen in solution and therefore also increases the probability of bubble nucleation. Although some bubble formation was observed, there were no major upsets to the fluid flow.

No bubble nucieation was ever observed to occur on the RVC bed. This observation combined with approximate obmic calculations suggested that most $\alpha$ all of the hydrogen evolution was cocurring on the tentalum current collector. In an effort to try to plate lead on the current collector, the fluid flow was reversed for the start of run C (downstreamcounterelectrode operation), A flow of $120 \mathrm{cc} / \mathrm{min}$ at $-0.975 \mathrm{~V}$ was passed through the reactor for 1 bour. The observed total current was not significantly different from the current observed for other runs at this polarization. There was also no decrease in current with time that would 
have indicated formation of a lead layer. The reactor was retumed to normal upstreamcounterejectrode operation, and a series of limiting current vs. flow rate points were taken.

Cassing became mare of a problem in this run than had previously been observed. Nucleated bubbles periodically dislodged up through the bed causing a stirring of the solution. No loss of potentiostatic control occurred, however, and the process maintained a quasi-steady state. The inaccuracies in flow rate caused by the bubble evolution made limiting-current measurements difficult or inaccurate. Only two reliable points were retained. The behavior of the bed degraded in performance in this run relative to the performance of the above two runs. The rate of hydrogen nucleation increased, and the efficiency of lead removal decreased.

In an effort to "regenerate" the bed and possibly improve the lead kinetics, the electrode was deliberately run alternately as an anode and cathode, as might be done in cycling a leadacid battery. The applied potential was cycled between $-0.018 \mathrm{~V}$ and $-1.1 \mathrm{~V}$ witb respect to a saturated mercurous sulfate reference electrode. (The potential difference between the $\mathrm{Hg} / \mathrm{Hg}_{2} \mathrm{SO}_{4}$ and $\mathrm{Hg} / \mathrm{Hg}_{2} \mathrm{Cl}_{2}$ reference electrodes was $+0.45 \mathrm{~V}$, measured in the feed solution.) At an applied potential of $-0.018 \mathrm{~V}$, the bed was acting as an anode, and at a potential of -1.1 $V$, the bed was a cathode. The anodic potential should not have been high enough to form any lead oxides, but it is well into the thermodynamically stable region for lead suifate. The ential was changed back and forth every 10 to 20 minutes for 2.5 tours. At the end of c ing, the polarization was set at $-1.1 \vee$ for 3.25 hours (23.5 bed volumes) before the first data were taken. (run D) A polarization curve was taken from $-1.1 \mathrm{~V}$ to $-1.55 \mathrm{~V}$ in increments of $-150 \mathrm{mV}$. No bydrogen evolution was obseryed, and the point at $-1.55 \mathrm{~V}$ was taken as limiting current.

The data for the four runs described above are summarized in table $3-1$. Only the points where gas nucleation did not upset the flow regime are presented.

Figure 3-16 summarizes the limiting-current results of runs A-D by plotting the Sherwood number vs. the Péclet number. Toe Sherwood number is the product of the average mass- 


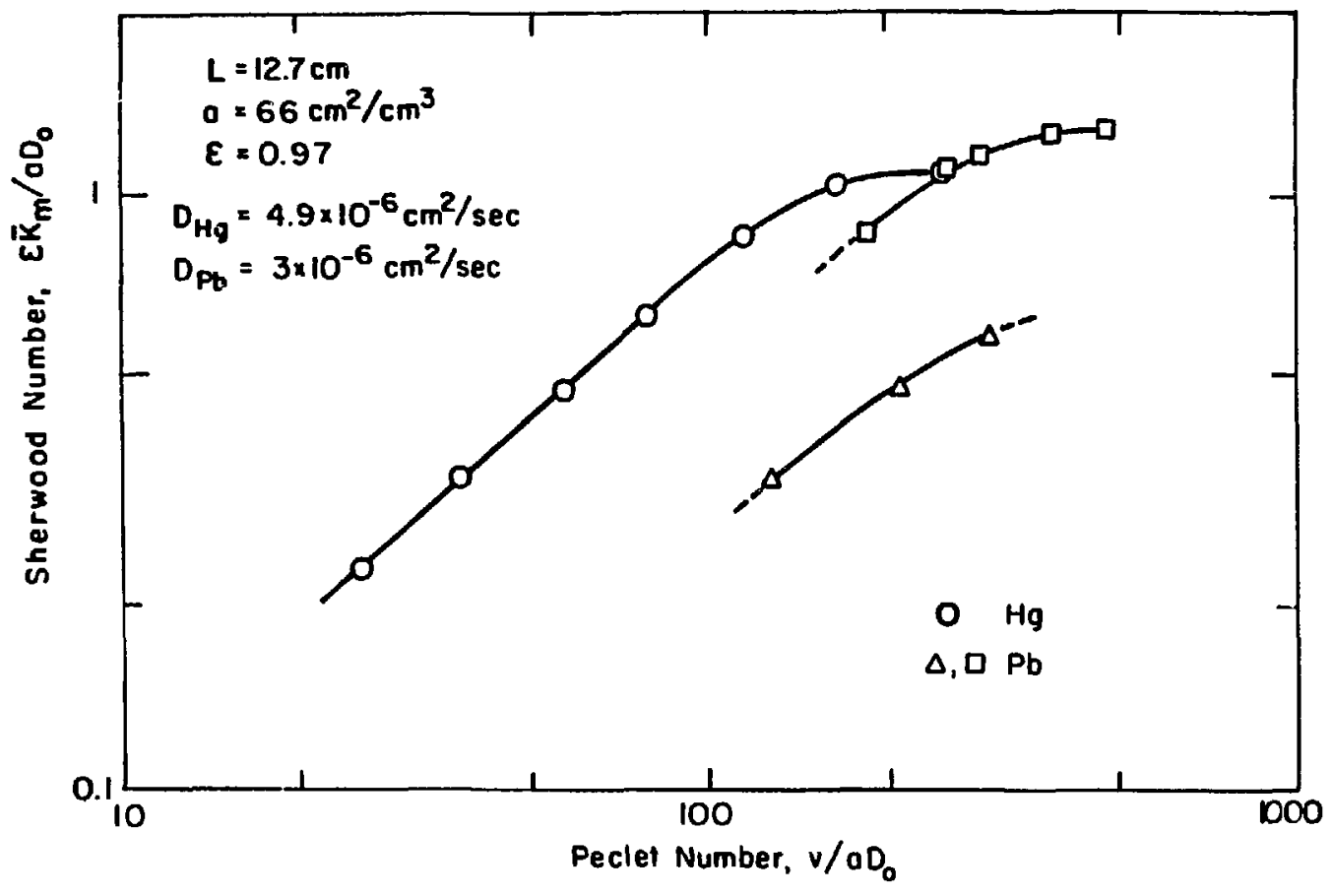

XBL839-646s

Figure 3-16. Sherwood number vs. Peclet number for the mercury-removal data and four sets of lead-removal runs. 
Table 3-1: Lead Removal Data

Run

Sample

$Q(\propto) / \min )$

I(mA)

$V-\Phi$

$c_{2} / c_{0}$

A

$\begin{array}{ll}\text { A-1 } & 112 \\ \text { A-2 } & 112 \\ \text { A-3 } & 114 \\ \text { A-4 } & 111 \\ \text { A-5 } & 111 \\ \text { A-6 } & 112 \\ \text { A-7 } & 116 \\ \text { A-3 } & 111 \\ \text { A-9 } & 116\end{array}$

12

14

16

19

25

34

45.5

59.5

78.5

$-0.2$

$-0.3$

$-0.4$

$-0.5$

$-0.6$

$-0.7$

$-0.8$

$-0.9$

$-1.0$

I.0

1.0

1.0

1.0

0.83

0.61

0.36

0.18

0.096

B

$\begin{array}{ll}\text { B-1 } & 47 \\ \text { B-2 } & 48 \\ \text { B-3 } & 49\end{array}$

479

$48 \quad 15$

48.5

26

B-4

B-6

B-7

B.8

B-9

B.10

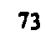

70

92

62

45

c

C. 3

C-4

C.6

72

51

100

37.5

$-0.5$

1.27

$-0.6$

$-0.7$

1.0

$-0.8$

0.63

0.28

352

60

$-0.9$

0.17

$-0.95$

0.031

61

48

$-0.95$

0.056

48

$-0.9$

$-0.9$

0.0174

D

$\begin{array}{ll}\text { D-1 } & 33.5 \\ \text { D-2 } & 30 \\ \text { D-3 } & 25 \\ \text { D-4 } & 31\end{array}$

56

$-0.975$

0.187

55

$-0.975$

0.142

54

$-0.975$

0.128

33.5

12.5

$-1.101$

0.902

25.5

$-1.252$

0.443

43

$-1.401$

0.127

67

$-1.550$

0.107

transfer coefficient and the porosity divided by the product of specific area and free-stream diffusion coefficieal It represents a dimensionless mass-transfer rate. The mass-transfer coefficients are calculated from the effluent concentration data using equation 3-29. In general, the Sherwood number has a sep:-ate functionality on the Reynolds and Schmidt numbers. For Reynolds numbers below 1, however, the velocity become independent of viscosity, and a separate dependence of the Sherwood aumber on Reynolds and Schnidt numbers is not 
expected.

Three curves are shown in Ggure 3-16. The circles represent data taken in the mercury removal system. Each of these points was very carefully measured and was reproducible, taken in neither increasing nor decteasing order of flow rate. The Sterwood number was calculated based on a measured mercury diffusion coeficient of $4.9 \times 10^{-6} \mathrm{~cm}^{2} / 3$. (A value of $3.0 \times 10^{-6}$ $\mathrm{cm}^{2} / \mathrm{s}$ brought the data in line with those reported by Fedkiw. ${ }^{53}$ The RVC bed contains $97 \%$ voids, however, and may exhibit different mass-transfer behavior from the types of beds considered in Fedkiw's work.)

The squares in figure 3-16 represent the data taken in runs $A$ and $\mathbf{B}$ discussed above. The diffusion cofficient used in the lead calculations was $3 \times 10^{-6} \mathrm{~cm}^{2} / \mathrm{s}$, as reported in the rotating-disk experiments. The mass-transfer behavior is seen to follow closely the trend of the mercury results but is displaced from the mercury curve. By varying the lead diffusion coefficient within the experimental error of the rotating-disk experiments, the berd in the two curve could be made to line up at the same Peclet number. However, the mass-transfer coeficients for the lead experiments will lie below the corresponding values for the mercury results. Two factors could account for this. First, none of the calculated polarization curves for lead deposition bad reached a definite, flat plateau at the polarizations used for the limitingcurrent measurement (sce figure 3-14). It is uncertain whether these results are completely at limiting current. Second, effluent concentrations are subject to the uncertainties discussed in chapter 2 for the atomic adsorption measurements.

The bottom curve of triangles represents data from russ $C$ and D. A similar dependence of the Sh number on Pe number is observed, but the bed has degraded in performance relative to runs $A$ and $B$. It is clear that the attempt to improve the behavior of the bed by cycling in run $D$ failed. More hydrogen nucleation was observed in the last two runs than previously. The most likely reason for the degraded performance is the reduction of available surface area, either by channeling effects caused by the presence of hydrogen bubbles, or by lead sulfate crystals 
that were not reduced. The rotating-disk experiments showed that $\mathrm{PbSO}_{4}$ could not always be reduced back to lead, even at extended periods of cathodic polarization. It is unclear why this mny occur here (or on the rotating disk) when a lead-acid battery can maintain its capacity after a period of open circuit. However, the lead-acid battery is best stored in a charged state, where there is no PbSO, discharge product. A phenomenon alled sulfatation ${ }^{\text {I4 }}$ is sometimes observed in the lead-acid battery where under certain conditions the $\mathrm{PbSO}_{4}$ recrystallizes in a form that is more dificult to reduce. Low charging currents for long periods of time arc used to try to regenerate the active material. Blaedel and $\mathrm{Wang}^{\mathrm{n}}$ found a limited lifetime for the RVC disks used in the anodic stripping voltammetry studies. Failure was characterized by a sharp increase in background current The mechanism of failure was not examined, but regeneration with simple chemical or electrochemical treatments was unsuccessful.

\subsection{Conclusions}

The use of reticulated vitreous carbon porous electrodes for the removal of lead from acid solutions is promising. The best removal of $98.3 \%$ represents close to a factor of ten improvement in effluene removal compared to what has been previously observed. ${ }^{45,75}$ The current collector appears to have limited reactor performance by catalyzing hydrogen evolution. By changing to a current collector with a higher hydrogen overpotential, improvements in bed performance can be expected. Blaedel and Wang ${ }^{76}$ used a glassy carbon, current-collector rod fit to the RVC bed. This type of design would be ideal for discrimination against current-cullector effects. Alematively, the catbode curreat collector could be placed at the front of the electrode. In this case the current efficiency would still be poor, but the rising hydrogen bubbles would neither stir the bed solution nor increase the obmic potential drop through the bed. The open-circuit corrosion reaction, however, will not be minimized.

Both the rotating-disk and atmospheric porous-electrode experiments showed that lead sulfate formation should be avoided, if possible. A corrosion reaction will take place during open circuit as was observed at the end of run $A$. The rate of this reaction ean be minimized, 
however, by selecting a current collector that has a high bydrogen overpotential. During operation, the applied poteatial should be maintained eathodic at all times. Delibetately cycling the electrode was shown not to improve the bed performance.

The degradation of the bed was probably due to lead sulfate formation. It would be of interest to find a suitable means for bed regeneration. After stripping the bed at anodic potentials, mercury could be plated again to determine if there were reductions in gassing

Of most importance, however, is a change in current-collector material. The current collector limited the performance of the bed with respect to both hydrogen production and corrosion.

\subsection{Higb-Pressure, Porous-Eectrode Experiments}

High-pressure, porous-electrode experiments were performed to investigate the effect of pressure on the current efficieniy of the lead-removal process. The experimental system, procedure, and results are described below.

\subsection{Introduction}

Raising the pressure of the packed-bed electrode could bave two important advantages. both related to the rate of the hydrogen side resintion. First, the solubility of hydrogen increases with pressure, allowing more hydrogen to be produced before nucleation acurs Buble nucleation is undesirable because it upsets the concentration gradients through the packed bed eausing increased effluent concentrations. Furthermore, the presence of an insulating gas phase causes the current lines to bend, thereby increasing the obmic potential drop through the bed. The second advantage of high-pressure operation is the increase in kivetic overpotential that is gained by the eathodic shift of the thermodynamic open-circuit potential (see Ggure 3-5). The importasce of this effect depends on the applied porential. If the applied potential is far into the Tafel region for hydrogen production, cell pressure will have a negligible effect on the current. On the other hand, if the applied potential is near the open-circuit potential for hydrogen 
production, the backward rate term (anodic term) will have a substantial effect on the amount of bydrogen produced. The disadvantages of the high-pressure cell are an increased complexity of the experimental sysiem construction and operation and a bigher capital cost for the industrial reactor. High-pressure operation requires high-strength materials. If metal is used, problems with corrosion and ground loops can occur.

\subsubsection{Experimental System}

The basic cell construction is a metal reactor that was coated with a resin to insulate the electrodes from the reactor walls. High-pressure operation up to 120 bar at flow rates greater than ten bed volumes per minute could be used in the reactor. The construction of the highpressure cell, the flow system, and the electrical set-up are described below.

\subsubsection{Cell Design}

A schematic of the cell is given in figure 3-17, and a photograph is given in figure 3-18. The cell was composed of five parts: two blind end flanges, two main electrode compartments, and a feed ring. The end flanges and anode and catbode chamber were fabricated to be interchangeable. The reactor was boled together and sealed with four Viton 0 -rings, one on each side of the feed ring and one in each end flange. A porous Kel-F॰ (3M Company, 5i iaul, MN) plate was fitted in the feed ring to provide a support for the top of the reactor bed. A more detailed drawing of the side view of the feed ring, reactor compartment, and end flange is given in figure 3-19. The drawing is approxirately to scale and shows a (maximum) reactor length of 4 inches. The end flanges ware sonstructed from nominal 3/4 inch Carpenter 20 stainless stoel (C-20 SS), and the reactor chamber used 2 inch schedwle 40 C-20 pipe (2.375 inches $O D, 5 / 32$ inches wall thickness). The feed ring, however, was fabricated from 1.5 inch thick polyvingi chloride (PVC).

A pholograph of an electrode chamber and the anode end flange is given in figure 3-20. Also seen is the platinum anode screen. The electrode chamber flanges were fitted with either 


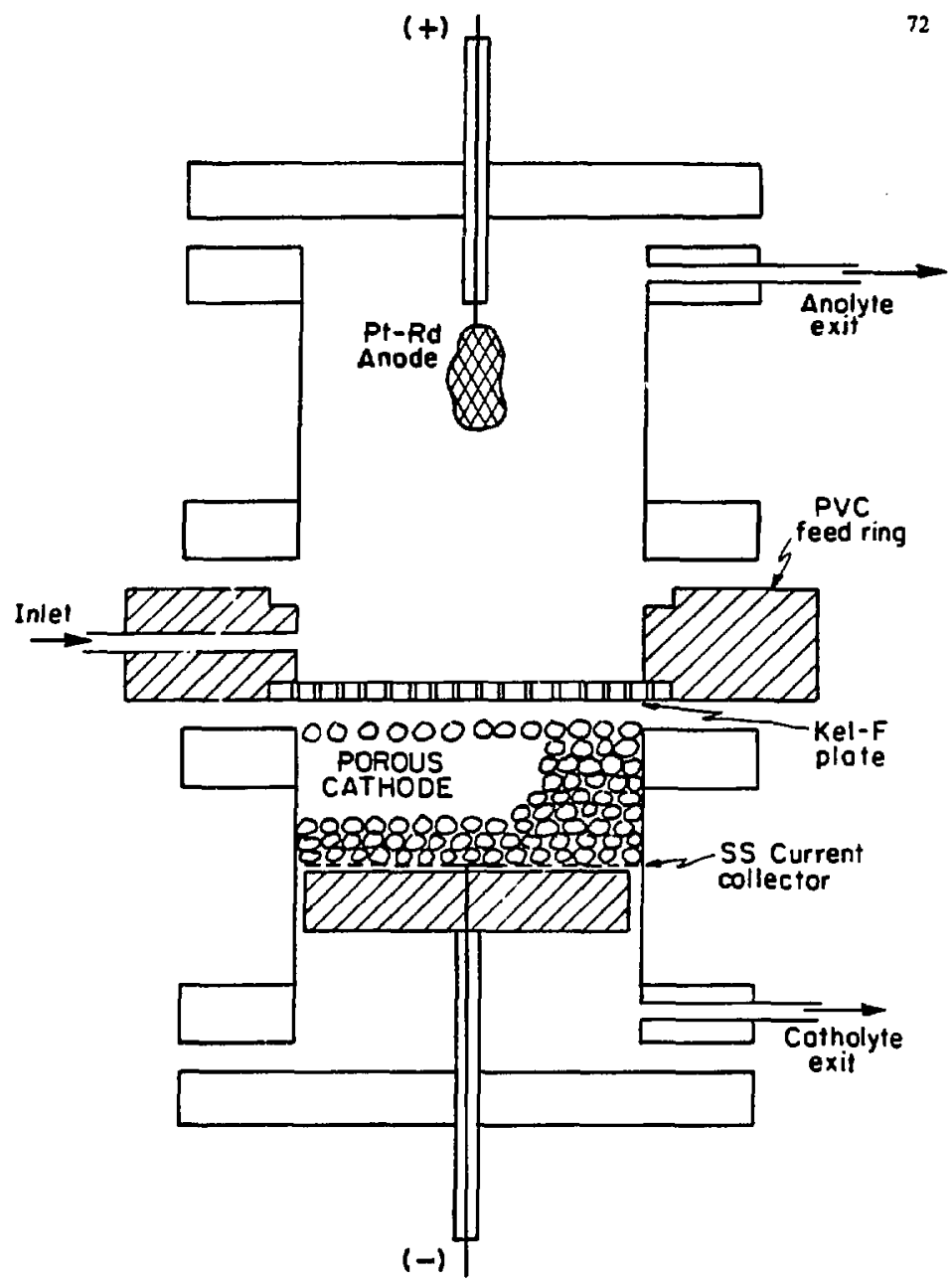

XBL $839-6466$

Figure 3-17. Schematic of the high-pressure, porous-electrode reactor. 


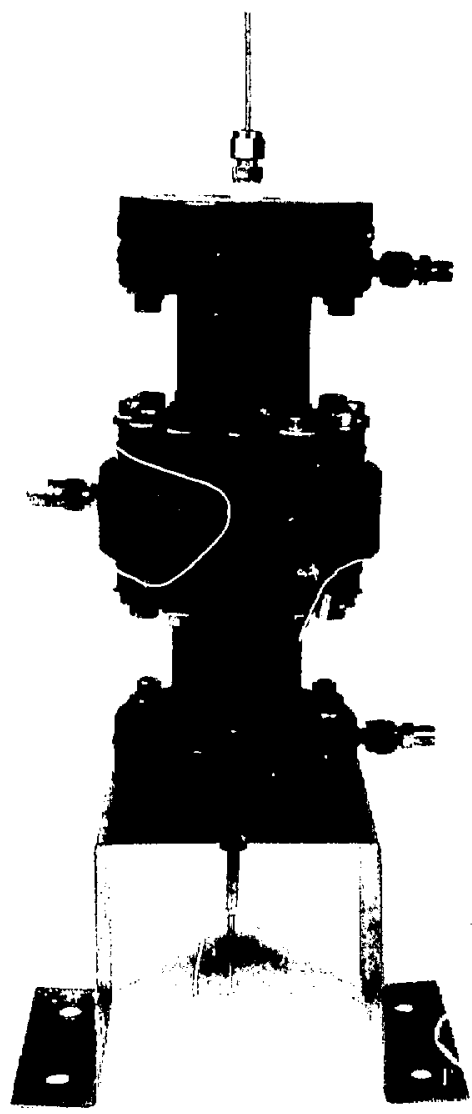

$\because$ liv, $r \cdot \ldots$ : :

Figure 3.18 Photugrapt ut the menbled high pressure re.ulu 


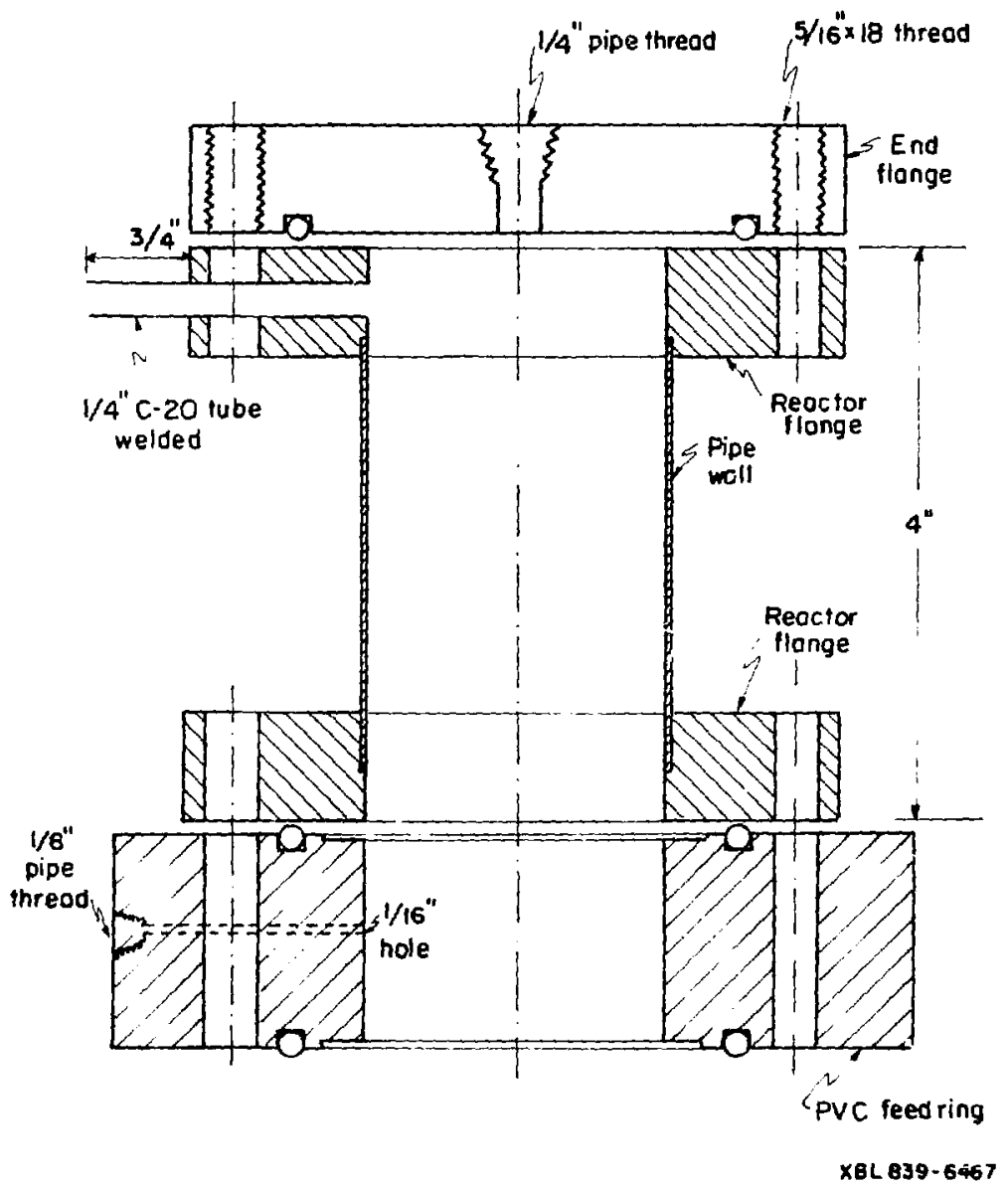

Figure 3-19. Detailed side view of the PVC feed ring, reactor compartment, and end flange. 

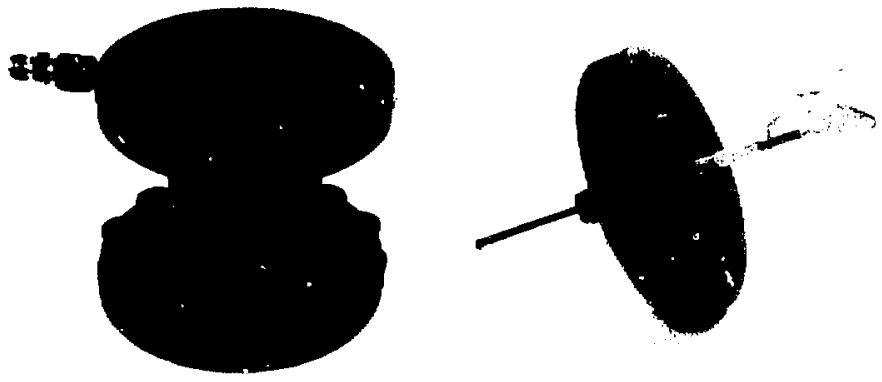

;Bk $8: 1-1$

Figure 3-20. Photograph of one of the reactor chambers and the anclyte end flange The insulating washers on the reactor chamber and the platinum anode screen are shown. 
six or twelve $3 / 8$ inch clearance holes, drilled on a $3.875: 9: h$ bolt circle. The flange with twelve holes mated with the PVC feed ring. The outer diameters were nominally 4.5 inithes, and the inner diameter was eut to tit the final pipe ID after welding. The fluid exiter the reactor via a 1/4 inch C-20 SS tube welded into the middle exit flange. The pipe used for the reactor compartment was welded to the two reactor flanges with C-20 filler rod from the inside of the flange. It was welded in a manner that gave a seamless joint after the assembly was bored true on a lathe. A seamless joint was important to good adherence of the subsequent Kynar coating of the reactor walls.

The end flange design is similar to the chamber flanges. Six $5 / 16 \times 18$ boles were drilled and tapped on the 3.875 inch bolt circle. An O-ring groove was cut to accommodate a 2.875 inch ID, 1/8 inch thick Viton 0 -ring, which sealed the reactor at the anolyte and cathol,te outles. The groove should have been (but was not) cut slightly oversize so that it could be cut down to the proper size after coating. A $1 / 4$ inch pipe thread was tapped in the middle of the flange to accommodate a fitting that sealed against the $1 / 4$ inch current-collector rod. This fitting was a $1 / 4$ inch male pipe-to-1/4 inch male tube, C-20 SS, Swagelok fitting drilled through with a letter $F$ (0.2570 inch) drill.

The top view of the PVC feed flange is given in figure 3-21. (Refer to figure 3-19 for a side view.) A 5/16 inch deep, 2 5/8 inch OD recess was machined on both sides of the PVC to hold the Kel-Fo plate. The recess was sligbtly deeper than the thickress of the Kal-Fo so that the plate was held in place but did not interfere with the O-ring seal. ${ }^{\dagger}$ The same O-ring groove and bolt-hole circle (twelve clearance holes) were used in the PVC feed ring as were used in the end flanges. Later six sleeves were machined and press-fit into six of the twelve clearance holes. It was necessary to do this to reduce clearance between the $5 / 16$ inch stud (which bolted the assembly together) and the PVC clearance hole. This helped minimize the expansion and contraction of the PVC during high-pressure operation. A 1/8 inch pipe thread was tapped into

\footnotetext{
'A previous deaign of the reactor sealed ditoealy on the Kel-F" plate. This required an extra O-ring machined into aach reactor chumber and caused the reactor to seal poorly under presure.
} 


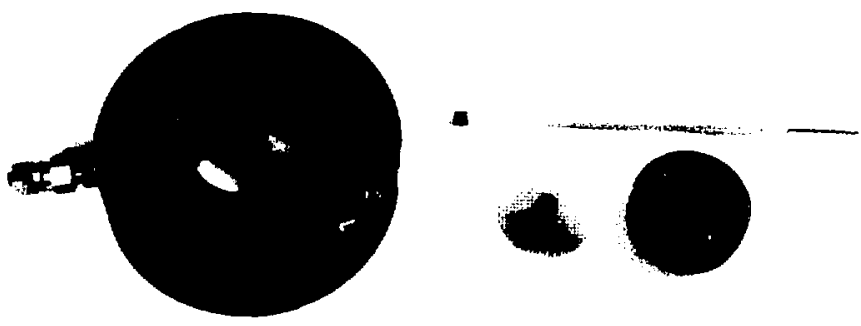

Figure 3-21. Photograph of the PVC feed ring and the disassembled, thret-part. current collector. 
the center of the feed ring, and a 1/16 inch hole was drilled from the pipe tap to the inside of the ring. Reactor reed entered the feed ring through the $1 / 8$ inch male pipe fitting and was split into the anolyte and catholyte compartments.

The interior of the reactor chamber, faces of the reactor flanges, and faces of the end flanges were all Kynaro coated by the R J. Chase Compeny, Incorporated, Union City, CA. Kynar is a high-molecular-weight polymer of vinylidene fluoride, containing $59 \%$ fluorine by weight. It is resistant to sulfuric acid solutions, and it provided electrical insulation of the reactor bed from the metal reactor surface. The presence of metal, in general, is undesirable in electrochemical applications (see appendix A).

\subsubsection{Current-Collector Design}

The current-collector design required several considerations. A way of providing electrical continuity to the porous bed outside the reactor while maintaining a fluid seal against 100 bar of pressure was needed. Furthermore, the reactor had to be electrically isolated from the current collector. These constraints led to an evolution of several current-collector designs, resulting in the final three-part assembly shown in figure 3-22. The actual current collector was a 16 mesh, 316 SS streen, shown at the top of the figure The middle section consisted of a PVC support for the scrsin, and the bottom section was the current-collector rod. (See also the photograph in figure 3-21.) The current-collector rod was insulated with polyethylene tubing and was fed out the bottom of the reactor through a Swagelok fitting. The rod could then provide electrical continuity from outside the reactor into the porous bed.

Electrical contact from the current-collector rod to the current-collector screen was made with a 5-40 SS screw (fabricated) spot-welded to the screen. During assembly, this screw was threaded into the head of the current-collecting rod, assuring electrical continuity from screen to :od. The PVC has a machined recess to acocinmodate the head of the $5-40$ SS screw, an O-ring to seal solution against the bead of the screw, a stainless steel insert (cross-hatched in the figure) epoxyed into place, and a $1 / 4 \times 40$ female thread to match the $1 / 4 \times 40$ thread on the 

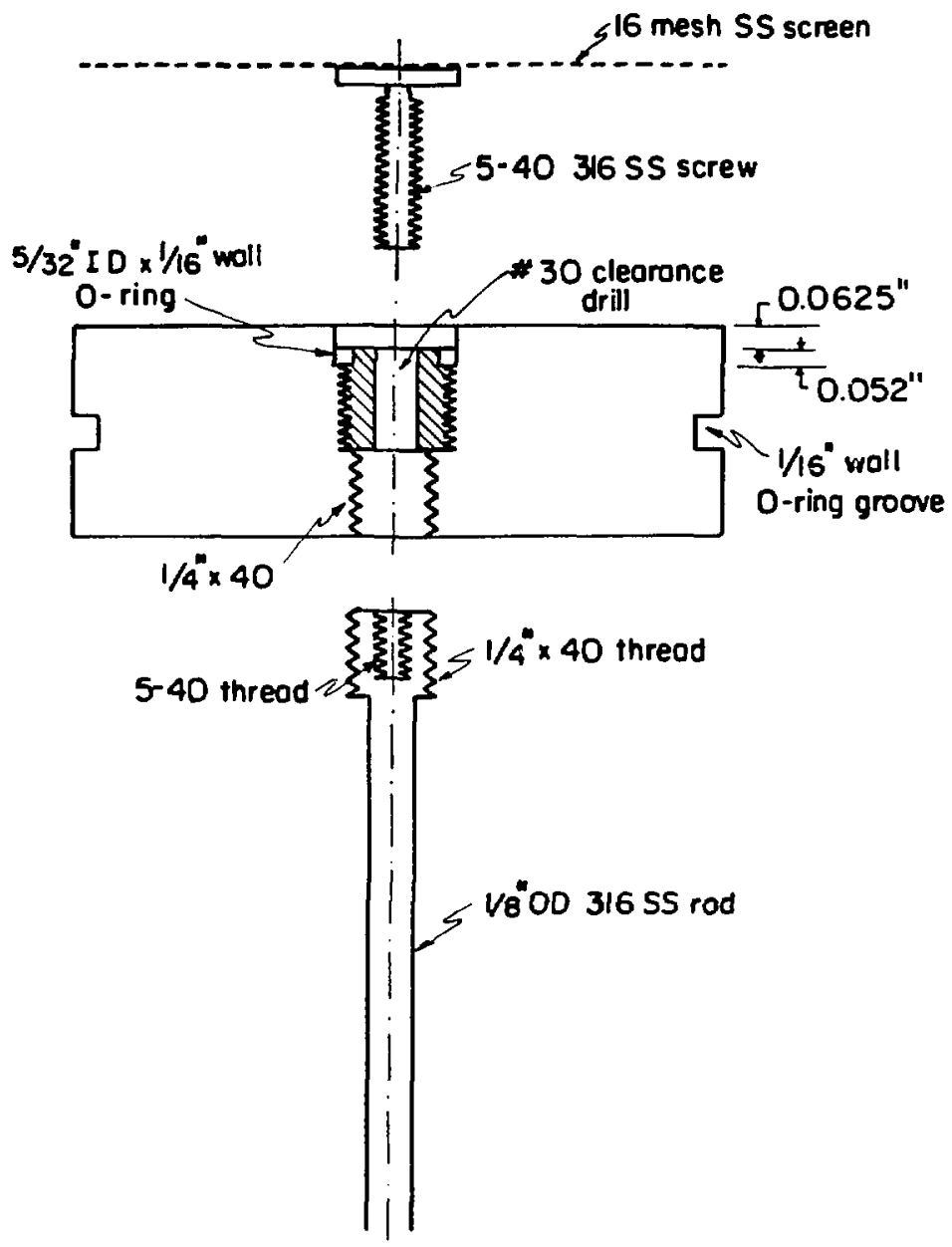

XBL B39-6468

Figure 3-22. Detailed schematic of the curreri-collector assembly. 
bead of the carrent-collecting rod. The stainless steel inser gave extra support for the threaded connections and additional assurance of electrieal continuity through the current-collector assembly. An earlier design used only a simple press-fit of current-collector rod to the 5-40 screw. In that design the $5-40$ female thread was in the PVC, instead of in the head of the curtsnt-collecting rod. This design failed due to the inability of the PVC threads to stand up under repeated use and under the stresses found in the high-pressure operation. Failure due to loss of continuity through the current-collector assembly was common until the present design was accepted.

A $1 / 16$ inch $O$-ring was used to seal the PVC at the reactor walls to prevent channeling of fluid around the packed bed. A series of holes were bored through the PVC with a number 71 drill to allow for fluid flow.

Figure 3-21 shows a $1 / 8$ inch ID. $1 / 4$ inch OD polyethylene tube that is fitted over the $1 / 8$ inch SS current-collector rod. The polyethylene coating served two functions. First, it eliminated any electrochemical activity on the surface of the rod by electrically isolating the metal from the solution. Second, it electrically insulated the current collector from the the reactor metal. The current-collector rod exited the inside of the reactor through a $1 / 4$ inch Swageiok nitting in the end flange. To seal the reactor at high pressures, a permanent compression ferrule that squeezes into the rod must be used. If a $1 / 4$ inch metal rod were used, the current collector would electrically short to the reactor wall. A short circuit at this point may appear harmless, but electrical isolation was required to prevent ground loops. Since the ferrule fitting squeezes into the rod and a single rod is not reusable from run to run (because of changes in bed height), the polyethylene tubing also served as an "easily" replaceable currentcollector coating.

\subsubsection{Flow System}

The flow system is shown schematically in figure 3-23. Reactant was pumped from a 55 galon, linear polyethylene Nalgene` feed tank by a BIF model 1731-13-9821 high-pressure 


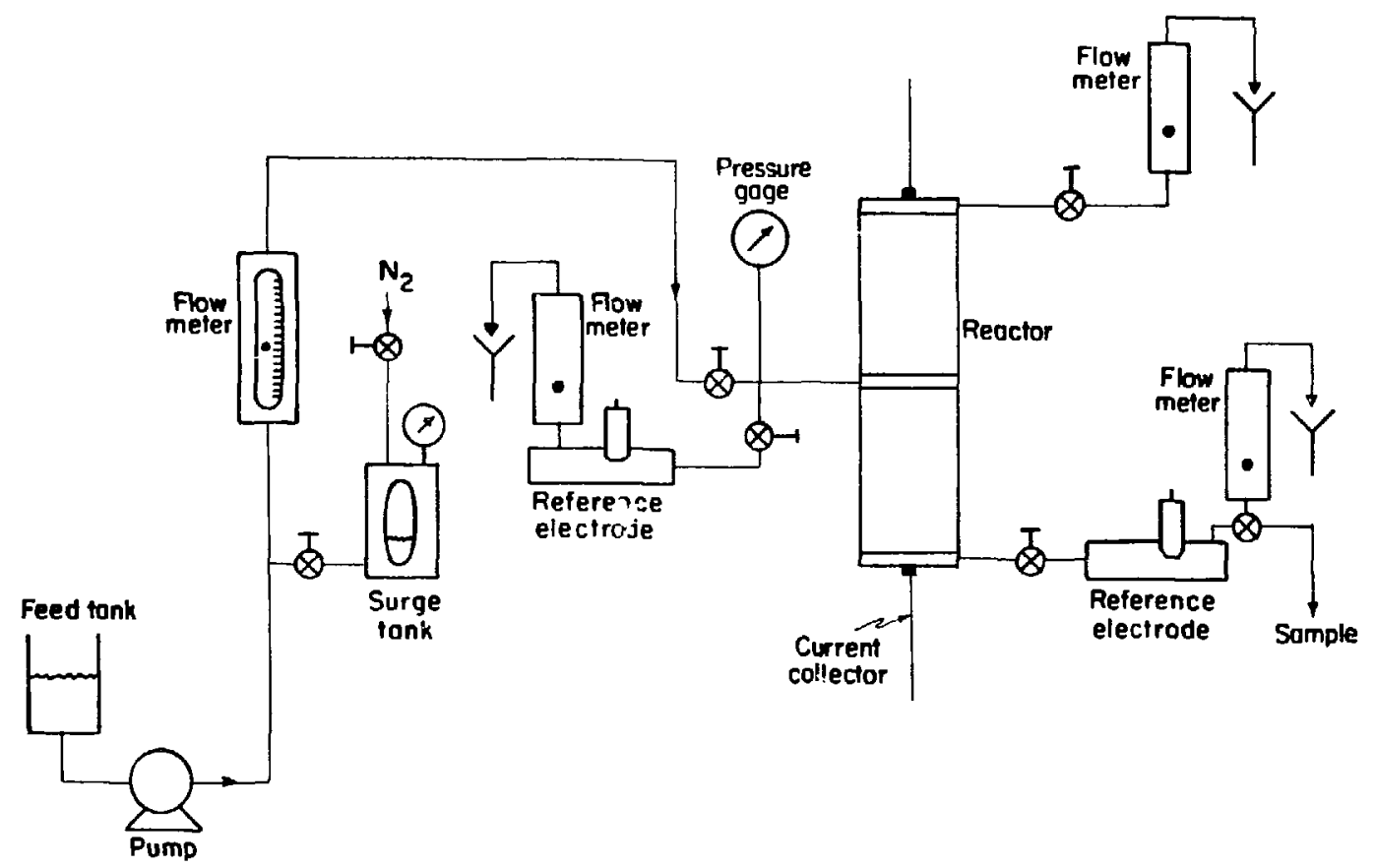

X日L839-6469

Figure 3-23. Schematic of the high-pressure fluid flow system. 
metering pump fitted with a Winsmith speed reducer. A "surge" tank with a nitrogen/fluid interface absorbed pressure fluctuations caused by the piston pump. The surge tank was an Ernst Gage Company model EST-1203 sight gage re-fitted with C-20 stainless steel. If the surge tank was taken out of the system, wide flow fluctuations were observed at high pressures. Fluid flowed past the surge tank and into a Brooks 1452 series high-pressure rotameter, also re-fit with C-20 stainiess steel. A small side stream of reactant solution was split off through the upstream reference-electrode compartment, just before entering the reactor. The feed stream entered the reactor and was split into the anode and cathode compartments. The catholyte left the reactor through the downstream reference-electrode compartment and flowed past a thermometer (not shown). Lab Crest flow meters monitored the anolyte and catholyte flows.

An Asheroft steel tube and socket pressure gage (0 to 250 bar) monitored the system pressure at the inlet of the reactor. The pressure gage was fitted with a diaphragm with a buttom housing of C-20 SS, so that no internal parts of the pressure gage were exposed to process fluid. The pressure gage was calibrated in the range of 5 to 150 bar, giving good accuracy in the operating range of the reactor. The maximum reactor pressure ever used was 120 bar. The valves used in the sulfuric acid system were all Whitey 3NTRF4, made of C-20 stainless steel. Nupro 2 micron ( SS-4TF-P2), 316 stainless steel, inline filters were used to protect the valves and to help control the flow system at the anolyte, catbolyte, and the upstream reference-e!ectrode outlets. All tubing was $1 / 4$ inch OD, C-20 stainless steel with the exception of three short sections of PVC, one at the reactor inlet and one at each exit. These $(1 / 4$ inch OD, 0.040 inch ID, 1.125 inch long) inserts provided electrical isolation of the reactor from the inlet and outlet metal piping.

The entire flow system from the outlet of the pump to the reactor outlets was enclosed for safety. A $3 / 8$ inch Lexan (polycarbonate resin, General Electric Company) plate was used for the front and top, and $3 / 4$ inch plywood was used around the sides, back, and bottom Valve extensions were fabricated so that flow adjustments could be made outside the enclosure. A 
photograph of the apparatus inside the enclosure is given in figure 3-24.

\subsubsection{Electrical Setup}

The electrical system used evolved with time as experimental difficulties were encountered. An overall system is shown in Ggure 3-25, although not all of this instrumentation was used for each rug. In some of the runs a Hewlett-Packard 6t01A DC power supply or a Pine Instruments RDE potentiostat was used in place of the AIS potentiostat shown in the figure. Potentiostatic control of the reactor was used for most of the runs by controlling the potential of the working electrode relatis $e$ to the upstream reference electrode (USRE). The downstream and upstream reference electrodes were Beckman Cold Label Lazaran \#19036 electrodes (silver/silver chloride internals), rated from $-0.5^{\circ} \mathrm{C}$ to $100^{\circ} \mathrm{C}$ at 0 to $1034 \mathrm{kPa}$. Special electrode chambers were fabricated to bold the electrodes in the process stream. An independent measu.ement of the cursent flowing in the cell could be made from the ohmic potential drop across tbe presision resistor placed in the anode lead. A similar resistor could be used in the cathode lead; however, potentiostatic control then becomes more difficult. This was done at times, howcver, to check to see whether the current flowing into the anode was the same as the current flowing out of the cathode. Two Keithley electrometers were used to monitor the two reference-electrode potentials independently. Thes: electrometers had an input impedance greater than $10^{14}$ ohms, with a low-im:-dance, uniky-gain output that could be sent to the strip-chart recorders. Note that the positive lead of the electrometer should always be attached to the high-impedance source (the

reference electrode) to minimize electrical interference (see appendix A). An isolation transformer is also shown in figure 3-25. It was used in some of the runs when experiencing electrical difficulties. A discussion of the isolation transformer also appears in appendix A

\subsubsection{Procedure}

Electrolytic solutions were made up from J. T. Baker reagent grade lead sulfate and Mallinckrodt analytical reagent sulfuric acid. The mixture was stirred continuously in a 55 


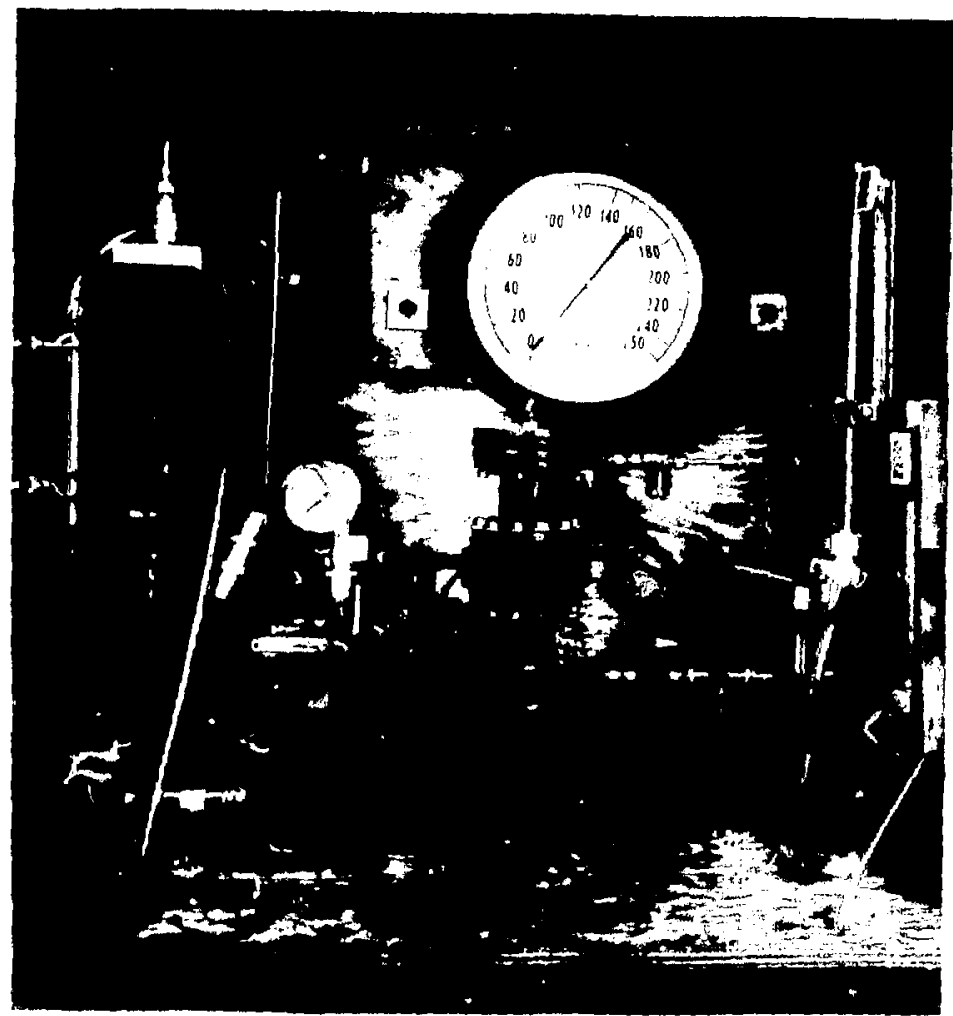

iㅐ $3, \ldots$,

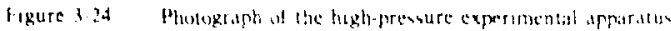




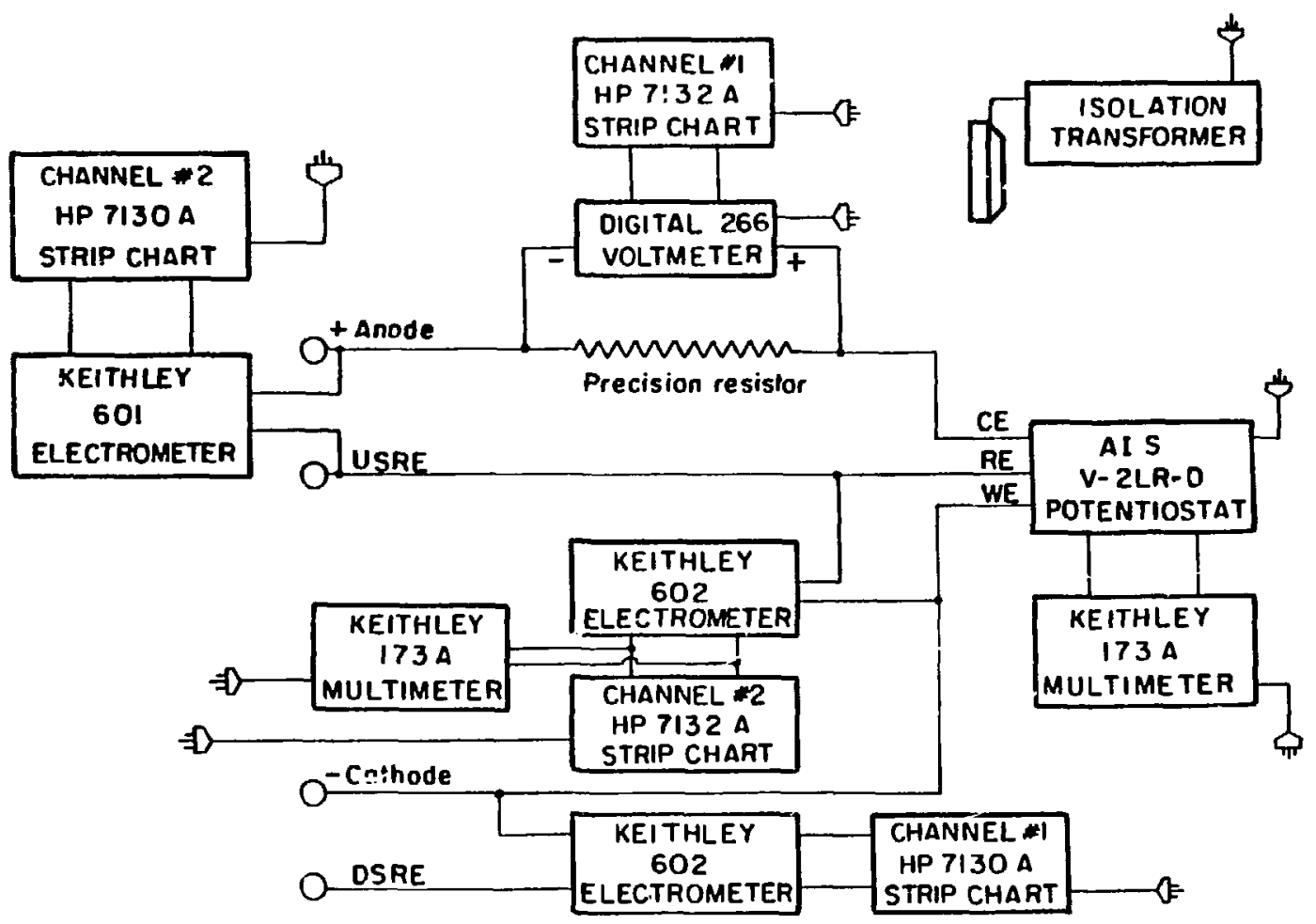

Figure 3-25. Schematic of the electrical system for the high-pressure experiments. XBL 839-6470 
gallon feed tank with a Lightnin mixer. (Other support :ä electrolytes used are noted below in the results.) Dilutions werz made from deionized water (SYBRON/Banstead model D3613 reverse osmosis and ion exchange) with a specific resistance greater than $16 \mathrm{MQ}$-cm. Feed solutions were sparged continuously with nitrogen to remove dissolved oxygen throughout the run.

At the beginnigg of each run, the current-collector rod was fited witb a new polyetbylene tube. The old ferrule (compression) litting and tubing were removed, and the new tubing was foree-fit over the $1 / 8$ inch rod with the aid of a heat gun. The current-collector rod, when fitted with tubing. was usually slightly oversize and had to be machined down to 0.250 inches on a lathe before it could be used in the reactor.

The reactor bed was packed by hand at the start of each run. An atter. ${ }^{2}$ was made to pack the spheres in a "close packed" configuration so that good electrieal continuity would be maintained among the spheres from back to front of the bed. Ary preparation procedure used for the electrode spheres is described under the specific reults below. When the packin!s was complete, the feed ring and anode and cathode compartments were bolted together with twelve $5 / 16 \times 18$ studs fitted with insulating washers. The insulating washers served to insu'ate the anode electrically from the cathode by breaking electrical continuity through the reactor bolts. After assembly, the current collector was adjusted so that the top of the active bed was pressed against the Kel-Fo plate fitted in the feed ring. At this point, the Swagelok ferrule was installed and tightened down so that it crimped into the polyethylene tube. A measurentent of the ohmic resistance of the top of the bed relative to the current-collector rod could be made before the top anolyte flange was installed.

It took approximately 45 minutes to pack and assemble the reactor. It wai installed in the fow system and filled with feed before applying a potential. The pressure of the reactor was controlled by adjusting the three outlet valves and the pump flow rate. 


\subsubsection{Results}

Many of the earlier experimental runs were plagued by both mechanical and electrical problems. Most of the mechanical failures centered around the loss of electrical continuity either through the bed or through the current-collector assembly, particularly at high pressuse. Numerous electrical grounding and shielding problems were sanifested in various ways. Much of the discussion in appendix $\mathbf{A}$ or bounding and shielding considerations is a direct result of the problems encountered in the bigh-pressure system. In general, it should be stated at the oulset that one shoujd minimize or eliminate any matral from the experimental system, even if the metal poten al floats.

The earlier runs used a different reactor and current-collector design from those given in figures 3-19 and 3-22. The earlier reactor design used a metal, Kynas'-coated feed ring that electrically insulated the inside of the reactor, but allowed electrical continuity through the outside of the reactor. Current could flow through the outside walls of the reactor leading to current loop through the electrolyte and reactor as discussed below. Earlier current-collector designs relied on a press-fit of the 5-40 SS serew to the head of the current-collector rod, i.e. the screw did not thread into the top of the rod as shown in figure 3-22. This particularly caused problems when the current-collector rod was stressed while sealing at high pressure.

Experimental runs discussed below fall into the two geneml classes of old and new reactor designs. Results from experiments usi:ug the old reactor design are presented first. Problems that oceurred are discussed, and a motivation for changing the design is given. These results are followed by a discussion of the results using the new reactor and current-collector designs.

The first experimental runs used a $0.8 \mathrm{M} \mathrm{Na}_{2} \mathrm{SO}_{4}$ electrolyte, instead of a sulfuric acid electrolyte. Gains in surface overpotential through the shift the equilibrium potential from a pH of 0 to a neutral solution can be seen in figure 3-5. vopper-coated, staj- ess steel, 1/8 incb spheres cleaned with stannous oxide in a jewel tumbler were used as the electrode bed. The copper spheres had been previously cxated with a copper cyanide strike, followed by plating 
from an acid copper bath in a porous electrode. 7 The spberes were first tumbled in a stannous oxide solution for a day and then rinsed and tumbled in detergent for another day. Some of the spheres lost part of the outer copper layer so that electrochemical reactions took place on a combined copper/stainless steel surface. A Hewlett-Packard 6101A power supply fixed the cell potential. The cathode potential relative to a downstream reference electrode was monitored with a Keithley electrometer. This run processed approximately 80 liters of saturated lead feed solution crar 2 days of operation al apgroximately 20 bar pressure. One temporary shutdown was necessary to repair a short between the anode and outside reactor wall, and the run ended when electrical continuity was lost through the cathode current collector. A breakdown of the reactor showed good lead deposition throughout the bed with s.o apparent variation of deposit from front to back of the bed. However, as a loss of cathode continuity ultimately caused the electrode failure. there is some question as to whether the bed maintained good electrical continuity throughout the run. These runs were "preliminary," and no effluent samples were takn. Other early runs failed mainly due to lack of good bed co'stinuity either between the packed spheres or througb the current-collector assembly.

Electrolyte was changed to $1 \mathrm{M} \mathrm{H}_{2} \mathrm{SO}_{4}$ in order to simulate more closely an industrial lead-acid battery electrolyte. This had both advantages and disadvartages to the operation of the reactor. A major disadvantage was the corrosion of the apparatus (largely before changing components to Carpenter 20 stainless steel) from the sulfuric acid electrolyte. Even 316 SS is atheked after repeated exposure. An advantage of the electrolyte is a reduced ohmic variaticn through the bed (equation $3-27$ ) due to its higher conductivity, At the same time, however, the bigher hydrogen ion concentration decreaus the magnitude of the ohmic variation that an be tolerated before the onset of hydrogen evolution. An added benefit of the acidified solution is the reduced tendency for oxide formation in the acid environment No separate acid dip is required to remove axide layers before packing the bed since the electrolyte itself was sulfuric acid. 
The first experiments with acid electrolyte used copper-plated 316 SS spheres, plated from an industrib: cyanide bath in a barrel plater. The spheres were degreased with trichloroethylene, anodically cleaned in an acid bath, rinsed with $\mathrm{H}_{2} \mathrm{O}$, rinsed in a $50 \% \mathrm{HCl}$ acid dip, plated with nickel from a $\mathrm{NiCl}_{2}$ bath, rinsed with water, and then plated from a $\mathrm{Cu}(\mathrm{CN})_{2}$ plating bath. Copper coatings were estimated to be 0.1 to 0.3 mil thick This procedure was found to work well for activating the surface in preparation for copper plating at limiting current ${ }^{n}$ and is a standard procedure in preparation for lead plating from a lead fuoborat, bath. Plating procedures and bath compositions are found in Metal Finishing ${ }^{\text {n }}$ and Electroplating Engineering Handbook." The barrel plating was done in the plating shop of Lawrence Berkeley Laboratory.

A Pine Instruments RDE 3 potentiostat was substituted for the power supply. This enabled control of the potential of the working electrode relative to a reference electrode, instead of control over the total cell voltage. In this way, the potentiostat automatically compensates for excursions in the anode balf cell. This potentiostat normally floats the working counter, and reference potentials off eartb ground.

The current-voltage behavior of a $25 \mathrm{~cm}$ long bed at 100 bar pressure is given in figure $3-$ 26. The limiting current corresponding to complete conversion is $2 \mathrm{~mA}$ A 50 percent reactant conversion corresponds to a limiting current of $I \mathrm{~mA}$ and is still a factor of 10 ten larger than the apparent limiting current in figure 3-26. Furthermore, not all of this current necessarily flowed through the abode bed (see disesssion below). Thus, we see very small turrents for very large applied potentials.

A breakdown of the reactor showed a variation of lead deposition through the porous bed. heaviest at the back of the electrode. The current-collector screen also showed evidence of some lead deposition. The variation of deposit is opposite to what would be expected from a limitingcurrent distribution and therefore indicutes a poorly conducting bed. A partial break in continuity within the current collector would account for the low cursents and the large negative 


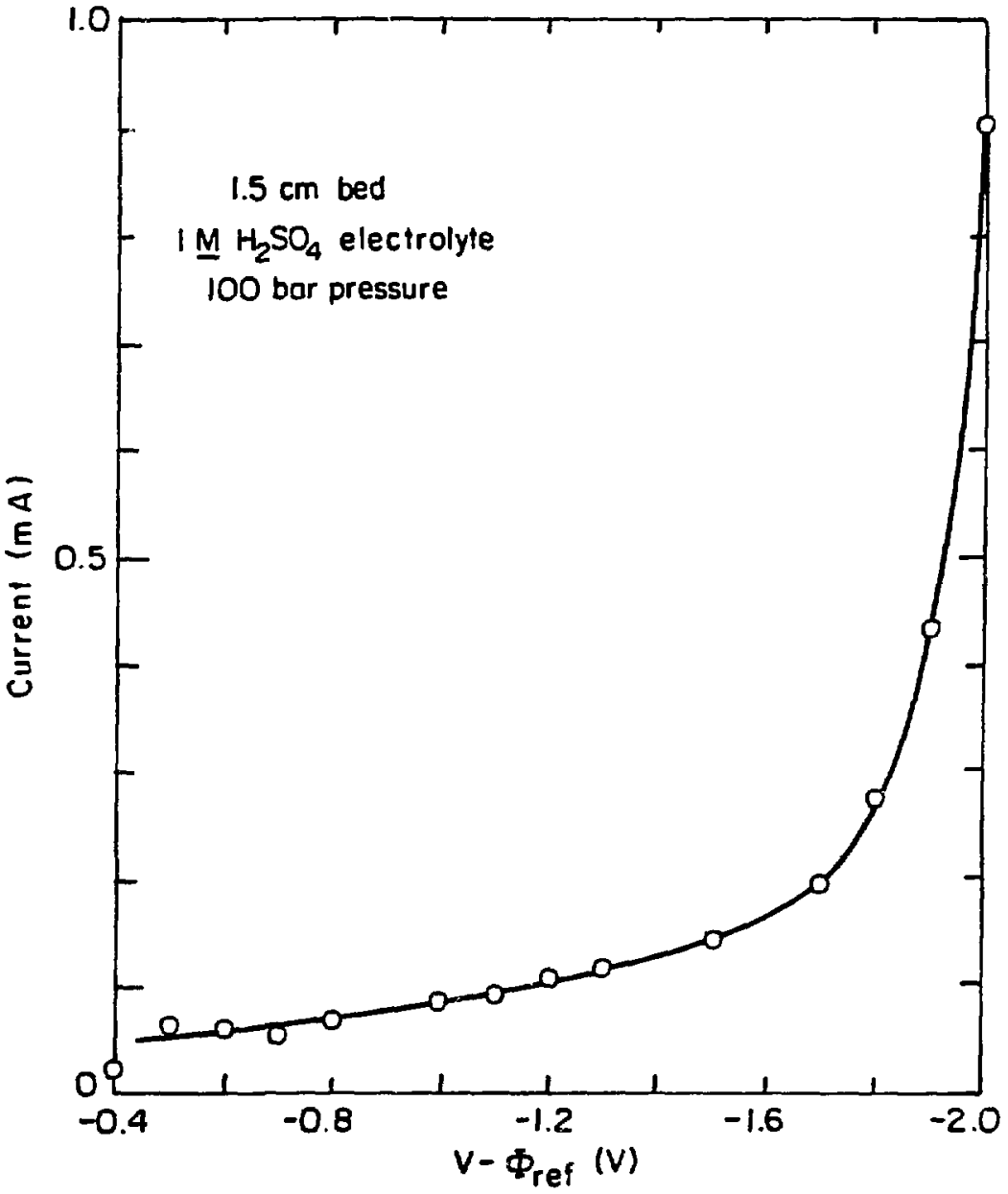

$X B L 839-6471$

Figure 3-26. Current vs. applied potential data at 100 bar pressure. 
applied voltages; the actual applied voltage would be equal to the values given in figure 3-26 plus a positive obmic term that depends on the current and resistance through the current collector.

A $0.8 \mathrm{M} \mathrm{Na} \mathrm{SO}_{4}$ electrolyte with enough sulfuric acid added to reduce the $\mathrm{pH}$ to 3 was tried in another run. This experiment was fraught with difficulties, and no lead was observed to deposit on the bed. However, two important experimental observations were niade in this run that led to design changes.

First, an "inversion" of potential was observed periodically throughout the experimental run. During an inversion the downstream referencelectrode potential became more positive than the measured upstream reference potential. This indicated an apparent reversal of current through the packed bed. A direct measure of the current entering the anode and leaving the cathode showed that the current was flowing in the correct direction. Furthermore, the total current entering the anode was equal to the total current leaving the cathode. Second, an interesting "passivation" phenomenon was observed where, upon raising the cell pressure at constant cell voltage, the current dropped significandy. For example a current of $0.5 \mathrm{~mA}$ at 20 bar pressure dropped to approximately $3 \mu \mathrm{A}$ at 100 bar pressure. When the pressure was decreased back to $20 \mathrm{bar}$, the current correspondingly increased to roughly the previous value. The trend, but not the exact values of the curtent, was reproducible.

The potential inversion observed an be explained by considering a secondary current loop flowing through the outside of the reactor. The metal tubing at the anolyte exit is electrically conducting with the metal tubing at the catholyte exit via the outside of the reactor wall. The potential of this metal is flosting from the potentials of the electrodes in the reactor. Therefore, the solution potential gradient from anode to catbode will induce the floating metal to act as a bipolar electrode. Electrochemical reactions such as the reduction of oxygen at the anolyre tubing and the oxidation of hydrogen at the catholyte tubing will now occur. The circuit is comple d through the outside of the reactor. Thus, current may flow in two parallel paths from 
anode to cathode. As more current bypesses the reactor by flowing through the path of the bipolar electrode, the ohmic potential drop through the bed will decrease. It still would not be expected, however, that the potential from the front to back of the bed would ever become zero or negative. The reference electrodes, bowever, are not placed right at the entrance and exil of the packed bed. The downstream reference slectrode was downstream of the exil catholyte tubing and therefore sensed all the cheric drop caused by the current flowing back toward the bed frum the current loop. The ufstream reference electrode was ptaced close to the front of the bed and therefore did not sense the ohmic variation from the anode to the inlet of the cathode. Thus, a potential inversion can be measured even though the packed bed is acting as a cathode. The actual potential variation that would be measured by local reference electrodes placed just upstream and downstream of the bed would be a positive number as shown in figure $3-4$. It is clear, bowever, that the current loop degrades the performance of the bed. Appendix A describes this current loop in more detail.

The effect of pressure on the reactor current could arise from several sources. An increase in pressure decteases the total current flowing tbrough the cell due to the oxygen reduction and bydrogen oxidation in the secondary loop. This effeet is not large enough, however, to account for a factor of 100 dcicease in curtent. It is likely, then, that a mechanical partial break in continuity through the current-collector assembly caused the decrease in current when raising the pressure. Recall that the current-oollector design still relied on a simple press-fit of the 5-40 SS screw to the head of the current-collector rod and did not actually thread into the rod as shown in figure $3-22$

Thus, two important design changes were made before startup of the next experimental runs. A PVC feed ring with insulating washers was fabricated to break electrical continuity through the bolts and outside of the reactor. (A metal feed ring could be used if care was taken to insure that the faces of the metal ring were completely coated and that the reactor bolts were insulated from the outside of the reactor.) Insulting the two reactor chambers broke the current 
loop described above. The new current-collector design and C-20 reactor design have been described above.

In summary, in the runs with the old reactor and curtent-collector design. lead was

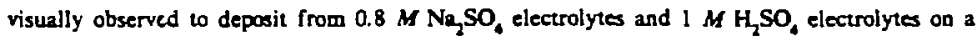
copper or a copper/stainless surface. Lead was also observed to form a coating on the 316 SS curreat-collector screen. The best medsured effluent removals, however, were only $44 \%$ from a $\mathrm{Na}_{2} \mathrm{SO}_{4}$ electrolyte at 110 bar pressure and $48 \%$ from a sulfuric acid electrolyte at 20 bar pressure. Frequently, mxasured effluent concentrations were larger than feed concentrations. especially during reactor upsets (such as during potential inversions).

The new reactor design, including the PVC inserts, was used only with sulfuric acid electrolytes. All these runs employed an AIS model V-2LR-D potentiostat. The first runs used copper-coated spheres for the electrode bed as described above.

Increases in currents greater than a factor of ten were observed over previous results for similar applied potentials. This is attributed to the improved current-collector design and the elimination of the current loop through the outside reactor wall. Af these large currents, the reactor operated under ohmic control. Thus, raising the pressure at constant applied potential increased the total current due to a lowering of the solution resistivity as the solubility of hydrogen increased. Data over a period of 104 hours at various pressures and applied potentials showed essentially no lead removal. This gave evidence that the lead deposition reaction and the bydrogen reaction did not occur in parallel at these high currents. One envisions a case where ali the available reaction sites are being used for hydrogen evolution so that there is no active surface area available for lead deposition. Furthermore, the severe turbulence at the electrode surface could cause mechanical detachment of any lead that does deposit. Previous successes on copper with the old reactor can be attributed to a poorly conducting bed which minimized the hycirogen reaction, but allowed lead deposition. 
In an effort to inhibit bydrogen evolution, a 50 parts per million $\mathrm{Hg}^{2+}, 1 M$ sulfuric acid solution was used as feed to the electrode. Approximately 40 liters of solution were processed over 24 hours. The observed currents at polarizations more negative than $-0.6 \mathrm{~V}$ were not significantly lower than the corresponding currents for the lead solution. This indicated that the bydrogen reaction was not inhibited by the mercury on the surface or that not enough mercury had been plated.

The measured effluent concentrations of mercury gave support to the hypothesis that bydrogen production and metal deposition do not necessarily occur in parallel. At an applied potential of $-0.2 \mathrm{~V}$ and a cursent of $45 \mathrm{~mA}, 54 \%$ of the mercury was removed, but increasing (cathodically) the potential to $-0.4 \mathrm{~V}(\mathrm{I}=201 \mathrm{~mA}$ ) removed only $25 \%$ of the inlet mercury. These data were for the same flow rate and pressure $(40 \mathrm{bar})$ and were taken in succession. The current efficiency for the first point is approximately $24 \%$ and drops to only $2.5 \%$ for the second point Possible improvements in bed performance could be gained from using more concentrated mercury feeds in an electrolyte with a higher pH. Longer processing times may also be needed if removal efficiencies are low.

The lead, sulfuric acid feed stream was resumed and processed over 90 hours. Data taken after the mereury process are given in figures 3-27 and 3-28. Figure 3-27 is for moderate pressures of approximately $40 \mathrm{bar}$ for a catholyte flow rate that varied around $25 \mathrm{cc} / \mathrm{min}$, and Ggure $3-28$ is for a pressure of 100 bar at $30 \propto / \mathrm{min}$. The curves are reproducible from forward to backward sweeps and are approximately linear. The higher slope for the 100 bar data reflects the increased electrolyte conductivity; the solubility of hydrogen increases with pressure, and the seduction of the nucleated phase decreases the ohmic potential drop.

Efluent measurements showed that no significant reductions is lead occurred throughout the run. Reactur breakdown showed some metal deposition with no apparent g: adients through the bed. Black, gray, and copper areas were seen on the spheres. No liquid mercury was observed in the bed; any mercury that was deposited amalgamated with the copper. Some of the 


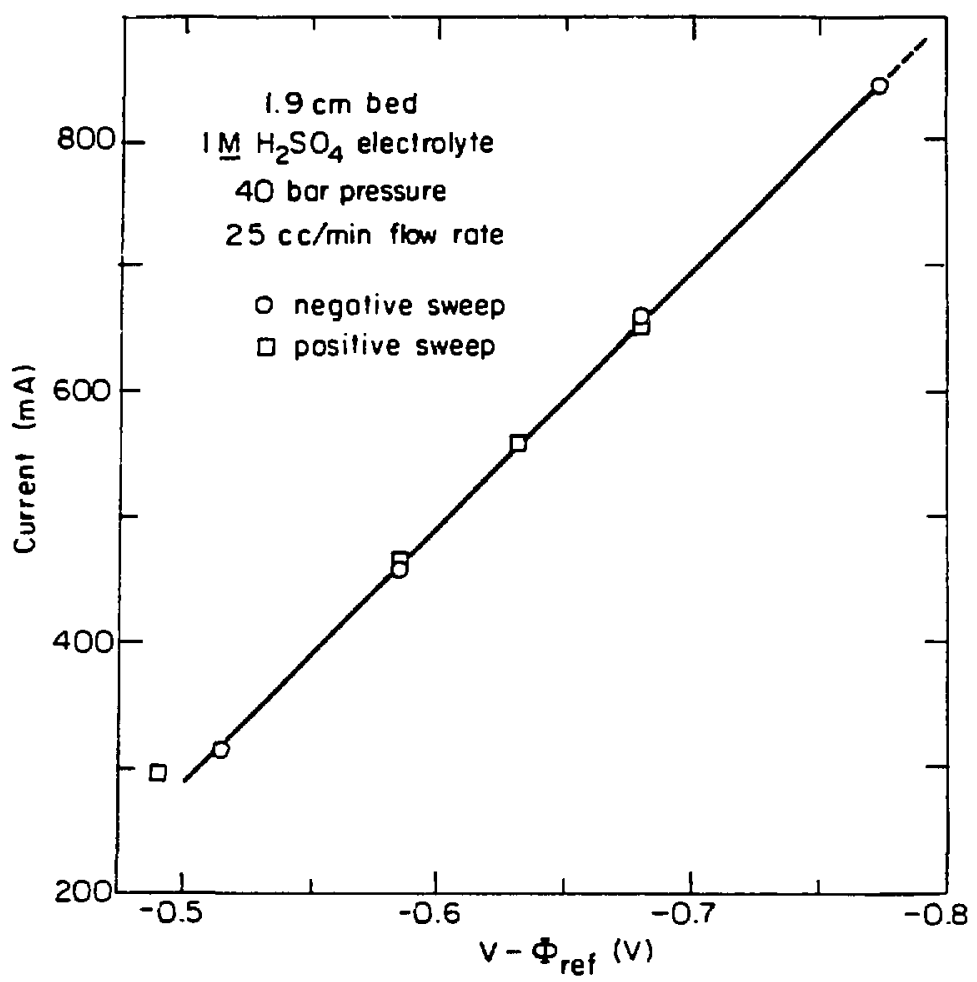

XBL $839-6472$

Figure 3-27. Current ys. applied potential data at 40 bar pressure after mercury deposition. 


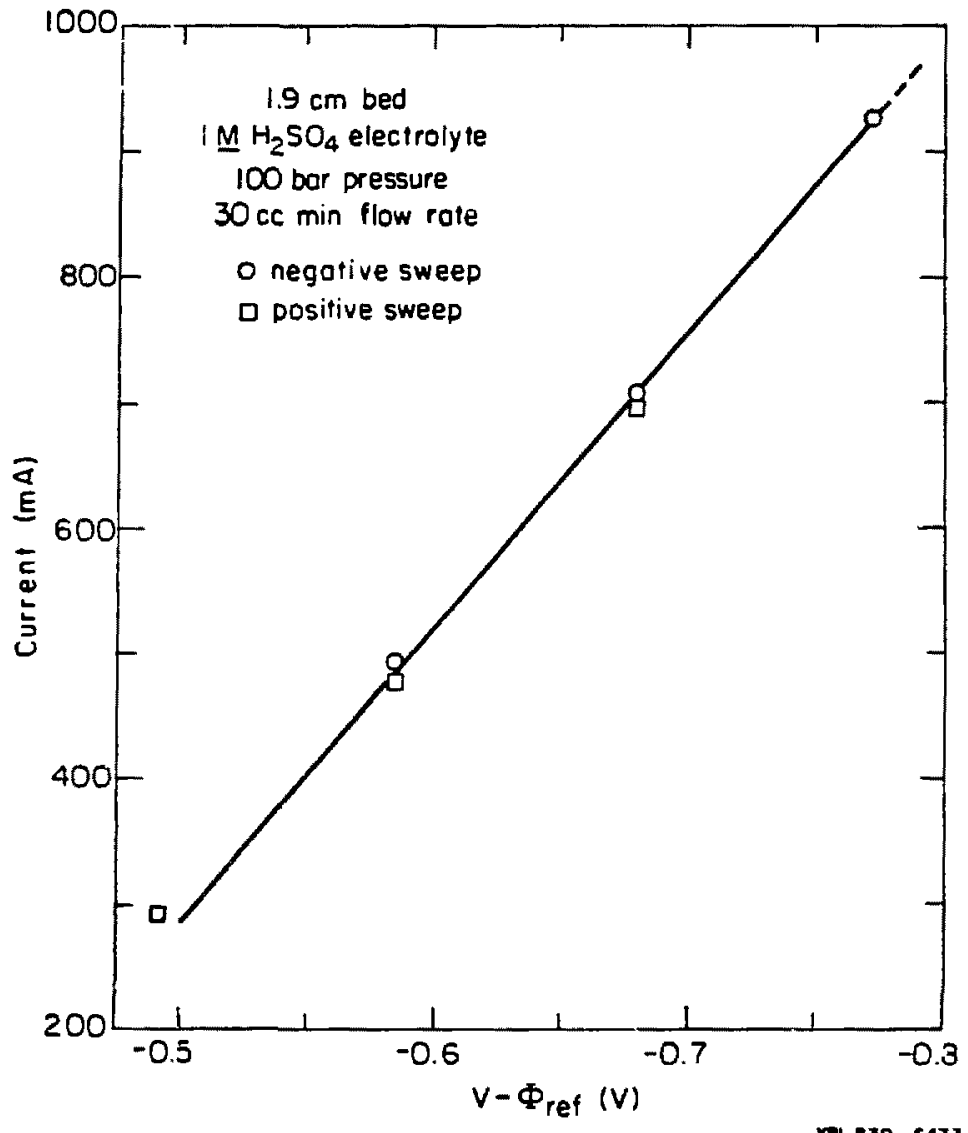

Figure 3-28. Current vs. applied potential data at 100 bar pressure after mercury deposition. 
metal adhesion was good, but flakes and particles broke off. The gray areas, probably a coppermercury amalgam, showed good resistance to scraping. The black spheres were less resistant to scraping, but had a thicker coating. There appeared to be a layer of grey coating underneath the black layer. The current-collector screen was discolored with what appeared to be a lead deposit This is surprising, bowever, as the obmic drop limited the back of the electrode to potentials more anodic than $-0.35 \mathrm{~V}$ during all the lead deposition runs.

As mechanical and electrical improvements were made to the bigh-pressure system, reactor currents increased and reactor performance decreased. The success or partial success of the previous runs ean be attributed to poor bed or curtent-collector conductivity. Poos adhesion in this last run could account for the lack of reactor improvement over the eight days of lead processing. This run made it clear that a copper substrate should not be used for plating lead from a low pH, sulfuric acid electrolyte. Improved pretreatments such as mercury plating could be used, but more success is likely using a different electrode substrate with a higher hydrogen overpotential.

Two alternative electrude substrates are lead and carbon. Lead may appear to be the ideal electrode substrate because of its high kinetic resistance to hydrogen production. Furthermore, any electrode substrate chosen will eventually become a lead bed after continued processing, the reactor bed would have to be regenerated only after the pores became restricted. Lead, bowever, easily forms an oxide layer when exposed to air. Therefore, a careful cleaning and preparation procedure must be performed before packing the reactor.

A coating of lead plated from an induserial fluoborate plating bath at Lawrence Berkeley Labomatory was applied to the copper-oated SS spheres. Lead plating over copper usually proceeds by first dipping the copper substrate in 10 to 20 volume percent fluoboric acid or $10 \%$ sulfuric acid solution to removal oxide films. Lead plating is then done in a lead fluoborate bath. It is important to note, however, that when lead is plated over lead, the plating cycle involves a mechanical and electrochemical cleaning followed by botb a nickel and copper strike 
before the lead plate; it is not recommended to plate lead directly over lead. The operating formulas for induserial plating baths have been established with the quality of the deposit in mind. They use currents below the limiting current to inhibit the formation of powdery deposits and additives to improve bath performance. The quality of the deposit is not of concern in the porous-electrode experimeats unless the deposit is so loosely adberent that it will not stay on the electrode. Thus, lead-coated spheres were tried in the reactor for a series of runs.

Mechanical polishing of the lead-coated spheres was done in a tumbler with 600 grit silicon earbide abrasive in distilled water. The spheres were then transferred to a solution of 25\% fuoboric acid (HBF) and rumbled for 5 minutes. This preparation left the surface bright, but approximately $5 \%$ of the spheres showed some exposed copper. The spheres were packed in the reactor under deionized water io belp frevent any re-oxidation of the lead surface.

The reactor was carefully packed to insure electrical continuity, and the feed was started. Before applying a potential to the system, the reference electrodes measured a potential difference of $+0.13 \mathrm{~V}$ from the downstream reference electrode to the upstrean reference electrode. This potential variation could be due to streaming potentials through the PVC or could arise from two different corrosion potentials setup at different ends of the bed. For example, a lead/hydrogen corrosion couple on copper toward the front of the bed and a lead/hydrogen corrosion couple on stainless steel at the back of the bed would setup a potential variation from the back to the front of the bed. The potential difference measured showed some time dependence and is therefore not likely due only to streaming potentials although they may contribute to the potential variation.

None of the runs that started with lead-coated spheres showed effluent concentrations less than inlet values, even for short reactor beds. Effluent concentrations exceeded inlet concentrations if the applied potentials were allowed to become too positive. But uven under the highest cathodic polarizations, lead deposition was inhibited, and even low dissolution rates were indiested from the effluent concentration measurements. The fact that dissolution rates did 
increase under more anodic potentials indicated that electrical continuity was maintained through at least part of the bed.

Potential inversions were observed to occur at times throughout the experimental runs with the lead-coated spheres. Recall, however, that the new reactor design broke the current-loop projlem that was causing the potential inversion in the previous runs. We must look for other causes for the inversion and ask if the inversion is hurting the performance of the bed. Also, no inversions were ever seen with the new reactor design when copper spheres were used (and total currents were much higher). It is likely, then, that the potential inversion may arise from more than one cause, but remains relatively constant so that it can be obscured by large ohmic frops through the bed.

In order to determine reasons for the inversion, voltage differences were monitored across the inlet and two outlet PVC inserts during the experimental run. The voltage differences were always positive with respect to the side closest to the two micron SS filter. As this filter is upstream of the inlet PVC and downstrean of the exit PVC, the measured potential difference could not be due to only a streaming potential through the PVC inserts. The potential differences across the inserts varied throughout the experimental run, but were greatest when the SS filters were observed to leak and corrode. These measured potentials are therefore likely due to an impressed corrosion potential. If no current passes through the solution, the referenceelectrode potentials are unaffected, and the bed performance is unaffected. Upon electrically bridging the PVC at the catbolyte exit, the working minus reference potential was experimentally observed to become more negative, which was expected from the observed voltages differences. Thus, this imposed corrosion potential could lead to a potential inversion if - ground loop existed that electrically connected both sides of the PVC. If the voltage difference arose only from streaming potentials, no difference would have oceurred upon electrically bridging the PVC inserts. 
A concentration cell could develop across the two micron filter during high-pressure operation. Hydrogen saturated at 100 bar upstream of the filter and saturated at 1 bar downstream of the filter would lead to current flow through the the fiter. However, the current flow would be in a direction that would drive the working minus reference potential more positive, an opposing effect to the potencial inversion.

Corrosion within the bed bas been mentioned above during open circuit. As the bed is polarized cathodically, these cortosion processes will be minimized It is possible, however. to run an overall cathodic current through the bed while maintaining a potential inversion that results from the local corrosion potentials. The potential variation would be negative from the front to back of the electrode, progress ihrough zero, and become positive as the ceurent is increased.

If the bed loses continuity with the current-collector soreen, but maintains some continuity within itself, a bipolar electrode an be induced from a potential gradient, arising say from the generation of hydrogen on the current-collector screen. The front of the electrode begins to act as a cathode and the back of the electroxle as an anode. The amount of curtent flowing through the solution could be seduced as it bypasses the solution by fowing through the bed. As lead is used up at the back of the electrode more current is forced through the solution. This increases the obctic drop, which will offset any constant :enoency for a potential inversion.

In one of the runs using the lead-coated spheres, it was observed that there was more of a tendency for potential inversions when increasing the pressure, for constant volumetric flow rates. Almost all the pressure drop is through the exit valves, and under high-pressure operation these values had to be almost shut. A streaming potential could develop across the valves during high-pressure operation that did not exist at the lower pressurs for a wider valve orifice.

\subsubsection{Conciusions}

The reactor and surrent collector were well designed for an elecirode bed of hard spheres. The reactor could be packed to give good electrical continuity through the bed, and it 
maintnined hydrostatic pressures up to 120 bar. (Eventually, the current collector may limit reactor performance as found in the low-pressure experiments, although lead was observed to plate on the current collector in some of the runs.) Many of the difficulties with the highpressure system were directly related to the presence of metal. A w"'er design would eliminate all metal-fluid contact throughout the system.

As the Iesign of th: reactor inproved, it became apparent that copper was not a suitable electrode substrate for plating lead, even for very long processing times where the current eficiency might bave been expected to improve with time. The severe bydrogen evolution on the bed prevented lead from plating for ary of the applied potentials. (The current efficiency of the lead fluoborate plating bath is reported to be near 100\%)

A lead bed proved very difficult to work with. It readily forms an oxide layer in air and requires a very carefully performed cleaning procedure. In all experiments with the lead spheres, lead dissolution was observed to occur. Once the bed has become peorly conducting for whatever reasons, lead corrosion can be expected to continue, esen at high applied potentials. The presence of another metal that can catalyze bydrogen evolution speeds up the dissolution process. If a lead bed were to be investigated further, a coherent sintered matrix that would not lose electrical continuity even if partially fissolved should be used.

A reticulated vitreous arbon bed would be an ideal choice for further investigations in the high-pressure oell. This is not recommended, however, until it is fully characterized at atmospheric pressure. It is especially important to investigate the effect of periods of oper circuit or other types of reactor upsets on the subsequent performance of the bed.

\subsection{Fow-By Porcus-Electrode Co-ffguration}

We should mention bere an alternative porous-electrode configuration seen at $\mathrm{t}^{\mathrm{t}} \mathrm{s}=$ bottom of figure 3-3. The fow-by configuration could find use in helping to circumvent the ohmic limitation of the flow-through slectrode. Since the fuid and current flow are perpendicular, the electrodes can be made thin to minimize the obmic potential drop, and they can be made long to 
achieve high conversions. The disadvantage of the flow-by configuration is the necessity of including a separator to avoid anolyte and catholyte mixing. The mathematical analysis is also inherently more complicated due to the two-dimensional nature of the problem Twodimensional modeling work has been done by Alkire and $\mathrm{Ng}_{\mathrm{g}}{ }^{-10}$ They treat a cylindrical packedbed electrode surrounded by a concentric counterelectrode. Trainham and Newman ${ }^{\text {s] }}$ present an engineeriug model that compares the performance on an economic hasis of the two porous electrode configurations for redox energy storage. The results of the computer optimization show that the low-by configuration is superior in this ease, where the dimensionless quantity $n E F D_{0} c_{0} / s_{R} \Delta \Delta \Phi_{2}$ is large. For dilute solutions (small values of $A n F D_{0} c_{0} / s_{R} \times \Delta \Phi_{2}$ ) the flow through configuration may continue to have merit. Fedbis presents a comparison of the performance of flow-through and flow-by electrodes operated at limiting current for an electrode of a given dimension. No cost differential was considered between running the reactor in the flow-through and flow-by configurations. Frt a given maximum obmic potential drop and desired conversion, he concludes that a flow-by electrode with a length to widtb aspect ratio greater than 5 will have a higher processing rate than a flow-through electrode. Risch ${ }^{83}$ compares the limiting-current performance of the best flow-through electrode and best flow-by electrode on the basis of cost. The geometric dimensions of the electrodes are both optimized over cost within the constraints of a given reactant conversion and a maximum allowable potential drop through the bed. He concludes that Fedliw's aspect ratio of $\mathbf{S}$ is only approximately correct, and be shows that for dilute concentrations, the flow-through electrode is preferred over the flow-by electrode. Al higher concentrations, the flow-by electrode is preferred An ultima'e design of either a flow-through or flow-by electrode must recognize that they can be run below the limiting current.

It is clear that the flow-by system holds sufficient promise that more detailed mathematical modeling and scale-up criteria are needed. The zinc-bromine secondary battery system as well as flow-redox energy storage systems have e olved to flow-by configurations. 


\section{Chapter \& Porows Battery Electrodes}

\section{Introduction}

Let us now focus attention on the use of porous electrodes for battery applications. Several levels of mathematical sophistication can be used to examine battery systems. Initially we should like to develop guidelines for screening prospective systems. Then, as development of both old and new systems continuls, we resort to more sophisticated mathematical models for the design and scale-up. Before going into details, let us consider some general aspects of battery systems.

\section{Orenier}

We wish to examine desirable characteristics for batteries so that we may define inberent limitations or areas needing development for new and existing systems. One recognizes that listing a set of desirable characteristics implies a particular application. In examing a new or old system we wish to look at advantages and disadvantages in terms of cost (perhaps amortized cost/cycle), energy and power density, shelf life, reversibility. energy and coulombic efficiencies, material utilization efficiency, cycle life, reliability, portability, safety, and availability of materials.

One of the first characteristics of a battery to be considered is its voltage and specific energy. Knowledge of the overall reaction allows calculation of the open-circuit potential from thermodynamic data Dividing the potential by the equivaleat weight ( $\mathrm{kg} / \mathrm{coul}$ ) yieids the theoretical specific energy of the electrode pair. Thus, more energetic electrode couples with lower equivalent weight will increase the theoretical specific energy. From a practical viewpoint, the advantage of more energetic couples must be weighed against the more severe materiais compatibihty requirements in the more corrosive enviranment. For new batteries the specific energy quoted is often a theoretical energy based only on the mass of active materials. The 
theoretical specific energy of the lead-acid battery is $218 \mathrm{~W}$-h/ $\mathrm{kg}$ based on the active materials $\mathrm{PbO}_{2}, \mathrm{~Pb}$, and $\mathrm{H}_{2} \mathrm{SO}_{4}$. Including the weight of the solvent (for an initial conccratation of 5 molal $\mathrm{H}_{2} \mathrm{SO}_{4}$ decreases the energy to approximately $100 \mathrm{~W}$-h/kg. The final specific energy including the weights of current collectors, excess active materials, separators, container, and connecting posts and including potential losses (three-bour discharge rate) is approximately 40 W-h/kg. A rule of thumb that the final specific energy is 25 to 30 percent of the theoretical specific energy has been found to be approximately erue for several systems. This rule should be used with caution, but it does illustrate the performance penalities associated with battery packaging and scale-up.

Knowledge of the specific energy of the system can be used to assess the promise of a given system Data on the specific power of the system are also needed to determine the ability of the battery to deliver energy at different rates. The maximum specific power that a battery can deliver can be approximately calculated by $(U / 2)^{2} / R_{1}$ where $U$ is the open-circuit potential and $R_{f}$ is the total internal area-specific resistance $\left(\Omega-\mathrm{cm}^{2}\right)$ times the total lo:ding density of material $\left(\mathrm{kg} / \mathrm{cm}^{3}\right)$. Contributions to the internal resistance arise from obmic, kinetic, and mass-transfer resistance. The ohmic area-specific resistance can be estimated on the basis of electrolyte conductivity and separator thickness. Battery designs with large current densities should keep overall area-specific resistances down to approximately $18-\mathrm{cm}^{2}$ and keep areaspecific resistances of the sefarator itself down to about $0.2 \Omega-\mathrm{cm}^{2}$. These calculations become more refined as we obtain more information on a system Higher specific energies and specific powers are important in applications where total weight or volume are importart. In electricvehicle applications, for example, a battery may not bave enough energy or power to carry itself and its support structure.

Three system efficiencies characterize the performance of a battery. Coulombic efficiency is a measure of the seversibility of the electrodes or the presence of side reactions. It is given by the ratio of the number of coulombs released during discharge to the number of coulombs 
required to charge the system back to its initial state. Energy eficiency is calculated by multiplying the coulombic effjciency by tbe ratio of average discharge voltage to average charging voltage. Differences in charge and discharge voltages are due to irreversibilities associated with the obmic potential drop in the solution and matrix and overpotentials associated with electrode kinetics and mass-transfer resistances. Coulombic efficiencies ean often approach 100 percent, while energy eficiencies are typically 50 to 80 percent. The method of charging and discharging the battery will affect both of these numbers.

The material utilization efficiency is the ratio of the actual coulombs passed during discharge to the theoretical amount of active material available. Utilizations depend on the rate of discharge as well as any imposed cut-off voltage. Utilization efficiencies vary widely between systems. The positive electrode of the lead-acid battery bas a $\mathrm{PbO}_{2}$ utilization of 50 to 60 percent in automotive plates and a utilization of only 25 percent in traction plates. Utilizations of the positive electrode in the lithium-aluminum/iron sulfide battery are greater than 80 percent. Material utilizations often decrease with cycling. Among the factors that can lead w material utilizations less than 100 percent are the isolation of active materials, solubility problems with reactants and products, and, as mentioned above, any imposed voltage cut-off. Isolation of active material can occur when an insoluble, insulating reaction product covers the active material. Highly nonuniform reaction distributions an lead to pore blockage. Differences in the molar volume of reactants and products cause porosity changes which can lead to matrix fracture.

The solubility of reactants and produets is important to material utilization as well as cycle life and shelf life. Dunning et al. ${ }^{\text {s }}$ identify a range of approximately $5 \times 1 \sigma^{-5}$ to $11.4 \times$ $10^{-5}$ molar for the desirable solubility range of a sparingly soluble reactant. The lower limit of solubility is based on the need to diffuse the reactant to the active sites from sparingly soluble crystallites. The ability to store the reactant in close proximity to the active site was listed as one of the advantages of porous electrodes. The upper limit of solubility can determine the shelf 
life of the celı because of self-discharge processes. In general, a soluble reactant on discharge will react if it can diffuse to the other electrode, while a soluble reactant on charge will be substantially inert if it diffuses to the otber electrode. A soluble discharge reactant can be permanently incorporated into the other electrode and aot be recoverable on charge. The magnitude of solubility also influences the redistribution of active material. The relatively high solubility of $\mathrm{ZnO}$ in $\mathrm{KOH}$ leads to marked concentration changes on cycling, and these can couple with the fluid flow to produce zine shape change ${ }^{16.57}$

We have mentioned above that the method of charging can affect the efficiencies of a given system. Ideally the charging process will restore the battery to its state at the onset of the discharge cycle. In general the charging process plays an important role in the cycle life and performance of a battery. Two common charging methods that may be used are constant current and constant voltage. These can be combined with voltage or current limits to help minimize side reactions, or for thermal management. Side reactions, however, often do occur on charge. If these reactions occur preferentially on one electrode, an imbalanic in state-of-charge occurs. The ability of the system to accept overcharge then becomes important. More sophisticated charging procedures can be developed, but may be prohibitively expensive depending on specific applications. In some redox energy storage systems, for example, a third electrode is used to correct for imbalances in state-of-charge.

Porous battery electrodes can be constructed in a variety of configurations. Often individual electrodes are constructed with a highly conducting, inert substrate (grid) that mechanically bolds the porous matrix in place. It should be sicong enough to withstand volume change on cycling, and it should be iner over tbe operating temperature and voltage ranges. For a battery plate with poorly conducting active materials, the grid is necessary to act as a current collector to conduct electrons to or from the reaction site. For moderately conducting active materials it can act as a secondary current $\infty$ llector. In electrode configurations using grids the current is collected from each piate and is connected in parallel with an 
interconnecting bus. The optimal desigh of the current-collecting grid and sitercell connectors is a scale-up problem that will be considered later. Anotbet batiery configurstion that can be considered is a bipolar arrangement. Such an arrangement eliminates the nied for a separate current-collecting grid for each electrode and may possibly minimize the voltage and weight performance penalties assocjated with the grid. Fere the positive and negative active materials are put on opposite sides of an inert, conducting substrate. Current lows straight through the cell stack and is collected at the ends. The materials constraints for the conducting substrate are severe; it must be substantially inert to both the oxidizing and reducing environment. Corrosion of the substrate will lead to short circuits.

Materials compatibility is often a major problem in new or old battery systems. Materials constraints may limit cycle life or prohibitively increase the cost of a system. For example, corrosion of the current-collecting grid is cited as a major failure mechanism for the lead-acid battery. Active material in ambient temperature $\mathrm{Li}$ electrodes becomes electronically isolated from its substrate, presumably due to reaction with impurities and the electrolyte itself. ${ }^{88}$ In general we look for a battery system where the active materials are compatibie with each other and the other support materiais required in the battery. We require the electrolyte, separator, bantery containes, intereonnecting bus and post, current collectors, etc. to be stable over the operating voltage and temperature ranges of our system while not calalyzing side reactions or otherwise reacting adversely with the system.

A separator is a major component of the battery package. It is required to separate the positive and negative electrodes in the battery so that they may be in close proximity without shoring. A common failure mechanism in early battery development is siorting of the pusitive and negative eiectrodes by dendritic growth of material through the separator. ${ }^{* 9}$ Separators must be electronic insulators, but have relatively high ionic conductivities. A separator with a high area-specific resistance $\left(\Omega-\mathrm{cm}^{2}\right)$ leads to a bigh obmic potential drop with subsequent poor periormance. Separators may also be required to have other desirable properties. Often they 
should be specifically conducting to only certain ionic species ${ }^{86,87}$ or must contain additives that inctease electrolyte wetting.

Costs, of course, must always be considered within a particular application. Besides the costs of raw materials, some other factors can be considered. Costs associated with safety. recyeling (particularly if availability of materials is low), and associated environmental factors need to be considered. A common basis for comparison of various alternatives of secondary batteries is the amortized cost of the system in $\mathbf{S / W - b - c y c l e . ~}$

\section{Micro-madeliog results}

Scale-up of porous electrodes is not straightforward. Simply increasing the thickness of an electrode, for example, does not necessarily bring about proportional increases in performance. We wish to develop a micto-model of the porous-electrode systern so that we can predict the effects of changing parameters such as electrode thicknesses on the behavior of the system. Having this information in hand then leads us to couple the micro-modeling to further scale-up considerations of plate area and lengths of intercell connectors.

In examining the micro-modeling of porous electrodes let us first consider the zero-time behavior $^{90}$ where concentrations are assumed to be uniform throughout the pore volume. Further let us ignore double-layer charging effects. Four dimensionless ratios govern the current distribution. These can be stated as a dimensionless current density

$$
\delta=\frac{\alpha_{i} F I L}{R T}\left(\frac{1}{\alpha}+\frac{1}{\sigma}\right) .
$$

a dimensioniess exchange curreat

$$
\nu^{2}-\left(\alpha_{n}+a_{r}\right) \frac{F a l_{0} L^{2}}{R T}\left(\frac{1}{\alpha}+\frac{1}{\sigma}\right),
$$

the ratio of transfer coefficients in the polarization eyuation $\alpha_{4} / \alpha_{2}$, and the ratio of effective solution and matrix conductivities $x / \sigma$. $\delta$ and $\nu^{2}$ are ratios describing the competing effects of ohmic potential drop and slow electrode loinetics. For large values of $\delta$ or $\nu^{2}$, the ohmic effect 
dominates with a nonuniform reaction distribution. For small values of $\alpha / \sigma$, the reaction occurs preferentially near the electrode-separator boundary at the expense of the region near the backing plate.

The nonuniformity of the reaction distribution for Tafel sinetics can be seen in figure 41. For Tafel kinetics the current distribution depends only on the parameter $\delta$ and the ratio $\alpha / \sigma$. Curves for linear polarization would exhibit similar behavior as in figure 41 . For linear behavior, the distribution becomes nonuniform for large $y$ and is independent of the total current. For both cases, the ratio of $\alpha / \sigma$ serves to shift the reaction distribution from one face to the other.

The distance to which the eaction can penetrate the electrode determines bow thich an electrode can be utilized. This penetration depth is characterized by

$$
\frac{L}{\nu}=\left(\frac{R T_{k \sigma}}{\left(\alpha_{\alpha}+\alpha_{z} ; a i_{0} F(\alpha+\sigma)\right.}\right)^{1 / 2} .
$$

Electroacs much thinner than the penetration depth behave like plane electrodes with an enhanced surface area Electrodes much thicker are not fully utilized because of ohmic limitations. For high current levels, in the Tafel range, the ratio $L / \delta$ will be more characteristic of the penetration of the reaction.

To continue to follow the discharge behavior of a porous electrode through the trensient behavior, we need to consider the tirns derivative in equation 3-1. Porous electrodes used in primary and secondary batteries invariably involve solid reactants and products, and the uatrix is changed during discharge. Consequently, no steady state is strictly possible. We may nonetbeless examine steady-state operation of a porous electrode. Just above we have considered the irreversibilities associated with electrode kinetics and ohmic potential drop. As the reaction proceeds, reactant is depleted at the pore-solution interface. This then represents an additional irreversibility. Newman and Tobias ${ }^{90}$ also treat a redox reaction in a perous electrode. Convection is assumed to be absent, and migration is neglected due to an excess of supporting electrolyte. The stoichiometric coefficients of the reactant and prcduct species are 


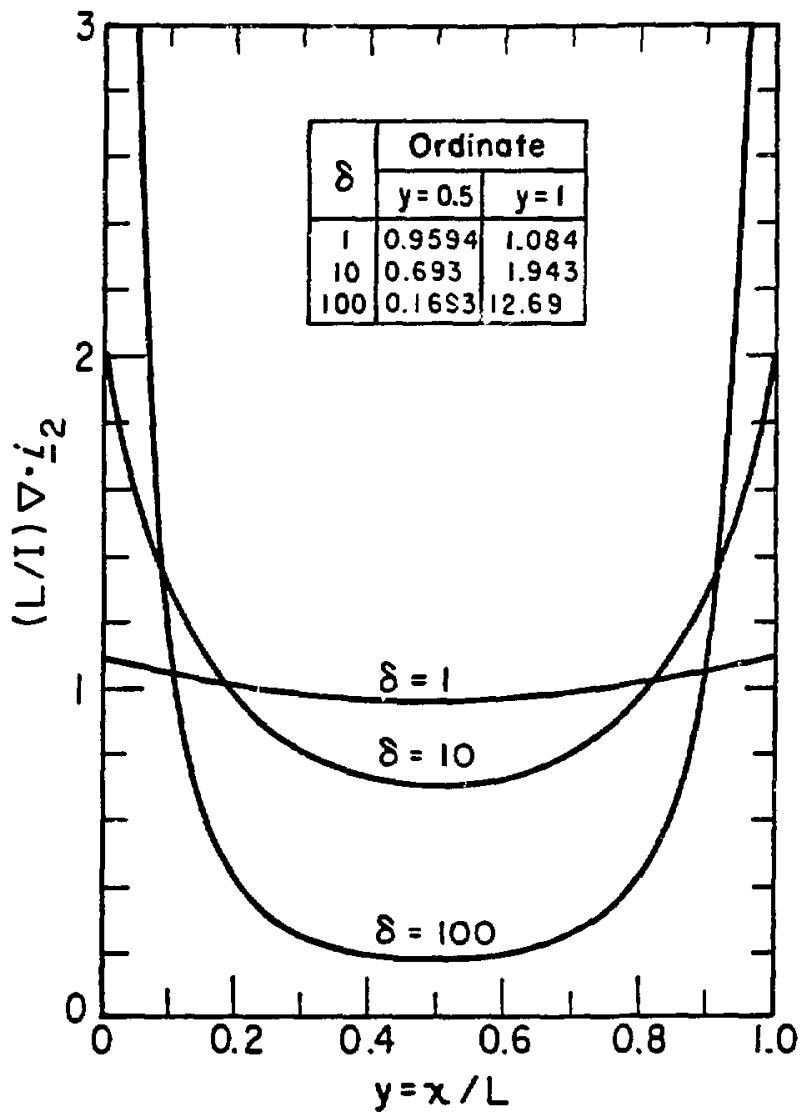

XBL 748-3782

Figure 41. Reduced current distributions for Tafel binetics with equal matrix and solution conductivities. 
taken to be $+\mathrm{I}$ and -1 . For a redox reaction equation $3-8$ is often written as

$$
\nabla \cdot I_{2}-a i_{0}\left\{\frac{c_{1}}{c_{1}^{0}} \exp \left[\frac{a_{2} F}{R T}\left(\Phi_{1}-\Phi_{2}\right)\right]-\frac{c_{2}}{c_{2}^{0}} \exp \left[\frac{-\alpha_{2} F}{R T}\left(\Phi_{1}-\Phi_{2}\right)\right]\right\} \text {. }
$$

Now $i_{0}$ is a constant representing the exchange current density at the composition $c_{1}^{0}, c \frac{0}{2}$. The potential difference $\phi_{1}-\phi_{2}$ is equal to $\eta_{3}$ plus an additive term which depends on the local solution composition. A new dimensionless group $\gamma_{l}=s_{1} I L / n F e D_{1} c_{i}{ }^{0}$ ean be formed due to the introduction of the diffusion coefficient of each species and a characteristic concentration. Another special case that can be treated is deposition from a binary electrolyte. The binary electrolyte formulation can be applied to sulfuric acid in lead-acid batteries or to the polysulfide in the sodium-sulfur cell if the melt is taicen to be composed of $\mathrm{Na}_{2} \mathrm{~S}$ and $\mathrm{S}$. This formulation also applies to systems with concentrated $\mathrm{KOH}$ electrolyte such as in $\mathrm{Ni}-\mathrm{Fe}$ and $\mathrm{Ni}-\mathrm{Zn}$ cells. although the solubility of $\mathrm{ZnO}$ must be ignored.

Often a system cannot be approximated by one of the limiting cases presented above. Full treatment of the complicated factors governing the behavior of the porous electrode requires the use of high-speed digital computation. Newman and Tiedemann suggest a computational method for battery electrodes involving a binary electrolyte. In general, reactant species are depleted during the course of discharge, and time must be included as a variable. Thus the couplef equations are solved simultaneously at each time step. Pollard and Newman ${ }^{91}$ treat the transient behavior of the lithium-aluminum/iron sulfide high-temperature battery for a constant-cursent discharge. Concentration distributions across the cell sandwich are presented at various times ibroughout the discharge.

In summary we can list a number of factors which an affect the performance of porous electrodes:

1. Charge and discharge methods affect battery efficiencies and cycle life.

2. The solubility of reactants and products can limit cycle life and shelf life.

3. Higher current densities yield bigher overp.entials, and thus a given eut-off potential is 
reached sooner.

4. The pores may become constricted or even plugged with solid reaction products. A nonuniform reaction distribution will accentuate this problem at the mouth of the pores.

5. Utilization of the solid fuel can be limited by covering of the reaction surface with reaction products.

6. Rates of mass transfer between crystallites and the reaction surface may become more limiting as the discharge exhausts the front part of the electrode. This could account for changes in the apparent limit of utilization with current density.

\section{Experimental Method}

Until now we have considered the mathematical modeling of porous battery electrodes. Experimental data are needed, of course, to insure that our understanding of the system is substantially correct. In construeting an experimental cell we want to eliminate any scale-up effects not included in the mathematical modeling so that we can directly compare experimencal and theoretical results. The scale-up effects of the current collector and interconnecting bus and post will then be considered separately.

The experimental system can be arranged in a mono-cell configuration vith une positive and one negative plate or as a bi-cell with a single positive electrode and two l'egative electrodex. The bi-cell arrangement represents a "section" of a positive and two bali negatives thet would be found in the scaled-up battery. The construction and symmetry of discharge of this cell would be similar to the scaled-up version. The mono-cell's main advantage over the bicell inay be in the ease and cost of construction.

A schematic of a bi-cell developed at Argonne National Laboratory ${ }^{\text {h }}$ is shown in figure 42. This figure shows heavy, highly conducting current-collecting sheets in the center of the positive electrode and at the back of the two balf negative electrodes. These current collectors promote a uniform current distribution across the face of the electrode by mir ;-izing the obmic potential drop in the currert-collecting sheet. This is important for comparison to one- 


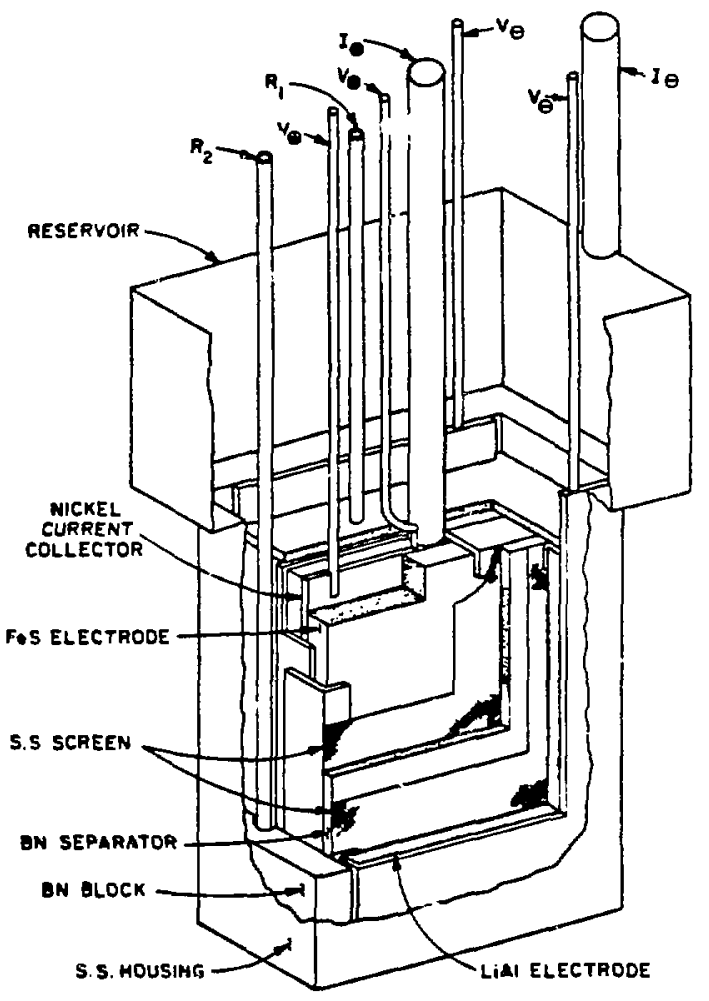

XBL $834-9115$

Figure 4-2. Bi-cell design of a positive and two half negative electrodes designed to promote - uniform current distribution across the electrode face. Reproduced from reference 92. 
dimensional micromodeling results or for use as data in subsequent scale-up ealculations. Separate voltage and sistent taps should be used to eliminate any error in voltage readings due to ohmic potential drop in the cell leads. Reference electrodes should be used it the experimental $\propto$ ell so that the tctal sell potential can be decomposed into contributions associated with the positive and negative electrodes. Although we will see that this decomposition is not necessary for our scale-up calculations, research effors at improving the battery neer to be largely direcred. to the limting electrode. Batteries are often designed so that the pasitive elecsrode limits the batiery capacity. This should then be the case with the experimental cell as well. In general it is important to use the same electrode thicknesses, amount of active naterial, excess electrolyte, temperature, separator material, etc. that is being considered for the scaledup version. Micro-modeling results can be used a a guide in the selection of some of these parameters. The cross-scational area of the test cell is not important since our experiment is designed to be one dimensional.

The current is measured during discharging or charging with a current-interruption technique. The cell potential during current flow $\left(\Phi_{p}-\Phi_{n}\right)$ and after 15 seconds of intertuption is interpreted accordilg to the equation

$$
=Y\left(U-\Phi_{p}+\Phi_{n}\right) \text {. }
$$

where $l$ is the current density from negative to positive plate $\left(A / \mathrm{cm}^{2}\right), Y$ is the conductance of a cell element $\left(\Omega^{-1}-\mathrm{cm}^{-2}\right), U$ is the apparent open-circuit potential $(V), \Phi_{p}$ is the potential of the positive plate (V), and $\Phi_{n}$ is the potential of the negative plate (V). This relationship assumes a linear polarization curve; however it can also be regarded as a step in the linearization of a ncnlinear problem. Values of $U$ and $\boldsymbol{Y}$ can be determined as a function of the state of charge for a given constant current density. Data for a lithium-aluminum/iron sulìde high-temperature cell taken at Argonne National Laboratory" are giver in figure 4-3. The use of reference electrodes

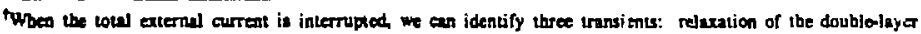
apecity, e locil equalizetion of cheree and concestsatios from tront to back of the electrode, and a reduction of concentracion eradients is the whole cell by diffusion actowe the separtor. In the current-interruption technique, we wish to wit lons enough for doublelayer charging to relas. A cheracteristic time for this is L'oC/a. The apperent open-arcuit potential will continue to rive a the otber transients continue. We choore Is seconda bere so that we may

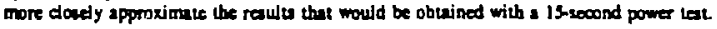




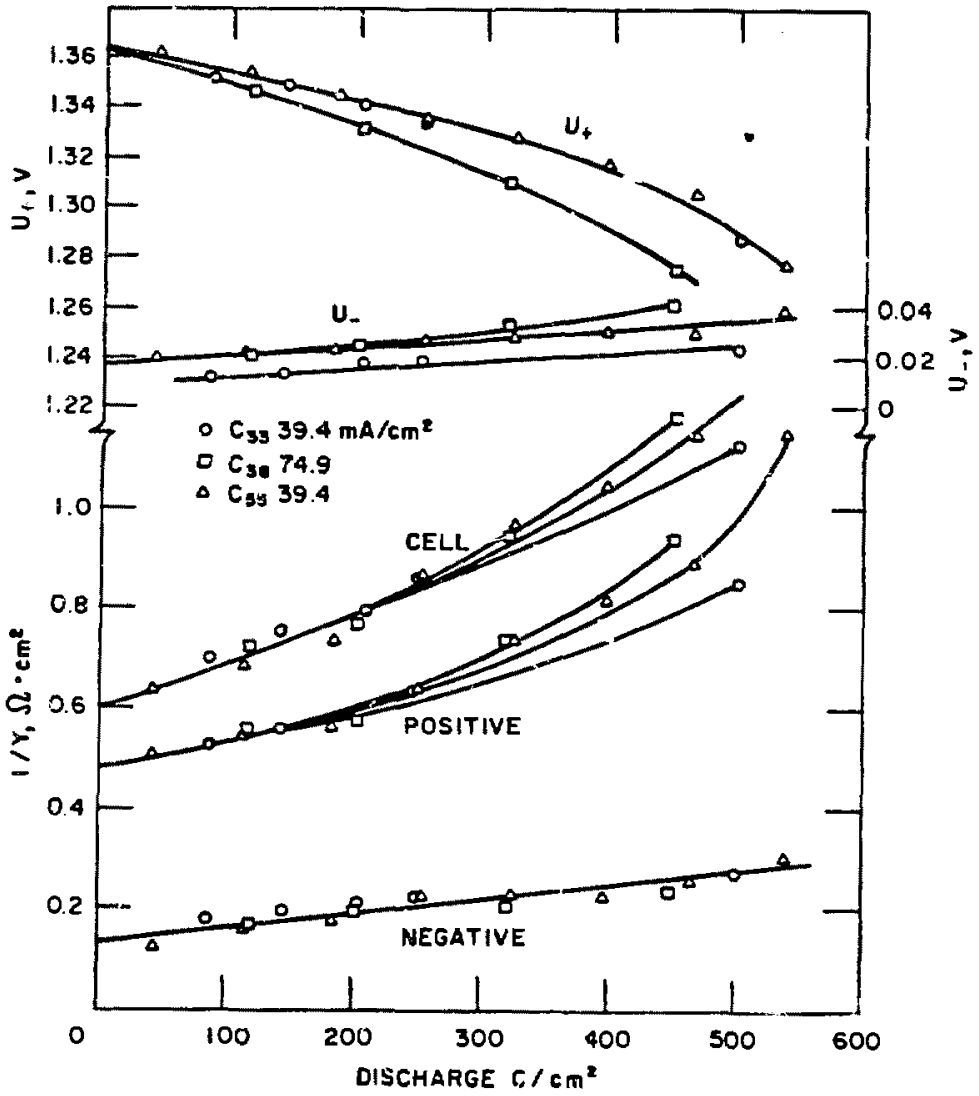

X8L 834-9116

Figure 4-3. Electrochemical characterintics $\left(U\right.$ and $Y$ ) on discharge for $\zeta_{p}-0.32 \mathrm{~cm}$ and 30 percent excess capacity in the negative electrode. Reproduced from reference 92. 
allows the decomposition of the cell potential and specific conductance into values for the individual electrodes. These values are related to the cell values by

$$
U=U_{+}-U_{-}
$$

and

$$
\frac{1}{Y}=\frac{1}{Y_{+}}+\frac{1}{Y_{-}}
$$

These results form a basis both for comparison to micro-modeling results and now for scaling up the plate size.

\section{Seale-up of Grid}

Cose weight, and volume considerations dictate that the current collectors will not be the heavy plates used in our test cell. The mass of the current collector that should be used for a given plate area is a scale-up consideration that is subject to optimization. Our goal is to develop a discharge curve for the plate as a whole (witb current collectors) based on individual cell elements shown in figure 4-3. Two common configurations for the current collector is the sheet current collector and a grid current collector. Tiedemann and Newman treat the nonuniform current and potential distributions in composite sheet electrodes ${ }^{93}$ and in battery plates with grid configurations.

The lead-acid battery use a current-collecting grid with the active material pressed between the ribs. A boneycomb grid has been used in experiments with the lithiumaluminum/iron sulfide battery. We choose as an operational current-collector model a rectilinear grid with horizontal and vertical elements $\mathbf{A}$ one-dimensional micro-model ${ }^{91,95}$ or data as in fgure 43 is coupled to a two-dimensional model of the grid Equation 45 can still be used, where the current, aree, and potentials are now local values for node points on the grid. The polarization parameters, $U$ and $Y$, are curve fit as functions of depth of discharge and local current density. Kirehhoff's current law is used with equation 45 to solve for the local potential distribution across the face of the plate during discharge. 
Results of this analysis give the overall plate bebavior as a function of state of charge. The current distribution actoss the face of the electrode is nonuniform at the beginning of discharge and becomes more nearly uniform as discharge proceeds because of the dependence of the electrochemical resistance and apparent open-cireuit potential on the state of charge. The overall behavior can now be represented by

$$
U-V=\Delta V=\left(R_{z}+\frac{1}{Y}\right) i \text {. }
$$

where $\Delta V$ is the voltage displacement from open circuit, and $R_{\boldsymbol{T}}$ is the resistance of the grid. Since $1 / Y$ and $R_{q}$ vary through discharge in ways that depend on the specific system, a general formulation of results cannot be made. However, we can consider the zero-time behavior of a system with constant polarization parameters and formulate the problem for the primary variables, $\Delta V$ the voltage displacement from open circuit, $I$ the total current leaving the grid, $A$ the area of the plate, $\boldsymbol{Y}$ the conductance of the cell element, $\boldsymbol{M}$ the mass of the grid, $\sigma$ the grid conductivity, $\rho$ the grid density, and $L_{p}$ the positive electrode thickness, four dimensionless groups govern the system. One of these, $L_{p}^{2} / A$, does not have direct relevance to the problem. We are left with

$$
\Pi_{1}=\frac{l}{2 A Y \Delta V}, \Pi_{2}=\frac{M \sigma}{\rho Y A^{2}} \text {, and } \Pi_{3}=\frac{M}{\rho L_{p} A} \text {. }
$$

$\Pi_{1}$ represents a ratio of overal] conductance $I / \Delta V$ to electrochemical conductance $2 A Y$. Stated anotber way, $\Pi_{l}$ is the ratio of the actual current leaving the tab to the current that would leave the tab if there were no obmic resistance in the grid. The factor of two in $\Pi_{1}$ reflects the fact that the cotal current leaving the grid tab is being collected from both sides of the plate. $\Pi_{2}$ represents a ratio of grid conductance $\frac{M \sigma}{A A}$ to electrochemical conductance $A Y . \Pi_{3}$ is the volume fraction of grid material.

Other minor dimensionless parameters must now be chosen before the results of the grid model can be plotted. These include the ratio of the tab width to plate width, relative tab position, aspect ratio of plate height to plate width, ratio of total grid material on horizontal 
elements to that in vertical elements, and the number of borizontal and vertical elements, Further, results can be presented for an infinitely conducting negative grid, a symmetric negative grid with equal conductivity, or a complete description of a positive and negative with different conductivities.

Figure 44 is a plot of dimensionless plate current vs. dimensionless plate area for the beginning of discharge. 94 The volume fraction of grid material has been taken to be 2 ero so that $L_{\boldsymbol{p}}$ does not enter as a parameter in this figure. Here the horizontal and vertical grid elements have the same amount of grid material, and a symmetric negative grid with equal conductivity is used. Figure 45 is an example of an improved grid. Extra conducting material has been added to the two columns of vertical elements below the tab and the horizontal elements across the top of the grid. The two center vertical elements are heavier by a factor of 11 , and the top horizontal elements bave 4 times the mass of the base elements. Figure $4-6$ is a dimensionless graph of plate current vs. plate area for this grid design. Here the negative grid has been assumed to be infinitely conducting. A comparison of figures $4-4$ and $4-6$ s'ows the improvement in overall conductance for the improved grid design. This improvement is actually due to two major effects, the reduction of ohmic potential drop in the improved grid design and the neglect of ohmic potential drop in the negative grid.

Figure 47 is a dimensionless correlation of the same data as in figure $4-6$. The dimensionless groups have been adjusted so that all the data closely follow the same curve. Here it is recognized that the grid necessarily displaces some active material, reducing the area for current within the bed. The active bed cross-sectional area is therefore $A-M / \rho L_{p}$. The area for current flow through the separator is $A$. Thus we correct the clectrochemical conductance $A Y_{0}$ by an additive contribution of separator resistance based on area $A$, and the rest of the electrochemical resistance based on area $A-M / \rho L_{p}$. The electrochemical resistance becomes 


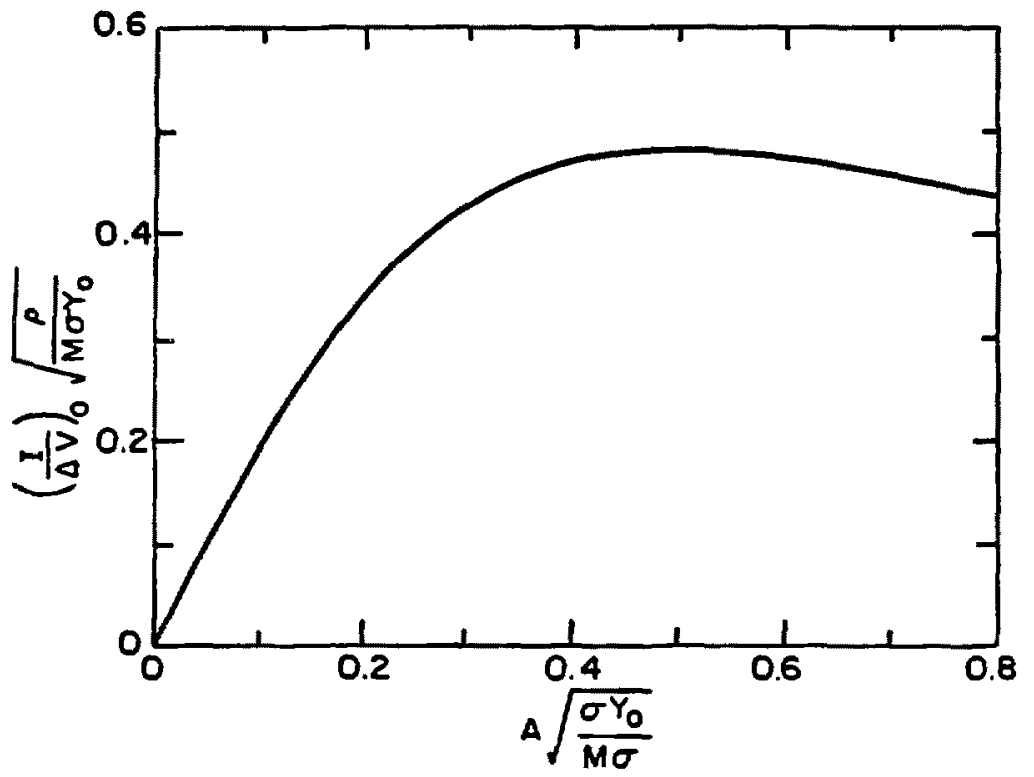

XBL 833-5454

Figure 4-4. Dimensionless plate current as a function of the dimensionless plate area at the beginning of discharge. Height to width ratio equals 0.8 . Ten percent tab is located $30 \%$ from the edge of the plate. $\zeta_{p}$ is taken to be infinite. Reproduced from reference 94 . 


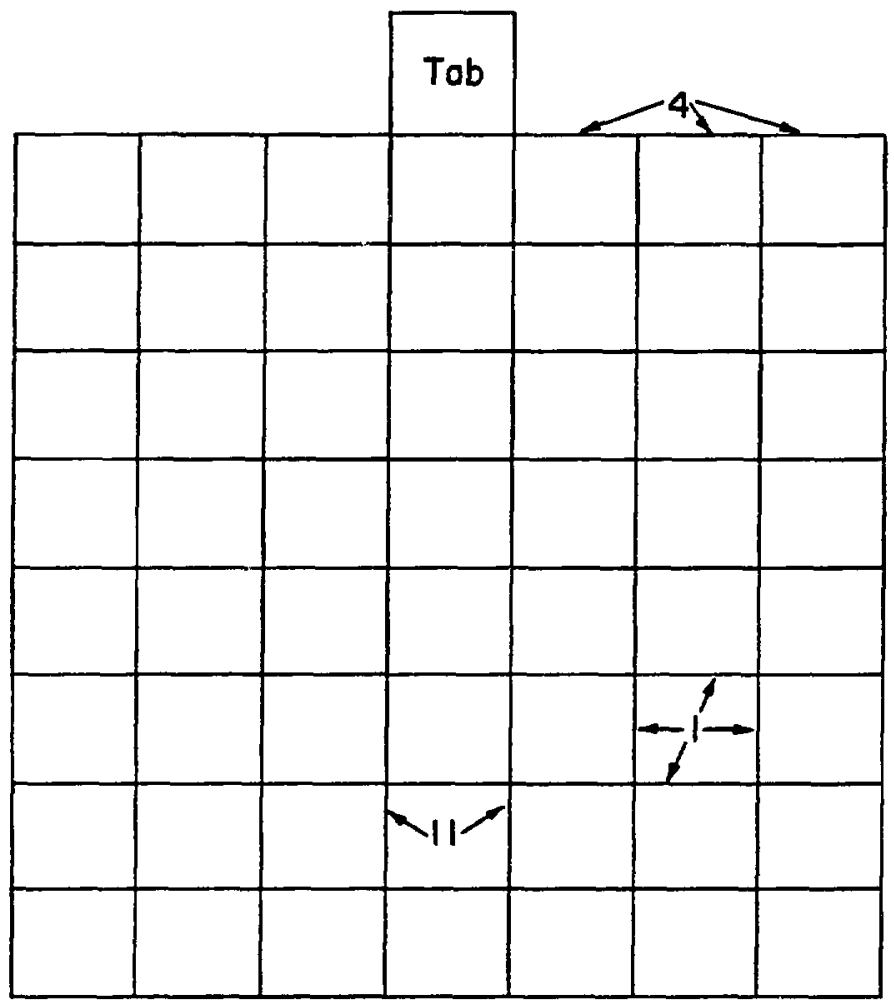

XBL B34-9114

Figure 4-5. Improved grid design with extra conducting material in the two vertical elements (11 times heavier) and top horizontal elements ( 4 times heavier). 


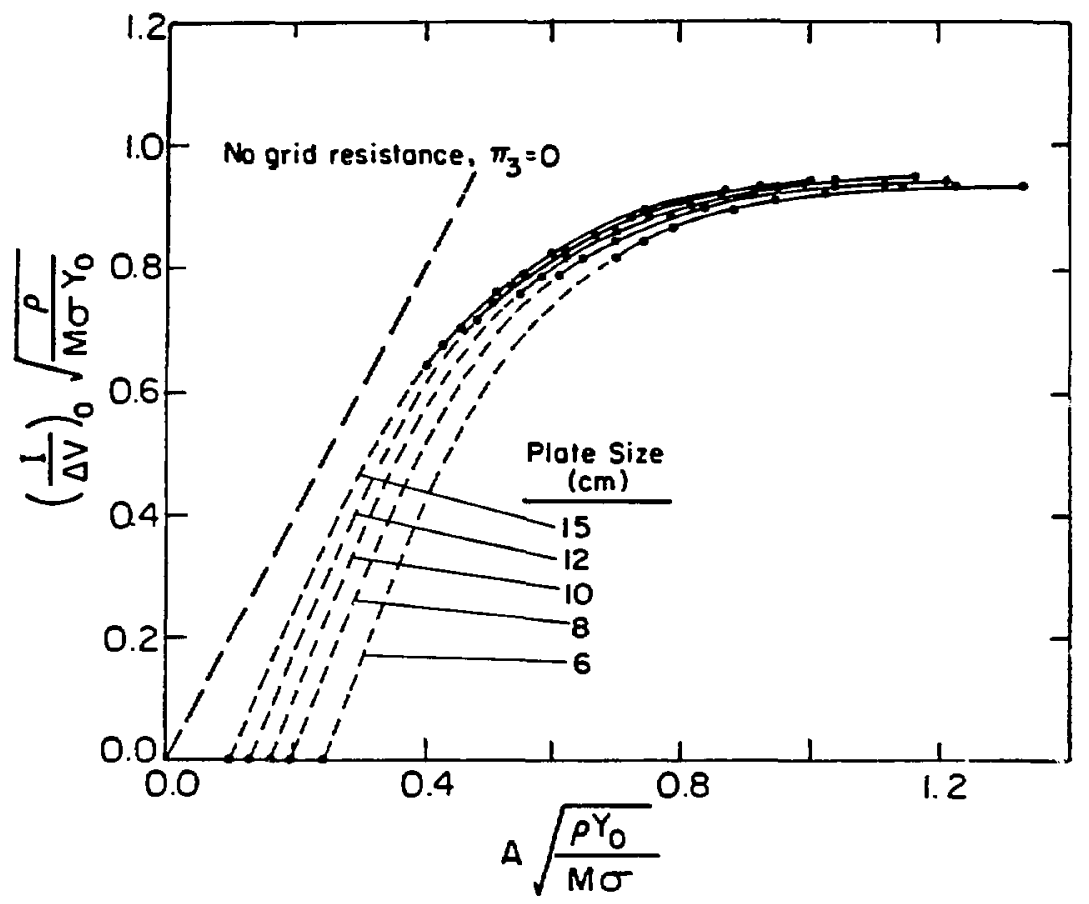

$X B L 833-5456$

Figure 4-6. Dimensioniess plate current as a function of the dimensionless plate area at the beginning of discharge for the improved grid design. 


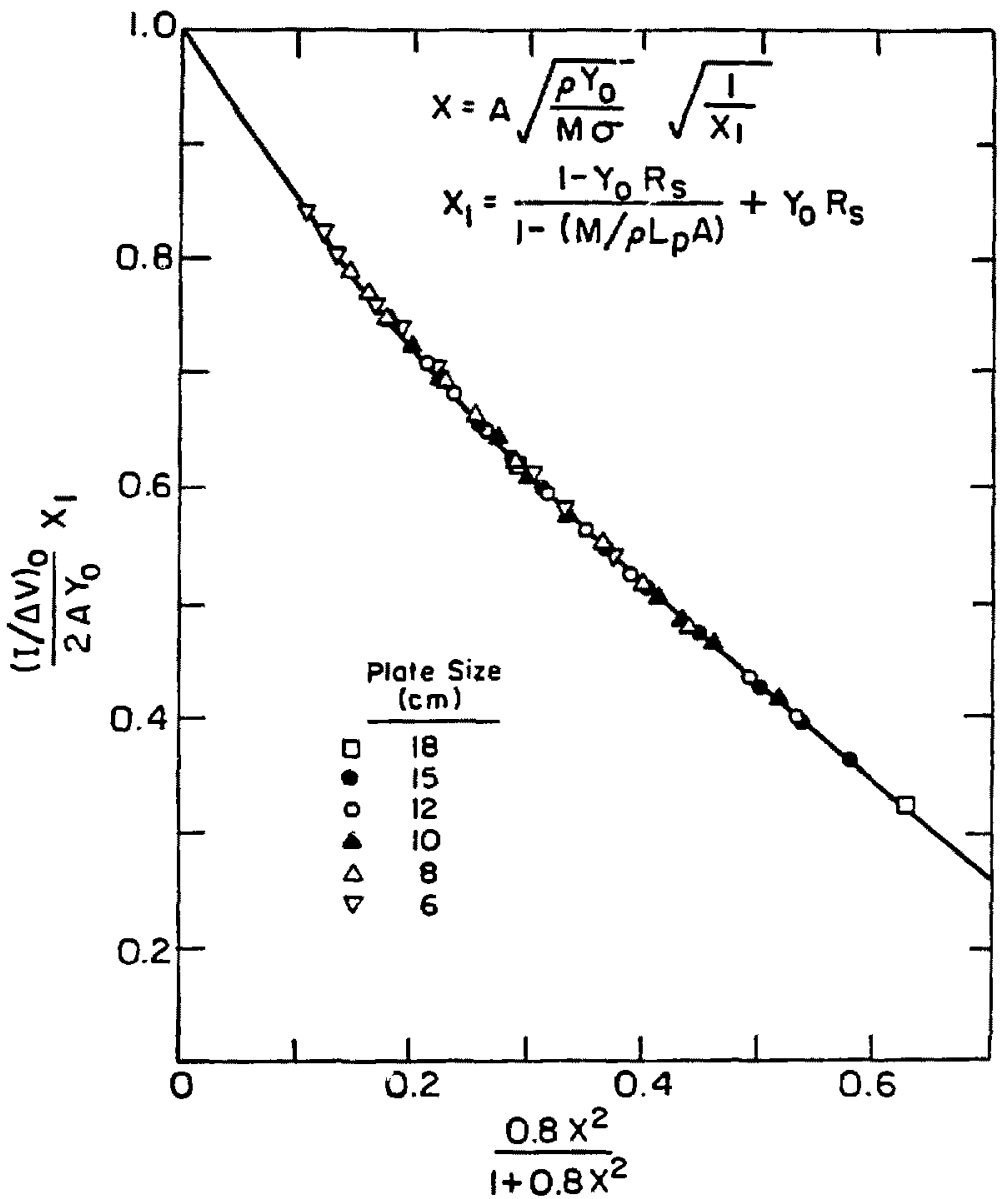

XBL $833-5460$

Figure 47. Dimensionless plate conductance vs. dimensioniess plate area based on a reduced area for current flow through the matrix bed. 


$$
\left(\frac{1}{Y}-R_{,}\right) \frac{1}{A-\frac{M}{\rho L_{g}}}+R_{p} \frac{1}{A}=\frac{1}{Y A}\left\{\frac{1-Y R_{p}}{1-\frac{M}{\rho L_{p} A}}+Y R_{p}\right\} .
$$

Thus, $1 / Y_{0}$ is replaced by

$$
\frac{1}{Y_{0}}\left\{\frac{1-Y_{0} R_{0}}{1-\frac{M}{\rho L_{p} A}}+Y_{0} R_{1}\right\}
$$

in plotting this figure. The value of the separator resistance $R_{1}\left(\Omega-\mathrm{cm}^{2}\right)$ can be estimated on the basis of electrolyte conductivity. The data plotted in this manner fall very closely on the same curve and have unity intercepts on both the ordinate and abscissa. The values of these interceps can be seen by eiamining asymptotic limits. Consider the case where the grid conductivity appraches infinity for a constant grid fraction. The value of the dimensionless plate area clearly goes to zero. The total plate conductance $I / \Delta V$ includes the effects of both the electrochemical conductance and grid conductance. Since the resistance of the grid goes to zero for an infinitely conducting grid, the total plate conductance reduces to only the electrocherrical conductance. Thus, the dimensionless plate conductance goes to unity. Now, for a finite grid conductivity and a grid Iraction approaching unity, we again have the dimensionless plate area approaching zero. Ais the active material reduces to zero relative to the grid, the resistance of the grid must become negligible compared to the electrochemical resistance in the active bed. The dimersionless plate conductance bebaves like

$$
\frac{I / \Delta Y}{2 A Y_{0}}\left\{\frac{1-Y_{0} R_{1}}{1-\frac{M}{\rho L_{p} A}}\right\}
$$

and must approach unity as $M / \rho L A d$ approaches unity. A third limit easily seen is for the cross-sectional area approaching infinity. The ordinate approaches zero while the dimensioniess plate area becomes infinite. By the nature of the way the abscissa is plotted, this infinite point is pulled back to a unity intercept. Furthermore, we expect this graph to behave linearly in this region. 
As pointed out above, figure $4-7$ is strictly valid for zero-time behavior. Our alternative to performing complex grid calculations to map out the overall conductance during discharge is to assume figure 47 is valid throughout discharge, replacing $Y_{0}$ with $Y$ and $(I / \Delta V)_{0}$ by $I / \Delta V$. Here we are recognizing the dependence of the polarization parameters on the average depth of discharge, but still assume that they are constant across the electrode face. $Y$ and $U$ actually depend on the local current density and local depth of discharge. This method should give a good approximation to the actual bebavior of the plate and reduces to an exact solution to the complete grid formulation as the current densities become more uniform Results showing the effect of the grid are given in figures $4-8,49$, and 410 . The overall plate conductance and electrochemical conductance are plotted as functions of the depth of discharge. Both are made dimensionless with $Y_{0}$, the electrochemical conductance at the beginning of discharge. Also plotted in figures $4-8$ and $4-9$ are the apparent open-circuit potential (see figure $4-3$ ) and the cell voltage. $V$ is determined by calculating the cell voltage as a function of deptb of discharge for an average current density. Figure 48 is for a $12 \times 12 \mathrm{~cm}^{2}$ plate with a grid weight that has been optimized for maximum specific energy. At the beginning of discharge we see that the plate conductance is only $42.8 \%$ of the value that would be obtained for no grid resistance. (Strictly spealing we are also assuming that the grid volume fraction is zero.) As discharge continues, the importance of the electrochemical resistance relative to the grid resistance increases, and $\frac{I / \Delta V}{2 A Y_{0}}$ becoms a larger fraction of $Y / Y_{0}$. Figure 49 is a similar plot for a $12 \times 12 \mathrm{~cm}^{2}$ plate, but a grid wejgbt that corresponds to maximum specific power. The heavier grid offers a smaller grid resistance, and therefore the dimensionless plate conductance is $66.3 \%$ of the value for no grid resistance. $U$ and $Y / Y_{0}$ remain unchanged, and the cell voltage $V$ is slightly higher due to a higher overall cell conductance. Figure 410 shows the effect of plate aree All three plate areas correspond to compiomise grid weights (see figure $4-11$ and discussion following). As the plates become smaller the grid penalty is seen to become less. However, the final specific energy of the cell will not continue to increase as the plates become 


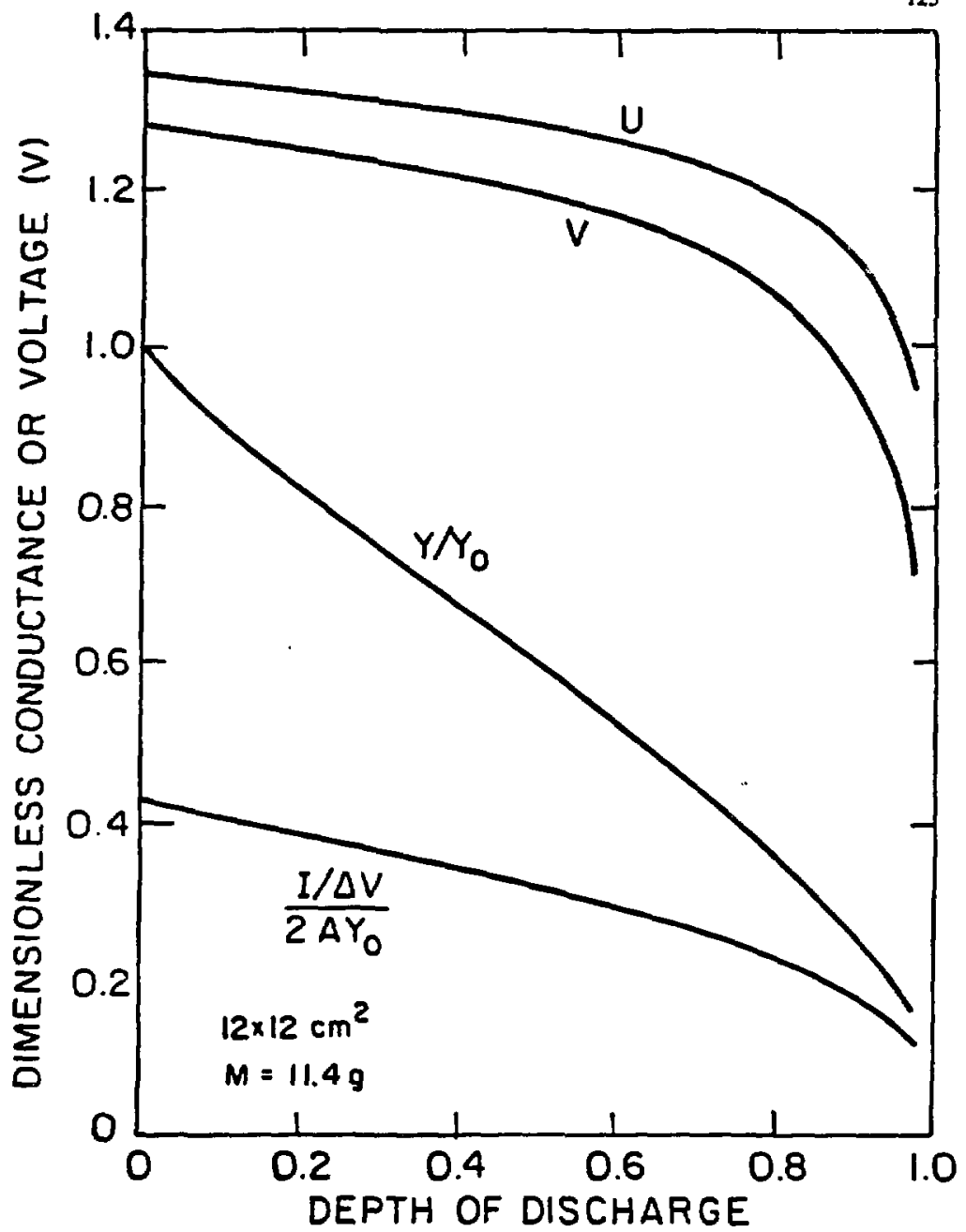

$X B L \quad 839-11790$

Figure 48. Apparent open-circuit potential, cell voltage, dimensionless electrochemical conductence, and dimensionless plate conductance vs. depth of discharge for a $12 \times 12 \mathrm{~cm}^{2}$ plate. Grid weight is optinized for traximum energy. 


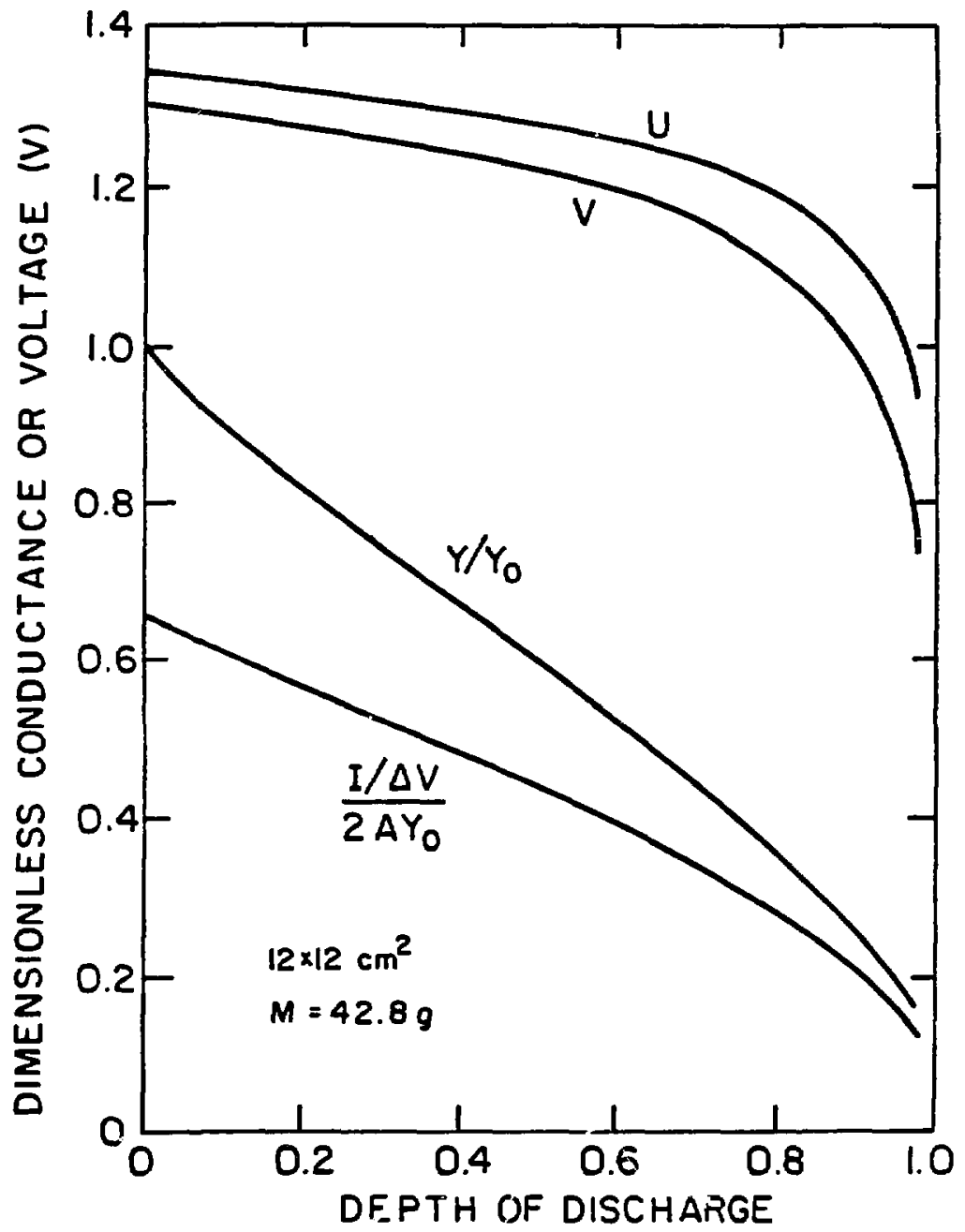

$X B L \quad 839-11791$

Figure 49. Apparent open-circuit potential, cell voltage, dimensionless electrochemical conduerunos, and dimensionless plate conductance vs. depth of discharge for a $12 \times 12 \mathrm{~cm}^{2}$ plate. Grid waght is optimized for maximum power. 


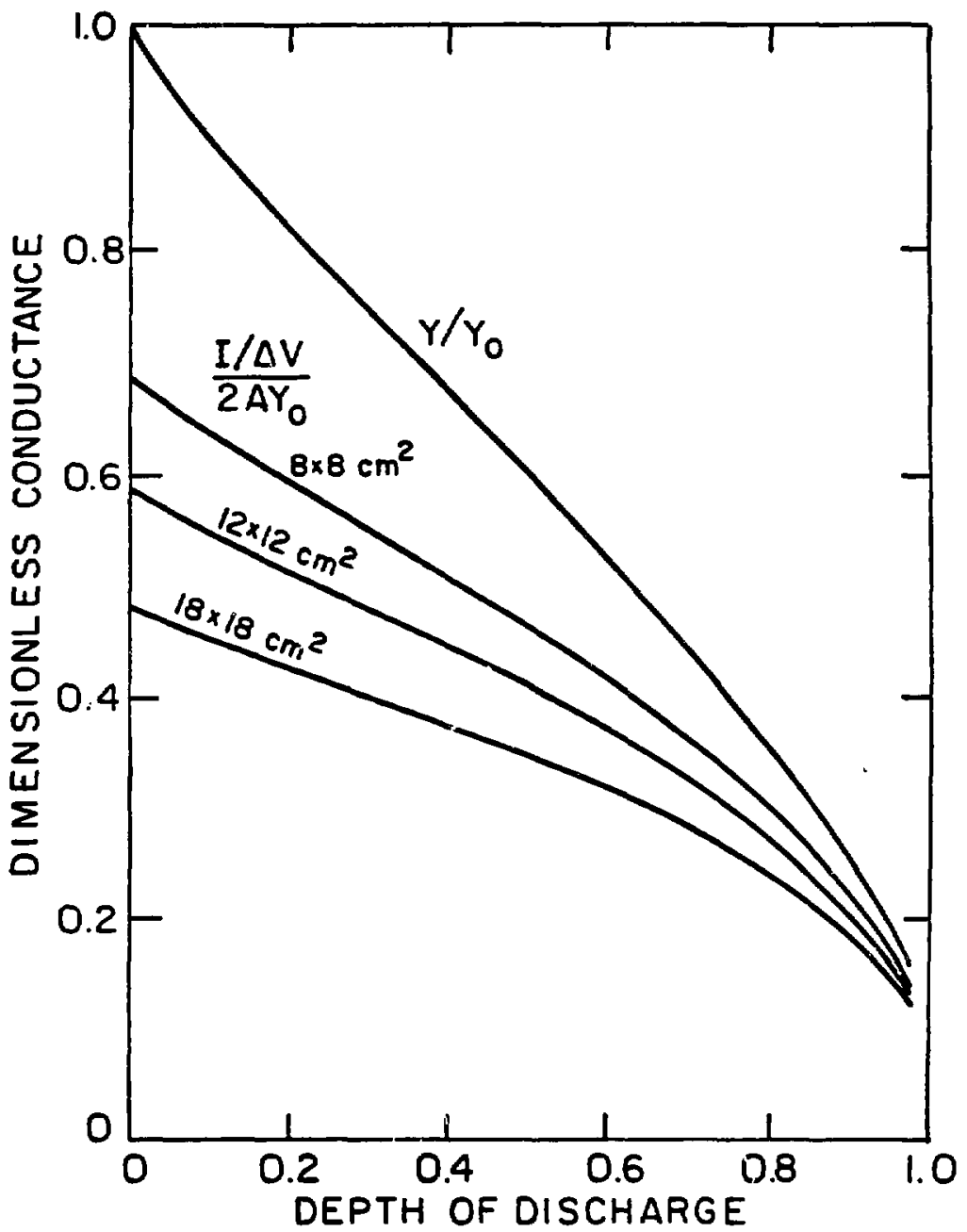

$X B L 839-11787$

Figure 410. Dimensionless electrochenical conductunce and dimensionless plate conductunce vs. depth of discharge for three plate areas. Grid weights are tuken to be the compromise weight for each plate. 
smaller because of the reduction of total amount of active material. A computer program can now be developed that uses data as i.l figures 43 and 47 to generate scale-up predictions for energy and power.

For a given plate size and grid weight, we can now calculate the specific energy and specific power through discharge. The calculations vary the average depth of discharge to a specified cut-off potential for a four-hour discharge rate. The results of these calculations, using the correlation in figure 47 and the data in figure 43 , are given in figure 411 . We immediately see a confliet in trying to optimize simultaneously the battery system for maximum energy and maximum power. Instead we choose an intermediate grid weight that gives a ratio of power to energy equal to the ratio of maximum power to maximum energy. For the $18 \times 18 \mathrm{~cm}^{2}$ plate this corresponds to 80.1 grams. Alternative compromises could be selected based on the particular applications at band.

For a given plate area we can explain the maximum in specific energy as follows. For small values of grid mass, the specific energy is low due to severe voltage penalties. As the grid weight increases, energy increases because of the higher average discharge voltage. Increases in grid weight, however, necessarily displace active material for a fixed flate area, which tends to decrease the speciaic energy. If the density of the grid is greater than the density of active material, the specific energy will decrease because of the added weight of the grid itself. Thus, the specific energy reaches a maximum where further increases in grid weight displace active material (and add weight) faster than can be compensated for by higher average cell voltages. The grid weight corresponding to maximum power (halfway through discharge) is much higher than the value for maximum energy because of the higher current at maximum power. Grid weights past the maximum power are becoming a significant factor in the total cell weight, tending to decrease the specific power. We also see from this figure that the maximum energy for the $12 \times 12 \mathrm{~cm}^{2}$ plate is higher than for the $18 \times 18 \mathrm{~cm}^{2}$ plate. This again represents a tradeoff of average cell voltage and amount of active material. 


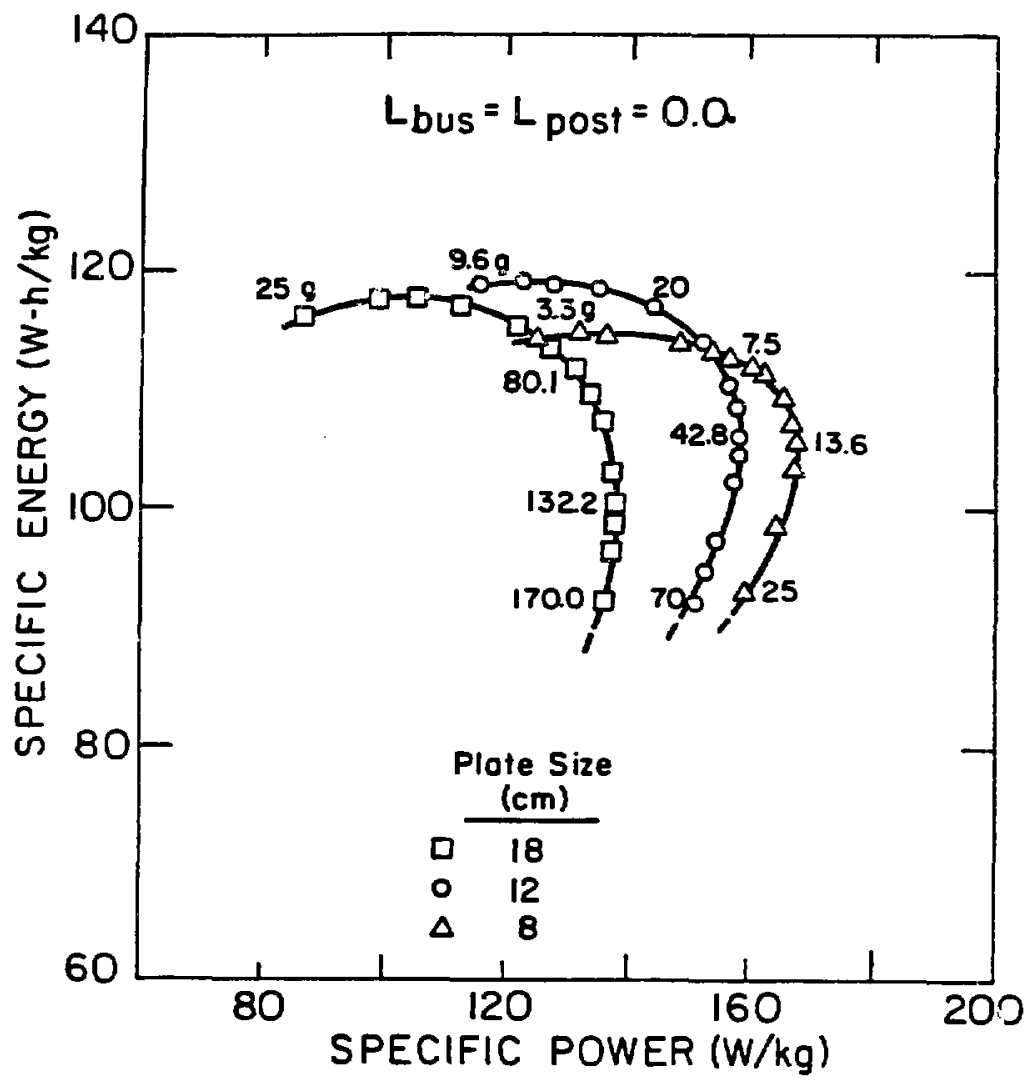

XBL 833-5459

Figure 4-11. Maximum specific energy vs. maximum specific power halfway through dizcharge for three plate sizes. The mass of the current collector is varying long each curve. 


\subsection{Scale-up of Bus and Post}

Having selected a natural system ratio for determining the grid compromise, we now recognize that our small plates must still be connected together in parallel with an interconnecting bus and that the cell must be connected in series 10 another cell with an interconnecting post. Two important new parameters of the length of interconnecting bus and length of interconnecting post must now be considered. Figure $4-12$ shows a symmetric arrangement of interconnecting buses for three positive electrodes. $\boldsymbol{L}_{b \text {, is }}$ isproximately equal to the sum of the widths of the positive electrode, negative electrode, and two separators. The post represents the cell terminal plus intercell connector that extends frotn one cell to the next cell. In our calculations we take $L_{\text {pons }}$ to represent only that part of the post associated with one cell, ie. the length of the terminal plus half of the length of intercell connector. The lengths of interconnecting buses for the positive and negative plates are taken to be the same, as are the post lengths. Given the post and bus lengths needed to connect our cells, an optimization of the distribution of conducting material among the parallel bus connections and the post connections can be made independently of other scale-up considerations. For a positive and negative plate combination

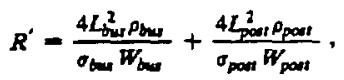

where $W_{\text {bus }}$ is the weight of the positive bus connector plus negative bus connector, and $W_{\text {part }}$ is the corresponding quantity for two post lengths. $R^{\prime}$ is the resistance of the bus and post combination. Manimizing $\boldsymbol{R}^{*}$ with respect to the total weight of bus and post held corstant yields

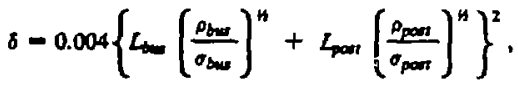

where $\delta-R^{\prime} W^{\prime} / 1000(\Omega-k g)$ and $W^{\prime}=W_{b u s}+W_{\infty \infty 10}(g)$. ( $W_{\text {post }}$, here, is that part of the post associateú with one positive electrode.) The important quantity that results from this optimization is 


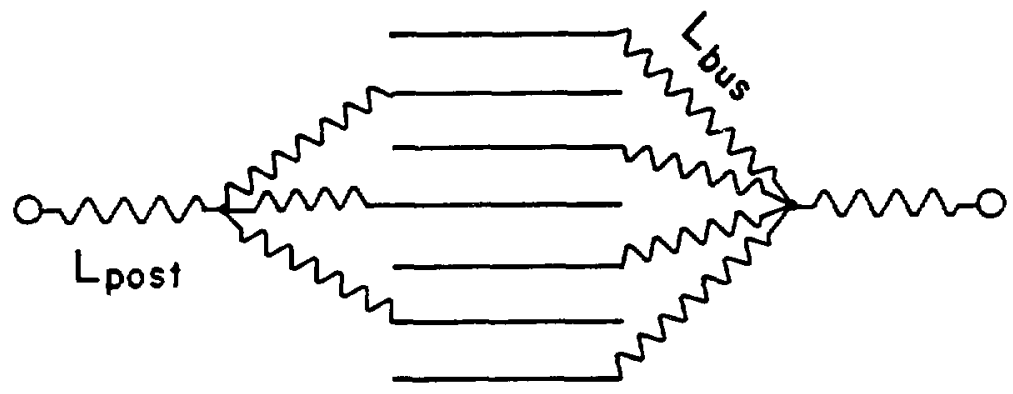

XBLB33-5461A

Figure 4-12. Symmetric arrangement of interconnecting buses and interconnecting posts for three positive electrodes. 


$$
L_{\text {bue }}\left(\frac{\rho_{\text {bus }}}{\sigma_{\text {bus }}}\right)^{1 / 2}+L_{\text {port }}\left(\frac{\rho_{\text {part }}}{\sigma_{\text {port }}}\right)^{1 / 2} \text {. }
$$

If the density of the bus and post are taken to be equal, we see that only the sum of the bus and post length is important to the scale-up predictions. We also note that the aumber of positive electrodes per cell is subject to variation. The number used will affect the final results for the power and energy, but does not afiect the optimum distribution of material over the bus and post per cell "section."

For a system of positive and negative plates, the equations become

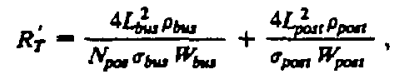

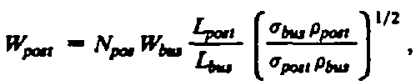

and

$$
W_{T}^{\prime}=w_{\text {par }}+N_{\text {pos }} W_{\text {bur }} \text {. }
$$

Here $R_{T}^{\prime}$ is the total resistance of the parallel bus and series post connections, and $W_{T}^{\prime}$ is the total weight of all bus and post connections. ( $W_{\text {pous }}$. Mere, is the total weight of all post connections.) The optimum distribution of bus and post weight for the positive and negative plate system is the same as in equation 414 with $R_{T}^{\prime}$ replacing $R^{\prime}$ and $W_{T}^{\prime}$ replacing $W^{\prime}$.

For a given plate size and grid weight, the calculated specific energies vs. specific powers will form a loop in the same manner as in figure 4-11 as the mass of the bus and post is varied from very small values to larger values. Thus, for each plate area and grid weigbt we can find a mass of bus and post that maximizes either the specific energy or specific power. As we isvestigate different grid weights (and thus different optimum post and bus weights) we can find values of the mass of grid, bus, and post that yield the maximum power. Similarly we search for values of grid weights and bus and post weights that yield the maximum energy. Now our compromise ratio is the value of the maximum power to this maximum energy. Thus, for each plate size our compromise design is for values of the mass of grid, bus, and poit that give a power to energy ratio equal to the compromise ratio. More than one combination of grid and 
bus and post weight will yield a power to energy ratio equal to the compromise value. The largest values of energy and power are selected from this collection of results to represent the best compromise design for a given plate area

The value of $\boldsymbol{R}^{\prime}$ optimized to yield the maximum power is

$$
R_{\text {ixp }}=\left(\frac{R_{1 \phi}}{W_{b}}\right)^{1 / 2},
$$

where $\boldsymbol{R}_{\sharp}$ is the electrochemical plus grid resistance $(\Omega)$ halfway through discharge (see figures 48 to 410 ), and $W_{6 \text { en }}$ is the base weight of the positive plus two half negatives "section." $\boldsymbol{W}_{\text {bess }}$ includes the weight of the grids, active material, electrolyte, a percentage of container weight (based on the number of positive electrodes), etc., but not the weight of the bus and post. Thus, once the plate area, current-collector weights, number of positive electrodes, and bus and post lengths are chosen, $R^{\prime}$ can be calculated from equation $4-19$ above to optimize the system for maximum power.

The value of $\boldsymbol{R}^{\prime}$ that optimizes for maximum energy takes the form,

$$
R_{\text {Max }}-\frac{\frac{1}{D O D} \int_{f}^{D 00}\left(\frac{U}{I}-R\right) d D O D}{1+\left[1+\frac{W_{\text {bar }}}{D D O D} \int_{0}^{D O D}\left(\frac{U}{I}-R\right) d D O D\right]^{1 / 2}} .
$$

where $R$ is the sum of the electrochemical plus grid resistance (cierived from figure 47). These optimums are always bounded by the boundary condition that the cell voltage can never fall below the cut-of voluge. For any depth of discharge the cut-off voltage can always be reached by setting $\boldsymbol{R}^{\prime}$ as

$$
R_{e=}^{\prime}=\frac{\left(U-V_{c u}\right)}{I}-R \text {. }
$$

For any grid weight we can also search for a value of $\boldsymbol{R}^{\prime}$ such that the resulting power to energy ratio is equal to a value selected as the compromise ratio. Here $R^{\prime}$ is the solution of the quadratic equation 


$$
A R^{\prime 2}+B R^{\prime}+C=0
$$

where

$$
\begin{aligned}
& A=I D O D, \\
& B=A R_{H}-\int_{0}^{\infty}(U-R J) d D O D,
\end{aligned}
$$

and

$$
C=\frac{U^{2}}{4 Q_{0} A L_{p}\left(1-\frac{M}{p L_{p} A}\right)}-R_{n} \int_{V}^{\infty}(U-R I) d D O D .
$$

$Q_{0}$ is the loading of active material in the positive electrode $\left(\mathrm{C} / \mathrm{cm}^{3}\right)$.

Figure 4-13 shows the specific energy of a $12 \times 12 \mathrm{~cm}^{2}$ plate with a post length of $2.0 \mathrm{~cm}$, a bus length of $1.0 \mathrm{~cm}$, and a grid weight of 25.75 grams. For low depths of discharge, the maximum energy is obtained for a bus and post resistunce optimized from equation 4-20. The energy that would be obtained for a value along the cut-off curve (equation 421 ) is lower. As the depth of discha ge increases, the maximum energy and cut-off curves become tangent where the energy calculated is the sarne. Depths of discharge greater than the tangent point along the maximum energy curve violate the side condition that the cell voltage is tot allowed to fall below the cut-off voltage. This is indicated in the figure by the dashed lines. Thus the maximum energy that can be obtained by optimizing the system for maximum energy is given by the value at the tangent point. We see, bowever, that slight increases in energy can be gained by selecting $\boldsymbol{R}^{\prime}$ to have the value that corresponds to the side condition. For depths of discharge greater than tbis absolute maximum, the energy falls off rapidly. Also shown on this curve is the specific energy corresponding to values of $\boldsymbol{R}^{\prime}$ selected for maximum power or the compromise. Depths of discharge pest the intersection of these curves with the cut-of curve again violate the side condicion and are represented by dashed curves. 


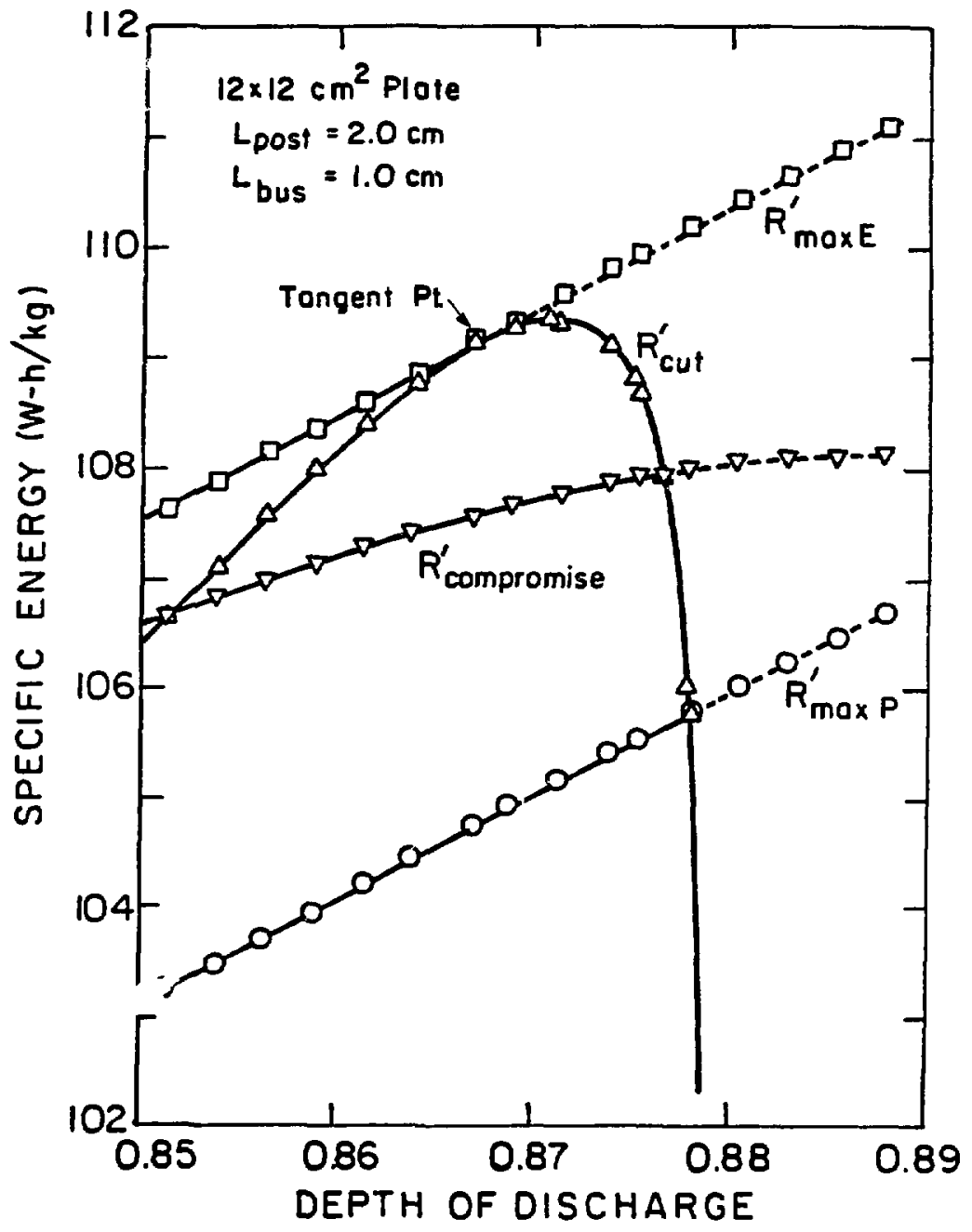

XBL 839-11795

Figure 4-13. Specific energy vs. depth of discharge for the post and bus weight calculated to pive the anximum energy, maximum power, the compromise ratio of power to energy, or the cut-off voltage. The figure is for a $12 \times 12 \mathrm{~cm}^{2}$ plate with a grid weight corresponding to the compromise value of 25.75 grams. 


\section{Results}

Figure 414 represents the composite prediction of specific energy vs. specific power as they relate to the size of plates and lengihs of bus and post. The results presented are for an iron curtent collector, taken to have a density of $7.86 \mathrm{~g} / \mathrm{ce}$ and a conductivity of $19,000 \mathrm{~g}^{-1}$. $\mathrm{cm}^{-1}$. Recall that each point given represents the best compromise of specific energy and specifie power for each plate area as discussed above. The performance penalty (weight and voltage) of including the interconnecting bus and post is readily seen. This graph can now be used to select the plate area which will give adequate performance at a suitable cost. The grid weights and plate areas used to generate figure $4-14$ are plotted in figure 415 . Also shown are the grid weights that correspond to maximum power and maximum energy. This figure, then, yields the grid weight that gives the maximum power, maximum energy, or compromise for each plate area and length of bus and post. It is seen that the optimum grid weight is not greetly dependent on the length of the bus and post, and that this dependence is actually undetectable for maximum specific power. These results suggest that we can improve our grid design without concern over interaction with the optimum post. and bus lengths and that improvements may be independent of depth of discharge as well. We also see that the optimum grid weight should be increased roughly in proportion to $A^{3 / 2}$.

Figure 4-16 represents the composite prediction of specific energy vs. specific power for a nickel current collector taken to have a density of $8.90 \mathrm{~g} / \propto$ and a conductivity of $32,520 \mathrm{~g}^{\prime}$ $\mathrm{cm}^{-1}$. The higher conductivity of nickel over iron will lead to lower associated voltage losses, but the nickel current collector will weigh more than the iron current collector for a given grid volume fraction. The percent improvement of nickel over iron varies from 1.5 to 5.7 percent for specific energy and 4.7 to 15.2 percent for specific power. The larger plates with the higher post lengths show the best improvement as these are the cases where the voltage losses are most important. Thus, we can construct larger cells with nickel before reaching the same voltage penalty. Figure 4-17 plots the dimensionless grid fraction v5. dimensionless area for the nickel 


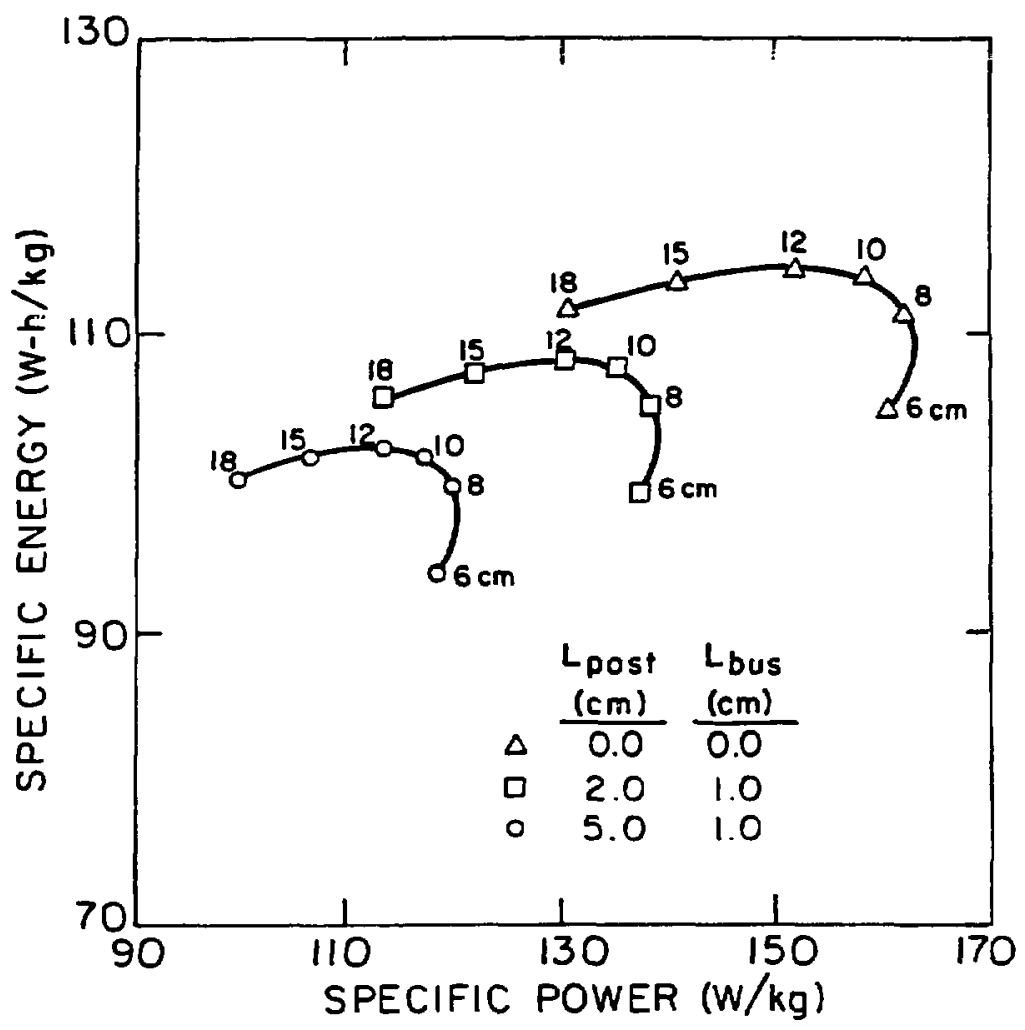

XBL833-5458

Figure 4-14. Composite, compromise predictions of the specific energy and specific power for various post and bus lengths and electrode areas for an iron current collector. 


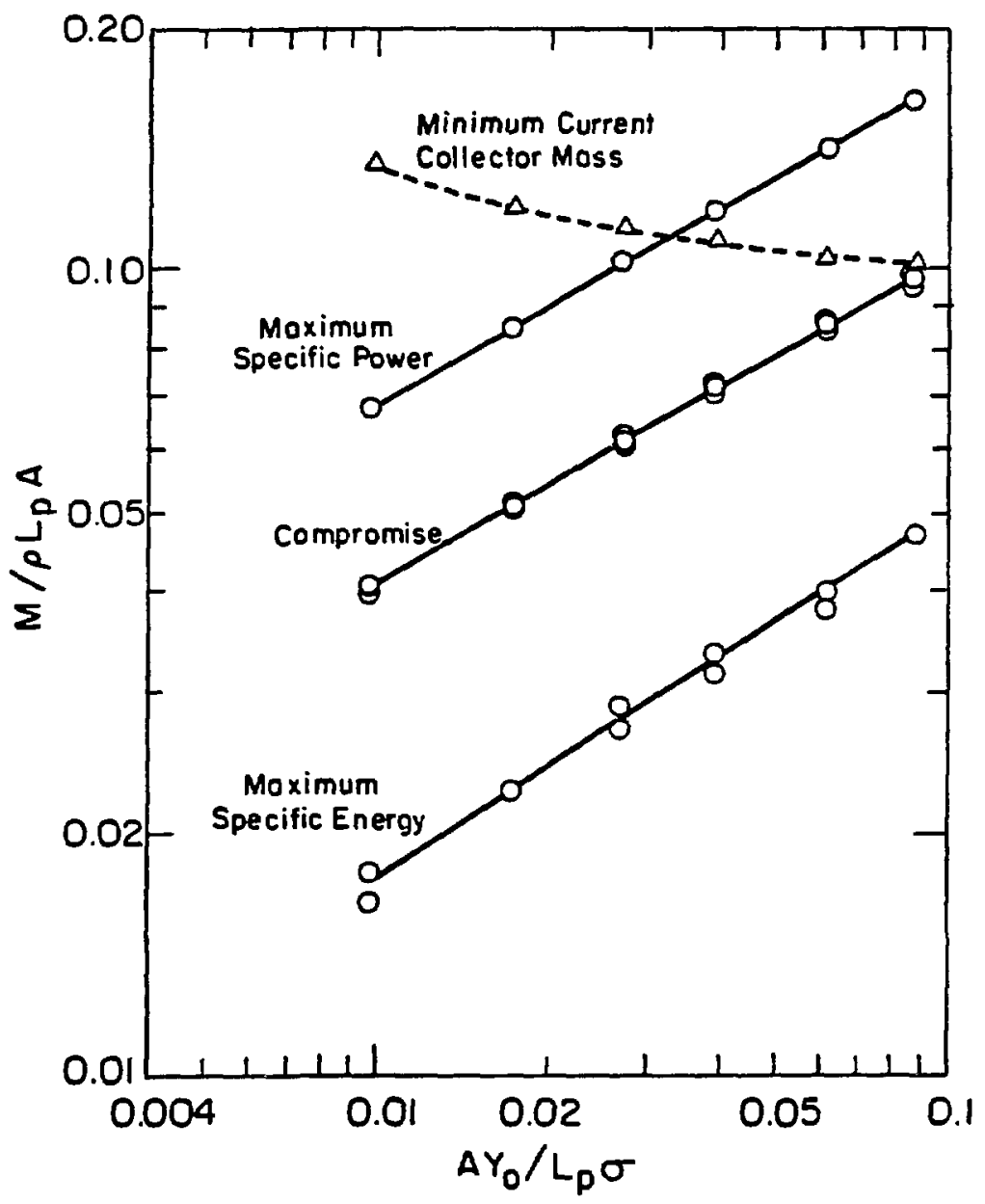

XBL $839-11796$

Figure 415. Dimensionless grid weight ys. dimensionless plate area along the maximum apecific enercy, maximum specific power, or the compromist design. 


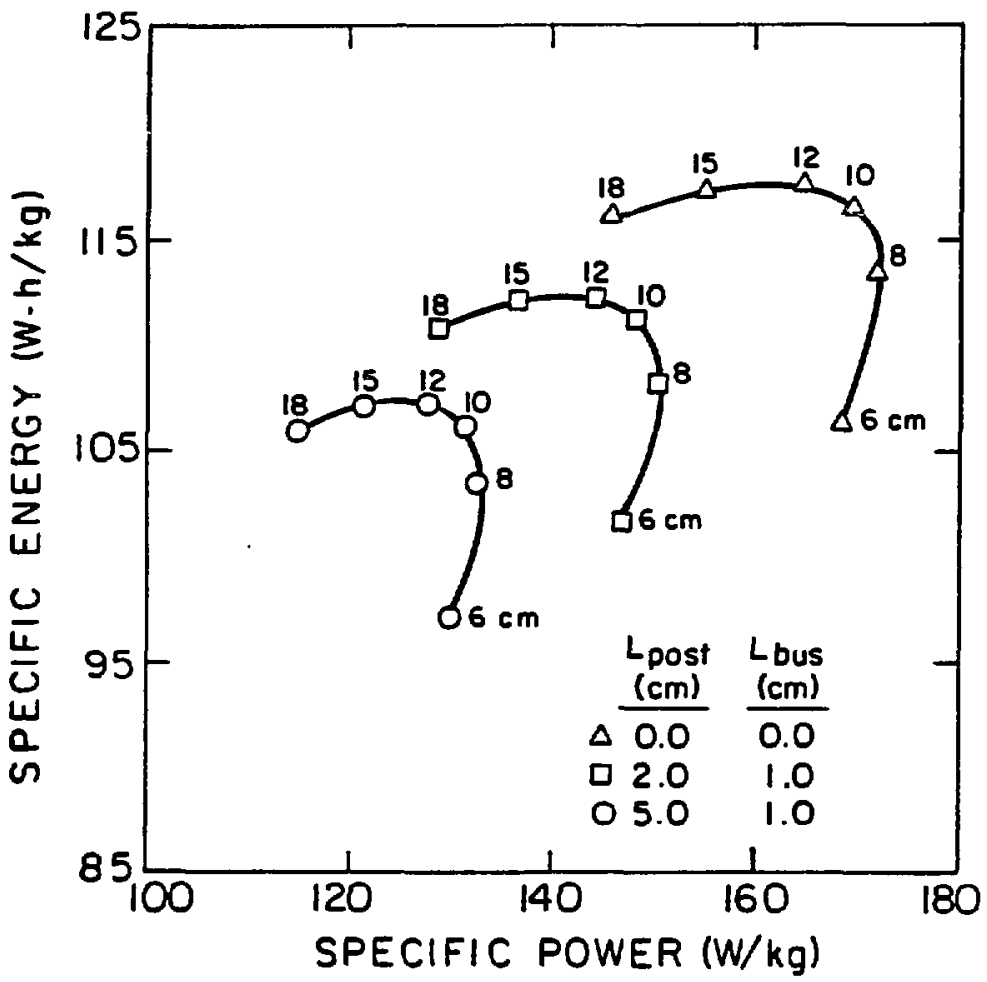

XBL $839-11792$

Figure 416. Composite, compromise predictions of the specific energy and specific power for various post and bus lengths and electrode areas for a nickel current collector. 


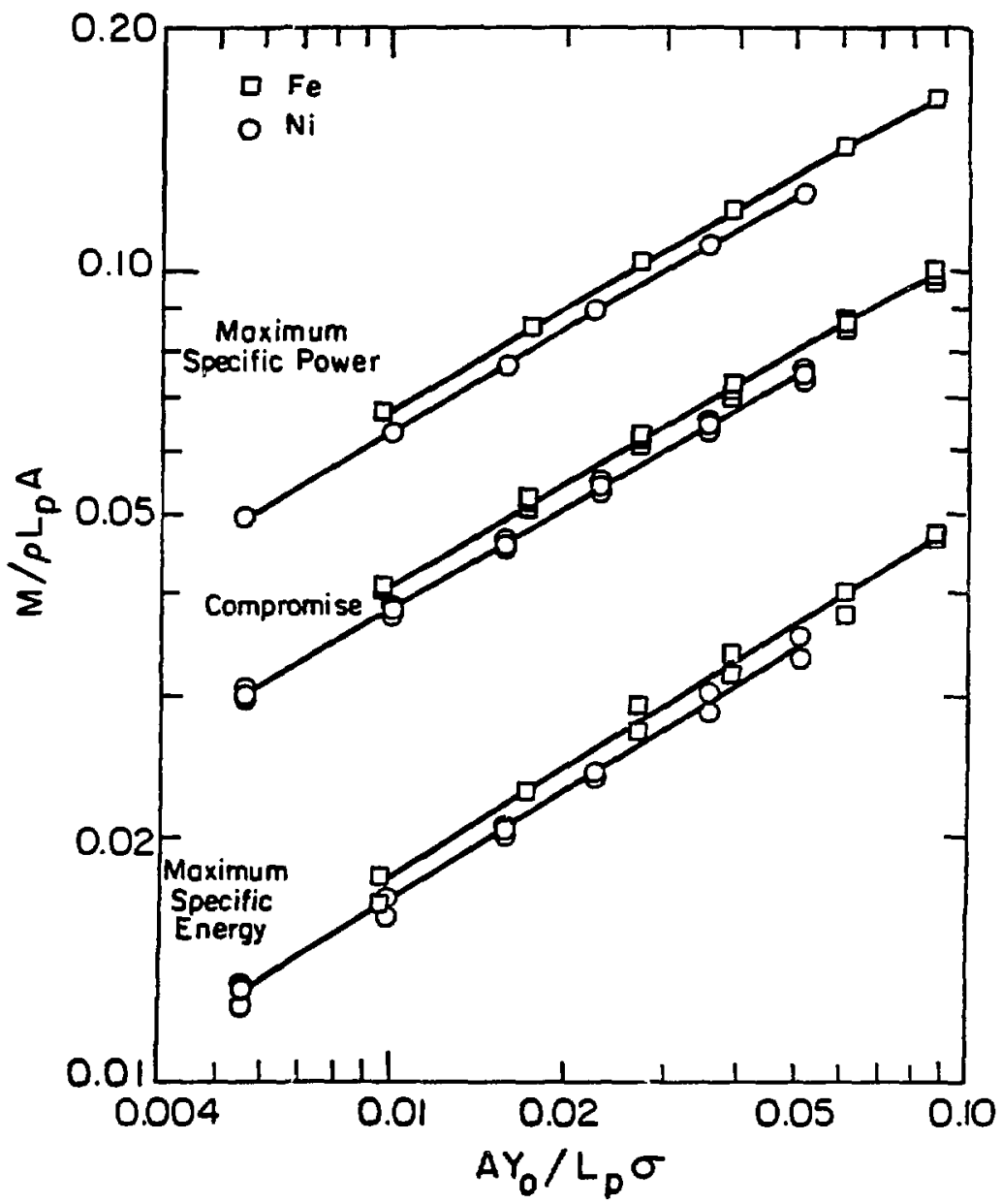

XBL $839-11788$

Figure 4-17. Dimensionless erid weight vs. dimensionless plate area along the maximum specific energy, meximum specific power, or the compromise design for a nickel and iron current collector. 
current callector. Aso shown for comparison are the data for an iron current collector from figure 4-15. For a given grid volume fraction, we can construct plates with a larger area for nickel than for iron, while remaining along any of the three curves.

\subsection{Monimum Qurrent-Collector Constraints}

Until now no consideration has been given to any minimum current-collector weight chat may be necessary to support the active materials through cycling. Figure 4-15 shows an additional curve labeled minimum current-collector mass. This was calculated on the basis that a certain thickness and area of eurrent collector was needed to contain the active materials independent of other considerations. For these calculations, the minimum. cerrent-collector thicloness was taken to be 0.010 inch. From figure $4-15$, it is seen that for the larger plate sizes, the grid weight corresponding to maximum power is greater than the minimum current-collector weight, and the grid weights corresponding :o the maximum energy all lie below the minimum cur :-collector weight. For the smaller plate sizes all calculated optimum or cospromise grid weights lie below the minimum Computationally, then, any time a grid weight is chosen that lic below the minimum grid weight, its value must be increased. Thus the grid weights corresponding to the maximum energy all lie along the minimum curve, and the grid weights corresponding to the maximum power lie on two curves. Figure 418 shows these results.

Figure $4-19$ shows the predictions of specific energy vs. specific power for an iron current collector subject to the minimum current-rollector constraints. Three families of curves are shown, and within each family, a curve corresponding to maximum energy and a curve corresponding to maximum power is given. The curves corresponding to the maximum energy are the same as the constraint curves since all grid weights corresponding to the maximum energy are the minimum grid weights as seen in figure 4-18. The curves corresponding to maximum power are discontinuous; the smaller plate sizes follow the constraint curve for maximum power, and the larger plate sizes seek their own intrinsic maximum. The constraint curves along the maximum power and maxi.num energy are the same for $L_{\text {bur }}=L_{\text {post }}=0$, but 


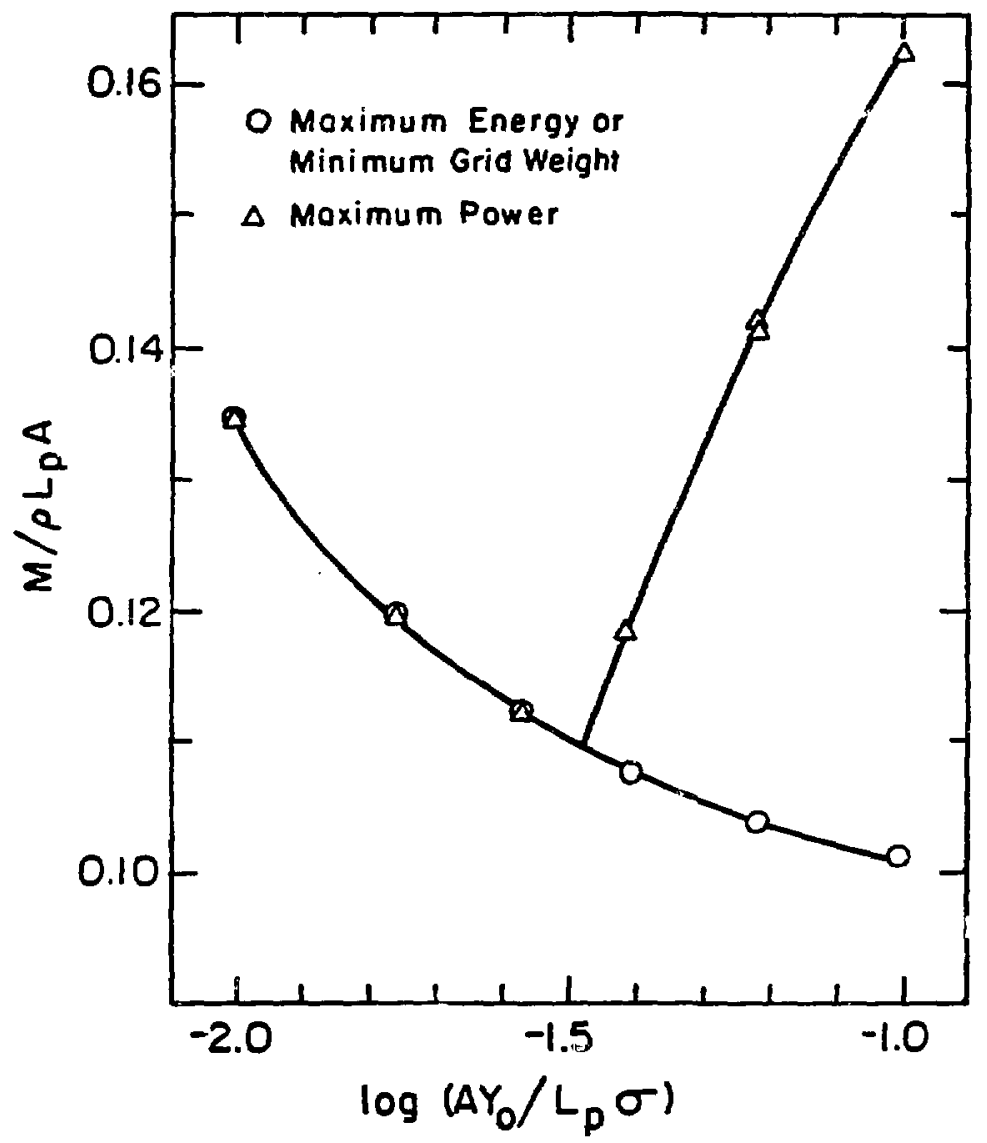

XBL 839-11786

Figure 418. Dimensionless grid weight vs. dimensionless plate area subject to minimum current-collector constraints. 


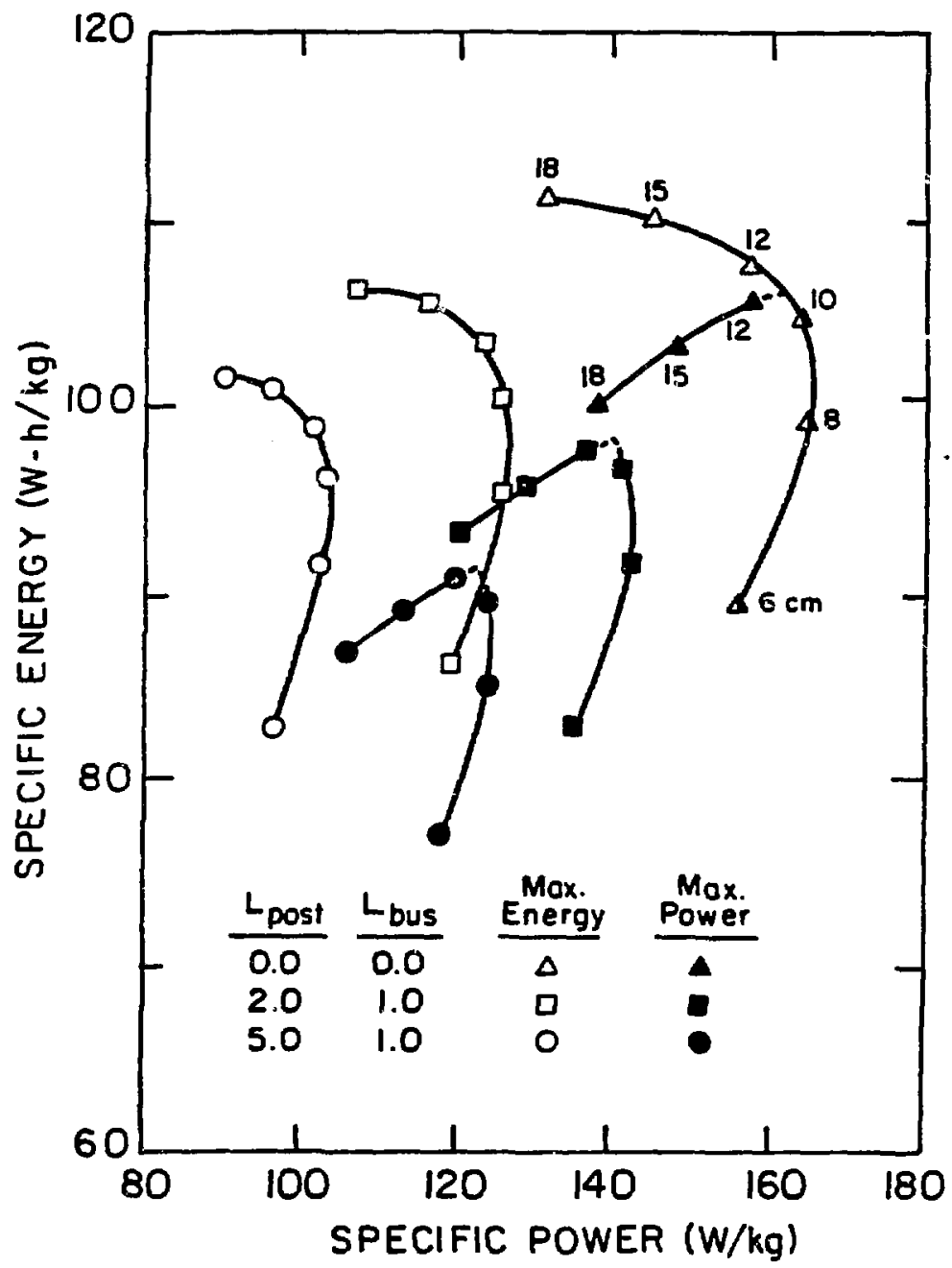

XBL 839-11789

Figure 419. Predictions of specific epercy vs. upecific power for an iron grid subject to the minimum eurrent-collector constraints. Results are shown for optinizing for maximum energy and meximum power. 
are two separate curves for finite post and bus lengths due to the separate optimization of $R^{\prime}$ (given in equations 419 to 421 ). In general, for smaller cells it may be stated that a current collector that is large enough to contain the active material will bave a weight large enough to approach or exceed the valuc corresponding to the design for maximum power. More detailed scale-up consideracions are needed for bigger plate sizes. Finally we should note that the value of the grid weight corresponding to maximum specific energy will defond on the discharge time. As we dectease the discharge time from the four-hour value used here, the grid weight will move upvard toward the value for maximum specific power.

\subsection{Efect of Dlseherge Time}

The effect of the average discharge time on the specific energy and maximum specific power is seen in figure 420 for a $15 \times 15 \mathrm{~cm}^{2}$ plate with a post length of $2 \mathrm{~cm}$ and an bus length of $1 \mathrm{~cm}$ The grid weights are varied from 10.0 grams to 120.0 grams. The grid weight corresponding to maximum energy for the $4 \mathrm{hr}$ discharge time lies just to the left of 25 grams at 22.6 grams. The maximum energy for the 2-hr discharge rate is shifted to a bigher grid weight of approximately 30 grams. The grid weight corresponding to maximum power lies at 80.0 grams for both cases. The value of the maximum power increases for the 2-br discharge time because the cut-off voltage is reached sooner, subsequently the open-circuit potential halfway through discbarge is slightly bigher for the 2-br discharge curve than for the 4 br dischargc curve. Thus, we see that increasing the average discharge rate increases the optimum grid weight for maximum energy up towards the value for maximum power. We have already seen that minimum eurrent-collector constraints are also weigbting the current-collector mass upwards toward the maximum power. Thus in choosing a compromise value of grid weight we may want to weight the compromise more in the direction of maximum power. 


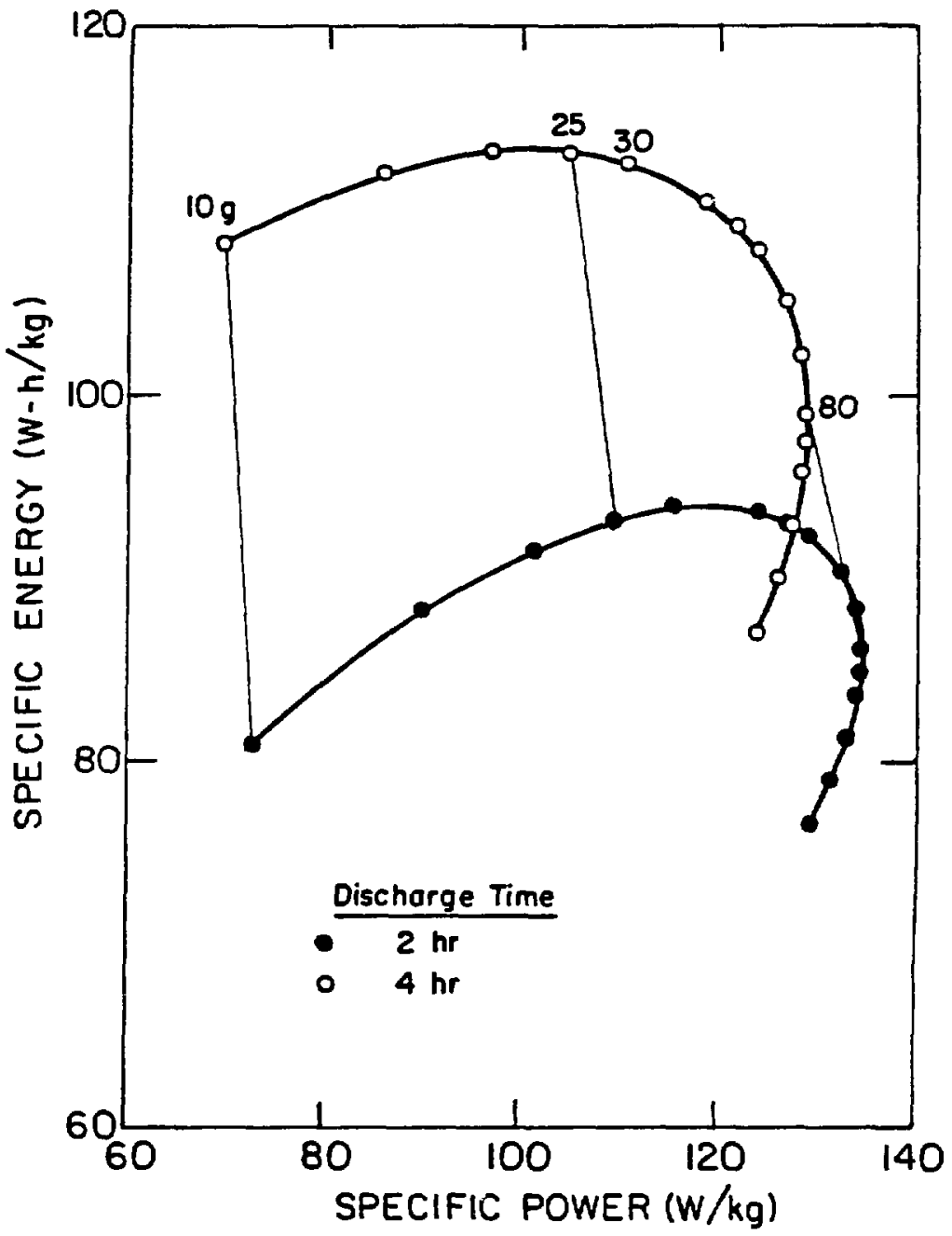

XBL $839-11793$

Figure 420. Effect of discbarge time on the specific energy and specific power of a 15×15 $\mathrm{cm}^{2}$ plate with a bus leagth of $1.0 \mathrm{~cm}$ and a post length of $20 \mathrm{~cm}$ 


\subsection{Design for Delivered Capacity}

In the designs presented so far, the delivered amperc-bour capacity of the battery has been a dependent variable. We have chosen the cross-sectional area and then varied the mass of grid and bus and post to give energy and power predictions. The depth of discharge of the cell at the cut-off voltage then yields the delivered capacity. An alternative design sequence is to specify a value for the total delivered capacity. In this case the area of the plate is varied until the optimum values of grid weight and bus and post weight are found so that the specified capacity is reached at the cut-off voltage. The results are shown in figure 421 . The solid points represent the delivered capacity for a 4 hr discharge rate optimized for the maximum energy or maximum power. For a constant grid mass and delivered capacity, the depth of discharge for the bus and post optimized for maximum power will be slightly larger than for the optimization for maximum energy. Thus the cross-sectional area will be slightly less for the maximum power. The grid mass along the absolute maximum power curve, however, is greater than the corresponding value for the maximum energy. This tends to increase the plate area for a constant delivered capacity. Thus the maximum energy and maximum power curves lie close to each other with the maximum power curve giving slightly higher plate areas. Having specified the total delivered capacity then yield the plate area along either the maximum energy or maximum power. The two curves labeled maximum energy and maximum power can then be used to determine the best energy or best power that can be obtained from a design at the specified capacity. For example, a 200 A-h delivered eapacity yields a plate area of $13.5 \times 13.5$ $\mathrm{cm}^{2}$ and a maximum obtainable energy of $113.6 \mathrm{~W}-\mathrm{h} / \mathrm{kg}$, or a plate area of $13.9 \times 13.9 \mathrm{~cm}^{2}$ and a maximum obtainable power of $131.7 \mathrm{~W} / \mathrm{kg}$. Compromise value could be plotted on this curve to give values of power and energy that correspond to the same grid and bus and post weights.

The example above assumed that we have one string of cells. If we specify two parallel strings of cells, the total delivered eapacity of each string is 100 A-h. This reduces the crosssectional area of plates needed to approximately $9.5 \times 9.5 \mathrm{~cm}^{2}$. At the same time, we have 


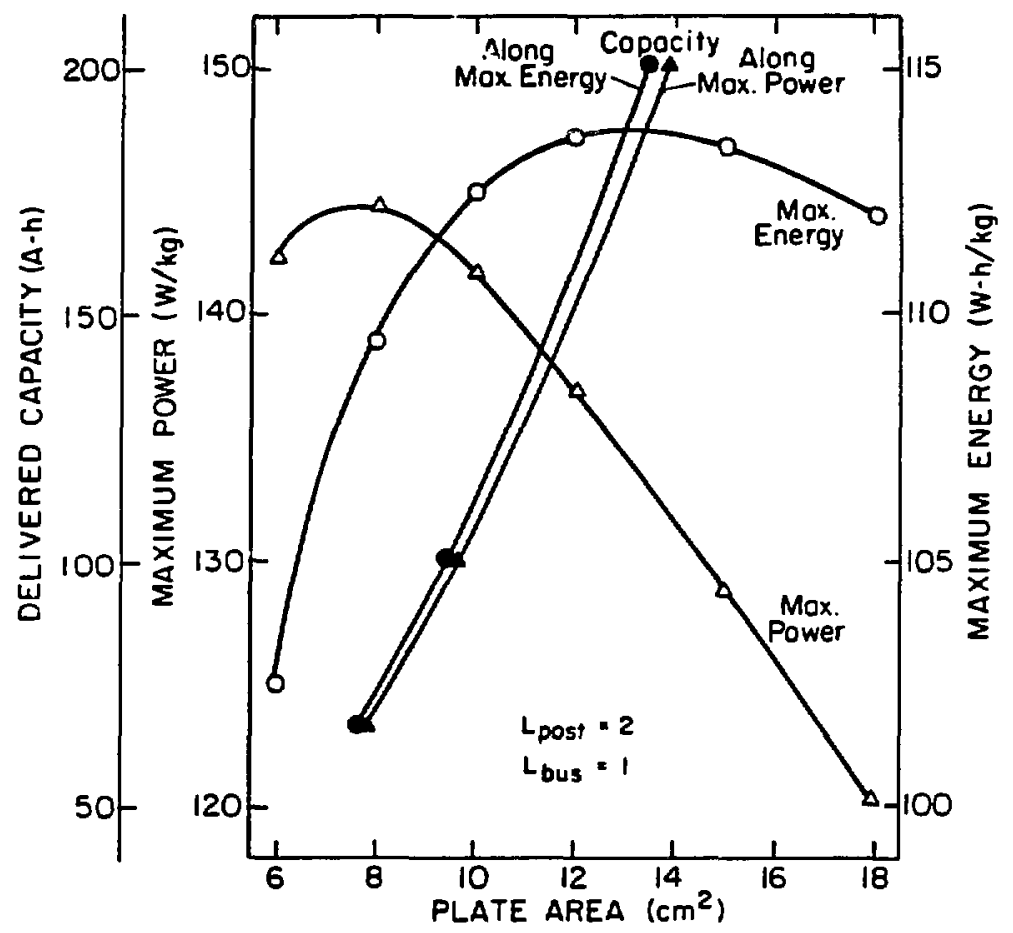

XBL $839-11794$

Figure 4-21. Effeet of delivered capecity, maximum power, and maximum energy on plate sree. 
increased the maximum deliverable power and decreased the maximum cbtainable energy. Thus, this figure can also be used to examine the effect of varying the number of parallel strings of cells in the battery.

All the results presented above for complete cells have used three positive electrodes. Figure 421, for example, an be used to determine the effect of multiple strings of three positive elestrodes, but it should not be used to determine the effect of using more positive electrodes in parallel in one string. The computer program, however, is general and not restricted to using three positive electrodes; other results can be easily generated.

In summary, we have shown how to account for the performance penalties associated with the grid and interconnecting bus and pose. 


\section{Notation}

specific interfacial area per unit volume of porous electrode, $\mathrm{cm}^{-1}$ cross-sectional area of the battery plate or electrode area, $\mathrm{cm}^{2}$ constant defined by equation $3-10$ quantity defined in equation $3-22$ concentration of species i per unit volume of solution, $\mathrm{mol} / \mathrm{cm}^{3}$ reference concentration of species $i$ per unit volume of solution, $\mathrm{mol} / \mathrm{cm}^{3}$ local surface concentration of species $i, \mathrm{~mol} / \mathrm{cm}^{3}$ feed concentration to flow-through electrode or surface concentration, $\mathrm{mol} / \mathrm{cm}^{3}$ exit concentration of reactant, $\mathrm{mol} / \mathrm{cm}^{3}$ electrical double-layer capacity, $F / \mathrm{cm}^{2}$ dimensionless dispersion coefricient defined in equation $3-22$ dispersion coefiricient, $\mathrm{cm}^{2} / \mathrm{s}$ diffusion coefficient of species $i, \mathrm{~cm}^{2} / \mathrm{s}$ depth of discharge, dimensionless Faraday's constant, $96487 \mathrm{C} /$ equiv current density, $A / \mathrm{cm}^{2}$ transfer current per unit of interfacial area, $\mathrm{A} / \mathrm{cm}^{2}$ exchange curtent density, $A / \mathrm{cm}^{2}$ superficial current density in the matrix, $A / \mathrm{cm}^{2}$ superficial current density in the pore phase, $A / \mathrm{cm}^{2}$ current density. $A / \mathrm{cm}^{2}$, or total current leaving tab, $A$ porc-wall flux of species $l, \mathrm{~mol} / \mathrm{cm}^{2}$ local mass-transfer coefficient between flowing solution and electrode surface, $\mathrm{cm} / \mathrm{s}$ 
$\bar{k}_{m} \quad$ average mass-transfer coefficient between flowing solution and electroo: surface, $\mathrm{cm} / \mathrm{s}$

$L \quad$ length of porous electrode, $\mathrm{cm}$

$\zeta_{7}$ thickess of positive electrode, $\mathrm{cm}$

$L_{\text {tw }} \quad$ length of interconnecting bus, $\mathrm{cm}$

$L_{\text {pan }}$ length of interconnecting post, $\mathrm{cm}$

mi molality of species $i, \mathrm{~mol} / \mathrm{kg}$ solvent

M current collector weight, 8

Mi molecular weight of species $i, g / \mathrm{mol}$

n

number of electrons transferred in electrode reaction, equiv $/ \mathrm{mol}$

$N_{\text {pos }} \quad$ number of positive electrodes

$\mathrm{N}_{\text {f }} \quad$ flux of species $i$, or superficial flux of species $i, \mathrm{~mol} / \mathrm{cm}^{2}-\mathrm{s}$

Qo loading density of active material in the positive electrode, $\mathrm{C} / \mathrm{cm}^{3}$

$\boldsymbol{R} \quad$ universal gas constant, $8.3143 \mathrm{~J} / \mathrm{mol}-\mathrm{K}$, or the electrochemical plus grid resistance, a

$\boldsymbol{R} \quad$ electrochemical plus grid resistance, $\mathbf{\Omega}$

$\boldsymbol{R}_{\sharp} \quad$ electrochemical plus grid resistance half way through discharge, $\Omega$

$R^{\prime} \quad$ effective ohmic resistance of bus and post, $\Omega$

$R_{T}^{\prime} \quad$ total resistance of parallel bus and post connections for the complete cell, $\Omega$

$R_{\text {s }} \quad$ resistance of grid, $\mathrm{D}-\mathrm{cm}^{2}$

$R_{1}$ rate of homogeneous production of species $i, \mathrm{~mol} / \mathrm{cm}^{3}-\mathrm{s}$, or sum of internal area specific resistances, $\Omega-\mathrm{cm}^{2}$

$R$ separator resistance, $\mathbb{R}-\mathrm{cm}^{2}$

$R_{0,1} \quad$ anode matrix resistance, $\mathbb{R - \mathrm { cm } ^ { 2 }}$

$R_{0,2}$ anolyte solution resistance, $R-\mathrm{cm}^{2}$

$R_{r, 1} \quad$ cathode matrix resistance, $D-\mathrm{cm}^{2}$

$\boldsymbol{R}_{\boldsymbol{r}, 2} \quad$ catholyte solution resistance, $\Omega-\mathrm{cm}^{2}$

$\boldsymbol{R}_{\boldsymbol{F}} \quad$ faradaic charge-transfer resistance, $8-\mathrm{cm}^{2}$ 


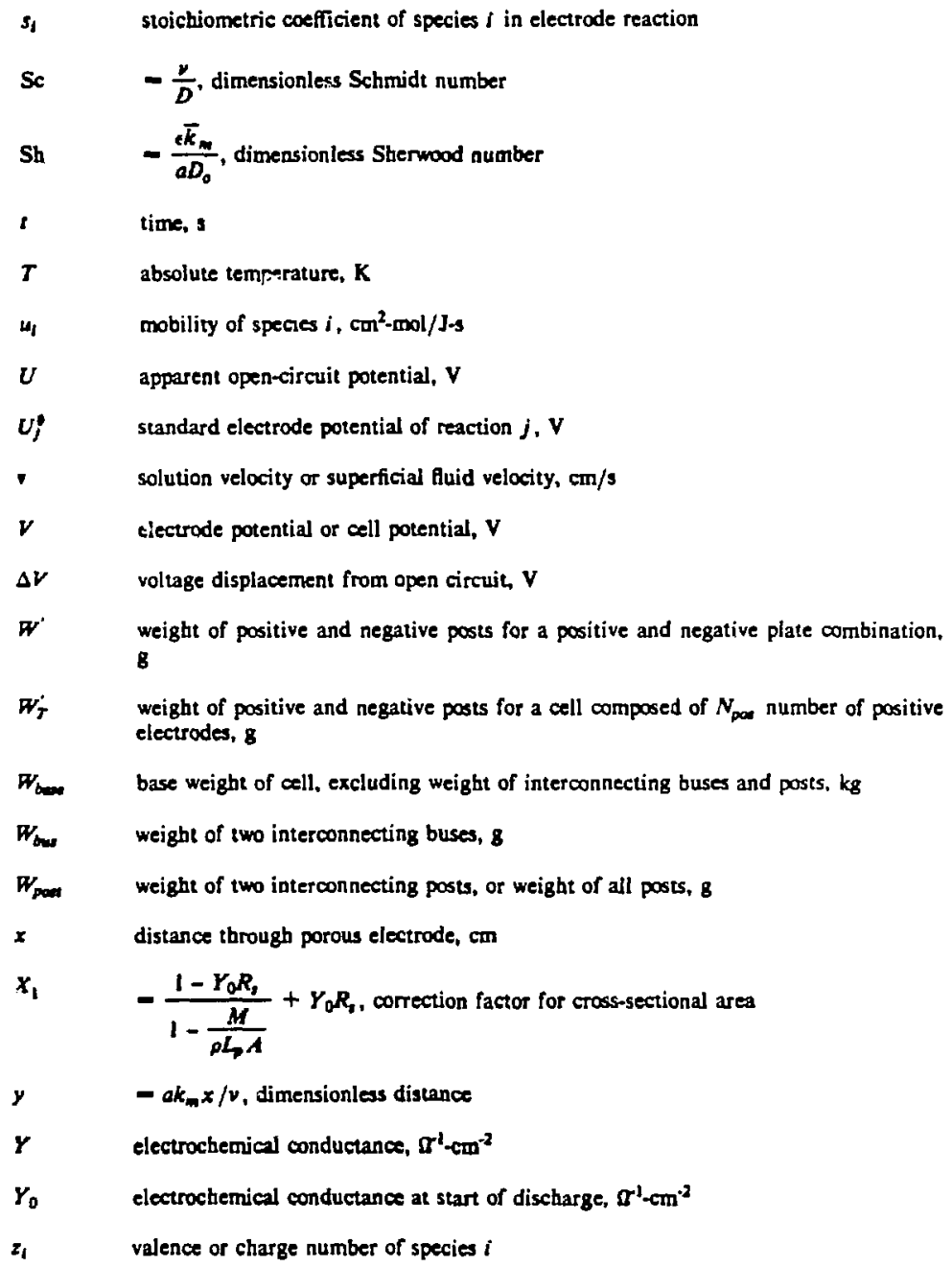




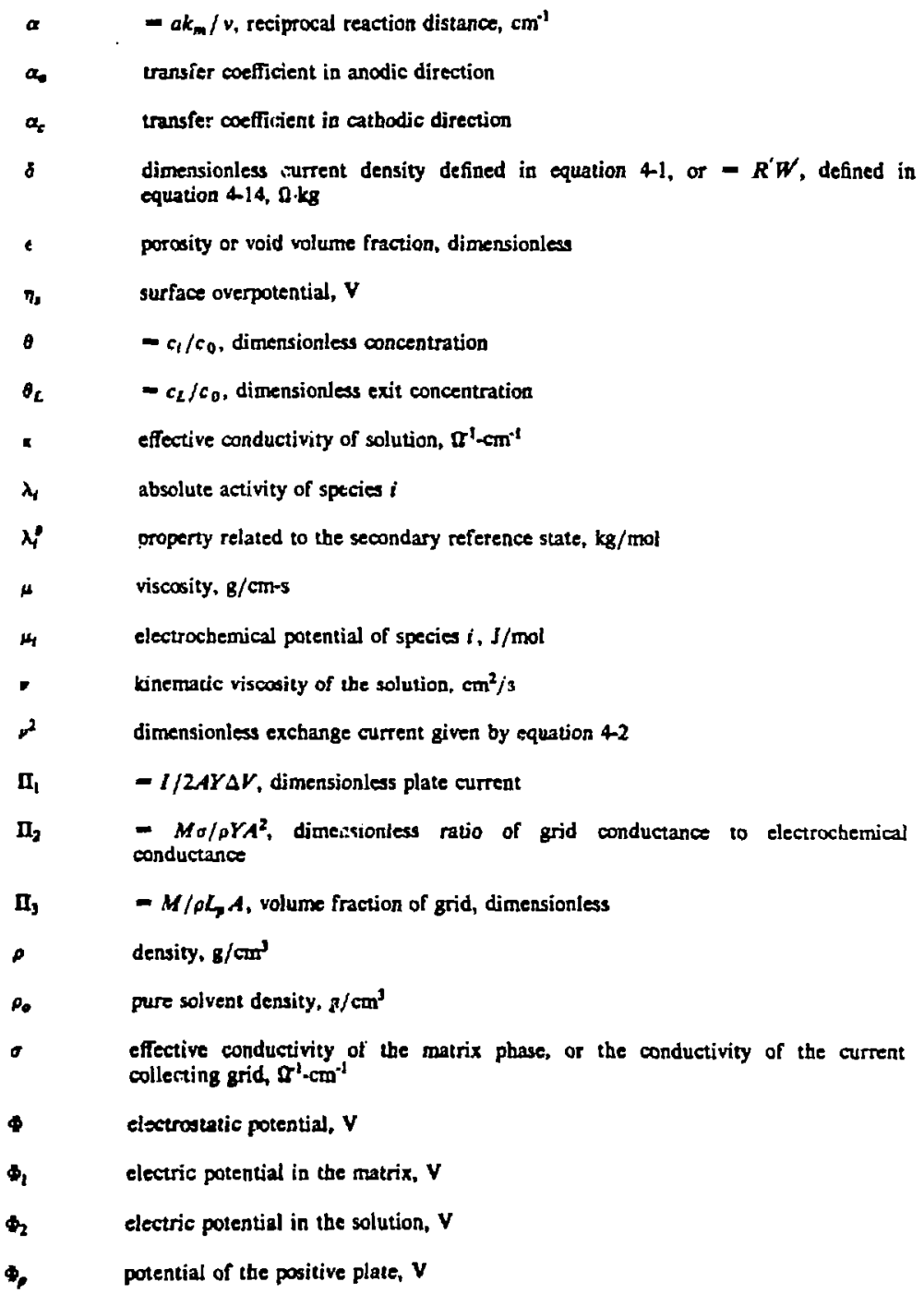



\$ potential of the negative plate, $V$
a routional velocity, $\mathrm{rad} / \mathrm{s}$

\section{SUBSCRIPTS}

bus interconnecting bus (parallel plate connections)

past inlerconnecting post (series cell connections)

- electrode surface, reactor inlet, or beginning of discharge

1 porous electrode matrix phase

2 porous electrode solution phase 


\section{References}

1. Lois R. Ember, "Environmental lead: insidious health problem," Chemical and Engineering News. June 23, 1980 28-35.

2 Gerald Partinson, "New smelting methods aim to get the lead out," Chemical Engineering, May 19, 1980, 93-94.

3. "New OSHA lead rule in the offing?" Chemical Engineering, May 16, 1983, 33.

4. "EPA report surveys heavy metals in waste sludges," Chemical Engineering. July 27, 1981, 35.

5. Nicholas Basta, "Getting the metal out of spent plating baths," Chemical Engineering, May 16, 1983, 22-25.

6. C W. Sheffield, "Treatment of Heavy Metals at Small Electroplating Plants," Fi xceedings of the 36th Industrial Waste Conference, 361981 (Pub. 1982) 485-492.

7. D. Y. Hsu, M D. R. Riddell, and Brian Bonamico, "Soda Ash Improves Lead Rerrnval in Lime Precipitation Process," Proceedings of the 36th Industrial Waste Conference, 36 1981 (Pub. 1982) 526-532.

8. Michael A Slapik, Edward L. Thackston, and David J. Wilson, "Improvements in foum flotation for lead removal," Journal Water Pollution Control Federation, 54 (1982), 238243.

9. Norman I. Shapira, Han Lieh Liu, John E Santo, Daniel Fruman, Charles Darvin, John Baransb, and Kenneth Mibalik, "Demonstration of a cross-fiow microfiltration system for the removal oi toxic heavy metals from battery manufacturing wastewater effluents." Chemistry in Water Reuse, 1 (1981), 281-309.

10. M J. Semmens and W. Marin, "Studies on Heavy Metal Removal from Saline Waters by Clinoptilolite," AJChE Symposium Series, 76 (1980), 367-376. 
11. Nord L. Gale and Bobby G. Wixson, "Removal of Heavy Metals from Industrial Efluents by Algae," Developments in Industrial Microbiology, 20 (1978) (Pub. 1979), 259-273.

12. R Veraraghavan and R P. Dumbal, "Electrochemical procass of treatment of plating efluent." Journal of the Electrochemical Society of India, 31 (1982), 27-32.

13. Anseim T. Kuhn, "The Electrochemical Treatment of Aqueous Efluent Streams," chapter 4 in Electrochemistry of Cleaner Environments, John O'M Bockris, editor, Plenum Press, New York (1972), 98-130.

14. A T. Kubn, "The Role of Electrochemistry in Environmental Control," chapter 5 in Modern Aspects of Electrochemistry, volume 8, J. O'M Bockris and B. E Conway, editors, Plenum Press, New York (1972), 273-340.

15. Douglas N. Benaion and John Newman, "Electrochemical removal of copper jons from very dilute solutions," Journal of Applied Elecsrochemistry, 2 (1972), 113-122.

16. Jokn Van Zee and John Newman, "Electrochemical Removal of Silver Ions from Photographic Fixing Solutions Using a Porous Flow-Through Electrode," Jourral of the Electrochemical Society, 124 (1977), 706-708.

17. Michael Matloaz and John Newman, "Use of A Flow-Through Porous Electrode for Removal of Mercury from Contaminated Brine Solutions," Proceedings of the Symposium on Transport Processes in Electrochemical Systems (The Electrochemical Society, volume 82-10, 1982), 53-63.

18. Wilbelm Oatwald, Elekrrochemie: Thre Geschichre und Lehre. Verlag von Veit Comp., Leiprig, 1896. Trunslated from German as Electrochemistry Fistory and Theory. Amerind Publishing Co. Pvt Ltd, New Delbi, 1980.

19. Elton J. Cairns and Earl H. Hietbrink in Comprehensive Treatise of Electrochemistry 3, edited by J. OM. Bockris, Brian E. Conway, Ennest Yeager, and Ralph E White, Plenum Press, New York, NY (1981) 422 
20. C. K Briggs and 1. Y. Borg, U. S. Energy Flow - 1982, Lawrence Livermoit Laboratory report UCID-19227-82, July 29, 1983.

21. Charles W. Tobias and others, Assessment of Research Needs for Advanced Eattery Systems, National Materials Advisory Board, Commission on Engineering and Technical Systems, National Research Council, publication NMAB-390, National Academy Press, Wasiungton D. C. (1982).

22. Gary G. Trost, Victoria Edwards, and John Newman, "Electrochemical Reaction Engineering," to appear as a chapter in a Chemical Reaction Engineering Handbook, edited by A Varma and J. J. Carberry. See also Lawrence Berkeley Laboratory report, LBL-15984 (1983).

23. A. C. Riddiford, "The Rotating Disk System," in Advances in Electrochemistry and Electrochemical Engineering, volume 4, edited by Paul Delahay and Charles W. Tobias (1966), 47-116.

24. Yu. B. Ivanov and V. G. Levich, "Izuchenie nestolkikh promezhutocbnykh produktov elektrodnylhb reaktsiï s pomoshch'yu vrashchayushchegosya diskovogo elektroda," Doklady Akademii Nauk SSSR, 126 (1959), 1029-1032. See English translation: Yu. B. Ivanov and V. G. Levich, "Investigation of Unstable Intermediate Products of Electrode Reactions by Means of a Rotating Disc Electrode," Proceedings of the Academy of Sciences of the USSR. Hhysical Chemistry Section, 126 (1959), 505-508.

25. A N. Frumkir and L. I. Nekrasov, "O kol'tsevom diskovom elektrode," Doklady Akademii Nauk SSSR, 126 (1959), 115-118. See English translation: A. N. Frumkin and L. I. Nekrasov, "Ring Disc Electrodes," Proceedings of the Academy of Sciences of the USSR. Physical Chemistry Section, 126 (1959), 385-388.

26. William H. Smyrl and John Newman, "Ring-Disk and Sectionted Disk Electrodes," Journal of the Electrochemical Society, 119 (1972), 212-219. 
27. W. J. Albery and M. L Hïtchman, Ring-Disc Electrodes, Clarendon Press, Oxford (1971).

28. D. $R$ Gabe and F. C Walsh, "The rotating cylinder electrode: a review of development," Journal of Applied Electrochemistry, 13 (1983), 3-21.

29. Der-Tau Chin, "Convective Diffusion on 2 Rotating Spherical Electrode," Journal of the Electrochemical Society, 118 (1971) 1434-1438.

30. E Kirowa-Eisner and E Gileadi, "The Rotating Cone Electrode," Jownal of the Electrochemical Society, 123 (1976), 22-24.

31. Th. v. Käman, "Über laminare und turbulente Reibung," Zeitschrift für angewandle Mathematik und Mecharik, 1 (1921), $233-252$

32 W. G. Cochran, "The flow due to a rotating disc," Proceedings of the Cambriuge Philosophical Society, 30 (1934), 365-375.

33. Veniamin G. Levich, "The Theory of Concentration Polarization," Acta Physicochimica U.R.S.S., 17 (1942), 257-307.

34. Veniamin G. Levich, Physicochemical Hydrodynamics, Prentice-Hall, Inc., Englewood Cliffs. New Jeisey (1962).

35. John S. Newman, Electrochemical Systems, Prentice-Hall, Inc, Englewood Cliffs, New Jersey (1973).

36. John Newman, "Resistance for Flow of Current to a Disk," Journal of the Electrochemical Saciety, 113 (1966), 501-502.

37. John Newman, "Current Distribution on a Rotating Disk below the Limiting Current." Journal of the Electrochemical Society. 113 (1966), 1235-1241.

38. John Newman, "Schmidt Number Correction for the Rotating Disk"" The Journal of Physical Chemistry, 70 (1966), 1327-1328. 
39. Howard Siegerman and George O'Dom, "Differential pulse anodic stripping of trace metals," American Laboratory (June, 1972).

40. "Differential Pulse Stripping Voltammetry of Water and Waste Water," Application Brief W-1, Princeton Applied Research Corporation, Princeton, New Jersey (1976).

41. A.T. Kubn editor, The Electrochemistry of Lead, Academic Press, Inc., New York, New York (1979).

42. Katbryn R Bullock, "The Effect of Anion Activity on Electrochemical Equilibria: Three-Dimensional Potential-pH Diagram for $\mathrm{Pb}_{2} \mathrm{H}_{2} \mathrm{SO}_{4} / \mathrm{H}_{2} \mathrm{O}$ System," Journal of the Electrochemical Saciety, 127 (1980), 662-664.

43. Kathryn $R$ Bullock, Glenn $M$ Trischan, and Robert G. Burrow, "Photoelectrochemical and Microprobe Laser Raman Studies of Lead Corrosion in Sulfuric Acid," Jownel of the Electrochemical Saciety, 130 (1983), 1283-1289.

44. Roman E Sioda and others, "Flowthrough porous electrodes," Chemical Engineering, February 21, 1983, 57-67.

45. John Newman and William Tiedemann, "Flow-through Porous Electrodes," Advances in Electrochemistry and Electrochemical Engineering, 11 (1978), 353-438.

46. John Newman and William Tiedemann, "Porous-Electrode Theory with Battery Applications," AIChE Journal, 21 (1975), 25-41.

47. M. Fleischmann, J. W. Oldfield, and L Tennakoon, "Fluidized bed electrodes Part IV. Electrodeposition of copper in a fluidized bed of copper-coated spheres," Journal of Applied Electrachemistry, 1 (1971), 103-112

48. S. Germain and F. Coodridge, "Copper Deposition in a Fluidised Bed Cell," Electrochimica Acta, 21 (1976), 545-550.

49. Sherlock Swann, Jr., and Richard Alkire, Bibliography of Electro-Organic Syntheses 1801-1975. The Electrochemical Society, Insorporated, Princeton, NJ. 1980. 
50. G. L Wierschem and W. K. Tiedemann, "Cycling Behavior of Lead-Acid Batteries for Electric Vebicles," Abstract INumber 102, Hollywood, Florida, meeting of the Electrochemical Society, October, 1980.

51. Liebenow, “Über die Betechnung der Kapazitht eines Bleiakkumulators bei variabeler Stronstärke," Zeitschrift fir Elektrochemie, 4 (1897), 58 (particularly p. 63).

52 Peter W. Appel and John Newman, "Application of the Limiting Current Method to Mass Transfer in Packed Beds at Very Low Reynolds Numbers," AChE Journal, 22 (1976), $979-984$.

53. Peter S. Fedkiw and John Newman, "Mass-Transfer Coefficients in Packed Beds at Very Low Reynolds Numbers," International Journal of Heat and Mass Transfer. 26 (1982), 935-943.

54. William G. Gray, "A Derivation of the Equations For Multi-Phase Transport," Chemical Engineering Science, 30 (1975), 229-233.

55. John Stephen Dunning, Anolysis of Porous Electrodes with Sparingly Soluble Reactants, dissertation, University of California, Los Angeles (1971).

S6. Peter Fedkiw and John Newman, "Low Péclet Number Behavior of the Transfer Rate in Packed Beds," Chemical Engineering Science. 33 (1978), 1043-1048.

57. Richard Pollard and John Newman, "Transport Equations for a Mixture of Two Binary Molten Salts in a Porous Electrode." Sournal of the Electrochemical Society, 126 (1979), 1713-1717.

58. P. V. Danckwerts, "Continuous How systems. Distribution of Residence Times," Chemical Engineering Science, 2 (1953), 1-13.

59. J. F. Wehner and R. H. Wilhelm. "Boundary zonditions of flow reactor," Chemical Engineering Science, 6 (1956), 89-93. 
60. James A Trainham and Jobn Newman, "The Effect of Electrode Placement and Finite Matrix Conductivity on the Performance of Flow-Through Porous Electrodes," Journal of the Electrochemical Society, 125 (1978), 58-68.

61. D. Norman Craig and George W. Vinal, "Solubility of Lead Sulfate in Solutions of Sulfuric Acid, Determined by Dithizone with a Photronic Cell," Sournal of Research of the National Bureau of Standards, 22 (1939), 55-70.

62. Tibor Erdey-Gruz, Kinetics of Electrode Processes, Wiley-Interscience Division, John Wiley and Sons, Inc., New York, New York (1972).

63. S. J. Bircher and William D. Harkins, "The Effect of Pressure on Overvoltage," Journal of the American Chemical Saciety, 45 (1923), $2890-2898$.

64. Max Knobel, "Effect of Pressure on Overvoltage," Jownal of the American Chemical Society, 46 (1924) 2751-2752.

65. H M Cassel and E Krumbein, "Über den Druckeinfluss auf die Überspannung der Elektrolyse des Wassers," Zeitschrift für Physikalische Chemie, A. 171 (1934), 70-82.

66. H. M Cassel and J. Voigh, "Die Wirschaftlichkeit der Druckeiektrolyse des Wassers," Zeitschrift des Vereines Deutscher Ingenieure, 77 (1933), 636-638.

67. G. J. Hills and D. R Kinnibrugh. "The Pressure Coefficient of the Hydrogen Electrode Reaction," Journal of the Electrochemical Society, 113 (1966), 1111-1117.

68. J. A Trainham and J. Newman, "A thermodynamic estimation of the minimum concentration attainable in a flow-through porous electrode reactor," Journal of Applied Electrochemistry, 1 (1977), 287-297.

69. James A Trainham and John Newman, "A Flow-Througb Porous Electrode Model: Application to Metal-Ion Removal from Dilute Streams," Journal of the Electrochemical Society, 124 (1977), 1528-1540. 
70. George W. Heise, "Porous Caivon Electrodes," Transactions of ti.e American Elecrochemical Society, 75 (1939), 147-166.

71. Joseph Wang, "Retieulated Vitreous Carbon-A New Versavile Electrode Material," Electrachimica Acta, 26 (1981), 1721-1726.

72. W. J. Blaedel and Joseph Wang, "Anodic Stripping Voltammetry at a Reticulated Mercury Vitreous Carbon Electrode," Analytical Chemistry, S1 (1979), 1724-1728.

73. J. Wang and H. D. Dewald, "Deposition of Metals at a Flow-Through Reticulated Vitreous Carbon Electrode Coupled with On-Line Monitoring of the Efluent," Journal of the Electrochemical Saciety, 130 (1983), 1814-1818.

74. Hans Bode, Lead-Acid Batteries, Wiley-Interscience John Wiley \& Sons, Inc. (1977), 336.

75. James Traisham and John Newman, "The Removal of Lead Ions from Very Dilute Solutions Using a Porous Flow-through Electrode," Inorganic Materials Research Division Annual Report 1973. 51-53. Lawrence Berkeley Laboratory. University of California, April. 1974, LBL-2299.

76. W. J. BlaedeI and Joseph Wang, "Characteristics of a Rotated Porsits Flow-Through Electrode," Analytical Chemistry, 52 (1980), 1697-1700.

77. Peter S. Fedliw, Mass Transfer Controlled Reactions in Packed Beds al Low Reynolds Numbers, disserzation, University of California, Berixeley (1978), LBL-8509.

78. Guidebook and Directory of Mesal Finishing, Metals and Plastics Publications, Inc., Hackensack, New Jersey (1978).

79. Electroplating Engineering Handbook, edited by A. Kenseth Graham, Van Nostrand Reinbold Company, New York, New York, third edition (1971).

80. Richard Alkire and Patrick K. Ng, "Two-Dimensional Current Distribution withín a Packed-Bed Electrochemical Flow Reactor," Journal of the Electrochemical Society. 121 
(1974), 95-103.

81. James A Trainbam and Jobn Newman, "A Comparison between Flow-Through and Flow-By Porous Electrodes for Redox Energy Sterage," Electrochimica Acta, 26 (1981), 455469.

82. Peter S. Fedkiw, "Ohmic Potential Drop in Flow-Through and Flow-By Porous Eectrodes," Journal of the Electrochemical Society, 128 (1981), 831-838.

83. Timothy K Risch, The Transpart Properties of Sodium Polysulfide Melts and A Theoretical Comparison of Flow-Through and Flow-By Porow Electrodes at the Limiting Current, M.S. thesis, University of California, Berkeley, California (in progress).

84. William Tiedemann, Electrochemical Engineering of Batteries, Short-Course Lecture Notes, University of California, Los Angeles, California, May 1978.

85. John S. Dunning, Douglas N. Bennion, and John Newman, "Analysis of Porous Electrodes with Sparingly Soluble Reactants," Journal of the Electrochemical Society. 118 (1971), 1251-1256.

86. King Wai Choi, Douglas N. Bennion, and Jobn Newman. "Engineering Aralysis of Shape Change in Zinc Secondary Electrodes I. Theoretical," Journal of the Electrochemical Society, 123 (1976), 1616-1627.

87. King Wai Choi, Drannan Hamby, Douglas N, Bennion, and Jobn Newman, "Engineering Analysis of Shape Change in Zinc Secondary Electrodes II. Experimental," Sownal of the Electrochentical Society, 123 (1976), 1628-1637.

88. S. B. Brummer, K M Abrabam, V. R Koch, and G. L Holleck, Review of the Status of Ambient-Temperature Secondary Lithium Batteries for Applicability to Laad Leveling and Electric Vehicles, EIC Corporation, Newton, Massacbusetts, July, 1980.

89. J. J. Lander, "Failure Modes and Mechanisms," in Zinc-Silver Oxide Batteries, edited by Arthur Fleiscier and John J. Lander, John Wiley \& Sons, Inc., New York (1971), 
457-469.

90. John S. Newman and Charles W. Tobias, "Theoretical Analysis of Current Distribution in Porous Electrodes," Journal of the Electrachemical Soctety, 109 (1962), $1183-$ 1191.

91. Richard Pollard and John Newman. "Mathematical Modeling of the LithiumAluminum, Iron Sulfide Battery I. Galvanostatic Discharge Behavior," Journal of the Electrochemical Society, 128 (1981), $491-502$

92. D. L Barney and others, Lithium/tron Sulfide Batteries for Electric-Vehicle Propulsion and Oher Applications, Progress Report for October 1979-September 1980, p. 71, Argonne, Dlinois, Argonne National Laboratory, February 1981. (ANL-80-128)

93. W. H. Tiedemann and J. Newman, "Nonuniform Current and Potential Distribution in Composite Sheet Type Battery Electrodes," Abstract number 169, Los Angeles, California meeting of the Electrochemical Society, October 1979.

94. William H. Tiedemann and John Newman, "Curtunt and Potential Distribution in Lead-Acid Battery Plates," Proceedings of the Symposium on Rattery Design and Optimization (The Electrocherical Society, volume 79-1, 1979), 39-49.

95. William H. Tiedemann and John Newman, "Mathematical Modeling of the Lead-Acid Cell," Proceedings of the Symposium on Battery Design and Optimization (The Electrochemical Society, volume 791, 1979), 23-38.

96. H. V. Malmstadt, C. G. Enke, and S. R. Crouch, with Gary Horlick, Electronic Measurements For Scientists, W. A Benjamin, Inc., Menlo Park, California (1974).

97. Ralph Morrison, Grounding and Shielding Techniques in Instrumentation, second edition, John Wiley \& Sons, Inc., New York (1977).

98. Instrumentation Grounding And Noise Minimization Handbook, Technical Report No. AFRPL-TR-69-1, January, 1965. Prepared for the Air Force Rocket Propulsion Laboratory. 
Research and Technology Division, Air Force Systems Command, Edwards Air Force Base, California. Processed by Clearinghouse for Federal Scientific and Technical Information of the U.S. Department of Commerce (AD 612027).

99. Robert L Wareham, "Reducing electronic noise in data-acquisition systens," Chemical Engineering, March 22, $1982,161-166$.

100. "Grounding and Shieiding in Electrochemical Instrumentation - Some Basic Considerations," Princeton Applied Research Corporation, Technical Note 117 (1978).

101. E Gileadi, E Kirowa-Eisner, and J. Penciner, Interfacial Electrochemistry An Experimental Approach. Addison-Wesley Publishing Company, Inc., Reading, Massachusetus (1975).

102. Keishley Electromeser Mearurements, second edition, Keithley Instruments, Inc., Cleveland, Ohio (1977).

103. Elecrrical Noise: Fundamenrals and Sources, edited by Madhu S. Gupta. A volume in the IEFE PRESS Selected Reprint Series. Copyright 1977 by the Institute of Electrical and Electronies Engineers, Inc., John Wiley \& Sons, New York, New York

104. Dale K Stalnaker and Arthur Lieberman, Design and Assembly Considerations for Redox Cells and Stacks, National Aeronautios and Space Administration, Lewis Research Center, Dor:'NASA/12726-10, NASA TM-82672, September, 1981.

105. Arthur M Darbie, "Avoid the pitfalls of power-supply connections," Electronic Desigm 4 (1970), D10-D20. 


\section{Appendix A. Instrumentation in Electrochemical System}

\section{A1. Introduction}

Problems with ground loops are encountered frequently in the experimental investigation of electrochemical systems. This appendix is concemed with the analysis of the causes of ground loops occurring in experimental systems and methods that may be used for their elimination. Resistive, capacitively coupled, and inductively coupled ground loops are discussed. Particular attention is paid to electrochemical systerns by way of example in the text. The end of the appendix discusses instrumentation that is commonly used in electrochemical experimentation, with emphasis on important aspects for system design.

Several references can be consulted for information on grounding considerations. ${ }^{\text {to }}$ (02 Malmstadh, et al. ${ }^{*}$ present a complete text on instrumentation for scientists with an appendix (including bibliography) on grounding and shielding. Morrison ${ }^{97}$ presents a comprehensive treatment of grounding and shielding problems in analog and digital instrumentation. Reference 98 includes complete system design practices including power-site lacations and installations as well as noise and grounding problems. References 100, 101, and 102 deal specifically with instrumentation in electrochemical systems.

\section{A.1. Ground Loop}

Ground (or current) loops are broadly defined bere to mean any DC or AC current flowing in a closed path that is not desired. This includes the ionic flow of current within an electrolyte as well as electronic flow in metals. Ground loops an be separated into those arising from Jesistive coupling within the system and capacitive and inductive coupling of system components with each other and with the external environment. The laiter coupling is often referred to as noise. Experimentally, a current loop could manifest itself in several ways. It can cause an instrument to read improperly or cause the control circuit of a potentiostat to overload. In most 
cases a ground loop will be obvious, due to a potentiostat overlaad or inability to control the system. Some ground loops are subtle, however, in that they are not readily detected by the experimental instrumentation; simply monitoring the applied potential and total cell current may not detect a current loop fowing within the experimental system, or $60 \mathrm{~Hz}$ noise flowing in signal 'ines may remain undetected without the use of an oscillescope.

It is useful to remember that ground loops can "originate" within the system or can be imposed on the system from outside interference. Let us first look at the typen of noise encountered in instrumentation.

\section{A.2. Noise Sources}

Eectronic noise is any unwanted disturbance or spurinus signal which affects the response of the experimental system Noise sources in measurements result in several types of interfering signals. The noise source is generally separable into fundamental noise which cannot be eliminated ${ }^{103}$ and excess noise which may be el.minated with careful design. The types of noise considered below are white, flicker, and interference noise.

White noise has a power spectrum that is flat. It can be considered to be a combination of all frequencies with the same amplitude, arising from Johnson (thermal) and shot noise. Johnson noise is produced by the random motion of electrons in a resist 2 due to tbertnal agitation. Shot noise arises in the random mution of charges across an interface, such as a junction in a semiconductor. Johnson and shot noise are considered fundamental noise, which cannot be completely eliminated.

Ficker noise bas power spectrum with an amplitude that falls off with increasing frequency. Flicker noise is an excess noise arising from imperfect instrumentation sucb as amplifier drift. Hopefully, this noise will be minimized by manufacturer design.

Interference noise is of most concern here. This is also an excess noise which can be minimized by careful design of the experimental system. It can lead to incorrect measurements 
or problerns with potential control.

Interferenc: noise arises from electromagnetic radiation. It has a power spectrum centered on particular frequencies. For example, electromagnetic interference from a power cord will give interference power spectrums centered at $60 \mathrm{~Hz}$ and also at harmonics of $120 \mathrm{~Hz}, 180 \mathrm{~Hz}$, etc. The amplitude of the interference is less at the harmonic frequencies than at $60 \mathrm{~Hz}$.

It is also possible to pick up noise sources at radio frequencies. This pickup can be caused by fluorescent lighes, power hand tools, hood exhaust fans, lab refrigerators, etc. These noise sources an have significant components in the 30 to $300 \mathrm{MHz}$ range. Elimination of the radio frequency interferences (RFT) is more difficult shan lower frequency pickup, and the rules for shielding against this noise are different. These interferences also bave a wider power spectrum than the disctete frequency noise. In order to be affected by this interference, the experimental system must have a component that is sensitive enough to react to the bigh frequencies. Electrochemical systems are more likely affected $t v$ signals at $60 \mathrm{~Hz}$ than signals at $300 \mathrm{MMz}$, but the particular experimental system should always be kept in mind.

In summary, of the types of noise considered above, interference noise is of the most concerp to the experimentalist. This interference is a sesult of capacitive and inductive coupling of electromagnetic radiation and the experimental systern It is emphasized that $\mathrm{iz}$ this bind of interference, no direct connections exist between the interfering source and the measurement system. In some cases the measuring system itself can be the interfering source. (Note that we have not considered some of the other ty pes of noise, such as quantizing noise that arises in the conversion of analog to digital signas.)

Now consider in more detail electromagnetic interference arising from eapacitive and inductive coupling of the system and the surroundings. 


\section{A.2. Electroungnetic lnterfereace}

Any conductor can act as an antenna for the pickup of electromagnetic interference through electrostatic and magnetic coupling. These are two separate effects that must be considereri when designing an experimental system.

\section{A.21. Eisctrostatic Efiects}

The tendency to pickup electrostatic interference is roughly proportional to the conductor's length and cross section, the voltage amplification which follows, and the resistance to common at the particular point in the circuit. Since electrochemical systems usually deal with bighimpedance reference-electrode circuits, this last point should be particularly well taken.

To understand capacitive coupling and bow to shield against these effects let us review some of the basic principles. A charged conductor when brought into close proximity to another conductor will induce a potential on that conductor. This is a result of the electrostatic fields that surround charged bodies and is referred to as capacitive coupling. A shield is used to overcome electrostatic interactions. Any conducting medium which totally encloses a system will completely shield that system from outside influences. The outside surface of the shield interacts with the external environment while the inside surface of the shield is affected by only the internal conductors. There can be no capacitive coupling of the conductors within the shield to conductors outside the shield, althougb there will be mutual-conductance interactions of the system within the shield. This is independent of whether the shield is grounded, floating, or at some other fixed potential. The shield, however, is not likely to surround the measuring instrumentation completely so that the inside shield surface takes on the same potential as the outside of the shield. As a practical matter, due to these influences we will want to fix the shield potential. This will be discussed below. 


\section{A.2. Magnetic Efrects}

An induced electric cur:ent is generated when a conductor cuts a varying magnetic field (or if the conductor itself is moving through a magnetic field) if the current can flow in a closed path. This is referred to as inductive coupling. The magnitude of this effect is dependent on the loop areas of the conductors, the rate of change of the magnetic field, and the distance between the magnetic field source and circuit. Magnetic fields can be generated from a variety of sources including $A C$ power lines and $A C$ motors and transformers. The electrostatic shielding discussed above is generally not belpful for shielding against inductive pickup. Magictic field lines are only partially attenuated by metallic enclosures. Whereas electrostatic shielding does not depend on the type of conducting surfacs, the effectiveness of shielding against magnetic fields depends on the permeability of mate rial as well as its thickness.

In summary, ncise can arise from electromagnetic interference through inductive and capacitive coupling. Both of these effects can be minimized by physically removing the disturbing signal from the experiment. Electrostatic pickup is inversely proportional to the circuit separation, and magnetically induced voltages are inversely related to the lux path (distance). Often, capacitive coupling is a mucb larger effect than inductive coupling. Electrostatically induced voltages from a power line may be an order of magnitude greater thau the corresponding magnetically induced voltage from the same power line.

We should also mention that interference can pass through an instrument through coupling of its own power supply with other components. Thus, noise problems can be present even when no external interfering lines are present.

\section{A.3. Resistive Ground Loops}

Before considering ground loops furber, it is useful to define the difference between an earth ground, represented by dat (you "rake" the earth) and a system common, represented by $\downarrow$. A system common is that point in the system that is chosen to be a reference for all or at least some voltages. There may be more thar one common in an instrument, but from a user 
standpoint probably only one of these will need to be considered. This system common may or may not be tied to the earth ground, depending on the design of the instruments being used. Some potentiostats are designed so that one of the electrodes is at or near the circuit common. The circuit common may be the chassis ground, which is connected to the third prong on the power cable. Often the output vollage and current monitors of a potentiostat are eferenced to (in common with) the worbing electrode.

Resistive ground loops flow due to an unexpected potential gradient. In electrochemical systems, a potential gradient can exist in any metal phase or the solution phase as well as at metal/solution interfaces. Current may flow in a loop through both metal and solution phases by coupling with an electrochemical reaction at the metal/solution interface. In the general sense, the metallic phases include totb the instruments' chassis and wires and any other metal present in the experimental system. Thus, among the problems that may occur, we can consider instrument-to-instrument, metal-to-metal (other than the instruments), fluid-to-fluid, and fluidto-metal (which can include a bipolar cell induced reaction) ground loops. The ground loops can result from a design error or from outside interferences. Some examples of ground loop problems are given below.

Instrument-to-instrument ground loops are suspected when the operation of one instrument seers to have an effect on another instrument. This interaction can be a result of a potential difference between the two instrument commons, which are frequently found to be at different potentials. The induced eurreat can cause a variety of measurement errors or system problems. (If two instruments are affecting each other, it may also be due to capacitive coupling of an interfering line with the instrument signal lines.)

An obvious metal-to-metal ground loop would occur in the construction of an electrochenical cell made of steel, where the anode and cathode could both conduct electricity to the cell wall. Al the current delivered to the electrodes would bypass the solution and flow through the inetal cell wal's. Another example is the flow of current through two instrument 
chassis that have heen connected together, but are at slightly different earth potentials. This is particularly important in instrumentation that is designed to use the chassis as the signal common.

A fluid-to-fluid current leakage might occur when the exit anolyte and catholyte streams are in contact with each other or when an exit bose is fed directly back into the feed tank In this case, a potential gradient is formed in the solution phase. This allows current to flow in more than one path from anode to cathode. The current loop might not manifest itself in a potentiostat overload, but instead as an unexpected potential reading in solution. A practical current-loop problem is encountered in bipolar cells where shunt currents bypass the electrodes by flowing through the solution. ${ }^{\text {ia }}$

Fluid-to-metal current leakage is a bit more subtie. Consider a case where the potentiostat earths the working electrode through the third prong of the power cord. Now any continuous path through the fluid that contacts any conductor which is also earthed can lead to current leakage. An exit bose placed down a drain pipe could serve as a source or sink for electrons. Any other system component that is eartbed can bave the same effect. A non-insulated pump that i : in common with the working electrode (both may be earthed with the third prong) an act as a second working electrode. Current flows in the electrolyte between the counterelectrode and any of several working electrodes. (Refer to figure A-1.) In the short-circuited example in the paragraph above, if instead of connecting both the anode and cathode to the metal container only the working electrode is connected, the whole contziner can serve as a source for current leakage. Thus, metal piping that is in common with the working electrode may draw current.

Continuing this example of the cell with metal walls, now isolate both the working and zounterelectrodes from the container. Now the container is "floating" as it sees no applied potential. Now it might seem that we are safe from curtent-leanage problems. However, at least two problems can still occur. The first is due to the presence of the potential gradient in solution. This gradient, when applied across a conductor will induce a potential in the 


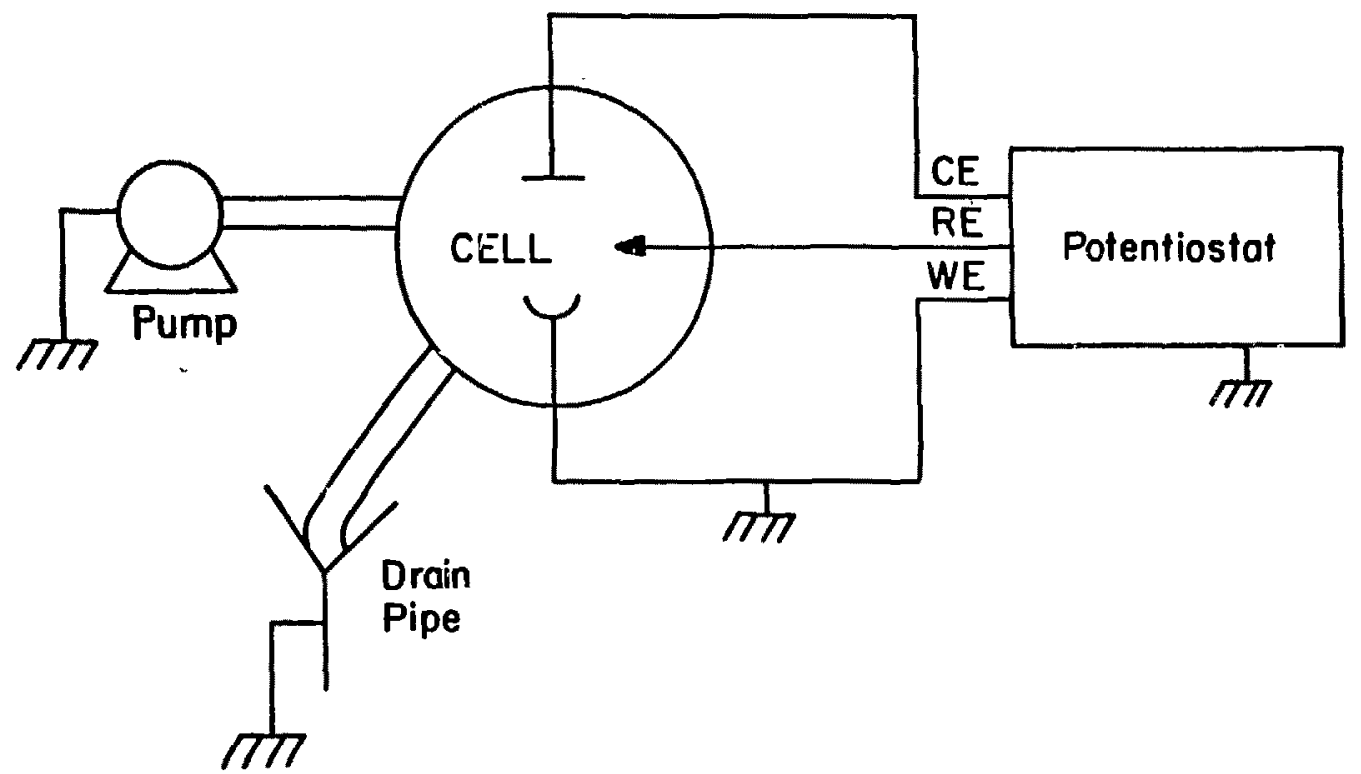

XBL 839-11879

Figure A-1. An example of current flow to multiple working electrodes due to incorrect ground connections. 
conductor as is done in bipolar cells. The cell wall can then arry on unwanted electrochemical reactions. Secondly, the presence of the floating metal wall is an invitation to induced currents from surrounding electromagnetic radiation. This in turn then affects the cell voltage.

Chapter 3 of this dissertation reports on experiments performed on the removal of lead from sulfuric acid solutions in a high-pressure porous electrode. During these experiments, a "poiential inversion" was observed where the downstream reference-electrode potential became more positive than the measured upstream reference-electrode potential. This is the reverse of what would be expected for the flow of cursent through the porous-cathode bed. (See figure 3 4.) Independent measurements of the current flowing into the anode and out of the cathode showed that an overall cathodic process was taking place in the electrode bed. Furthermore, the current entering the anode was the same magnitude as the current leaving the cathode. This is an example of a more subtle ground-loop problem involving a bipolar-induced electrochemical rezction. It is worthwhile to look at this problem in more detail.

A schematic of the high-pressure reactor unde. consideration here is shown at the top of figure A-2. The interior walls and faces of the entire reactor assembly were insulated from the solution with a Kynar coating. This included the cathode chamber, anode chamber, and feed ring, but not the two small sections of metal tubing at the anolyte and catholyte exits. These were made of Carpenter 20 stainless steel for corrosion resistance to the sulfuric acid, but they were not electrically insulated from the solution. The reactor in figure A-2 is an earlier design than the reactor shown in figure 3-19. The imporant difference is the manner in which the reactor was held together at the feed ring In earlier experiments (figure A-2) the reactor chambers were bolted to a threaded, metal feed ring. This allowed a path for current flow through the outside of the reactor. The two sections of mezal nubing at the reactor exits. therefore, are not insulated from either the solution or each other.

During reactor operation, a potential gradient is formed from the anode to cathode. This is represented in the bottom of figure A-2 by a straight line. The potential in solution at the 


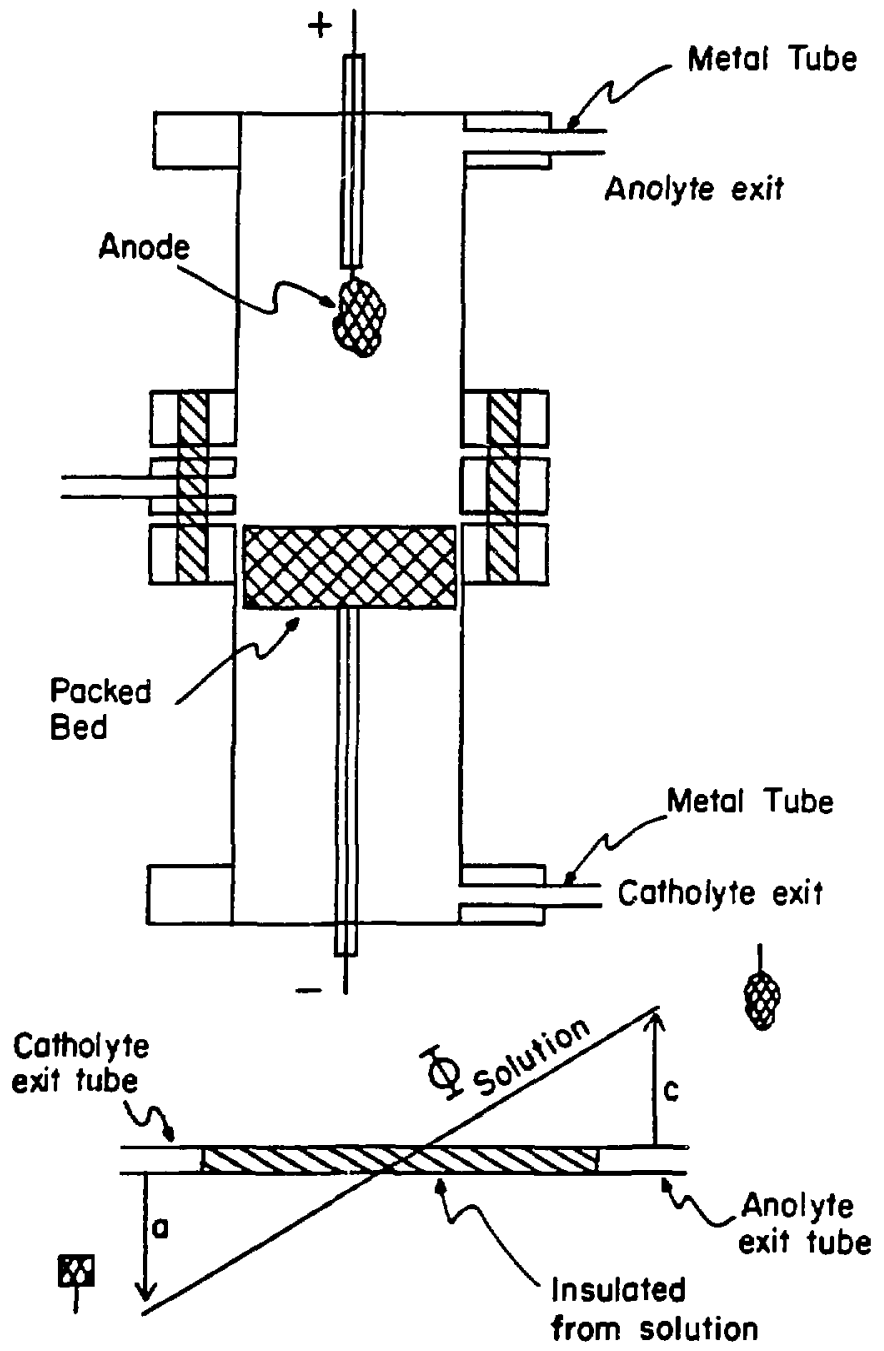

XBL $839-118 B 2$

Figure A-2. Schematic of an "early" high-pressure reactor showing a bipolar induced reaction at the anolyte and catbolyte exits. 
anolyte exit is positive with respect to the potential in solution at the catholyte exil. Since the metal tubing (and outside of the reactor) is floating from any ground or common, the potential gradient in solution can induce the metal to act as a bipolar electrode. The outside of the reactor completes the circuit: if the outside of the reactor was not conducting, no current would flow. The bottom of figure A.2 shows the electrode potential relative to the gradient of potential in solution. The anolyte exit tubing becomes a cathode, and the catholyte exit tubing becomes an anode.

Current now has the opportunity to flow in two parallel paths from anode to cathode, thereby bypassing much of the hed. It is still not clear, bowever, why a potential inversion would be measured. To understand the potential inversion, a simplified equivalent circuit is given in figure A-3. Or particular importance is the placement of the reference electrodes relative to the path of current tbrough the cell. Current entering the counterelectrode undergoes an electrochemical reaction to give oxygen. Normally, current flows through the solution resistance $R_{2}$, reacts at the cathode, and leaves the catbode bed through the current collector. In the altemative parallel path, current reacts at the counterelectrode, fows through solution

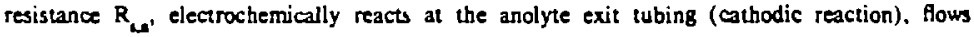
through the outside of the reactor, electrocbemically reacts at the catholyte exit tubing (anodic reaction). flows through solution resistance $R_{n c}$, reacts at the working electrode, and flows out the current collector. The charge-transfer resistance of the reactions taking place at the exit tubing is shown as an added resistance for current flow through the outside path. No mention bas been gade yet as to what reactions take place at the tubing If the solution in contact with the tubing was the same at both the anode and catbode exits, we might expect to need a minimum potential gradient from counterelectrode to working electrode of $1.23 \mathrm{~V}$ to drive a water decomposition reaction in the outside curtent loop. Here, however, the system acts more like a fuel cell in that oxygen produced at the counterelectsode can be reduced at the anolyte exit, and bydrogen that is produced at the working electrode can be oxidized at the catholyte exit. Thus, to predict how the current will distribute itself between tbe two parallel pachs, a 


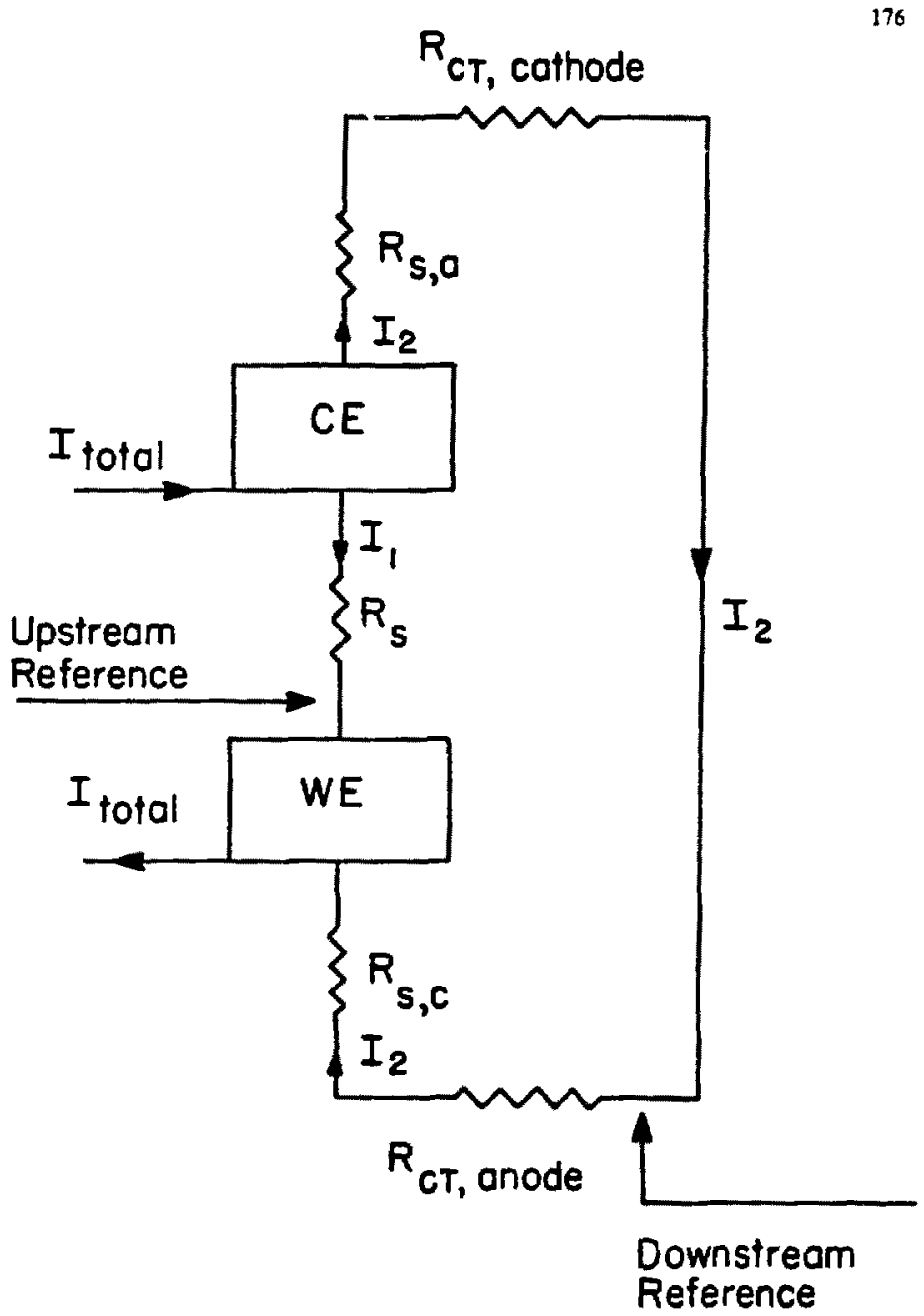

XEL $839=11886$

Figure A-3. Equivalent cireuit illustrating the current loop of Ggure A-2. Subscripts a and $c$ represent the anode and catbode compartments, and subscript 5 refers to the wlution. $R_{c r}$ represents the shargotransfer resistance. 
more detail drawing than figure A-3 can be introduced. Tais drawing would include a voltage source for each electrochemical reaction under consideration.

The potential inversion can now be explained by looking at the flow of current through the outer loop. The downstseam reference electrode is located in the catholyte exit stream In this location, the reference electrode senses all the current flowing through $R_{2,}$. The solution potential, therefore, is positive relative to the exit of the par' ! bed. The upstream reference electrode, however, is placed near the top of the packed bed. It senses only a small fraction of the ohmic drop through $R_{i}$. Thus, its potential is positive relative to the bed exit only by an amount equal to the ohmic drop through "je bed. Therefore, even theugh the potential variation is positive from front to back of the bed, the potential difference as measured with the reference electrodes can be negative. The magnitude of the potential inversion depends on the amount of current that flows in the outer loop. Clearly, the performance of the bed is burt by the presence of the current loop.

\section{A4 Grounding and Shielding}

Now consider some ways to eliminate some of the grounding and pickup problems. Of most importance is to try io eliminate ground loops that flow through instrument signal lines.

As mentiened above, two commons are not necessarily at the same voltage. This is sometimes true within the common of one instrument, but is especially true when considering earth grounds. The earth is unavoidably involved in all instrumentation systems and in the power generation of electricity. It is often used as a zero reference potential in instriments and is used as a source and sink for electrons in safety grounding. It is not safe to isolate power systems Irom earth, and the National Safety Code requires neutral connections to earth at certain prescribed locations. Tte utility currents flowing in earth vary considerably. Since the earth's conductivity is a function of geographic location and weather, etc., it is clear that potential differences will exist between one earth ground and another. (In the design of an instrument facility, the placement of underground copper or iron pipe along primary power lines 
for trapping ground currents would be considered.)

Figure A-4 shows a voltage amplifier with gain, where the source common and amplifier common are at different voltages. The noise voltage is added to the signal voltage and then amplified to give an erroneous output voltage. One method for overcoming the ground-loop errot in figure $A-4$ is through the use of a differential amplifier, shown in figure A-5. Any voltage difference that exists between grounds is canceled so that amplifier ground and source grounds need not be the sas:. The output of the differential amplifier can even be single-ended, where the common is tied to earth ground. Figure A-5 represents an isolated differential amplifier in the sense that the input signal lines are completely isolated from the output signal lines and chassis ground. Not all differential amplifiers are isolated. Differential amplifers can be purchased witb differential inputs and single-ended outputs, such as the Keitbley model 604 electromeier/differential amplifier.

Anotter approact to the grounding problem in figure $\mathrm{A}-4$ is to insure that the voltage amplifier common and signal common had only one connection, with a highly conducting wite or strap. Figure A-6 illustrates the elimination of ground loops in an amplifier by connecting the two commons to a single point at the signal source. Thus, we may state a general rule that the circuit should be connected to only one common point. This rule applies to the shields of instruments as well.

Shielding is the technique used to help minimize ground-loop problems arising from electromagnetic pickup. Instruments often use the outer chassis for a shield, and instrument lines an use coaxial or triaxial cable as a shield. If the outer braid of the coaxial cable is used for signal processing as well as a shield, the noise rejection will be inferior than using triaxial cable where the signal lin's and shield can be kept completely separate. General rules should be followed with regard to shielding. All shields, including the electrometer shields, should be connected to one point, if possible. This point should be the system common. The top of figure A-7 illustrates the way ground loops may occur when grounding the shields at several points. 


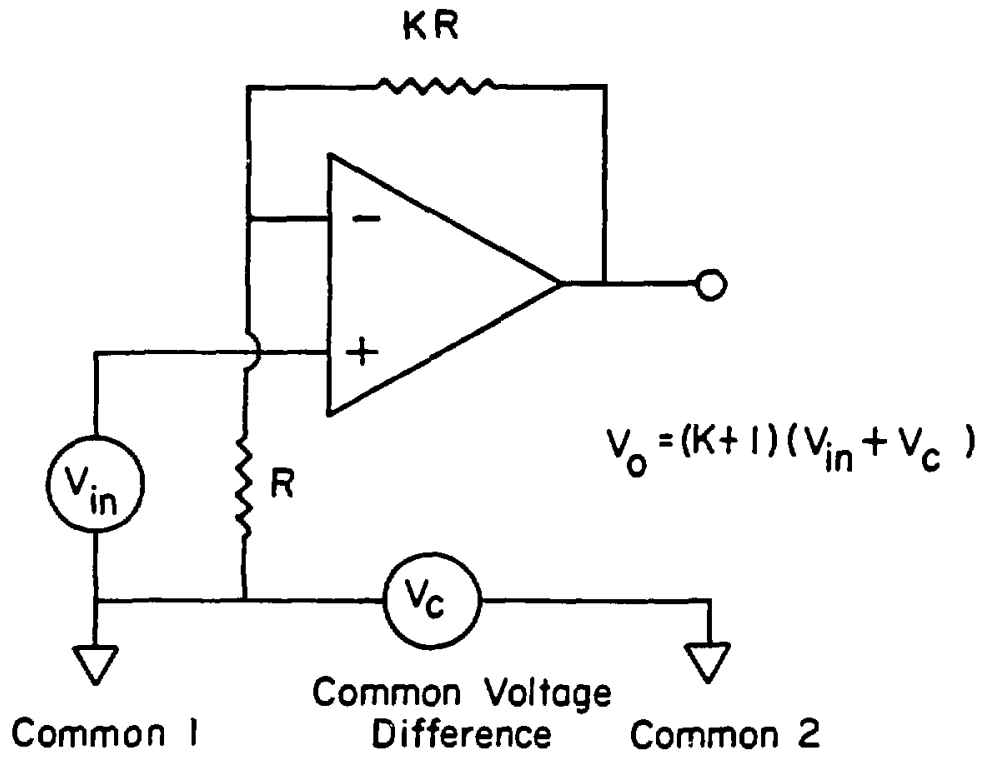

YBL $839-11878$

F-gure A4. Scbematic of a voltage follower with gain amplifying a voltage difference between commons. 


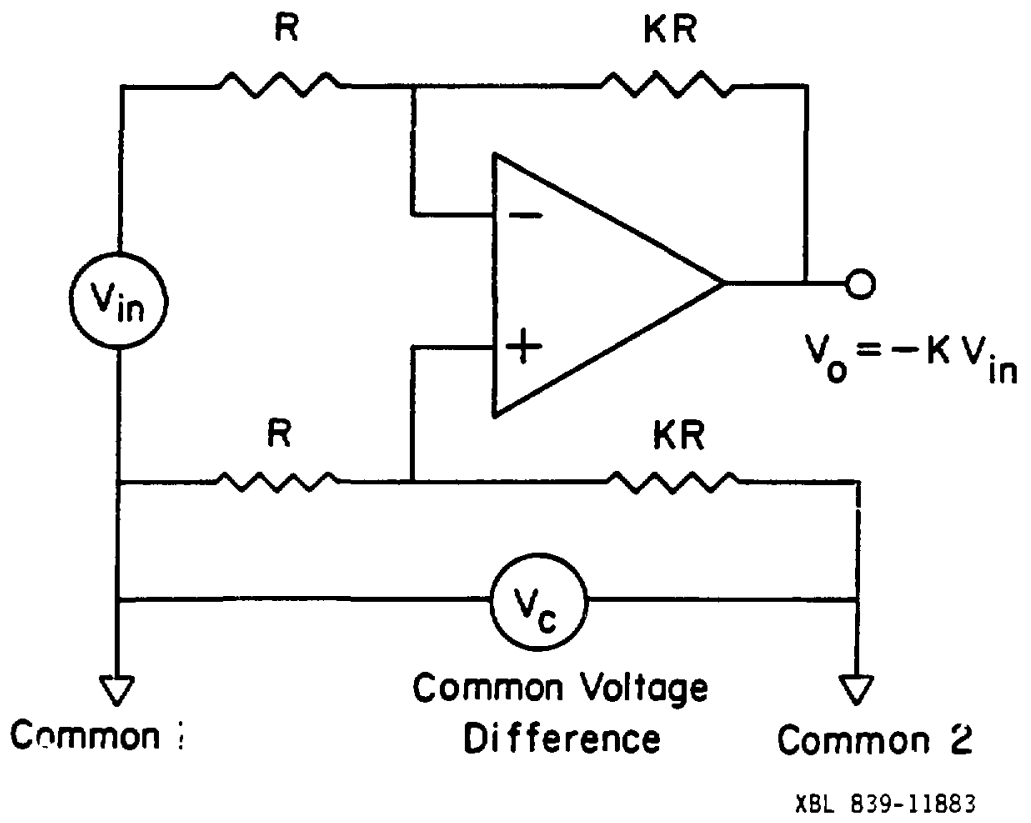

Figure A-5. Elimination of the ground loop of fgure A-4 with a differential amplifier. 


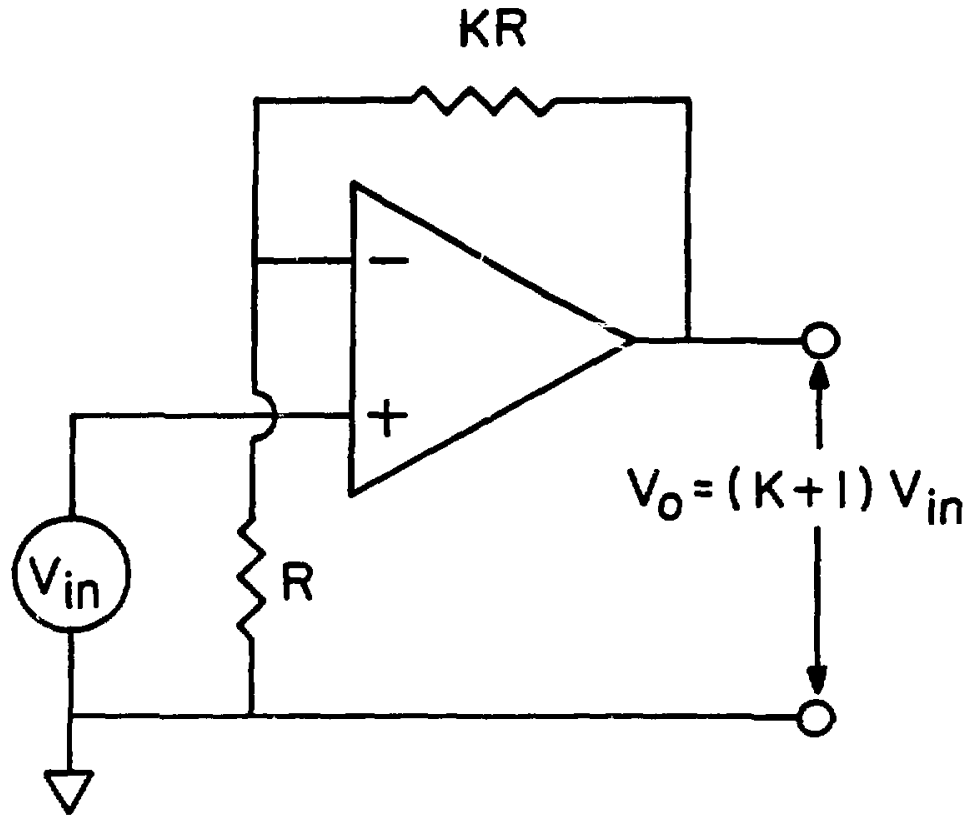

XBL 839-11885

Figure A-6. Elimination of the pround loop of figure $A-4$ by connectilg commons to only one point. 

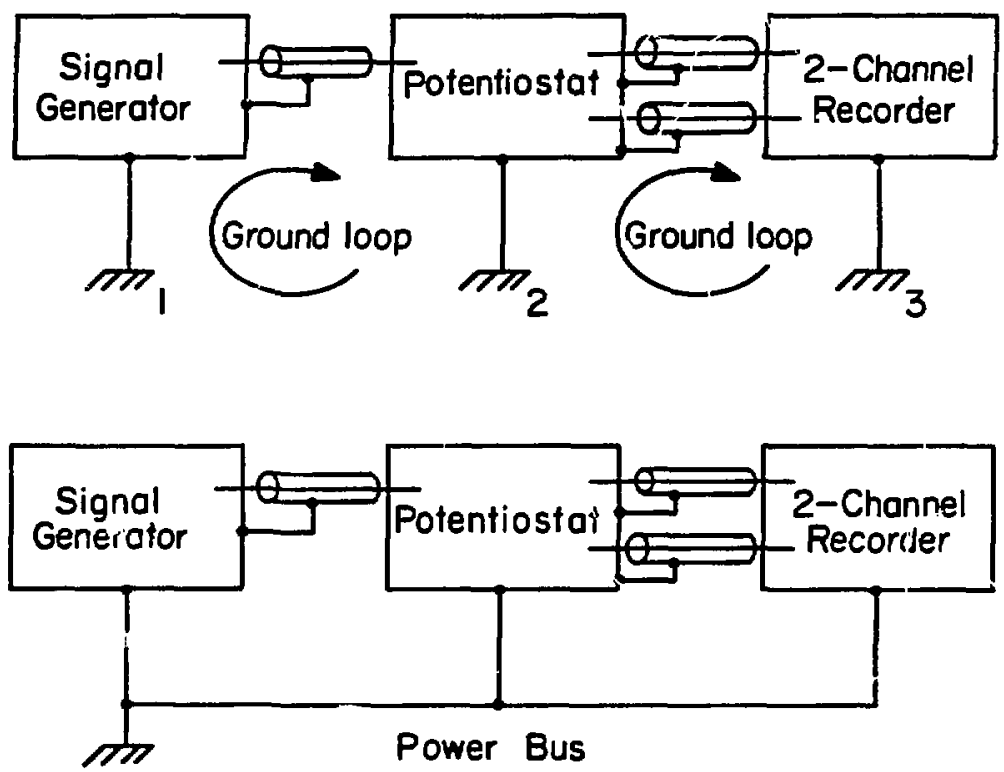

XBL B39-11876

Figure A-7. Ilustration of eround loops Dowing through several instruments because of multiple ground connections (top of figure), and the elimination of this ground loop by coanecting all chassis grounds to one point (bottcon of figure). 
Here three instruments are shown that have been designed io operate with the circuit common connected to the chassis, which in two is connected to the third prong on the power plug. The instrumenis are flugged into different outlets so that each common is at a different griund potential. Coaxial eable is shown where the outer braid of the cable acts 28 a shield as well as the return path for current fijw. As a resulh ground loops flow through the chassis and instrament wires. To prevent this, all shields should be connerted together and grounded at only one point- the same point as the circuit conmon. (See the bottom of figure A-7.) If necessary, separate paths to the circuit common can he made to avoid errors due to ohmic drops in the retum circuit. In the case of connecting instrument chassis logether that are earthed through the third prong, it is recommended to connect all power eables to a multiple-outlet power bus, and then connect the bus to the utility power at one foint. It is important to maintain a good ground (third-prong) connection through the bus. Now suppose in this example that both input lines are floating off earth ground and that separate shields connect the instrument chassis together. Ground loops that flow in the shields are not flowing directly tbrough the instrument lines. This is less baraful, although shield currents can still capacitively couple witb the instrument lines. It is best to miniunize shield currents, if possible.

As a final note on figure A-7 we observe that semoving the third prong from the power outlet eliminates the ground-Icop problem. Doing so, however, not only removes the shield of the instrument, but bypasses the safety ieature of the instrument.

We have said above that it is best to connect all shields to one system common. This is nol always possible, however. If the chassis of an instrument is earthed, it carnot be connected to the system common if it is necessary to flout the system common from earth ground. Some potentiostats, for example, fioat ihe electrodes off ground and ust the working-electrode potential as the system common. In this case, a shield on the bigh-impedanr, reference-electrode line should be to the potentiostat common, instead of earth. Again, the reference-electrode shield should be terminated at one end only or shield currents could affect the instrument lire. 
There is an exception to the rule on shield connections when shielding against highfrequency noise. As the frequency of the signal increases, the impedance and inductance of the center of the conducting wire increase so that the current flows on the surface of the wire (the shin effect). The impedance of the conductor is increased, and effective shielding now requires multiple connections of the shield to common, instead of one connection. Thus, two shields may be requited when shielding against low and bigh-frequency interference.

We have mentioned above that triaxial wire is useful font separating the current-carrying lines from the shield. When this setup is used, the input lines are often twisted. Twisting, the wires minimizes both magnetic and electrostatic pickup. Recall that magnetic pickup is proportional to the circuit loop area and the rate of change of the magnetic field. Thus. magnetic effects are minimized because the loop areas have been reduced. (The limitation in reducing the loop area to zero is the thickness of the insulation surrounding the wires.) It is also B od practice to route and twist the AC power cords together to er neel out magnetic fields. The effects of capacitive coupling of the input wires to a disturbing line are also minimized by twisting the wires. If both input leads capacitively couple in approximately the sans way, the same interference is presented to both lines. If a differential amplifier is used, the induced noise will cancel.

In very high-impedance circuits, the signal cable can limit the performance of system A coax cable, for example, has a characteristic resistance and eapacitance from center conductor to outer braid. Thus, surrent can leak from the inner to outer connector through resistive or eapacitive coupling. Resistive coupling occurs when current flows througb the cable insulation. High-frequency signals become distorted as they pass through the cable due to the cable capacitance Both of these problems can ie solved by driving the shield of the cable to the same potential as the signal. This is done with the low-impedance output of a separate "guard" amplifier. Since the voltage difference between signal and sbield is zero, no resistive or capazitive coupling can occur. Also, since the shield is driven from a low-impedance source, the 
tendency to pickup electrostatic voltages is small. A separi c outer shield can be used if necessary. The AIS potentiostat used in the experimental work in chapter 3 drives the outer braid of the coexial reference-electrode input. In using an electrometer to make $\mathrm{pH}$ measurements, Keitbley ${ }^{102}$ recommends using the unity gaip output of their electrometer to guard the shield on the pH electrode.

We should stress again tbat capacitive and inductive coupling are reduced when the disturbing source is removed from the instrument lines. In general, all power lines should be routed iogether to minimize the magnetic belds generated, and all instrument lines should be routed as far away from the power lines as possible.

An isolation trassformer can be useful for the isolation of $\mathrm{AC}$ signals. An instrument isolation transformer is shown in figure A-8. The new common line is now isolated from the common inlet, eliminating any DC ground loops due to two ground connections. Isolation transformers can also be used on the inlet power line to belp eliminate ground loops between the system ground and powet-company ground. There is a rejection of any DC interference or voltage that may be carried along a power line. The rejection of AC interference depends on the design of the transformer. Generally, fuctuations in input voltage in the primary winding would magnetically couple to the secondary winding and be seen as fiuctuations in output voltage. The isolation transformer, however, does attenuate certain noise frequencies. It can flter out mueh of the bigh-frequenc; noise that is carried along the main power line, such as radio and television signals, automotive ignition, etc. if they are properly shiclded. If no electrostatic shielding were used, the bigh frequencies would capacitively couple across the isolation transformer. The shieldiog is not completely effective, and there may still be ground Joop due to capacjtive coupling from the primary to seconilary side of the coil.

The isolation transformer gives the opportunity to reference a system to a known ground, instead of the power-company ground. Since the neutral wire of the power line is :ied to earth ground at the power company or somewhere along a substation, the earth potential varies with 


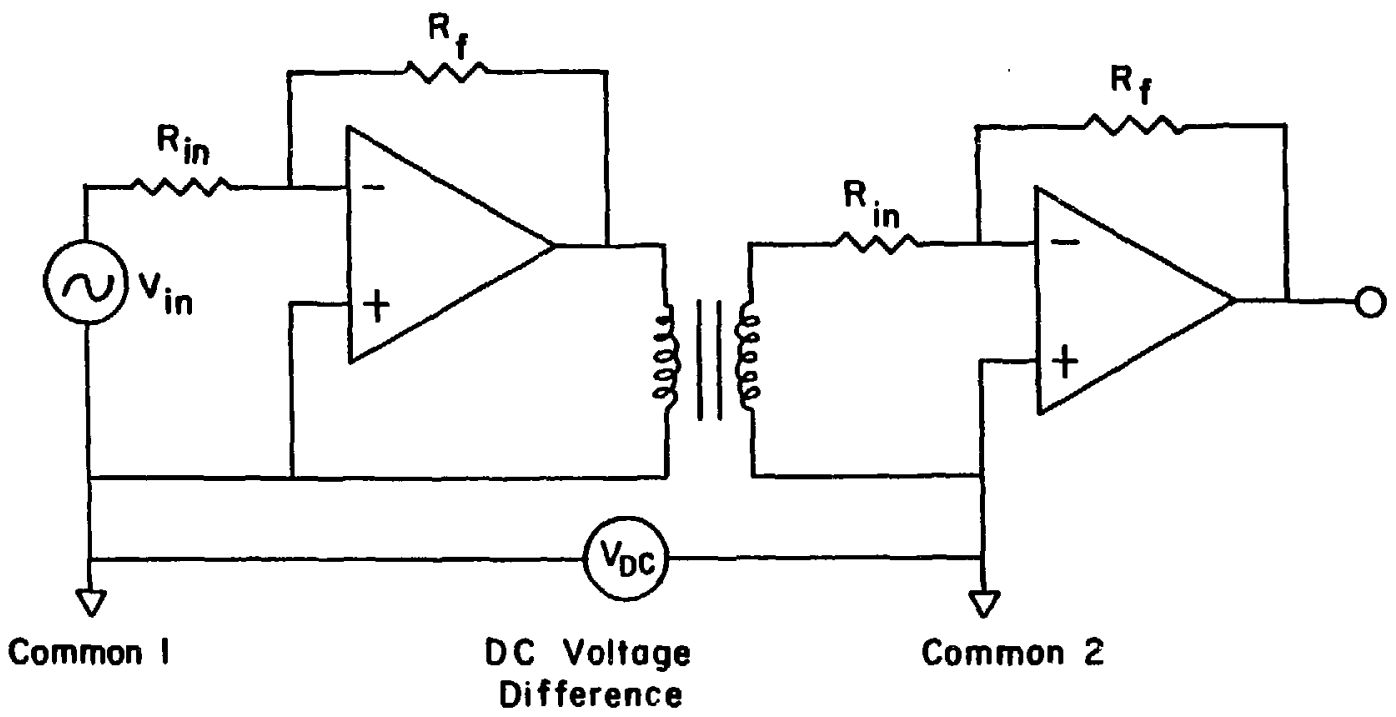

XBL $839-11884$

Figure A-8. Use of an isolation transformer for the isolation of AC signals from DC interference. 
the neutral-line potential. In the absence of the isolation transiormer, fluctuations or interferences in line voltage may he seen by the case of the instrument. Use of the isolation transformer belps to stop the power-line noises caused by motors, relays, ete. from being carried through the instrumentation. Again, if the transformer is shielded well, electrostatic coupling from primary to secondary windings will be minimized. As a final note on isolation transformers, one should not use them indiscriminately. In some esses onc can change from one ground-loop problem to another (througb capactive coupling actoss the transformer). Also, transformers or regulators can change the impedance of the AC line so that equipment that was designed to see the power-company voltages, has trouble with the regulated voltages. ${ }^{105}$

Problems with power-line grounds and interference could be eliminated by using instruments that are battery powered and operate on DC current. In general, it is recommended that battery-powered instrumentation be used, if possible. This is especially true when troubleshooting tbe electrical system If needed, battery packs can be purchased that convert DC to AC current. Avoiding the generation of any AC signals, however, has the added benefit of eliminating the possibility of electromagnetic interference from the $A C$ line to the instrument lines.

In summary, grounding and shielding of instruments should be considered in some detail when setting up the experimental system Manufacturer specifications apply to very clean environments, and it is up to the user to insure that the system is as noise-free as possible. In extreme situations it may be necessary to fabricate a special amplifier for isolation. A variety of isolation amplifiers are now available that an be used in place of operational amplifiers, even for LC signals. They use optical isolators or DC-to-DC conversion techniques to achieve very high isolation.

\section{A.S. Electrocherical Instruments and Design}

Generally, it is useful to draw a circuit diagrams of the experimental apparatus and instrumentation. All electrical connections should be included with particular attention paid to 
how the instrument or other electrical component (such as a pump or tbermocouple) is grounded. Since electrochemical systems also include a conducting electrolyte phase, it is necessary to include the solution path through the apparatus in these diagrams. In this manner, ground loops that are shown in figure A-1 become apparent. The circuit diagrams can also be useful for keeping in mind which instrunent lines are high impedance and therefore the most susceptible to noise.

Sometimes the interactions of instruments need to be considered in detail. An ideal voltage amplifier, for example, can supply unlimited current to a load source, and the amplifier itself does not load the source voltage because of an infinite input impedance. Furthermore, the output voltage can be considered to be isolated from the input voltage completely. The mure realistic voltage amplifier bas a finite input and output impedance, and the output stage of the amplifier can be loaded by another instrument. Furthermore, not all amplifiers bave isolated outputs. It is sometimes desirable, then, to consider explicitly the input and output impedance of the various system components when deciding on bow the electronics will interact when connected to a particular system. Instrument specifications usually give both the output impedance of the instriment and the cuinimum input impedance required of any measuring instrument. The specifications of potentiostats give the maximum output voltage and current that can be delivered to an electrochernical cell.

The following is a discussion of some of the instrumentation frequenly used in electrochemical systems. An example of some considerations of system design is given based on the previous discussion.

An electrometer is an important instrument used in the reference-electrode measurements. One type of voltage electrometer is shown schematically in figure A-6 as a voltage follower with gain. It accepts a differential input, indicates the voltage, and provides an output. The electrometer input impedance must be very high so that refererice-electrode polarization is minimized. Generally, it might be stated that a good reference electrode can tolerate a nanoamp 
of current draw. Thus an input impedance of at least $10^{9}$ ohms is important. The electrometer shown in figure A-6 references the outpat low to the input low, so that an isolation of input to output commons is not achieved. The output, however, would be considered buffered from the input in that currant would have to flet through a large resistance before the source voltage would be affected.

One might now ask how to make a pH measurement (figure A-9) with an electrometer based on the circuit diagram of figure A-6. For example, is it important to worry about which lead should be conrected to the glass electrode and which lead to the reference electrode? Interference considerations. aside, it seems that it makes no difference how the leads are connected since the electrometer input will see the series resistance of the glass and reference electrode. Since the electrometer 'sutput is buffered, which lead passes through the system low is not important. Note, however, the the high-impedance input to the electrometer is the + lead in figure A-6. This input is the most sensitive to interfere'rce pickup. Since an interference in the source voltage will most likely be dissipated through the lowest impedance line, and since we want to keep the bigh-impedance input from seeing interference that will be amplified, it follows that the highest impedance line should be connected to the high input Furthermore, if the bigh-impedance line was connected to input low and the voltage output was sent to a recorder, we would end up with a very long high-impedance line that could pick up interierence from several pies of equipment. Thus, the high-impedance line should be connected to the highimpedance input. An incorrect hookun of an electrometer to an electrochemical cell is given in figure A-10.

A potentiostat is used quite of ten in electrochemical measurements. It is of ten useful to draw one of the equivalent, operational-amplifier circuits for the potentiostat as shown in figure A-11. This potentiostat is shown with an internal power source for setting the reference voltage, and explicitly shows the working electrode as a system common. Different manufacturers have different grounding systems for their potentiostats. One model earths the common rail of their 


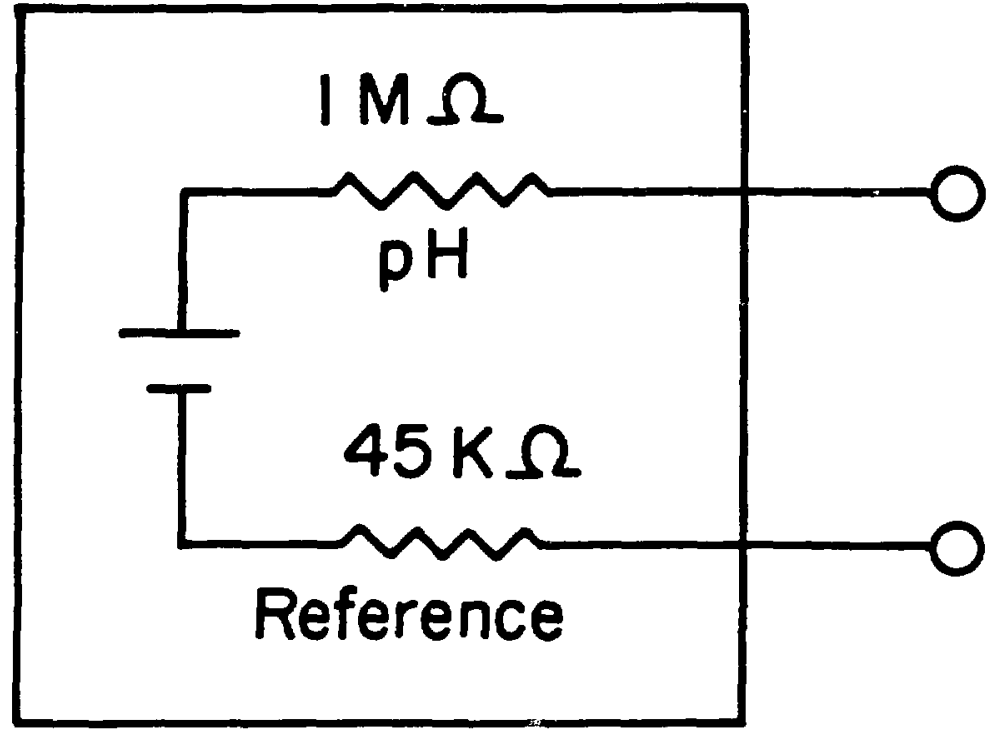

XBL 839-11877

Figure A-9. Equivalent cireuit of a pH system. The glass pH electrode is taken to have a resistance of $1 \mathrm{M} \Omega$ and the reference electrode a resistance of $25 \mathrm{kn}$. 


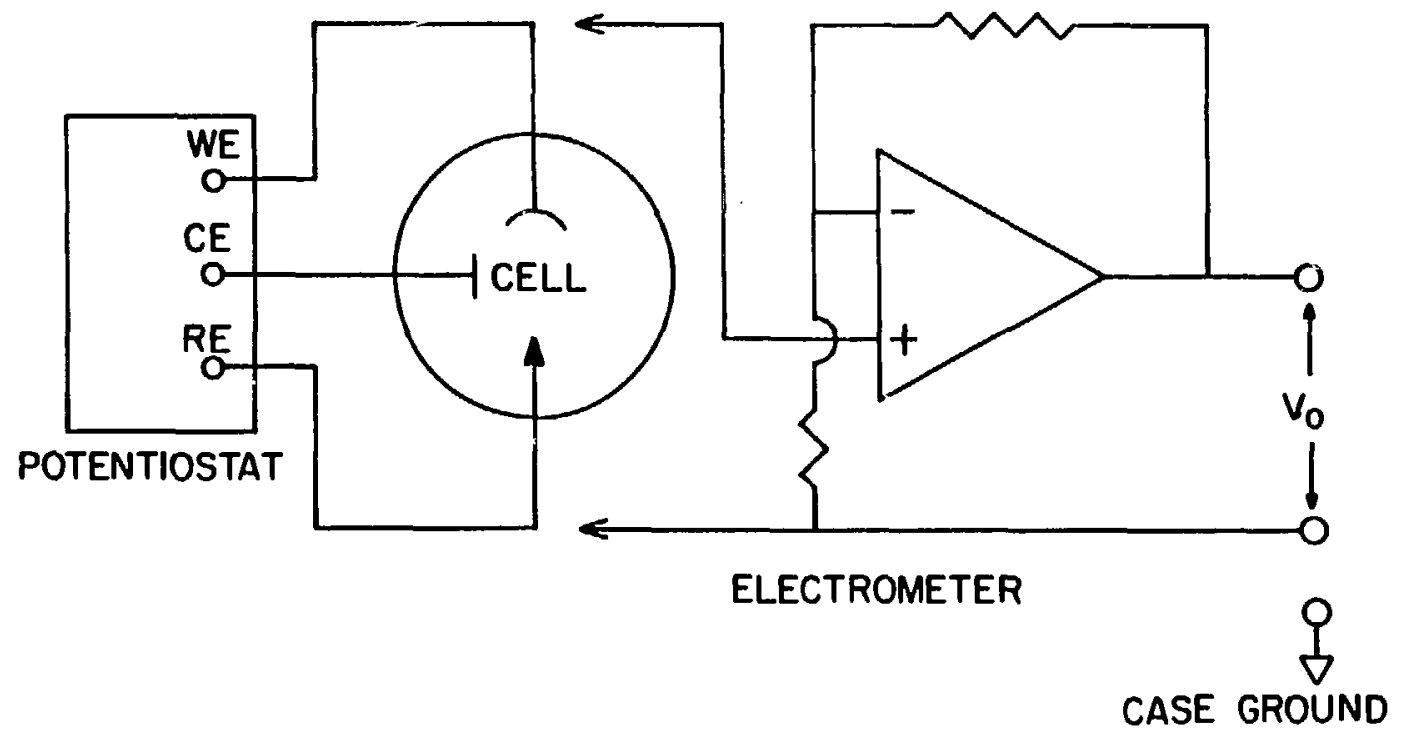

XBL $839-11880$

Figure A-10. Incorrect connection of an electrometer to an electrochemical cell. 


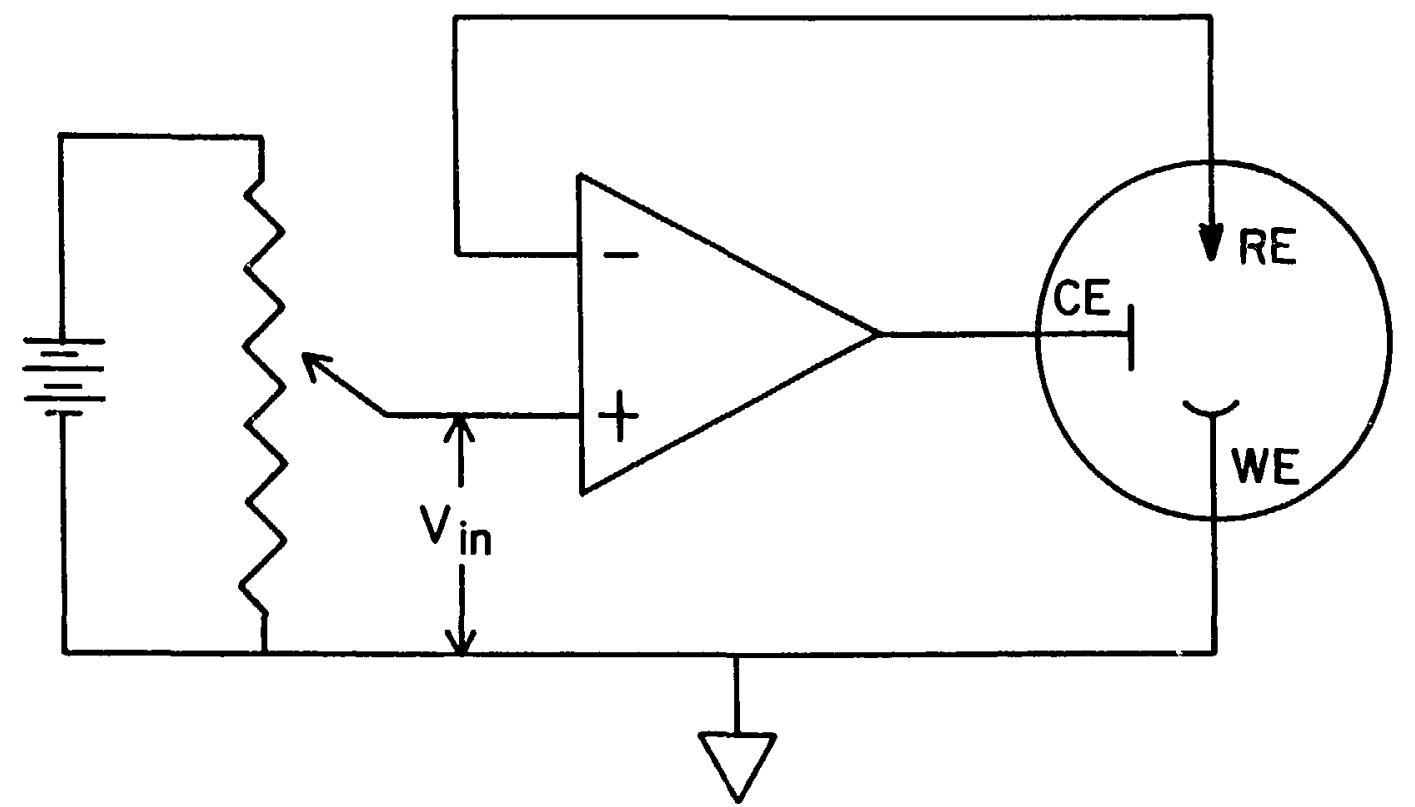

XBL 839-11881

Figure A-11. One possible equivalent circuit for a potentiostat using operational-amplifier notation. 
output monitors, while floating all the electrodes. However, either the working or counterelectrode ean be earthed if desired. Another model floats their electrodes of earth ground, but has the common rail of the output monitors at the working-electrode poteritial. Here, the working electrode could be eartbed if desired. Some potestiostats tie the working electrode to earth ground. To float the working electrode one would have to use an isolation plug and bypass the safety feature of the instrument. Thus, it is seen that for more than the most simple potentiostatic experiments, one must be careful in choosing the correct potentiostat to control the cell.

As noted above, the tendency to pick up electrostatic interference is related to the impedance of the line and the length and cross section of the line. In this sense. Princeton Applied Research Corporation has a good system with their potentiostat They provide a "remote" high-impedance electrometer to measure tbe reference voltage. This avoids long lines from the reference electrode to the potentiostat so that less pickup should occur. Another way to eliminate the long reference-electrode lines is to meastre the reference-electrode voltage with an electrometer and then use the low-impedance output to drive the input to the potentiostat. Since the low-impedares output is in parallet with the high input impedance of the potentiostat, the line will be a low-impedance line. Proper connections must be maintained as discussed above. Buffer amplifiers, with a high input impedance and low output impedance can also be purchased for this use.

In summary, are stould be caken at the early stages of the experiment to follow certain rules governing the grounding and shielding of instrumentation. Simple design considerations. such as the routing of power cables away from instrument lines and maintaining a correct connection of instrument commons, can prevent problems later on. 


\section{Appendix B. Computer Program}

The following is a list of variables used in the computer programs for chapter 4.

\section{Variable Listing}

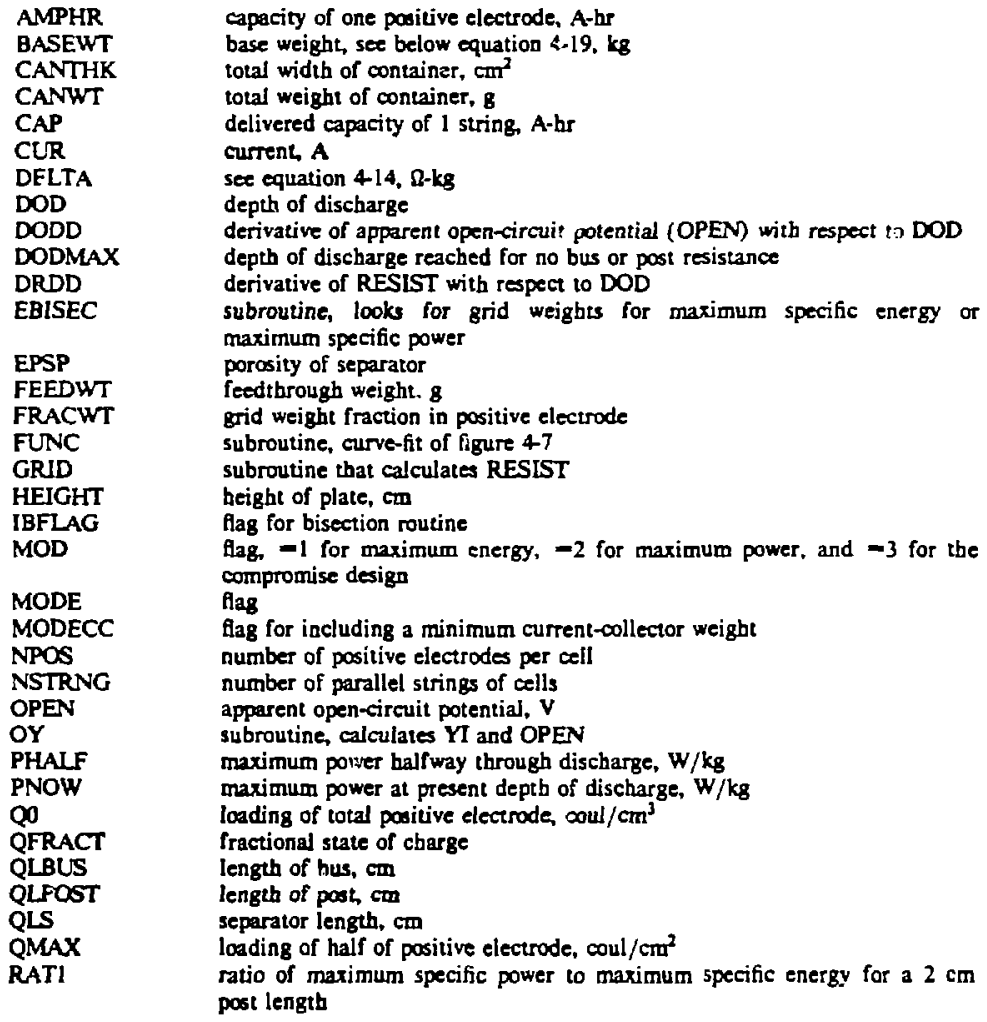


RAT2

RESIST

RHBUS

RHGRID

RHPOST

RHPUST

RPRIME

SI

52

SHUS

SEPEFF

SGRID

SPOST

THICK

TAMPHR

TIMAD

TOTCAP

Uo

VCUT

WAMN

WAMP

WBUS

WELEC

WIDTH

WN

WP

WPOST

WPRIME

YI

Yo ratio of maximum specific power to maxmimum specific energy for a $5 \mathrm{~cm}$ past length

$\Delta Y / I$, see figure $47, \Omega$

tensity of bus, $\mathrm{g} / \mathrm{cm}^{3}$

density of positive grid, $\mathrm{g} / \mathrm{cm}^{3}$

density of post, $8 / \mathrm{cm}^{3}$

desity of post, $8 / \mathrm{cm}^{3}$

bus and post resistance, see equations 416,4-19,4-20, and 4-21, a

integral of open-circuit potentials

intergral of resistances

sonductivity of bus, $\mathbb{Q}^{-1}-\mathrm{cm}^{-1}$

separater resiscance, $\Omega-\mathrm{cm}^{2}$

conductivity of grid, $\boldsymbol{\Omega}^{-1}-\mathrm{cta}^{-1}$

conductivity of post. $\mathbf{I}^{-1}-\mathrm{cm}^{-1}$

thickness of positive electrode, $\mathrm{cm}$

total capacity of cell, A-hr

time of discbarge, sec

total delivered capacity wanted (mode $=2$ or 4 ), A-hr

iritial apparent open-circuit voltage, $V$

cutoff voltage, $v$

weight of active material in the negative electrode, $g$

weight of active material in the positive electrode, $\mathrm{B}$

weight of two bus lengths for complete battery, 8

weight of electrolyte, 8

width of plate, $\mathrm{cm}$

negative grid weight, $B$

pasitive grid weight, 8

weight of two post lengths per positive, 8

total weight of buses and post for a complete cell, 8

array of values of $Y$ as a function of depth of discharge, $\Omega^{1}-\mathrm{cm}^{-2}$

initial value of electrochemical conductance, $\Omega^{-1} \mathrm{~cm}^{-2}$ 
The following program was used to predict the behavior of the lithium-aluminum/iron sulfide battery.

\section{PROGRAM DESIGN}

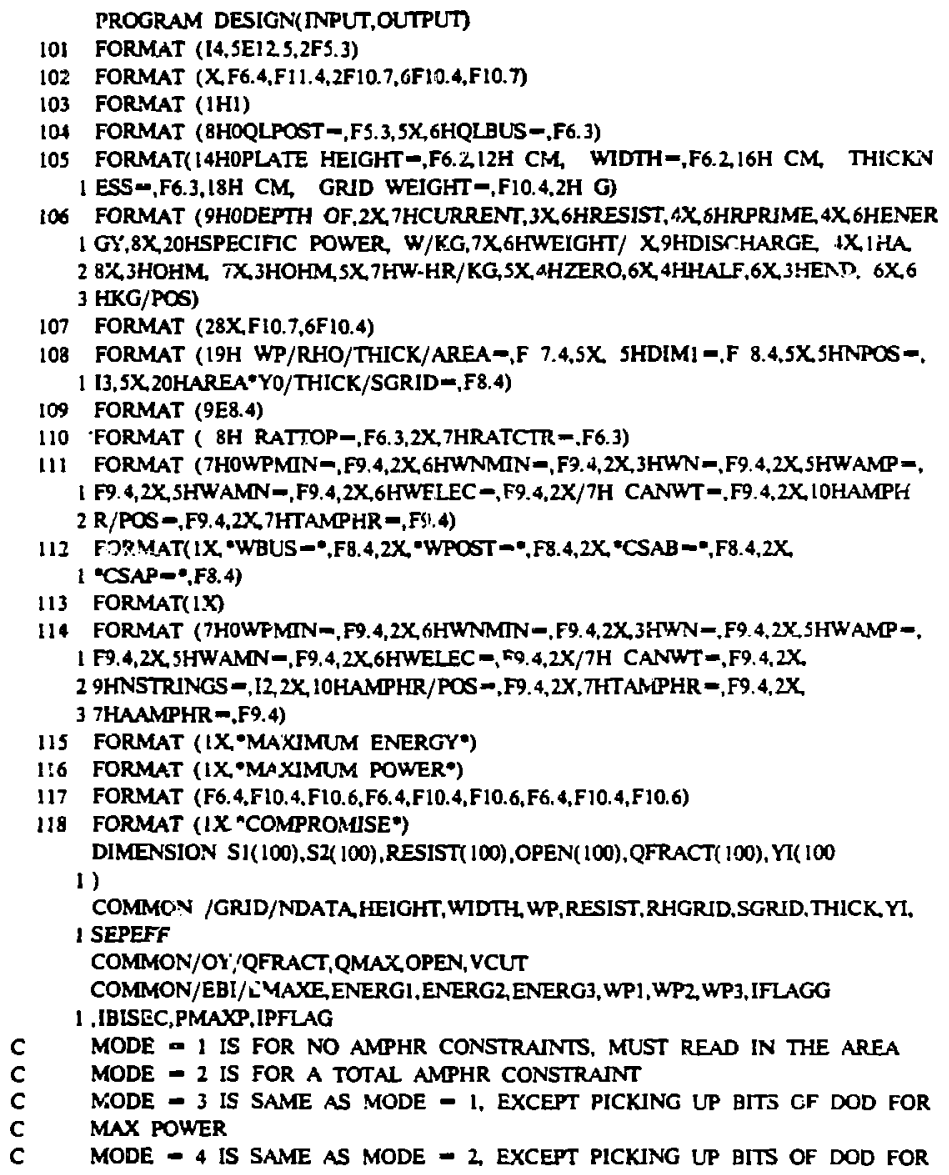




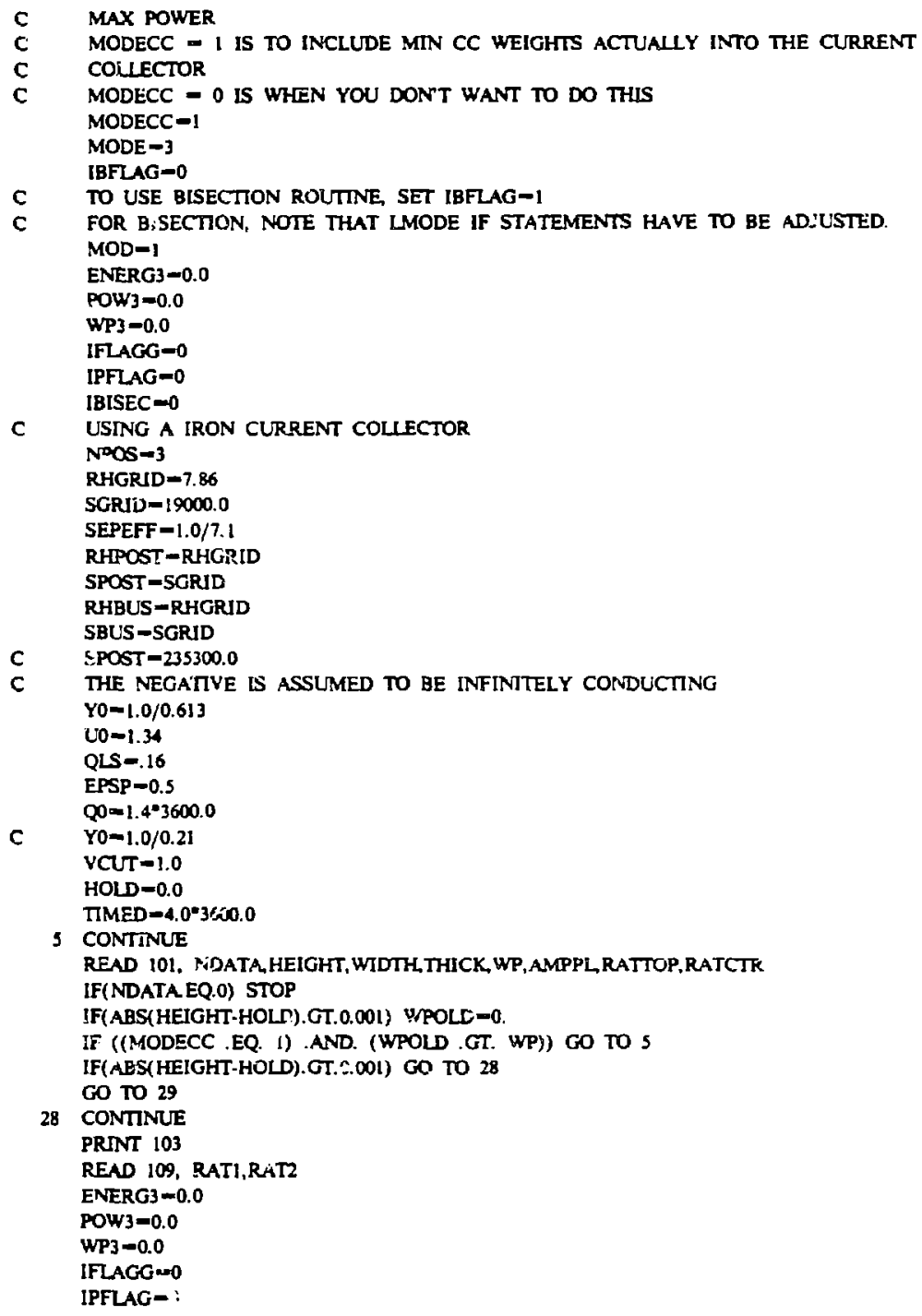




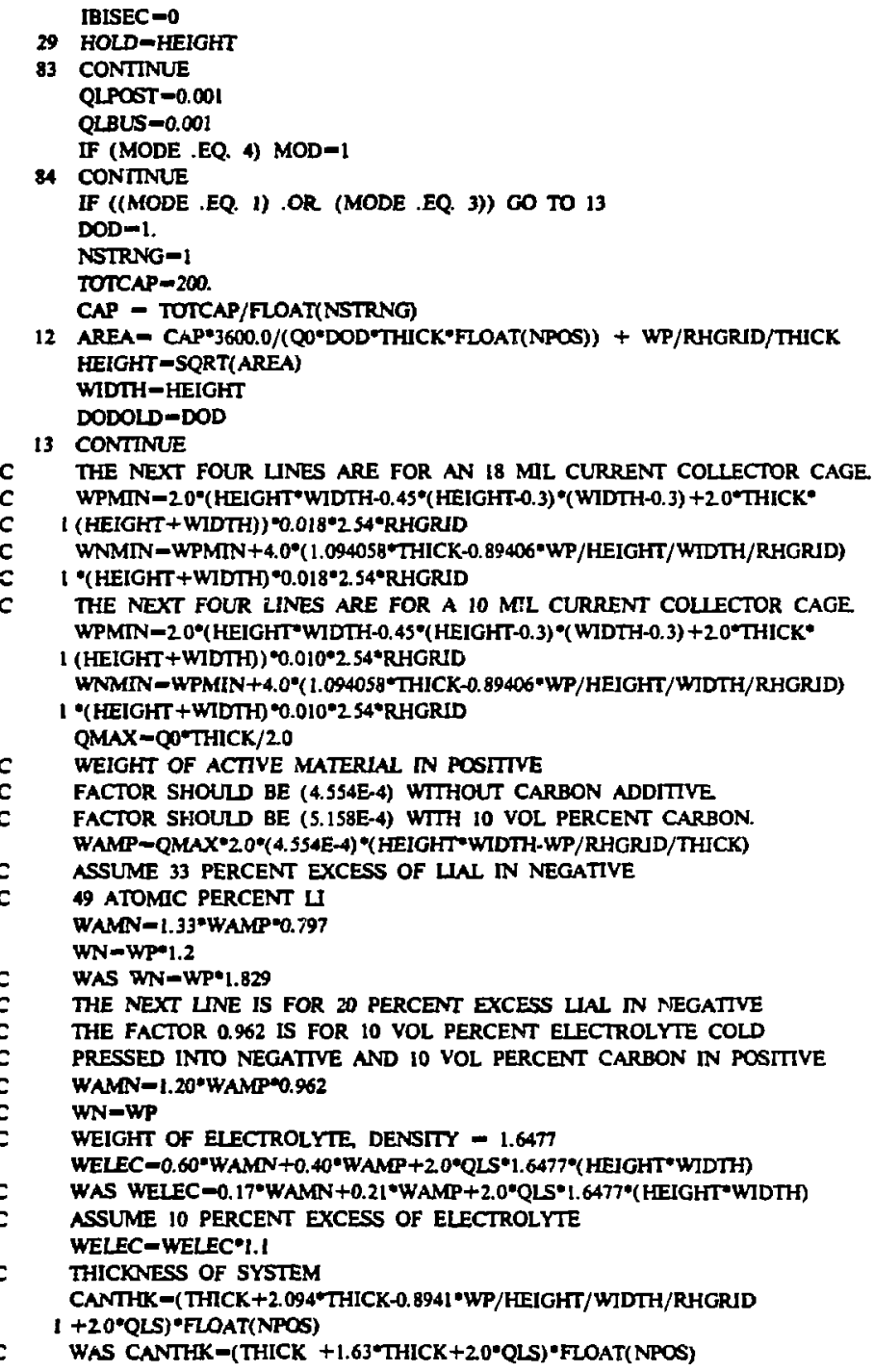


C CAN MATERIAL, 0.061 CM THICK

CANWT $-\left(\right.$ CANTHK" $\left(20^{\circ}(\right.$ HEIGHT +1.5$)+2.0^{\circ}($ WIDTH +0.4$\left.)\right)+(\text { HEIGHT }+1.5)^{*}$

I (WIDTH+0.4) 20$) * 7.86 \bullet 0.061$

AMPHR $=Q^{\circ}$ (HEIGHT'WIDTH'THICK-WP/RHGRID) $/ 3600.0$

TAMPHR - AMPHR $F L O A T(N P O S)$

IF (MODECC .EQ. 0) GO TO 46

WPOLD-WP

IF (WPMIN .GT. WP) WP-WPMIN

IF (WP .GT. WPOLD) 60 TO 84

IF (WNMIN .GT. WN) WP-(0.0926303*(HEIGHT+WIDTH) *RHGRD"THICK

$1+$ WPMIN/1.2)/(1. +0.075691*(HEIGHT+ HIOTH)/HEIGHT/WIDTH)

IF (WP .GT. WPOLD) $\mathrm{CO}$ TO 84

46

FEEDWT $=50.0$

BUSWT $=20.0$

WEIGHT - (CANWT+FEEDWT + BUSWT)/FLOAT(NPOS) +WAMP+WAMN+WP+WN+WELEC

IF(WPMIN.GT.WP) WEIGHT -WEIGHT + WPMINWW

IF(WNMIN.GT.WN) WEIGHT -WEIGHT+WNMINWN

BASEWT - WEIGHT/1000.0-0.02/FLOAT(NPOS)

CALI GRID

27

CONTINUE

DIM1 = HEIGHT'WIDTH*SQRT(RHGRID*YO/WP/SGRID)

FRACWT-WP/RHGRID/THICK/HEIGHT/WIDTH

DIMGT - FRACWT"DIMI $* 2$

IF ((MODE .EQ. 2) .OR (MODE .EQ. 4)) GO TO is

PRINT 113

PRINT 113

PRINT 105. HEIGHT, WIDTH.THICK.WP

PRIVT 110 , RATTOP,RATCTR

PRINT 111, WPMIN, WNMIN, WN, WAMP, WAMN, WELEC, CANWT, AMPHR, TAMPHR

PRINT 108, FRACWT,DIM1,NPOS,DIMGT

PRINT 113

PRINT 106

15 CONTINUE

$S i(1)=0.0$

S2(1) $=0.0$

$E ?=0.0$

E4 $=0.0$

1 DELTA-0.004"(QLBUS*SQRT(RHBUS/SBUS) +QLPOST'SQRT(RHPOST/SPOST)) ${ }^{* 2}$

IF (QLPOST .LT. O.5) LMODE $=0$

IF ((QLPOST .GT. 0.5) .AND. (QLPOST .LT. 4.)) LMODE=2

IF (QLPOST .GT. 4.) LMODE-5

IF ((MODE .EQ. 2) .OR (MODE .EQ. 4)) GO TO 16

PRINT 113

PRINT 104, QLPOST,QLBUS

16 IF ((MODE .EQ. 4) .AND. (MOD .GT. 1)) GO TO 24

DO 2 I-2NDATA

DOD-1.0QFRACT(I)

DODD=(OPEN(I)-OPEN(I-1))/(QFRACT(I-1)-ỌFRACT I))

DRDD $=$ (RESIST(I)-RESIST(I-1))/(QFRACT(I-1)-QFRACT(I))

CUR - DOD/TIMED'QD"THICK"(HEIGHT'WIDTH-WP/RHGRID/THICK)

V-OPEN(I)-RESIST(I)*CUR 


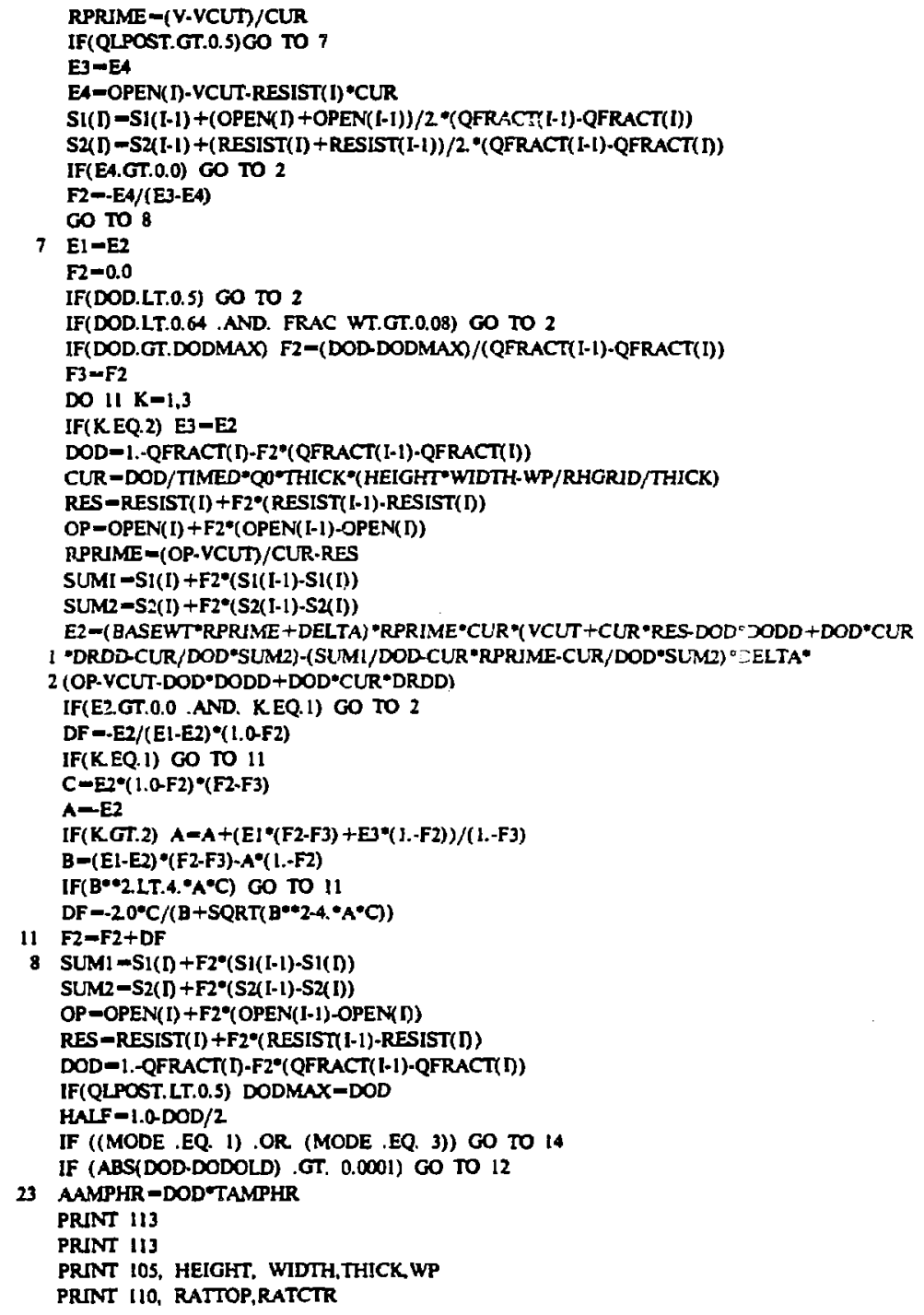


PRINT 114, WPMIN, WNMIN,WN, WAMP, WAMN, WELEC, CANWT,NSTRNG,AMPHR,

1 TAMPHÖ,AAMPHR

PRINT 108, FRACWT,DIMI,NPOS,DIMGT

PRINT 113

PRINT 106

PRINT 104, QLPOST,QLBUS

IF (QLPOST .LT. 0.5) GO TO 14

IF ((MODE .EQ 4) .AND (MOD .EQ. 1)) PRINT IIS

IF ((MODE .EQ. 4) .AND. (MOD .EQ. 2)) PRINT 116

IF ((MODE .EQ. 4) .AND. (MOD .EQ. 3)) PRINT 118

14 IF ((MODE .EQ. 4) .AND. (MOD .GT. I)) GO TO 9

CUR $\Rightarrow$ DOD/TIMED ${ }^{\circ} 0^{*}$ THICK$^{\circ}$ (HEIGHT'WIDTH-WP/RHGRD/THICK)

RPRIME-(OP-VCUT)/CUR-RES

RMAX-(SUM1/CUR-SUM2)/DOD

RMAX $=$ RMAX/(1.0+SQRT(1.0+BASEWT/DELTA*RMAX))

MOD-l

IF(RMAX LT.RPRIME) RPRIME-RMAX

R3-RMAX

WEIGHT-BASEWT+DELTA/RPRIME

DO 3 K-2NDATA

3 IF(QFRACT(K).LT.HALF) GO TO 4

$K=$ NDATA

$4 \mathrm{~L}-\mathrm{K}$

F-(HALF-QFRACT(L-1))/(QFRACT(L)-QFRACT(Li))

RHLALF - $1.0 /(1.0 /$ RESIST(L-1) + F* (1.0/RESIST(L)-1.0/RESIST(L-1)))

OHALF $=$ OPEN $(L-1)+F^{*}(\operatorname{OPEN}(L)-O P E N(L-1))$

9 PNOW-OP* $2 / 4.0 /($ RES +RPRIME)/WEIGHT

PO=OPEN(1)"• $2 / 4.0 /$ (RESIST(1) + RPRIME)/WEIGHT

PHALF-OHALF" $2 / 4.0 /$ (RHALF+RPRIME)/WEIGHT

VV-OP-CUR'RES-CUR'RPRIME

ENERGY $=Q^{\circ}$ (HEIGHT'WIDTH'THICK-WP/RHGRID)/WEIGHT"(SUMI-DOD'CUR 'RPRI

1 ME-CUR'SUM2) $/ 3600.0$

WPRIME=DELTA/RPRIME"1000. FLOAT(NPOS)

XX-QLPOST/QLBUS"SQRT(SBUS'RHPOST/RHBUS/SPOST)

WBUS -WPRIME $/(1 .+\times X) /$ FLOAT(NPOS)

WPOST =WBUS'XX'FLOAT(NPOS)

CSAB - WBUS/RHBUS/(2."QLBUS)

CSAP-WPOST/RHPOST/(2.QLPOST)

RCUT-(OP-VCUT)/CUR-RES

IF(MOD.GT.1) GO TO 10

DODE-DOD

IF (IBFLAG .EQ. O) GO TO 72

C FROM HERE TO STATEMENT LABEL 72 IS FOR ENERGY BISECTION

IF (LMODE .EQ. 0) GO TO 72

C IF (LMODE .EQ. 2) GO TO 72

IF (LMODE .EQ. S) GO TO 72

IF (IFLAGO .EQ. 1) GO TO 72

IF (IFLACG .EQ. 3) GO TO 72

IF (ENERG3 ,LT, 0.001) GO TO 76

CO TO 77

76 ENERG3-ENERGY 
CO TO 70

77 IF (ENERGY ,GE ENFRG3) GO TO 70

GO TO 71

70 ENERG1-ENERG3

WPI -WP3

ENERG3-ENERGY

WP3 $-W P$

CO TO 72

7! ENERG2-ENERGY

WP2-WP

IFLAGG-I

IBISEC $=0$

WPS $=$ WP

72 CONTTNUE

EMAXE-ENERGY

PRNT 102, DOD,CUR, RES, RPRIME, ENERGY, PO, PHALF,PNOW, WEIGHT, VV, RCUT

PRINT 112, WBUS, WPOST, CSAB.CSAP

RMAX-SQRT(RHALF"DELTA/BASEWT)

IF((RMAX GT.RPRIME) .AND. (QLPOST .GT. 0.5)) GO TO 6

RPRIME $=$ RMAX

WEIGHT - BASEWT +DELTA/RPRIME

$\mathrm{R} 4=\mathrm{RMAX}$

MOD-2

IF (QLPOST .LT. 0.5) GO TO 9

IF ((MODE .EQ. 1) .OR (MODE .EQ. 2)) GO TO 9

$24 \mathrm{KJ}=1-3$

E2 -100 .

DO $18 \mathrm{~J}-\mathrm{KI}$,NDATA

El $-E 2$

$\mathbf{F Z}=\mathbf{0}$.

F3-F2

DO $19 \mathrm{~K}=1.4$

IF(KEQ.2) $E 3-E 2$

DOD-1.-QFRACT(J)-F2"(QFRACT(J-1)-QFRACT(J))

CUR-DOD/TIMED ${ }^{\circ} 0^{\circ}$ THICK"(HEIGHT'WIDTH-WP/RHGRID/THICK)

RES-RESIST(J) +F2*(RESIST(J-1)-RESIST(J))

OP-OPEN(J) +F2"(OPEN(J-1)-OPEN(J))

SUM1 - S1(J) +F2*(SI(J-1)-SI(J))

SUM2 $-S 2(J)+F 2 \cdot(S 2(J-1)-S 2(J))$

HALF=I.0-DOD/20

DO $20 \mathrm{KK}=2$ NDATA

20 IF(QFRACT(KK).LT.HALF) GO TO 2I

KK-NDATA

$21 \quad \mathbf{L}=\mathbf{K K}$

F-(HALF-QFRACT(L-1))/(QFRACT(L)-QFRACT(L-1))

RHALF = 1.0/(1.0/RESIST(L-1) +F"(1.0/RESIST(L)-1.0/RESIST(L-i)))

OHALF $=$ OPEN $(L-1)+F^{*}(\operatorname{OPEN}(L)-O P E N(L-1))$

RMAX-SQRT(RHALF'DELTA/BASEWT)

KP'RME-RMAX

WEIGHT-BASEWT +DELTA/RPRIME

IF (MOD .EQ. 2) R4-RMAX 


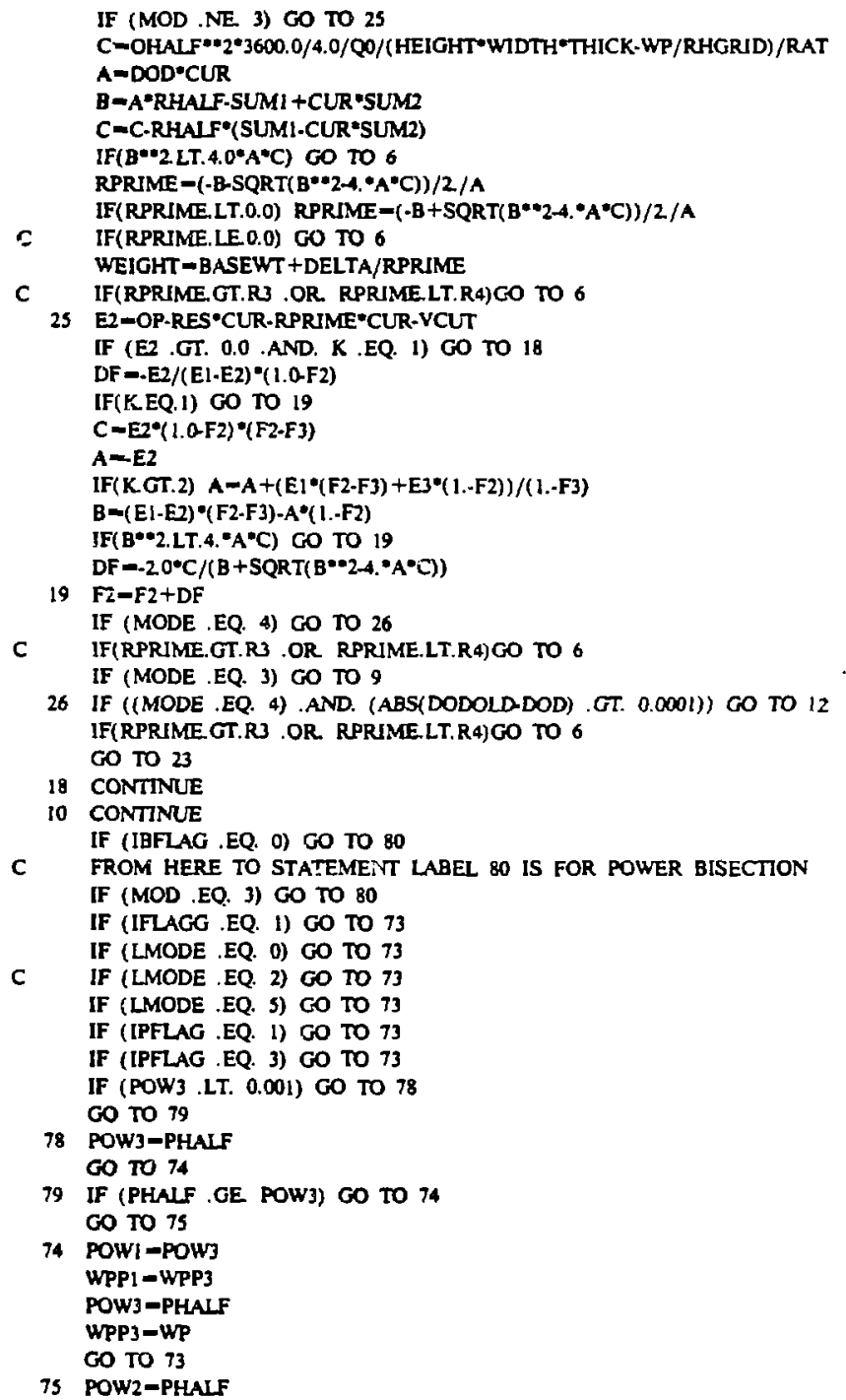




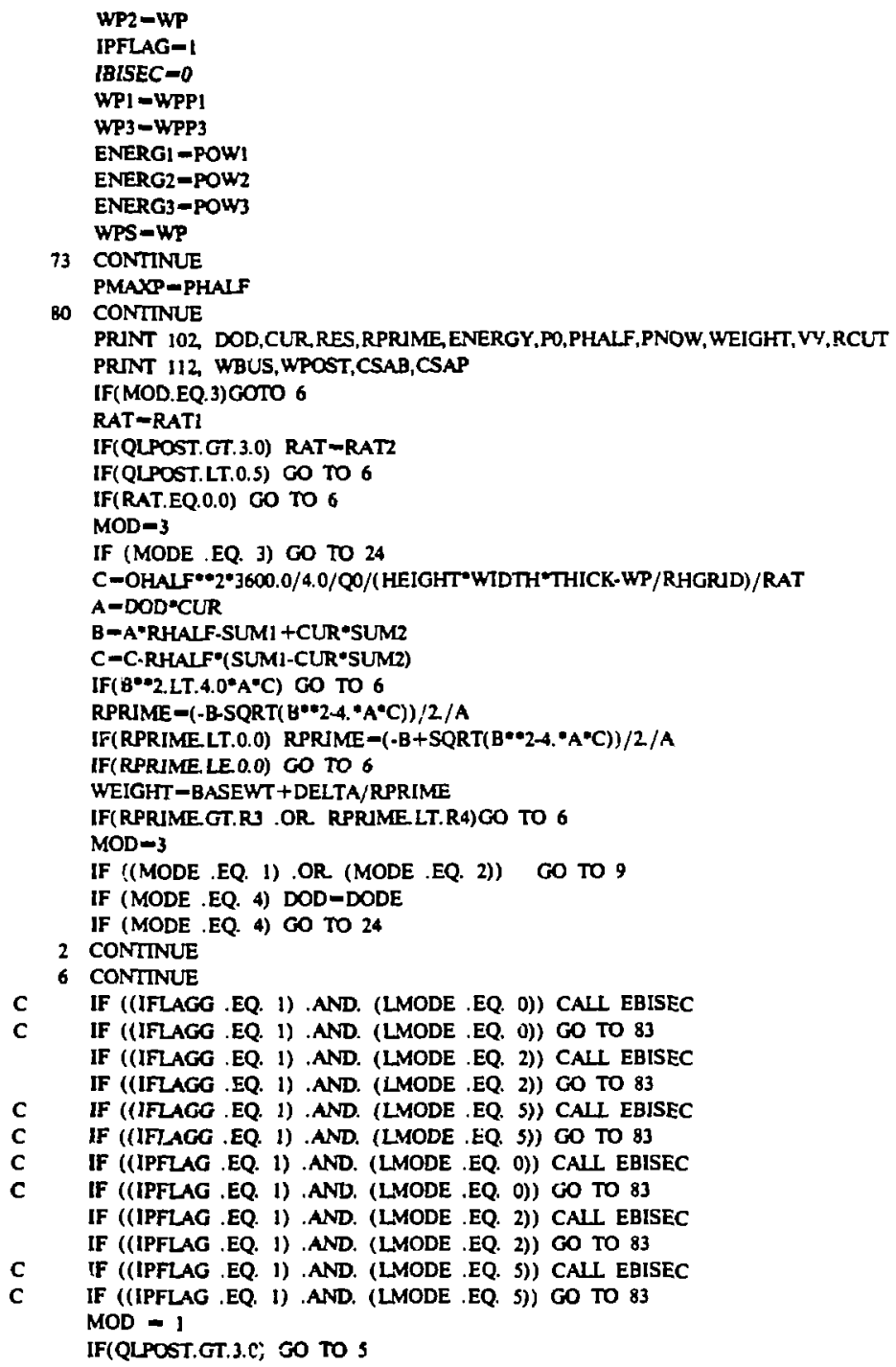




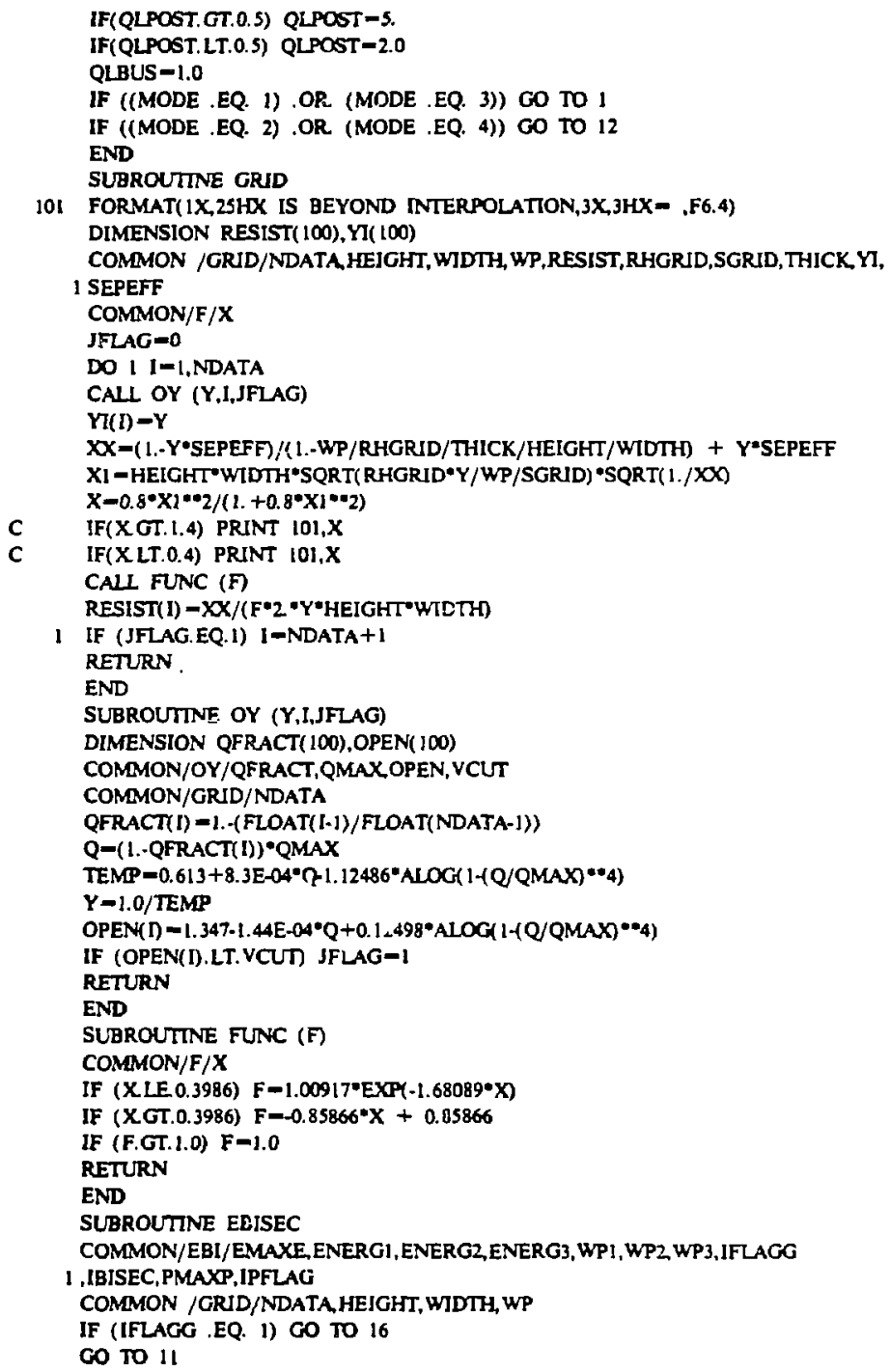


16 ENERGY EMAXE

GO 1013

11 IF (IPFLAG .EQ. 1) GO TO 12

GO TO 13

12 ENERGY =PMAXP

GO TO 14

13 IF (ABS(ENERGY-ENERG3) .LT. 0.000I) IFLAGG - 3

IF (IFLAGG .EQ. 3) GO TO 10

GO TO 15

14 IF (ABS(ENERGY-ENERG3) .LT. 0.0001) IPFLAG=3

IF (IPFLAG .EQ. 3) GO TO 10

GO TO IS

is CONITNUE

IF (IBISEC .EQ. 1) GO To 1

IF (IBISEC .EQ. 2) GO TO 6

$W P-(W P l+W P J) / 2$

[BISEC-I

RETURN

1 IF (ENERGY .GT. ENERG3) GO TO 2

GO TO 3

2 ENERG2-ENERG3

WP2-WP3

ENERG3-ENERGY

WP3 -WP

GO TO 4

3 ENERG I-ENERGY

WPI $=$ WP

" CONTINUE

5 WP-(WP2+WP3)/2.

IBISEC -2

RETURN

6 IF (ENERGY .GT. ENERG3) GO TO T

GO TO 8

7 ENERGI-ENERG3

WPI - WP3

ENERG3 - ENERGY

WPJ -WP

GO TO 9

8 ENERG2-ENERGY

WP2-WP

- CONIINUE

WP-(WPI + WP3) $/ 2$

IBISEC-1

RETURN

10 CONTINUE

RETURN

END 
The following program was used to follow (trace) the behavior of the specific energy as a function of depth of discharge for a bus and post optimized for maximum specific energy, for a bus and post optimized for maximum specific power, for the compromise bus and post mass, and for the bus and post mass that yield the cut-off voltage at a given depth of discharge. Refer to figure 4-13.

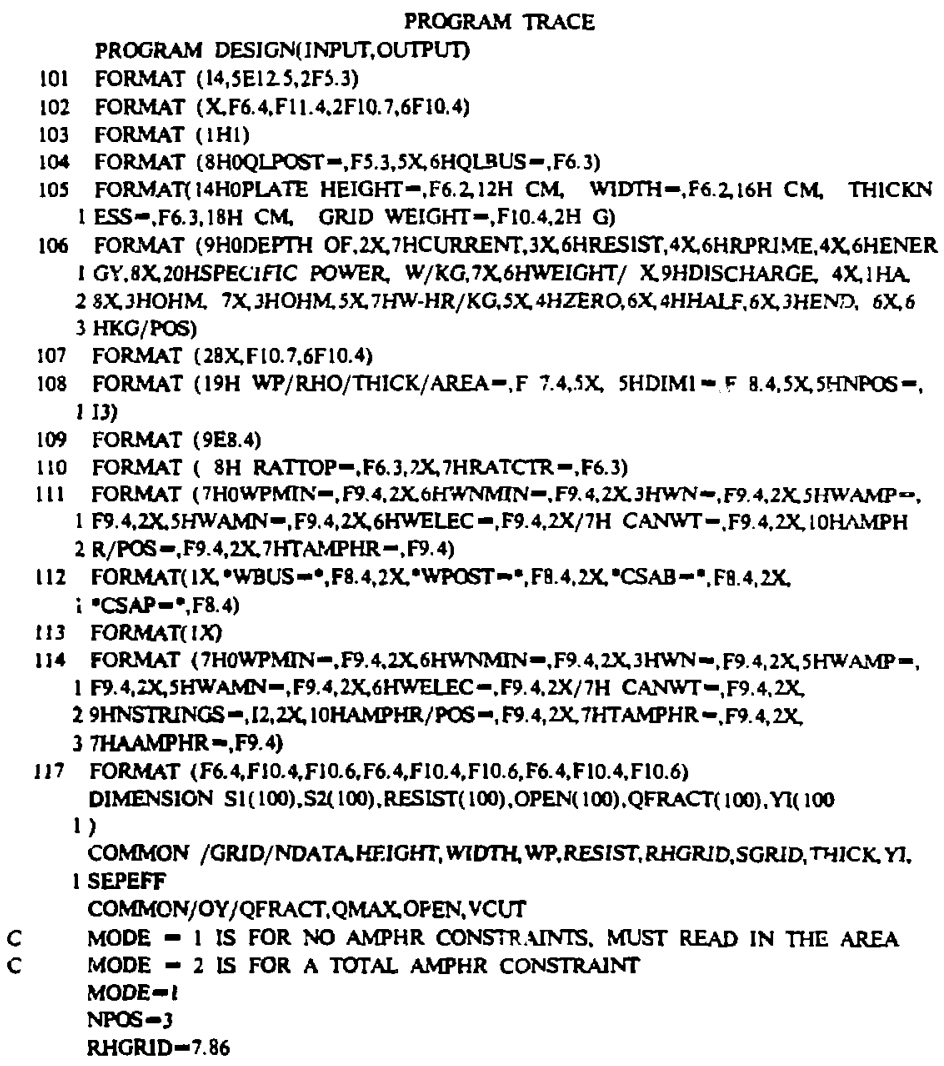




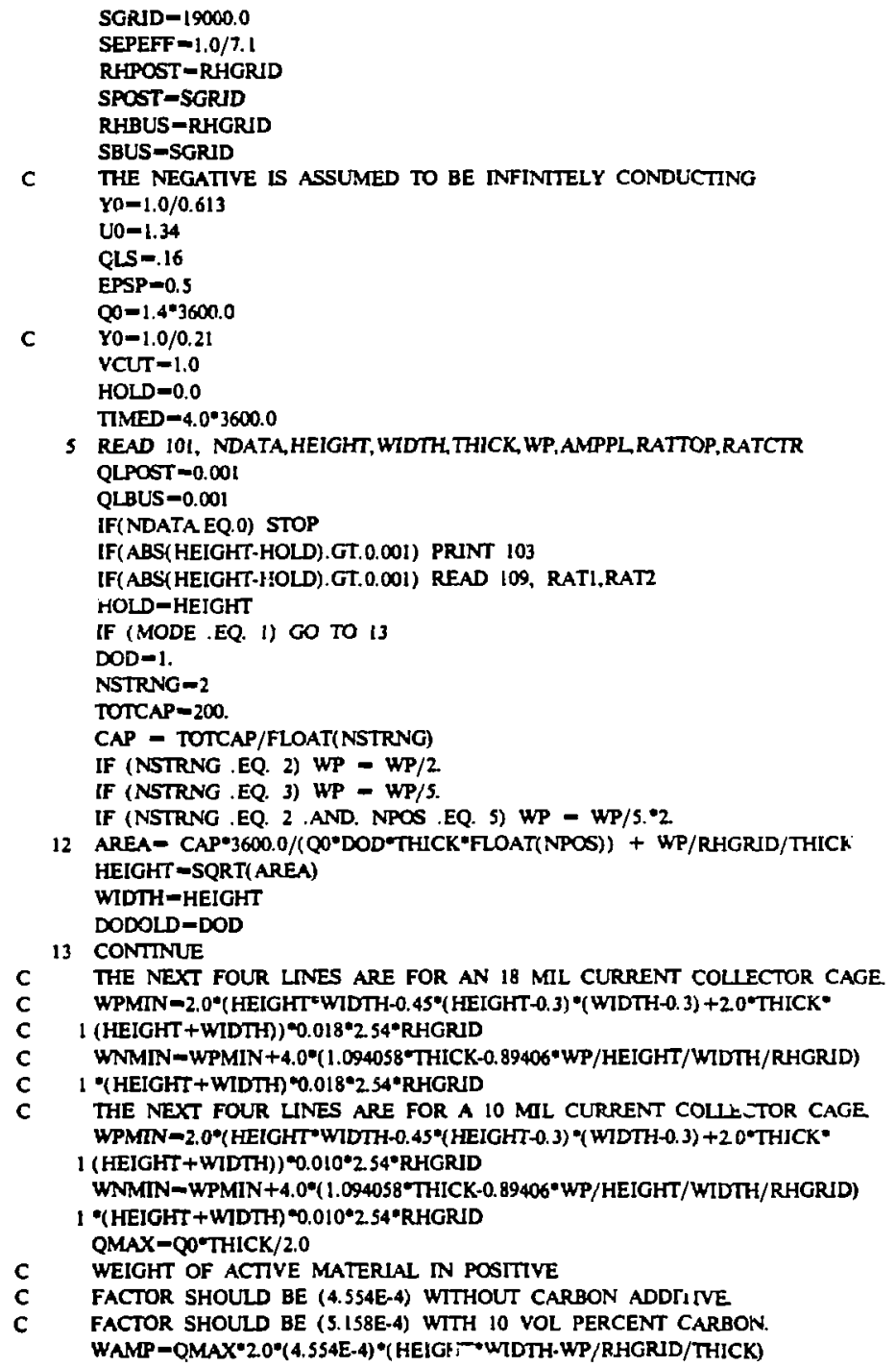


C ASSLME 33 PERCENT EXCESS OF LIAL IN NEGATIVE

C 49 ATOMIC PERCENT LI

WAMN-1.33॰WAMP•0.797

WN-WPe 1.2

C WAS WN-WP*1.82Y

C THE NEXT LINE IS FOR 20 PERCENT EXCESS LIAL IN NEGATTVE

C THE FACTOR 0.962 IS FOR 10 VOL PERCENT EIECTROLYTE COLD

C PRESSED INTO NEGATIVE AND 10 VOL PERCENT CARBON IN POSTTIVE

C WAMN $-1.20^{\circ}$ WAMP"0.962

C WN-WP

C WEIGHT OF ELECTROLYTE, DENSITY - 1.6477

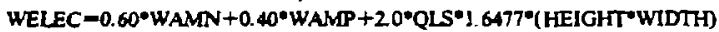

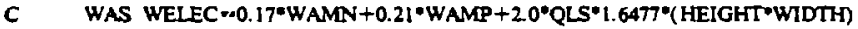

C ASSUME 10 PERCENT EXCESS OF ELECTROLYTE

WELEC-WELEC"1.1

C THICKNESS OF SYSTEM

CANTHK - (THICK + 2094'THICK-0.8941 'WP/HEIGITT/WIDTH/RHGRID

$\left.1+20^{\circ} \mathrm{QLS}\right)$ "FLOAT(NPOS)

C WAS CANTHK=(THICK + 1.63"THICK+20"QLS) "FLOAT(NPOS)

C CAN MATERLAL, 0.061 CM THICK

CANHT $=\left(\right.$ CANTHK* $\left(2.0^{\circ}\right.$ (HEIGHT + 1.5$)+2.0^{\circ}($ WIDTH +0.4$\left.)\right)+(\text { HEIGHT }+1.5)^{*}$

I ( Y TDTH +0.4) 2.0$) * 7.86^{\bullet} 0.061$

AMPHR $=Q 0^{\circ}$ (HEIGHT*WIDTH*THICK-WP/RHGRID) $/ 3600.0$

TAMPHR -AMPHR*FLOAT(NPOS)

FEEDWT $=50.0$

BUSWT -20.0

WEIGHT - (CANWT+FEEDWT+BUSWT)/FLOAT(NPOS) +WAMP+WAMN+WP+WN+WELEC

C IF(WPMIN.GT.WP) WEIGHT - WEIGHT + HPMIN.WP

C IF(WININ.GT.WN) WEIGHT - WEIGHT+WNMIN WN

BASEWT - WEIGHT//000.00.02/ + LOAT(NPOS)

CALL GRID

27 CONTINUE

DIM! -HEIGHT'WIDTH'SQRT(RHGRI'YU/WP/SGRID)

FRACWT -WP/RHGRID/THICK/HEIGHT/WIDTH

IF (MODE .EQ. 2) GO TO 15

PRNT 113

PRINT 113

PRNT 10S, HEIGHT, WIUTH,THICK, WP

PRNT 110 , RATTOP, RATCTR

PRNT III, WPMIN, WNMIN, WN, WAMP, WAMN, WELEC,CANWT, AMPHR, I AMPHR

PRINT 108, FRACWT,DIMI,NPOS

PRINT 113

PRINT 106

15 CONTTNUE

$\operatorname{Si}(1)=0.0$

$S 2(1)=0.0$

$E 2=0.0$

$E 4=0.0$

1 DELTA-0.004"(QLBUS*SQRT(RHBUS/SBUS) +QLPOST"SQRT(RHPOST/SFOST) ${ }^{* * 2}$

$F L A G=0.0$

PILAG 1 
IIFLAG-3

IF. (MODE .EQ. 2) GO TO 16

C PRNT 101, NPOS,DELTA

PRINT 113

PRINT 104, QLPOST,QLBUS

16

CONTINUE

DO 2 I-2NDATA

OD-1.O-QFRACT(I)

IF (KFLAG EQ. 3 .AND. I ,GT. IMAX) I=IMAX

DODD-(OPEN(I)-OPEN(I-1))/(QFRACT(I-1)-QFRACT(I))

DRDD-(R'SIST(!)-RESIST(I-1))/(QFRACT(I-1)-QFRALT(I))

CUR-DOO/TIMED'QO"THICK"(HEIGHT"WIDTH-WP/RHGRID/THICK)

$V=$ OPEN(I)-RESIST(I)*CUR

RPRIME-(V-VCUT)/CUR

IF(QLPOST.GT.0.5)GO TO 7

E3-EA

E4-OPEN(I)-VCUT-RESIST(T)*CUR

Si(I) -Si(1-1) +(OPEN(I) +OPEN(I-1))/2*(QFRACT(I-1)-QFRACT(I))

S2(I) -S $2($ I-1) +(RESIST(I) +RESIST(I-1))/2*(QFRACT(I-I)-QFRACT(I))

IF(EA.GT.0.0) GO TO 2

$F 2=-E 4 /(E 3-E 4)$

IMAX-1

DOD - 1.-QFRACT(I)-F2*(QFRACT(I-1)-QFRACT(I))

IF(QL.POST.LT.D.S) DODMAX =DOD

GO TO 8

7

CONTINUE

$F 2=0.0$

IF (KFLAG .EQ. 1) GO TO g

IF (KFLAG .EQ. 3) ro TO 8

E1 $-E 2$

$F 2-0.0$

IF(DOD.LT.0.5) GO TO 2

IF(DOD.GT.DODMAX) F2-(DOD-DODMAX)/(QFRACT(I-1)-QFRACT(I))

$\mathbf{F 3}=\mathbf{F 2}$

DO $11 \mathrm{~K}-1,3$

IF(K.EQ.2) E3-E2

DOD-1.-QFRACT(1)-F2*(QFRACT(I-1)-QFRACT(I))

CUR - DOD/TTMED'Q'THICK"(HEIGHT"WIDTH-WP/RHGRID/THICK)

RES-RESIST(I) +F2*(RESIST(I-I)-RESIST(I))

OP $=$ OPEN(I) +F2*(OPEN(I-1)-OPEN(I))

RPPIME-(OP.VCUT)/CUR-RES

SUM1 $-S 1($ B) + F2"(S1(I-1)-SI(I))

SUM2-S2(I) +F2*(S2(I-1)-S2(I))

E2-(BASEWT RPRIME+DELTA) "RPRIME"CUR"(VCUT +CUR "RES-DOD"DODD + DOD*CUR 1 "DPDD-CUR/DOD'SUM2)-(SUMI/DOD-CUR"RPRJME-CUR/DOD'SUM2) *DELTA*

2 (OP.VCUT.DOD'DODD+DOD'CUR・OROD)

IF(E2.GT.0.0 .AND. KEQ.1) GO TO 2

$D F=-E 2 /(E 1-E 2) \bullet(1.0-F 2)$

IF(KEQ.1) GO TO ॥

$C-E 2{ }^{\circ}(1 . Q F 2) \oplus(F 2-F 3)$

$A=E 2$ 


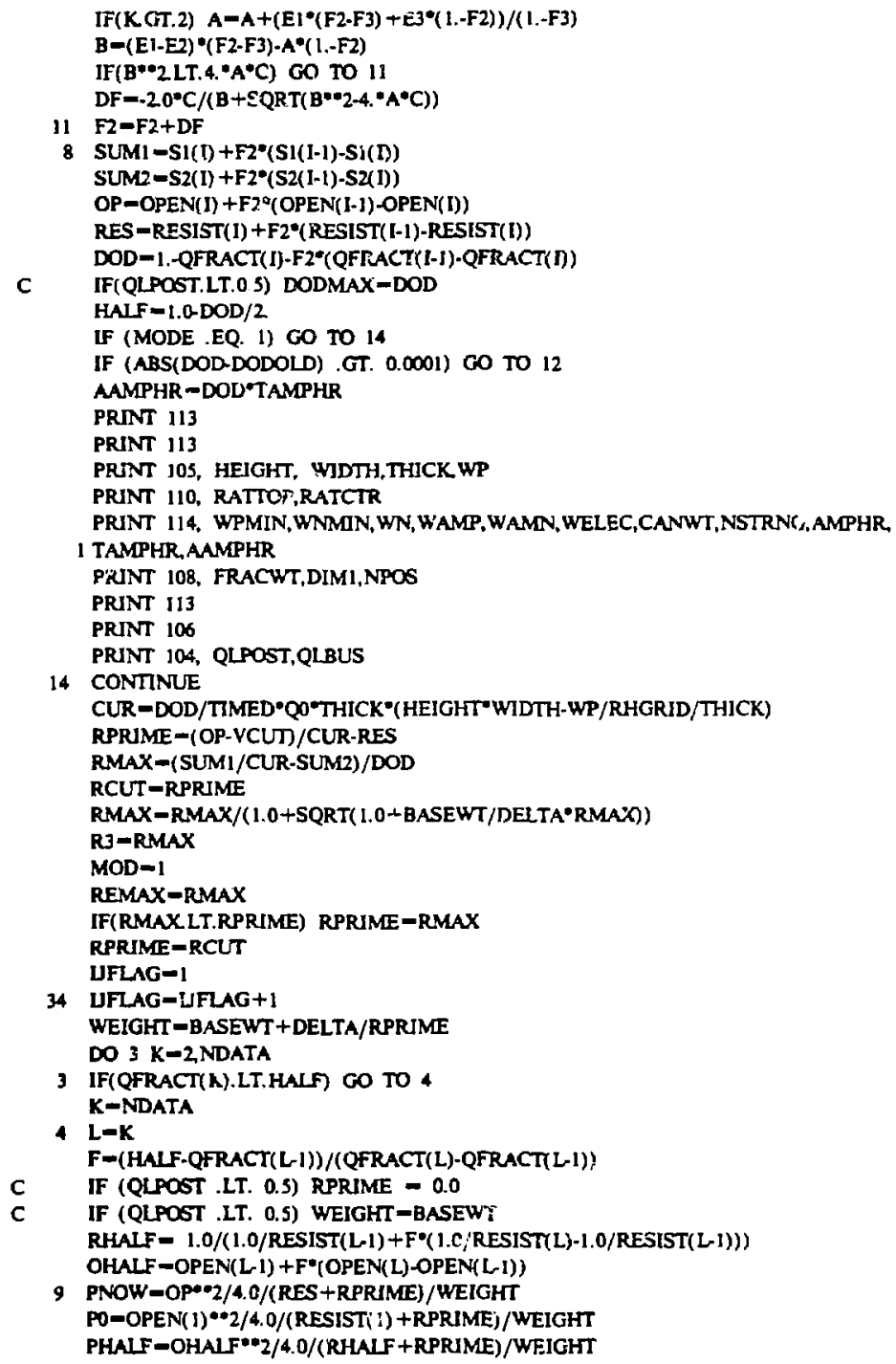


VV=OP.CUR・RES-CUR"RPRIME

ENERGY $=Q^{*}$ (HEIGHT ${ }^{*}$ WIDTH*THICK-WP/RHGRID) /WEIGHT*(SUMI-DOD*CUR *RPRI

I ME.CUR "SUM2) $/ 3600.0$

WPRIME-DELTA/RPRIME"1000. "FLOAT(NPOS)

XX-QLPOST/QLBUS"SQRT(SBUS"RHPOST/RHBUS/SPOST)

WBUS-WPRIME/(1.+XX)/FLOAT(NPOS)

WPOST - WBUS ${ }^{*} X^{\star}{ }^{*}$ LOAT(NPOS)

CSAB-WBUS/RHBUS/(2*QLBUS)

CSAP-WPOST/RHPOST/(2. QLPOST)

IF(MOD.GT.1) CO TO 10

IF (LFLAG .EQ. 2) PRINT 127

IF (UFLAG .EQ. 3) PRINT 128

127 FORMAT(IX.RCUT,ECUT")

128 FORMAT(IX,"REMAX,EMAX")

PRINT 102, DOD,CUR, RES,RPRIME,ENERGY,PO,PHALF,PNOW, WEIGHT, VV

C PRINT 112, WBUS, WPOST,CSAB,CSAP

IF (UFLAG .EQ. 2) RPRIME-REMAX

IF (IJFLAG .EQ. 2) GO TO 34

RMAX-SQRT(RHALF•DEITA/BASEWT)

IF(RMAX GT.RPRIME) GO TO 6

RPRIME-RMAX

WEIGHT - BASEWT +DELTA/RPRIME

R4-RMAX

$M O D=2$

GOTO 9

CONTINUE

IF (MOD .EQ. 2) PRINT 125

IF (MOD .EQ. 3) PRINT 126

FORMAT (1X,"MAX POWER")

FORMAT ( $\mathrm{X}$-RATIO")

PRINT 102, DOD,CUR, RES,RPRIME, ENERGY, PO, PHALF, PNOW, WEIGHT, VV

C PRINT 107, RPRIMEENERGY,PO.PHALF,PNOW, WEIGHT,VV

C PRINT 112, WBUS, WPOST, CSAB,CSAP

IF(MOD.EQ.3)GOTO 66

RAT-RATI

IF(QLPOST.GT.3.0) RAT-RAT2

IF(QLPOST.LT.Q.5) CO TO 66

IF(RAT.EQ.0.0) GO TO 66

$C=$ OHALF"*2*3600.0/4.0/Q0/(HEIGHT*WIDTH*THICK-WP/RHGRID)/RAT

A-DOD'CUR

B-A'RHALF-SUM1 +CUR'SUM2

C-C.RHALF'(SUMI-CUR'SUM2)

IF(B*2LT.4.0*A*C) CO TO 66

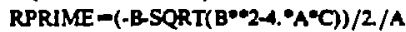

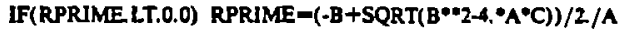

IF(RPRIME.LE.0.0) CO TO 66

WEIGHT =BASEWT+DELTA/RPRIME

C IF(RPRIME.GT.R3 .OR RPRIME LT.R4) GO TO 66

$M O D=3$

Go to 9

66

CONTTNUE 
IF (KFLAG .EQ. 2) GO To 99

IF (KFLAG .EQ. 3) GO TO 99

E4-OP-RES ${ }^{\circ}$ CUR-RMAX'CUR-VCUT

IF (FLAG .NE. O.D) CO TO 99

IF (QLPOST .LT. 0.5) GO TO 99

IF (IIFLAG .EQ. I) GO TO 88

EI-E2OLD

$\mathbf{F} 2=0.0$

F3 - F2

DO $81 \mathrm{~K}-1,3$

IF(KEQ.2) E3-E2

SUMI $-S I(J)+F^{\circ}(S I(1-1)-S I(I))$

SUM2-S2(I) + F2*(S2(I-1)-S2(I))

OP-OPEN(I)+F2*(OPEN(I-1)-OPEN(I))

RES-RESIST(I) + F2"(RESIST(I-1)-RESIST(I))

DOD= 1.-QFRACT(I)-F2"(QFRACT(I-1)-QFRACT(I))

CUR -DOD/TIMED ${ }^{\circ} 0^{\circ}$ THICK$^{\circ}$ (HEIGHT'WDTH-WP/RHGRID/THICK)

RMAX-(SUM1/CUR-SUM2)/DOD

RMAX-RMAX/(1.0+SQRT(1.0+BASEWT/DELTA•RMAX))

E2=OP-RES ${ }^{\circ} \mathrm{CUR}^{-R M A X}{ }^{\circ} \mathrm{CUR}-\mathrm{VCUT}$

E2OLD-E2

IF(E2.GT.0.0 .AND. KEQ.1) CO TO 88

$\mathrm{DF}=-\mathrm{E} 2 /(\mathrm{E} 1-\mathrm{E} 2)^{\circ}(1.0-\mathrm{F} 2)$

IF(KEQ.1) GO TO 81

C-E2"(1.0-F2)"(F2-F3)

$A=-E 2$

$\operatorname{IF}\left(\mathrm{KGT.2)} A-A+\left(E 1^{*}(F 2-F 3)+E 3^{*}(1 .-F 2)\right) /(1 .-F 3)\right.$

$B=(E 1-E 2)^{\circ}(F 2-F 3)-A^{*}(1 .-F 2)$

IF (B"*2LI.4."A*C) GO TO 81

$\mathrm{DF}=-2.0^{\circ} \mathrm{C} /\left(\mathrm{B}+\mathrm{SQRT}\left(\mathrm{B}^{\circ} 2-4^{\circ} .^{\circ} \mathrm{A}^{\circ} \mathrm{C}\right)\right)$

$81 \quad F 2-F 2+D F$

IIFLAG - 1

88 CONTINUE

IF (IIFLAG .EQ. I) FIAG=-1.0

IF (IIFLAG .EQ. 1) CO TO 8

GO TO 2

99 CONTINUE

IF (FLAG.GT.0.0) Go TO 97

FLAG-1.0

$F 2=0.05$

IF (KFLAG .EQ. 3) F2 $=0.01$

$97 \quad F 2-F 2+0.1$

IF(F2LT.0.999) GO TO 8

IF (QLPOST .LE 0.5) GO TO 6

IF (KFLAG .EQ. 3) GO TO 6

KFLAG-KFLAG+1

FLAG $=1.0$

IF (KFLAG .EQ. 3) GO TO 2

E2-10.

IF (KFLAG .EQ. 2) GO TO 16

2 CONTINUE 
6 IF(QLPOST.GT.3.0) GO TO 5

IF(QLPOST.GT.0.5) QLPOST $=5$.

IF(QLPOST.LT.0.5) QLPOST $=2.0$

QLBUS-1.0

IF (MODE .EQ. 1) GO TO 1

IF (MODE .EQ. 2) GO TO 12

END

SUBROUTTNE GRUD

101 FORMAT(IX,25HX IS BEYOND INTERPOLATION,3X,3HX- ,F6.4)

DIMENSION RESIST(100), YT(100)

COMMON /GRID/NDATA, HEIGHT, WIDTH, WP, RESIST,RHGRID,SGRD, THICK, YI,

1 SEPEFF

COMMON/F/X

JFLAG $=0$

DO 1 1- 1 ,NDATA

CAIl OY (Y,I,JFLG)

$\mathrm{YI}(\mathrm{I})-\mathrm{Y}$

XX-(1.-Y*SEPEFF/(1.-WP/RHGRD/THICK/HEIGHT/WIDTH) + Y*SEPEFF

X1 = HEIGHT 'WIDTH"SQRT(RHGRID*Y/WP/SGRID) *SQRT(1./XX)

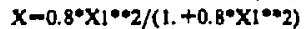

C IF(XGT.1.4) PRINT 101,X

C IF(XLT.0.4) PRINT 101,X

CALL FUNC (F)

RESIST(I) $=X X /\left(F^{*} 2\right.$. Y $^{*} \mathrm{HEIGHT}$ WIDTH $)$

1 IF (JFLAG.EQ.1) I-NDATA+1

RETURN

END

SUBROUTINE OY (Y,I.JFLAG)

DIMENSION QFRACT (100),OPEN(100)

COMMON/OY/QFRACT,QMAX,OPEN,VCUT

COMMON/GRID/NDATA

QFRACT(I) -1.-(FLAT(I-1)/FLOAT(NDATA-1))

Q-(1.-QFRACT(I))"QMAX

TEMP=0.613+8.3E-04॰Q-1.12486"ALOG (1-(Q/QMAX) **4)

$Y=1,0 /$ TEMP

OPEN(I) - $\left(.347-1.44 E-04{ }^{*} \mathrm{Q}+0.32498^{\circ} \mathrm{ALOG}\left(1-(\mathrm{Q} / \mathrm{QMAX})^{* * 4)}\right.\right.$

IF (OPEN(I).LT.VCUT) JFLAG-1

RETURN

END

SUBROUTINE FUNC ( $F$

COMMON/F/X

IF (XLE 0.3986) F-1.00917'EXP(-1.68089॰X)

IF (XGT.0.3986) F $=0.85866^{\circ} X+0.85866$

IF (F.GT.1.0) $F-1.0$

RETURN

END 
This report was done with suppon from the Department of Energy. Any conclusions or opinions expressed in this repont represent solely those of the author(s) and not nocessarily those of The Regents of the University of California. the Lawrence Berkelcy Laboratory or the Department of Energy.

Reference to a company or product name does not imply approval or recommendation of the produet by the University of California or the U.S. Department of Energy 10 the exclusion of others that may be suitable. 